\title{
Human resource management practices and learning for innovation in developing countries : pharmaceutical firms in Mexico
}

Citation for published version (APA):

Santiago Rodriguez, F. (2010). Human resource management practices and learning for innovation in developing countries : pharmaceutical firms in Mexico. [Doctoral Thesis, Maastricht University]. Universitaire Pers Maastricht. https://doi.org/10.26481/dis.20101221fs

Document status and date:

Published: 01/01/2010

DOI:

10.26481/dis.20101221fs

Document Version:

Publisher's PDF, also known as Version of record

Please check the document version of this publication:

- A submitted manuscript is the version of the article upon submission and before peer-review. There can be important differences between the submitted version and the official published version of record.

People interested in the research are advised to contact the author for the final version of the publication, or visit the DOI to the publisher's website.

- The final author version and the galley proof are versions of the publication after peer review.

- The final published version features the final layout of the paper including the volume, issue and page numbers.

Link to publication

\footnotetext{
General rights rights.

- You may freely distribute the URL identifying the publication in the public portal. please follow below link for the End User Agreement:

www.umlib.nl/taverne-license

Take down policy

If you believe that this document breaches copyright please contact us at:

repository@maastrichtuniversity.nl

providing details and we will investigate your claim.
}

Copyright and moral rights for the publications made accessible in the public portal are retained by the authors and/or other copyright owners and it is a condition of accessing publications that users recognise and abide by the legal requirements associated with these

- Users may download and print one copy of any publication from the public portal for the purpose of private study or research.

- You may not further distribute the material or use it for any profit-making activity or commercial gain

If the publication is distributed under the terms of Article $25 \mathrm{fa}$ of the Dutch Copyright Act, indicated by the "Taverne" license above, 
To Mauricio, Sebastián and Verónica 
Datawyse, Universitaire Pers Maastricht ISBN 978-94-6159-028-2 


\title{
HUMAN RESOURCE MANAGEMENT PRACTICES AND LEARNING FOR INNOVATION IN DEVELOPING COUNTRIES:
}

\author{
PHARMACEUTICAL FIRMS IN MEXICO
}

\section{PROEFSCHRIFT}

ter verkrijging van de graad van doctor aan de Universiteit Maastricht, op gezag van de Rector Magnificus, Prof. mr. G.P.M.F. Mols, volgens het besluit van het College van Decanen

in het openbaar te verdedigen op dinsdag 21 december 2010 om 16.00 uur

door

\section{Fernando Santiago Rodriguez}

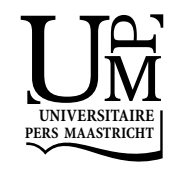




\section{Promotor:}

Prof. dr. Robin Cowan

\section{Copromotor:}

Dr. Ludovico Alcorta, UNIDO, Vienna

\section{Beoordelingscommissie:}

Prof. dr. Pierre Mohnen, voorzitter

Prof. dr. Gabriela Dutrénit, Universidad Autónoma Metrolitana, Mexico

Prof. dr. Luc Soete

This research was posible thanks to funding from the Concil of Science and Technology, Mexico (CONACYT) and UNU-INTECH/UNU-MERIT 


\section{Contents}

Introduction: A study on human resource management practices and learning for innovation

Chapter 1: Development of human resources for innovation: Reappraising the con9 tribution of firms

1. Introduction

2. How non-academic environments contribute to the development of human resources for science, technology and innovation

2.1. The role of public policy

2.2. Labour market dynamics and careers in science and technology

2.3. Development of human resources for STI in private firms

3.Management of human resources and firm's performance

3.1. Do management practices influence innovation?

3.2. The intermediary role of learning

3.2.1. Individual learning

3.2.2. Organisational learning

3.2.3. Learning strategies: exploration and exploitation

4. Human resource management practices and learning for innovation in developing countries

Chapter 2: Analytical framework and methodological approaches to research on human resource management practices for learning and innovation

1. Introduction

2. Analytical framework

2.1. Organisational practices

2.2. Knowledge bases

2.3. Interactions with external agents

2.3.1. Learning from external markets for knowledge

2.3.2. Human resource management and external interactions

3. Internal, external, combined learning strategies

4. Human resource management practices and innovation: Methodological approaches

4.1. Six alternative, yet complementary approaches

Chapter 3: Research hypothesis, variable definition, data and data sources in this thesis

1. Introduction

2. Human resource management practices relevant for learning and innovation

2.1. Training

2.2. Remuneration

2.3. Empowerment

2.4. Strategic hiring

3. The data in this thesis

3.1. Primary Data

3.1.1. Quantitative Data

3.1.1.1. Data on learning strategies of pharmaceutical firms

3.1.1.2. Controls on firms' characteristics

3.1.1.3. Indicators on management practices

3.1.2. Qualitative Data

3.1.2.1. The interviews

3.2.Secondary data sources 
1. Introduction

2. Pharmaceutical innovation

2.1. Drug discovery and pre-clinical tests $\quad 68$

2.1.1. Drug discovery

2.1.2. Pre-clinical tests

2.2. Clinical trials

2.3. Drug manufacturing

2.3.1. Good Manufacturing Practice

2.3.2. Manufacturing process

2.3.3. Innovation in drug manufacturing

2.3.4. Learning through generic drugs

2.4. Ongoing Studies and product life-cycle support 81

3. Final comments

\section{Chapter 5: Pharmaceuticals in Mexico}

1. Introduction

2. Historical account of the Mexican pharmaceutical industry

3. The industry today

3.1. The local market

3.2. Prices

3.3. Public procurement

3.4. Presence of multinational affiliates

$\begin{array}{ll}97 \\ \text { affiliates } & 97\end{array}$

3.5. Foreign trade $\quad 98$

3.6. The competitive environment 100

$\begin{array}{ll}\text { 3.7. Property rights } & 101\end{array}$

4. Learning and innovation $\quad 103$

4.1. General environment around R\&D 104

4.2. Drivers of pharmaceutical R\&D in Mexico 106

4.3. R\&D performance $\quad 108$

4.4. R\&D outcomes $\quad 111$

4.5. Basic research 113

$\begin{array}{ll}\text { 4.6. Clinical research } & 115\end{array}$

$\begin{array}{lr}\text { 5. Concluding remarks } & 116\end{array}$

Chapter 6: Human resource management practices for learning through in-house $\quad 117$ R\&D: pharmaceuticals in Mexico

$\begin{array}{ll}\text { 1. Introduction } & 117\end{array}$

2. Variable definition $\quad 118$

2.1. Dependent variables $\quad 118$

2.2. Explanatory and control variables $\quad 119$

$\begin{array}{ll}\text { 2.3. Research strategy } & 119\end{array}$

3. Empirical results $\quad 121$

3.1. Learning behaviour of pharmaceutical firms in Mexico 121

3.2. Human resource management and learning through in-house R\&D 121

$\begin{array}{ll}\text { 3.2.1. Knowledge exploitation or exploration } & 122\end{array}$

3.2.2. Learning through different kinds of R\&D $\quad 123$

3.3. Effects from different types of training $\quad 124$

4. Discussion and concluding remarks $\quad 125$ 
Chapter 7: Learning from external markets for technology: Is there a role for human resource management practices?

2. Variable definitions and research strategy 138

2.1. Dependent variables 138

2.2. Independent variables $\quad 140$

2.3. Research Strategy 140

3. Empirical results 141

3.1. Participation in external markets for knowledge 141

3.2. Human resource management practices by source of external knowledge 143

3.3. Econometric results 144

3.3.1. Embodied and disembodied knowledge acquisition 144

$\begin{array}{ll}\text { 3.3.2. Markets for innovation: joint R\&D } & 145\end{array}$

3.3.3. Markets for technology: licensing 145

3.3.4. Learning from distinct training providers 146

$\begin{array}{ll}\text { 4. Discussion and concluding remarks } & 147\end{array}$

Chapter 8: Do human resource management practices contribute to combined 161 learning strategies in developing countries?

1. Introduction 161

1.1. Dual learning strategies in the pharmaceutical industry 161

2. Data and research strategy 163

2.1. Research strategy 164

3. Empirical results 165

3.1. Learning and technology acquisition 166

3.2. Econometric results 168

3.2.1. Basic model: Joint internal and external learning strategies 168

$\begin{array}{ll}\text { 3.2.2. Changing definitions of internal and external learning strategies } & 169\end{array}$

4. Discussion and concluding remarks 173

Chapter 9: Integrated view: human resource management practices and learning for 185 innovation

1. Lessons from a study on human resource management practices and learning for 188 innovation in a developing country context

Bibliography

Annexes

Annex 1

Annex 2

Samenvatting

Curriculum vitae 


\section{List of Tables}

3.1: Enhanced human resource management practices and Firm's (innovation) performance 48

3.2: Control variables about pharmaceutical firms in Mexico

3.3: Variables on human resource management practices in Mexican manufacturing and available through ENESTYC, 2005

3.4: General description of interviews carried out as part of this study

5.1: Pharmaceutical industry: Main global markets, 2008. (Sales through retail pharmacies)

5.2: Characteristics of the Mexican pharmaceutical industry, 2003; as a share of total manufacturing

5.3 Mexico: Average drug prices to the final consumer for old ( $>15$ years) and new medicines ( $<10$ years); Mexican pesos

5.4: Mexico, leading foreign companies, 2005

5.5: Mexico: Expenditure in Science and Technology activities by selected sectors, 1997-2005

5.6: Mexico: Gross Expenditure in R\&D by main industry, 2000-2005

5.7: Innovative performance of the Mexican pharmaceutical industry, 2004-2005

5.8: Conacyt's investment in projects involving interactions of firms and other agents, 2001-2006 113

6.1: Indicators on in-house R\&D performance by pharmaceutical firms in Mexico 118

6.2: Correlation analysis of variables on management practices and firm characteristics included in this study $\quad 129$

6.3: Summary statistics for the Pharmaceutical industry in Mexico, 2004

6.4: Frequency analysis of the explanatory and control variables included in the analysis

6.5: Influence of management practices on knowledge exploitation and exploration by pharmaceutical firms in Mexico

6.6: Probit analysis: management practices and learning in the Mexican pharmaceutical industry

6.7: Changes in probabilities and marginal effects for models in 6.6

6.8: Testing the influence of internal and external training on performance of in-house R\&D

7.1: Means for technology acquisition from external markets: pharmaceutical firms in Mexico

7.2: Learning from external markets: Pharmaceutical industry in Mexico, 2004

7.3: Correlation analysis among variables denoting technology acquisition from external markets for knowledge

7.4: Mexico: Human resource management practices and control variables included in the analysis by type of external market for technology

7.5: Influence of management practices on learning from external markets, embodied and disembodied technologies

7.6: Mexico: Influence of human resource management practices on learning from external technology markets, with alternative definitions of training

7.7: Mexico: Influence of human resource management practices on learning through external technology in disembodied form, with alternative definitions of training

7.8: Mexico: Influence of human resource management practices on learning through joint R\&D activities, with alternative definitions of training

7.9: Mexico: Influence of human resource management practices on learning through technology licensing, with alternative definitions of training

8.1: Mexico: Correlation analysis for the choice of joint learning strategy by pharmaceutical firms

8.2: Frequency of learning strategies of pharmaceutical firms in Mexico

8.3: Characterisation of human resource management variables included in the analysis, by type of learning strategy

8.4: Bivariate probit models for joint adoption of internal and external learning strategies

8.5: Bivariate probit models for joint adoption of internal and external learning strategies, by different types of in-house R\&D

8.6: Bivariate probit models for internal and external learning strategies underpinning knowledge exploitation and exploration activities

8.7: Bivariate probit models for learning strategies combining in-house R\&D for knowledge exploitation and exploration, with the acquisition of embodied and disembodied technologies from external markets

8.8: Bivariate probit models for learning strategies including knowledge exploration and external R\&D

8.9: Bivariate probit models for internal and external learning strategies underpinning knowledge exploita-

tion and learning through external markets, By external training provider

8.10: Bivariate probit models for internal and external learning strategies underpinning knowledge exploitation and learning through external markets. By external training provider

8.11: Conditional probabilities for models in s 8.9 and 8.10 , respectively; by type of strategy and external training provider 


\section{List of Figures}

1.1 Alternative approaches to investigate the role of non-academic factors on the development of human resources for science, technology and innovation.

1.2 Schematic representation of a proposed approach to research on human resources and innovation performance at the firm level

2.1 Interactive dimensions condition a firm's learning and innovation activities

2.2: Approaches to research on human resource management practices and firms' performance

4.1: Phases of the pharmaceutical innovation process

4.2: Public policy process in Pharmaceuticals

4.3: Schematic representation of the primary manufacturing process for biopharmaceuticals

5.1 Mexico: Structure of the Pharmaceutical industry

5.2: Main pharmaceutical product classes in Mexico as of July 2006

5.3: Distribution of volumes and values of sales in the Mexican pharmaceuticals by type of market. Million

units and US\$ million

5.4: Mexico, investment in innovation related activities by manufacturing firms, 2005

5.5: Distribution of R\&D investment among the different phases of the development of a new drug: where

\section{Abbreviations and Acronyms}

$\begin{array}{ll}\text { ABPI } & \text { Association of the British Pharmaceutical Industry } \\ \text { AMIIF } & \text { Asociación Mexicana de Industrias de Investigación Farmacéutica, Mexico } \\ \text { ANAFAM } & \text { Asociación Nacional de Fabricantes de Medicamentos, Mexico } \\ \text { ANIQ } & \text { Asociación Nacional de la Industria Química } \\ \text { API } & \text { Active Pharmaceutical Ingredient } \\ \text { Banxico } & \text { Banco de México } \\ \text { BRICS } & \text { Brazil, Russia, India, China, South Africa } \\ \text { CANIFARMA } & \text { Cámara Nacional de la Industria Farmacéutica, Mexico } \\ \text { CANACINTRA } & \text { Cámara Nacional de la Industria de la Transformación, Mexico } \\ \text { CCINSHAE } & \text { Coordinación de Centros Nacionales de Investigación y Hospitales de Alta Especialidad, Mexico } \\ \text { cGMP } & \text { Current Good Manufacturing Practices } \\ \text { CNS } & \text { Central Nervous Systems } \\ \text { CRO } & \text { Contract Research Organization } \\ \text { COFEPRIS } & \text { Comisión Federal para la Prevención contra Riesgos Sanitarios, Mexico } \\ \text { CONACYT } & \text { Consejo Nacional de Ciencia y Tecnología, Mexico } \\ \text { DRUID-DIME } & \text { Danish Research Unit in Industrial Dynamics-Dynamics of Institution and Markets in Europe } \\ \text { EIA } & \text { Encuesta Industrial Annual, Mexico } \\ \text { ENESTYC } & \text { Encuesta Nacional de Empleo, Salarios, Tecnología y Capacitación } \\ \text { FCCT } & \text { Foro Consultivo Científico y Tecnológico, Mexico } \\ \text { GLOBELICS } & \text { The Global Network for Economics of Learning, Innovation, and Competence Building Systems } \\ \text { DDS } & \text { Drug Delivery Systems } \\ \text { DNA } & \text { Deoxyribonucleic Acid } \\ \text { ESIDET } & \text { Encuesta sobre Investigación y Desarrollo Tecnológico } \\ \text { FDA } & \text { Food and Drug Administration, US } \\ \text { FDI } & \text { Foreign Direct Investment } \\ \text { GCP } & \text { Good Clinical Practice } \\ \text { GDP } & \text { Gross Domestic Product } \\ \text { GERD } & \text { Gross Expenditure in R\&D } \\ \text { GI } & \text { Generic Interchangeable } \\ \text { GLP } & \text { Good Laboratory Practice } \\ & \end{array}$




\begin{tabular}{ll} 
ICH & International Conference on Harmonisation on Good Clinical Practices \\
IDRC & International Development Research Centre \\
IIA & Independence of Irrelevant Alternatives \\
INEGI & Instituto Nacional de Estadística, Geografía e Informática, Mexico \\
IND & Investigational New Drug \\
IM & Integrated Manufacturing \\
IMSS & Instituto Mexicano del Seguro Social \\
IPR & Intellectual Property Rights \\
ISSSTE & Instituto de Seguridad y Servicios Sociales de los Trabajadores del Estado \\
JIT & Just-in-time \\
NAFTA & North America Free Trade Agreement \\
NASCI & North-American Industrial Classification System \\
NCE & New Chemical Entity \\
NSR & National System of Researchers \\
NSI & National System of Innovation \\
OECD & Organization for Economic Cooperation and Development \\
R\&D & Research and Development \\
PAT & Process Analytical Technology \\
SARS & Severe Acute Respiratory Syndrome \\
SME & Small and Medium sized Enterprises \\
STI & Science, Technology and Innovation \\
STPS & Secretaría del Trabajo y Previsión Social \\
SNI & Sistema Nacional de Investigadores \\
TQM & Total Quality Management \\
TRIPS & Trade Related aspects of Intellectual Property Rights \\
UNAM & National Autonomous University of Mexico \\
UAM & Metropolitan Autonomous University, Mexico \\
UNU-Intech & United Nations University-Institute for new technologies \\
UNU-MERIT & United Nations University-Maastricht Economic (and social) Research (and training) centre on \\
WHO & Innovation and Technology \\
& World Health Organization \\
\hline
\end{tabular}




\section{Acknowledgements}

Pursuing a PhD is said to be a lonely and lengthy process, one that challenges personal determination and self-esteem. As time went by I indeed came to realize how much frustration and anger one has to endure; how much effort it is required to remain motivated while dealing with all sorts of feelings towards the thesis, the supervisors and the host institute. Fortunately I also learned that the PhD process is all the more fun and rewarding if one can find the right companions for the journey. Substantial portions of my thesis were written while in Maastricht, Mexico City, Vienna, Montreal, and Ottawa. It is impossible to list all those that accompanied me in the process leading to obtaining my degree; I am lucky to have met all of them.

It all began with reference letters from Vanessa Rubio, Leonardo Torre, Antonio Galan and Ed Steinmueller. Permanent encouragement came from life-long friends, Margarita Luna, Manuel Sánchez, Norma Noyola, Cesar Hernández, Verónica Flores and Jonathan Noriega; Paula Villavicencio, Cedrian López, Margarita Pérez, Carmen González, Marco Guzmán, Enrique Santillán, July Díaz, Claudia de Fuentes, and many others, former classmates or former colleagues at the Mexican government. Agustín García-López and Jana Boltvinik remain reference for my career and interest in policy and the public service.

Once in Maastricht, Semih Akcomak, Ekin Keskin, Marion Motari, Yoseph Getachew, and Abraham Garcia posed me the challenge of keeping up with work while pursuing a very active social agenda. The tales from the nights out or the several (day-)trips together would provide content for a full saga on PhD student wilderness. Kerstin Haaland, Saeed Parto, Susana Ravasa, and Francisco Toro complemented the group. Bertha Vallejo was very supportive throughout my first days in Maastricht. Ngoc Pham made the perfect roommate for a few months. Asel Doranova, lonara Costa, and Shuan SadreGhazi hosted me at different moments during my visits to Maastricht as I became increasingly mobile. Nico Rasters helped in record time to translate into Dutch the summary of the thesis. Florian Kaulich, Gorazd Resonja, Andrea Manica and Beate Wegscheider were great company in Vienna.

I greatly enjoyed the interaction with all my fellow students at UNU-MERIT, but Ezequiel Taczir, Lilia Stubrin, Zakaria Babutzide, Ibrahim Bolat, Flavia Pereira, Radhika Perrot, Branca Urem, Noi Nantawan, Nora Engel, Daniel Vertesy, Sergey Filipov, Luciana Marins and a long list of visiting and exchange students deserve special mention. Then there are all those who joined football irrespective of weather conditions; Bianca Boligescu, Henri Espinosa, and other friends at the Maastricht School of Governance.

This thesis could have never been possible without the support and confidence from Gabriela Dutrénit and her group at UAM Xochimilco, Javier Jasso, Karla Pacheco, Elena Esquer, Carlos Robles, Rivelino Flores, Bethel González and others at the organisations participating in this study. The breakthrough in data collection 
was possible thanks to Adriana Ramirez who guided me through the process of accessing data from the Instituto Nacional de Estadística, Geografía e Informática (INEGI), Mexico. Also at INEGI, Gerardo Leyva and Abigail Durán granted access to the data, and Gabriel Romero and Cándido Aguilar helped in the processing.

My deepest appreciation for Rae Wasdroop and Ann Kelledy, from UNUINTECH, for their help dealing with Dutch immigration; they made possible for my family to join me in The Netherlands. Wangu Mwangui, Eveline in de Braek, and Ad Notten were most helpful facilitating life at UNU-INTECH, eventually UNU-MERIT.

Although the most extraneous circumstances led to her withdrawal as formal supervisor Lea Velho deserves a very special mention both as a mentor and friend. Sunil Mani and Wilfred Dolfsma always kept a word of encouragement for me as well. It took some time to set things in motion but I enjoyed the endless talks, about all sorts of things, sometimes including my thesis, with my supervisor, Ludovico Alcorta. Not only did I learn his real name is different, but that he has a special sense of humor and an infinite capacity to deal with my complaints. Robin Cowan was the institutional figure in all this process, always keen to support my request for almost anything I needed, from travel to reference letters. Thanks to both for keeping their fait on me. Pierre Mohnen provided with very concrete pieces of advice on the analytical sections of my thesis. Geert Duysters showed it is possible to do your own research while caring for the career of the students. The discussions at the Ivory Tower certainly enriched academic life at the Institute.

The Globelics community offered permanent intellectual guidance, opportunities for networking and, most importantly, space to make long-lasting friendships with both senior and junior innovation scholars. My new colleagues at IDRC have helped in the transition from academia to the real world of work on science, technology and innovation and its relevance for development from a practitioner's perspective.

My greatest debt is with my family, particularly my eldest son, Mauricio. I was the father that lived on a computer screen, the father that he could only see for a few months every year and that was permanently busy doing research. I am impressed by his capacity to deal with the distance and his growing ambitions to become a scientist himself. Veronica patiently played the role of both father and mother, while managing to keep her career going back in Mexico. Trust they at least enjoyed part of this adventure. Little Sebastian, who recently joined the family, will miss the fun but not the stories from his big brother. Nohemi (my mother), Victor, Margarita, Alfonsina, Samuel, Elizabeth, Erika, Mirna and Gaby were permanently present. Mrs. Maricela and Mr. Fernando diligently looked after my family whenever I was away.

As I begin to digest my experiences at UNU-MERIT, its changing social dynamics, and all the transformations the institute underwent during my stay, I would like to believe the balance is positive. I just hope students there will remain a balancing force and would continue to actively make the institute a place worth to be in. 


\section{Introduction}

\section{A study on human resource management practices and learning for innovation}

The use of the systems of innovation framework to study learning and innovation dates back to the mid-1980s (Freeman 2002; Lundvall et al., 2002). The most immediate roots trace back to three pioneering works: ${ }^{1}$ Freeman's (1987) study on the Japanese innovation system; Nelson's (1993) analyses of the systems of innovation in a number of developed and "dynamic" developing countries from a historical perspective; and Lundvall's (1992) propositions on user-producer interactions as bases for the construction of national innovation systems. These seminal works have led to substantial research intended to refine the foundations and analytical tools of the framework.

Notwithstanding its newness the concept of systems of innovation is rapidly becoming the common language of scholars and policy makers (Lundvall et.al, 2002; Smith 2000), ${ }^{2}$ who are adapting and applying it to the study of developing countries. In addition to the chapters on Argentina, Brazil, South Korea and Taiwan in Nelson (1993), others have conducted research on Latin America (Alcorta and Peres 1998; Cassiolato et.al, 2003; Cimoli and Constantino 2000), Asia (Chang and Shih 2004; Mani 2002) and Africa (Muchi et.al, 2003). The large and dynamic economies of Brazil, Russia, India, China, South Africa (BRICS) and Mexico have received the most attention in the literature (IDRC 2007; Dutrénit et al 2010).

A relevant lesson to emerge from the literature on systems of innovation is that learning and innovation are interactive, socially embedded processes that take place within particular socioeconomic, institutional and cultural contexts (Gibbons et.al, 1994; Lundvall 1988 and 1992). Strongly linked to this is the focus on determinants of innovation at the micro level and more specifically, the learning processes of firms (Edquist and McKelvey 2000; Lundvall 1992; Lundvall et.al, 2002). The quality and quantity of human resources is cited among the top factors that contribute to this learning and innovation (Barney 1991; Leonard-Barton 1992).

Researchers have striven to identify and understand the factors that determine both the quantity and quality of human resources for science, technology and

\footnotetext{
${ }^{1}$ Freeman (1995) and Lundvall et al., (2002) acknowledge that inspiration for seminal contributions to the literature on systems of innovation go back to Adam Smith and notably, the German philosopher Friedrich List.

${ }^{2}$ Comprehensive accounts of the factors explaining such rapid diffusion are found in Smith (2000), Lundvall et.al, (2002) and Freeman (2002)
} 
innovation (STI). Significant research is conducted on the development and performance of universities and other higher education and research organizations. This is understandable as sound empirical evidence shows the critical role of such organizations to research capacity building and innovation. In such a way those organizations significantly shape the functioning of systems of innovation in general (Nelson 1991; Pavitt 1998), and developments in labour markets in particular (Lijima and Tachiki 1994; Velloso 2002).

In the case of developing countries, the supply biased approach is applied to study the development of human resources for STI. For instance, in his book on systems of innovation Nelson argued that the lack of synergy between industry and post-secondary institutions in South Korea was a result of the strong teaching orientation of its education organizations (Nelson 1993). In the cases of Argentina, Taiwan and Brazil attention centred on the performance, development, structure and quality of formal education systems (Nelson 1993). More recent research addresses education in general and universities in particular, as important background in exploring and analysing economic activities and the knowledge inputs that lead to industrial innovation (Cassiolato et.al, 2003; Cimoli and Constantino 2000). These studies typically carry out international comparisons of structures and performance of education and training systems. These works underpin what Freeman (1995) called league tables of cross-country rankings of average years of schooling; enrolment rates by core knowledge-fields; education levels among different cohorts of population and particularly, of the labour force; quality as measured through educational attainment and output in a number of S\&T indicators, among others. Examples are found in Alcorta and Peres (1998); Chang and Shih (2004); Lichtenberg (1994); Nelson (1993); Oyelaran-Oyeyinka and Barclay (2004) and Valenti and del Castillo (2000).

By contrast the study of determinants of the demand for human resources usually limits to assessing the capacity of an economy, notably private firms, to accommodate the supply of highly qualified human resources. Arguably in order to develop, absorb and use economic relevant knowledge, shaping strong education systems is sine qua non condition for success. Sound empirical evidence and theoretical reasons support recurrent concerns regarding the contribution of education systems to building the supply of human resources (Nelson 1959; Pavitt 1998). This narrow focus on the role of supply raises questions as to whether some other factors have been overlooked.

This thesis seeks to explore and identify factors other than academic environments that contribute to the effective development of human resources for STI. In particular it sheds light on the relationship between human resource management practices and learning for innovation in developing countries. To this end, the thesis draws heavily on and contributes to three strands of literature, namely: (1) systems of innovation, with a specific focus on developing countries; (2) 
human resource management practices and innovation performance at the level of the firm; and, (3) learning through R\&D. These are outlined below.

First, in relation to the literature on systems of innovation and the economics of innovation more generally, this thesis departs from traditional inquiries into the strengths of the systems framework, and instead examines some of its shortcomings. It emphasizes weaknesses associated with the approaches typically used to identify determining factors in the development of human resources for scientific and technological activities, notably R\&D. To date, research in the field focuses narrowly on supply rather than the demand for those human resources.

Firms are the locus of learning and innovation, how they carry out activities that bolster these areas influences the actions of other relevant agents in the environment. In other words firms shape and guide the operation of systems of innovation (Nelson and Winter 1982). If this is the case, then it is important to investigate how firms contribute to the development of human resources for STI. In recent works by Lundvall et al. (2002), (White 2002) and Arundel et al. (2007), for example, attention is drawn to the role played by human resource management practices as mechanisms shaping learning environments and research, capacity building within organizations, in fact, the functioning of systems of innovation.

Second, the thesis draws from recent research on the linkages between human resource management practices and performance at the firm level, and specifically, studies that emphasize innovation as relevant performance indicator. The thesis addresses the influence of management practices on learning and innovation in developing countries. This focus represents a major contribution to the field, as research in this area has traditionally examined the case of developed countries. By exploring developing countries, new insights can be gained regarding the role human resource management practices play in fostering absorptive capacities and innovation within firms operating in catching up contexts.

Third, by tapping into research on individual and organizational learning, this thesis identifies some relevant factors explaining learning for innovation at the firm level. Previous studies have addressed the context in which firms operate, the nature of learning and innovation processes inside organizations, and the learning objectives firms pursue over time. Consistent with literature on developing countries, this thesis interprets R\&D as referring to learning, a mechanism that promotes absorptive capacity and which supports technology capability-building (Dutrénit 2000; Kale and Little 2007). The analysis differs from traditional views of innovation that emphasize such outcomes as patent counts, number of products/processes and corresponding degrees of novelty, which are unable to provide a comprehensive picture of the complex learning processes that firms undertake.

The analytical framework used in this thesis distinguishes between learning as a strategy, and learning in terms of the knowledge gained by the firm. Firms pursue 
diverse objectives during the innovation process, encourage different learning strategies, and require distinct types of knowledge flows in order to generate new and creative ideas. R\&D is a core component of the learning process. Moreover, different knowledge requirements associate with distinct R\&D outcomes that in turn, show distinct degrees of novelty, at least for the firm. Contingent on these factors, firms adopt different types of human resource management practices. It follows then that the contribution of such practices to innovative performance should differ as well.

This thesis differs from previous studies in the field, as it emphasizes the importance of examining learning. It also circumvents some challenges encountered in previous research where the intention is to trace direct links between human resource management practices and innovation at the firm level. Such studies find it difficult to explain how and why management practices underpin innovation. So far the role of learning as an intermediary process remains insufficiently explored in both the systems of innovation and management literature. While the data collected for this study steered the focus of the analysis on learning at the organization level, the underlying logic is that such learning reflects and feeds back and forth to learning at the individual level. Chapter 1 explains this in detail.

As an additional contribution to the literature, this thesis seeks to provide a clearer understanding of how human resource management practices underpin learning for innovation in a single industry. This approach allows for a more in-depth appreciation of the context in which such a relationship emerges; in other words, how both local and global factors shape a firm's learning and innovation efforts. For instance, the environment impacts business strategies and perspectives, notably incentives and directions for investment in R\&D. Thus, the analysis that will be undertaken here will follow from the predominant view in the literature regarding the importance of understanding the characteristics of and differences in innovation processes across industries and, arguably, countries (Laursen and Foss 2003; Lorenz and Wilkinson 2003; Lundvall et al 2007). This makes it possible to identify the areas where countries, firms and ultimately human resource management practices are able to contribute to industry learning and innovation.

This thesis focuses on the pharmaceutical industry; and more specifically on the role of human resource management practices as determinants of learning in this area. This is an interesting case, as pharmaceuticals have quite significant socioeconomic, health and ethical implications on human beings; the industry invests intensively in R\&D. It is an industry where distinctions between research and development activities result in very specific patterns of specialization in how firms and countries contribute to innovation in the industry. Moreover such distinction implies that the type of personnel and associated working conditions also differ across the different stages of the pharmaceutical innovation process.

In this context, the presence of a fairly complex pharmaceutical industry in a 
developing country such as Mexico raises concerns in terms of the capacity of local pharmaceutical companies to carry out and profit from their technological efforts (Guzmán 2005; Katz et.al, 1997). It also brings into question the extent to which such efforts contribute to further advancement of human resources development for innovation in the country. In response to these gaps, this thesis addresses the following questions:

$>$ Do management practices contribute to learning at the firm level in Mexican pharmaceutical firms? If so, how? If not, why?

$>$ Which practices have the greatest impact on learning, and thus pharmaceutical R\&D in Mexico?

$>$ How do management practices shape a pharmaceutical firm's interaction with other agents in the system of innovation during performance of R\&D?

In order to examine these questions the thesis is organised as follows: A substantial literature review in chapter 1 documents how the actions of agents in nonacademic environments, notably firms, contribute to the development of human resources for innovation. The chapter discusses the role of human resource management practices as mechanisms underpinning innovation performance at the level of the firm. It also highlights the role of R\&D as a learning mechanism supporting innovation and innovation capacity building in latecomer firms.

Following this background, Chapter 2 presents the analytical framework. The chapter splits in two main sections. First it highlights the importance of understanding certain environmental factors, including the knowledge base of a firm, and the general characteristics of innovation processes framing the activities of the human resources involved in learning and innovation. This makes it possible to appreciate the context where firms operate, and consequently to understand what is feasible for them in terms of learning, innovation and, ultimately, human resource management practices. The second section outlines six alternative yet complementary analytical approaches to conducting research about management practices, learning and innovation. The discussion here draws attention to the case of Mexico. These six approaches inform the empirical analysis of this thesis.

Chapter 3 splits into two related sections. Based on an extensive literature review, section 1 defines the variables on human resource management practices relevant for the analysis. The second section describes the data and data collection methods used in this thesis.

The empirical analysis is structured in two parts. Part 1 is presented in chapters 4 and 5 . Chapter 4 characterises pharmaceutical innovation at a global level. It outlines the several stages and corresponding learning processes, and the interesting technological trends of recent years. It also identifies the areas within the innovation process where developing countries are more able to participate and how they 
do so. The chapter suggests the need to pay more attention to R\&D and other innovation-oriented activities carried out at the advanced stages of the innovation cycle, which is where developing countries concentrate the bulk of their technological efforts. Complex scientific and technological developments in pharmaceuticals, the time consuming and burdensome procedures required for new drug testing and development attract considerable attention in the literature. This notwithstanding, recent initiatives launched by health authorities in the leading American pharmaceutical market seek to favour innovation in drug manufacturing. Increased automation, systematization and enhanced scientific-based management of manufacturing processes expect to enhance efficiency, workplace conditions, and product quality and safety. The diffusion of such initiatives to developing countries raises interesting issues for research.

Chapter 5 introduces the pharmaceutical industry in Mexico. The country is an interesting case for study, considering the relative influence of its economy in Latin America. Moreover, the country is the tenth largest pharmaceutical market in the world, and the second largest in Latin America, and is in close proximity to the dynamic US pharmaceutical market. By looking at the Mexican experience, some interesting conclusions can be drawn with regard to the role of technology and employee conditions of the pharmaceutical industry in Latin America. The chapter characterises pharmaceutical-related learning and innovation activities in Mexico. Hence, it examines the context in which human resource management practices come into play during learning and innovation processes in the country.

Part 2 contains the econometric analyses. Chapters 6 through 8 explore the linkages between human resource management practices and learning for innovation. Based on the case of the pharmaceutical industry in Mexico, the work follows Delery's (1998) suggestion as to the importance of looking at how management practices influence performance. The three interconnected chapters consider how a similar set of human resource management practices underpins distinct learning strategies within a firm. Based on traditional transaction costs theory (Williamson 1975 and 1985), the analysis first focuses on individual choices of learning strategies. In this scenario firms may produce technology based on internal technological efforts (chapter 6); alternatively, firms can tap external knowledge sources as an exclusive means to acquire technologies (chapter 7). Finally, learning strategies are taken as being not mutually exclusive (Veugelers 1999). Knowledge flows obtained from external markets for technology, complement learning efforts in-house (chapter 8).

The three econometric chapters use distinct definitions of $R \& D$, thus implying the different knowledge requirements that firms need to fulfil in order to innovate. In line with knowledge-based theories of the firm, firms can either exploit knowledge available within their customary knowledge base, or seek out knowledge thus far unavailable to them. The empirical analyses reveal positive linkages 
between management practices and learning at the firm level, and indicate that relationships are contingent on factors such as the expected outcome from R\&D, or the novelty of the knowledge required by the firm.

Chapter 9 concludes with an integrative view of management practices and learning for innovation in the pharmaceutical industry in Mexico. Building on the empirical analysis, the chapter offers some recommendations for further research on the linkages between management practices and learning for innovation in Mexico and other similar developing contexts. 



\section{Chapter 1}

\section{Development of human resources for innova- tion: Reappraising the contribution of firms ${ }^{1}$}

\section{Introduction}

The introductory chapter argued that the innovation systems approach remains an underdeveloped area of research. ${ }^{2}$ There are a number of challenges, particularly with regard to studying the case of developing countries. A major weakness stems from traditional analyses of the processes supporting development of human resources for STI activities, notably R\&D. Much attention is paid to investigating how learning within educational organizations underpins the supply of such resources. By contrast, still relatively little is known about the extent to which other agents, such as firms, can also contribute. Further exploring these issues should enhance the analytical power of the systems of innovation framework. Potential research topics are many, from macro to micro, from public policy to labour markets and firm related aspects; section 2 of this chapter addresses these topics in greater detail. Section 3 discusses some recent studies on the influence of human resource management practices on innovation performance at the firm level; these constitute the basic theoretical underpinnings of this thesis. The discussion here highlights some issues requiring further research; in particular the role of learning as an intermediary process between human resource management practices and innovation performance. Addressing firms in a developing country context, section 4 argues about the importance of looking at $R \& D$ as a learning mechanism requiring a strong commitment and effort at both the individual and organizational levels.

\section{How non-academic environments contribute to the development of human resources for science, technology and innovation}

There are at least two broad, but to a certain extent, complementary perspectives to analyse how non-academic agents contribute to the development of human resources for STI (Figure 1.1). On the one hand, the literature indicates the role of

\footnotetext{
${ }^{1}$ This chapter benefited from comments and suggestions by people attending a mid-term progress Seminar at UNU-Intech, 2005; participants at the 2nd Globelics Academy, particularly Rui Baptista and Pedro Conceição; the $3^{\text {rd }}$ and $4^{\text {th }}$ Globelics Annual Conferences 2005 and 2006, respectively; Gabriel Yoguel and Jorge Katz.

${ }^{2}$ Lundvall et al (2002), Freeman (2002) and Malerba (2002) provide more ample discussion.
} 
policy interventions, particularly through activities promoting human resource development. On the other hand there is the dynamics of labour markets. Each of these is discussed in more detail below.

Figure 1.1 Alternative approaches to investigate the role of non-academic factors on the development of human resources for science, technology and innovation.

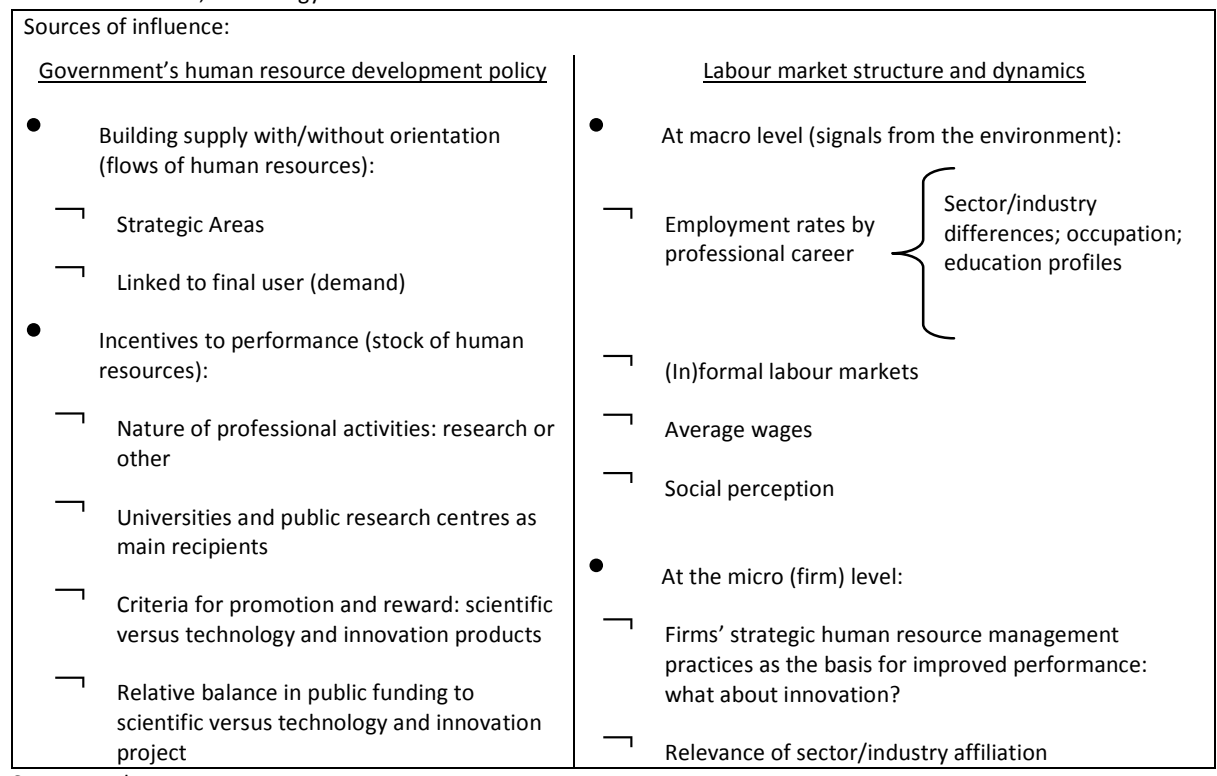

Source: author

\subsection{The role of public policy}

Different rationales support public interventions in STI including the development of human resources in the field. The argument of market failures is recurrent. Governments compensate for the missing or inadequate investment by the private sector in socially relevant areas, but with unattractive rates of return. Alternatively public policies compensate for system failures, including coordination and the nature of linkages among agents in systems of innovation (Smith 2000). Adoption of an evolutionary perspective hints at the capacity of public policy: (i) to adapt and adjust through sequencing and packaging of policy interventions (Kuruvilla et.al, 2002); and, (ii) to allow for the complementary actions needed to impact on performance, motivations and reactions of the agents involved (Metcalfe 1994; Mohnen and Roller 2005).

With regard to public policy, particularly in support of human resource development, research focuses on government's contribution to building scientific and technological capabilities (Mani 2002; Sanz-Menéndez and Cruz-Castro 2005). Based on evidence related to postgraduate scholarship programs in countries such as Mexico and Spain, Ortega et.al, (2002), Sanz-Menéndez and Cruz-Castro (2005) 
and FCCT (2006) documented how governments assign priorities, or promote the development of specific knowledge-fields particularly at the tertiary level. Consideration of the demand for human resources often restricts to whether government-sponsored programmes meet the requirements of final users. In other words, the extent to which supply and demand for qualified human resources matches in labour markets (Quinn and Rubb 2006; Teichler 1999; Wei 2005).

Arguably the contribution from public policy is more complex. Lijima and Tachiki (1994), Govinda (1998) and Kuruvilla et.al, (2002) show how public policy interventions in some Asian countries have contributed to the supply of human resources by coordinating and aligning it with the requirements of other agents, notably firms. This approach makes sense as the internal labour dynamics of firms ultimately reflect those of the larger labour markets of a country-see section 2.2.

Governments can guide the activities of researchers in public institutions; even transfer part of those resources to the private sector. In this manner public organizations contribute to capacity building and the balancing of supply and demand for human resources (Sanz-Menéndez and Cruz-Castro 2005). Alternatively by implementing differentiated sets of incentives, sanctions and rewards, governments can promote particular activities in the labour market, guide further development of the stocks of human resources, and to a certain extent, inform individuals' choices of professional careers (Castaños-Lomnitz 2004; Ruíz 2004). This is the result of supporting and financing specific research activities, but not others, via research grants, competitive funds, enhanced recognition and other pecuniary and non-pecuniary incentives (AMC-FCCT 2005). Similar effects stem from the definition and application of specific criteria to evaluate research performance. People develop different professional paths in response to specific incentives; they can do more basic or applied research, or to work on a public research organization or an R\&D unit within a firm (AMC-FCCT 2005).

\subsection{Labour market dynamics and careers in science and technology}

Back in 1992 Lundvall's seminal work on innovation systems recognised the notable absence of analyses of national education and training systems (Lundvall 1992). For reasons that he unfortunately did not explain, he did not address what he qualified as an 'extremely important' element of systems of innovation: education systems. Lundvall decried the resulting gaps in knowledge about factors influencing the supply of human resources, namely: the characteristics and determinants of expenditure in education and training, enrolment rates in science and engineering, availability of skilled workers, and so on. Lundvall stressed the limited understanding we have about formal and informal education and training systems conditioning innovative capabilities across countries, but also about social norms and values reproduced through education. He called for the integration of "education and training 
systems and innovation systems in one single analytical framework" (Lundvall 1992:14-15).

A decade later Lundvall and his colleagues observed the persistent lack of indepth scrutiny of education systems and, it would appear, a lack of interaction between such systems and other agents shaping systems of innovation (Johnson and Lundvall 2003; Lundvall et.al, 2002). In response, they highlighted missing factors related to the supply of human resources. They also brought attention to, without necessarily addressing, the need to increase awareness and understanding of market demand and its relationship to the development of human resources for innovation. In their view research has ignored the influence of labour market dynamics, the organization of and the logic behind processes of knowledge creation, learning and human resources development within firms and networks.

Recent studies point to the absence of systematic research on how the functioning of labour markets shape individuals' choice of professional study and career (Taczir 2009). There is a need to learn what perceived and existing incentives within STI render it an attractive option for prospective students and employees (Quinn and Rubb 2006; Velloso 2002); furthermore what draws people to careers in engineering versus management. In a study on Portuguese firms, Texeira (2004) proposed that factors such as market, product and process strategies, and the conscious and intentional behaviour of firms, determine demand for human capital and the consequent contribution to performance. These factors are equally or even more important than a large pool of educated and skilled labourers.

The Canberra Manual for the measurement of human resources in S\&T clearly asserts that students entering into or already attending college or university only become part of the stock of human resources in S\&T upon graduation (OECD 1995:32). Educational institutions and labour markets respond to different incentives and have distinct working dynamics (OECD 1995 and 1998). Consequently, it is pertinent to learn why, when, how, and to track how many students choose STI as a path of study and/or employment. Equally relevant is to find out why people avoid study (and work) in this field? Low numbers of people working in STI in developing countries reflect something more than poor absorptive capacity of local labour markets.

Related to the above, unlike recurrent interest in learning about what factors entice students at the tertiary level to a career in science and engineering, so far little is known about the conditions and incentives behind the work of industrial researchers in developing countries. Literature suggests that different organizations, notably industry and universities, have distinct perceptions of knowledge as an imperfect public good (Arrow 1962; Nelson 1959; Pavitt 1998; Stephan 1996). It makes sense to think that a professional career in industrial research follows a different path as compared to one in academic research (Gibbons and Johnston 1974; NSF 2004; Stephan and Audrestsch 2000). The question is why careers in 
academic and industrial research differ from each other, what determines their attractiveness? Are there any differences in how such research careers develop in developed and developing countries?

\subsection{Development of human resources for STI in private firms}

A third dimension from the perspective of demand confronts the questions of whether firms contribute to the development of human resources for S\&T and innovation, and if so, how they do so. Some of the literature suggests that the answer is yes, firms contribute to such a process. Moreover firms do so by means of human resource management practices that impact work environments, and in turn people's capacity and willingness to become involved in STI. The view that firms are sources of learning and innovation implies that they are producers and not merely users of highly qualified human resources. These topics will be explored in more depth in the remaining sections of this chapter.

\section{Management of human resources and firm's performance}

In his analysis of the spread of Japanese management techniques to developing countries, Kaplinsky (1995) criticised economists for their traditionally narrow approach to production as a technical outcome of different combinations of productive factors. In his opinion such a limited view is problematic as it abstracts firms from the richer social context in which they operate. Moreover it fails to explain how the application of individual combinations of factors yields very different outcomes contingent on the way production is organised (Nelson 1991; Wilkens and Pawlowsky 1997). Kaplinsky (1995) further asserts that productive inputs are mobilised within particular social structures

In line with the above, the literature demonstrates increasing interest in understanding the alternative knowledge management practices used by firms, ${ }^{3}$ and the characteristics of high-performance work-practices in high-performance workplaces. ${ }^{4}$ Scholars address the broad socioeconomic contexts framing the adoption of innovative organisational strategies; ${ }^{5}$ practices shaping dynamic workenvironments, ${ }^{6}$ and how they assist in responding to competitive market pressures, improve production, productivity, financial performance and so on. ${ }^{7}$ Enhanced work practices put great premium on investment in a firm's intangible assets, ${ }^{8}$ and rely strongly on innovative organisational practices and continuous development of

\footnotetext{
${ }^{3}$ Argote et.al, (2003) and Collinson (2001)

${ }^{4}$ Barton and Delbridge (2001), Lorenz and Wilkinson (2003) and OECD (1998)

${ }^{5}$ Doeringer et.al, (2003), Legewie et.al, (2000)

${ }^{6}$ Hemmert (1998), Livesay et.al, (1996), OECD (1998), Terziovski and Morgan (2006)

${ }^{7}$ Bae and Rowley (2004), Bartlett et.al, (2002), Beret et.al, (2003), Ichniowski et.al, (1997), OECD (1999)

${ }^{8}$ Alic (1995) and Sargent and Matthews (1997)
} 
human resources. ${ }^{9}$ In summary, management practices assist in organising and coordinating knowledge creation and exploitation in systems characterised by complex social relations (Laursen and Foss 2003). At least in part, such is the logic of studies linking management interventions to increased efficiency, productivity gains and so on. ${ }^{10}$ Nothing prevents the use of this same logic to study the allegedly positive relationship between management practices and firms' innovation performance (Laursen and Foss 2003; Michie and Sheehan 1999 and 2003).

\subsection{Do management practices influence innovation?}

Nelson and Winter (1982) assert that firms are responsible for most innovations. Consequently, learning about internal organisation and work practices sheds light on how systems of innovation function and are built (Coriat and Weinstein 2002; Hemmert 1998). To complement analyses of R\&D efforts and other technology development processes, it is necessary to investigate the experiences of workers, engineers, salesmen, and so on, and their perceptions of daily operations (Hemmert 1998; Lundvall et.al, 2002). As stated by Lundvall (1992), whenever challenges arise in production or post-production, changes need to be made that will ultimately shape the firm's innovative efforts. In his view, workers' daily experiences contribute to signal the direction in which such changes should proceed; organisational strategies frame the complex set of interactions taking place within and outside the boundaries of a firm (Smith 2000; Zanko et.al, 1998). Arguably these and related factors determine the direction and intensity of the innovative practices that firms carry out (Lundvall et.al, 2002). Ultimately innovation involves more than the simple transfer of knowledge from academic or other connected environments to the productive sector (Gibbons et.al, 1994).

Dynamic work-practices present potential implications for the contribution of human resources to innovation systems. Higher job complexity requires greater interdependence, communication and feedback among firms and between firms and their customer-supply bases (OECD 1998; Okada 2004). This is true at the 'shopfloor' level, but also for the organisation, management, training, reward for continuous creativity, and enhancement of skills featured by innovation-related personnel (James 2002; Mumford 2000). In addition to changing education requirements, greater weight is placed on continuous learning, training and improved performance (Gray et.al, 2004; OECD 1998). Heterogeneity means that there are multiple optimal ways to organise human resources to carry out innovation (Hemmert 1998; Senge 1990).

Lorenz and Wilkinson (2003) assert that research still needs to document the

\footnotetext{
${ }^{9}$ Barton and Delbridge (2001), Gray et.al, (2004)

${ }^{10}$ Boseli et.al, (2005), and Ichniowski et.al, (1997)
} 
conditions required for high-performance workplaces to become a generalised model to manage human resources; what are the consequences of such adoption? Subject to debate is the extent to which the dynamic organisational model constitutes a new 'best-practice' method that can be adopted across sectors and national boundaries; that is, whether it is possible to develop heterogeneous models applicable to diverse national and institutional contexts. Research should be conducted on how firms' unique characteristics, the external environment and even the internationalisation of activities contribute to the adoption and impact of highperformance work-practices (Doeringer et.al, 2003; OECD 1998).

\subsection{The intermediary role of learning}

Few studies have explored the factors linking management practices to innovation performance. Thus, there is poor understanding of the mechanisms that can explain such a relationship (Laursen and Foss 2003; Lorenz and Wilkinson 2003), and the absence of a coherent theory on what Delery (1998) terms the "transmission mechanism" from human resource management practices to innovation performance. This thesis addresses this gap by examining firms in the context of developing countries. It contends that the difficulty in capturing such a transmission mechanism derives from customary approaches to research. For instance Lorenz and Wilkinson (2003) assert that researchers frequently assume linear relationships--from adoption of specific sets of management practices to innovation, leaving little room for more heterogeneous organisational strategies within single industries. It is customary to look at innovation outcomes---products/processes, and their degrees of novelty--radical/incremental; this oversimplifies the richness of the processes involved. Underestimated it is the study of the latent processes associated with the organisation of innovation-related staff.

A firm's human resources constitute both factors of inducement and a limit to performance (Leonard-Barton 1992; Penrose 1959). The services those resources render to the firm, rather than their presence, is what matters for performance. The ways to channel those services are conditioned by how resources are organised and used. Building working environments conducive for all these processes to take place is imperative for firms wanting to improve performance and, more specifically, their capacities to innovate. In this regard Amabile (1996), Mumford (2000) and James (2002) argued that research should further explore factors underpinning creativity, ways in which creative thinking spreads across groups, organisations and the wider environment in which firms operate. This assumes continuous searches for ways to organise personnel, particularly those involved in, but not limited to, R\&D.

Alternatively, recent work by Lorenz and Valeyre (2005) and Arundel et.al, (2007) on organisational and management practices, learning and innovation, argue for the value of examining more carefully the effects of management practices on 
individuals' and thereby, organisational learning. Accordingly the main hypothesis in this thesis is that learning is one intermediary mechanism between human resource management interventions and innovation performance at the firm level. Wright et.al, (2001) support this hypothesis; they propose that human capital and knowledge are bridging concepts between management systems and firms' core competencies. ${ }^{11}$ Dynamic capabilities in the sense of Teece et.al, (1997), constitute a renewal component that ties all those four concepts over time.

Human capital, as a stock for the firm, constantly changes through the creation, transfer, and integration of knowledge flows in ways that are valuable, rare and inimitable (Barney 1991). Therefore, "people management systems create value to the extent that they impact the stock, flow, and change of intellectual capital/knowledge that form the basis of core competencies" (Wright et.al, 2001:715). Such factors as increased knowledge, skills and abilities need to accompany people's capacity and motivation to perform (Combs et.al, 2006).

Figure 1.2 depicts the elements of the framework guiding the work in this thesis, namely: human resources management practices and the latent learning processes linking such practices to innovation performance at firm level. The figure suggests that learning processes inside the firm decompose into both individual and organisational forms. In terms of the work in this thesis, ${ }^{12}$ the logic is as follows: The upper part of Figure 1.2 shows the traditional way to study the linkages between human resource management practices and firm's performance. Based on a productivity function, scholars explore how adoption of certain human resource management practices-whether individually or in bundles-- contributes to innovation performance. As noted earlier, although researchers find positive relationships, subject to debate is why this is so.

By introducing the notion of learning as intermediary process between human resources management practices and innovation, brings research onto a longer but, arguably, more illuminating path. It is necessary to learn how management practices influence cumulative learning processes within organisations. The process starts with the learning activities of individuals, subject to management interventions, and continues in a cumulative manner throughout the organisation. Individual and organisational learning are processes within a series of feedback loops spanning different dimensions and instances within and outside the organisation.

\footnotetext{
${ }^{11}$ Human capital consists of human (the knowledge skills, and abilities of people), social (the valuable relationships among people), and organisational (the processes and routines within the firm) factors (Wright et.al, 2001)

${ }^{12}$ At first sight Figure 1.2 looks rather lineal, other arrows, indicating additional and more complex relations among the different components, can be added. For instance, from innovation performance back to individual/organisational learning. Based on the relevant literature this thesis effectively deals with the influence of human resource management practices on innovation performance at firm level. Accordingly, the decision was made to keep the graphic representation as simple as possible.
} 
Figure 1.2 Schematic representation of a proposed approach to research on human resources and innovation performance at the firm level.
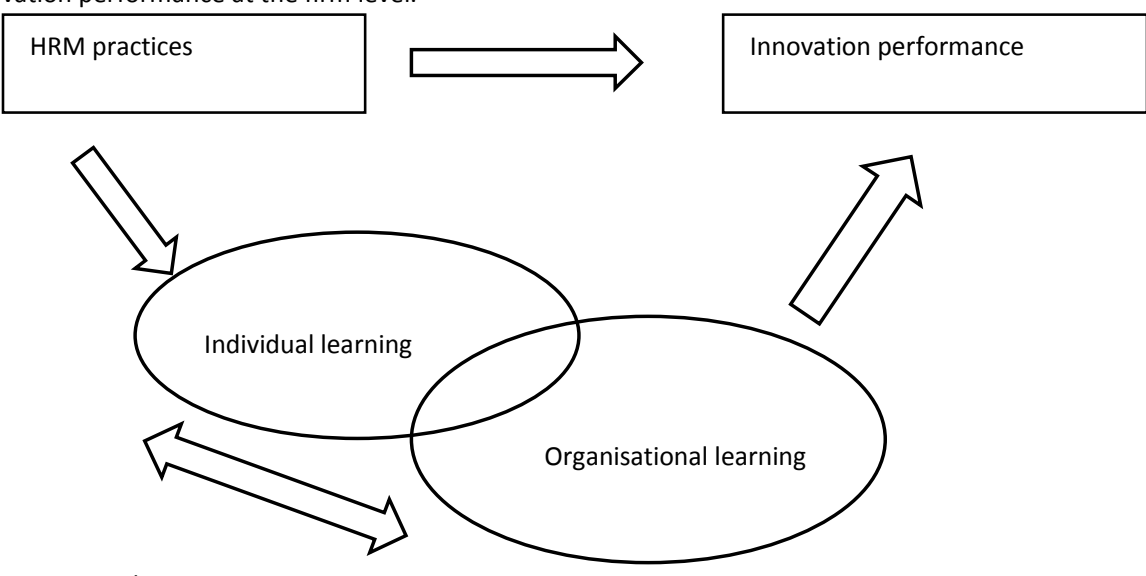

Source: Author

\subsubsection{Individual learning}

Knowledge creation within organisations is a complex, cumulative, multilayered process. It begins at the individual level since employees are the building blocks of any organisation (Nelson and Winter 1982; Nonaka 1994; Nonaka and Takeuchi 1995). Simon (1991) suggests that organisations only learn through their members and/or by employing new members who add knowledge previously unavailable. The cognitive potential of organisations is, to a considerable extent, determined by accumulated skills and knowledge of their individual members (Nelson and Winter 1982). In this regard, the literature on cognitive and behavioural sciences points out that individual learning involves processes of continuous creation, destruction and re-creation of cognitive structures (Ambrosini and Bowman 2001; Fiol 1994; Fiol and Lyles 1985). Individuals scan the environment for information, select, prioritise and adapt what they find, interpret their findings and apply them to their existing cognitive structures (Lane and Lubatkin 1998). Fiol (1994) points out that this process needs not be conscious or intentional and does not necessarily immediately modify behaviour. Rather, it leads to new interpretations or meanings of available information. A comparison of different interpretations takes place until a new understanding of the issues at stake is achieved. All dimensions of learning feed on each other and result in a series of loops and interactions that are difficult to explain by individuals within organisations, but which clearly take place.

Vinding (2006) suggests that the amount, level and quality of knowledge available within organisations positively correlate with the size of the stock of knowledge feeding organisational learning. This, in turn, allows for better judgement in the search, selection and analysis of even newer internal and external information. Education is one of the key inputs for building individuals' expertise, 
some of which can be codified into articles, books, drawings or other forms of storable figurative communication. Yet education is not sufficient to build an advanced level of individual knowledge. Brusoni (2002) and Loasby (2002) assert that the application of the principle of division of labour to knowledge, results in specialisations along disciplinary, functional or institutional lines, as well as the emergence of scientific knowledge that increases the productivity of knowledge and provides frameworks and foci for addressing a variety of issues. The more individuals advance in their areas of specialisation, the more expertise they acquire and the larger their potential contribution to organisational knowledge. Cohen and Levinthal (1990) and Lundvall and Johnson (1994) expand the role of knowledge specialisation by arguing that expertise involves not only substantive technical know-how, but also capacity to access relevant information.

Individuals' knowledge and their learning skills can be substantially augmented by what Amabile (1997) calls "something extra", or creative thinking. Creativity is defined as the production of novel ideas in any domain and creative thinking refers to a cognitive style favourable to taking new perspectives on problems, an application of techniques (or 'heuristics') for the exploration of new cognitive pathways, and working styles conducive to persistent, energetic pursuit of one's work. Amabile (1997) and Sternberg et.al, (1997) claim that creativity often requires being at the forefront of emergent research, combining analytical and practical abilities, and possessing traits such as being an independent thinker, having inner motivation and drive; and taking risks. They suggest that creativity is best nurtured within an environment conducive to exploration.

The importance of individual knowledge for organisational learning is further underscored by the fact that a significant part of the knowledge accumulated by individuals is tacit (Nonaka 1994; Nonaka and Takeuchi 1995; Polanyi 1966). Tacit knowledge refers to meaning acquired through experience and is difficult to formalize or communicate. It emerges during the actions and activities that individuals undertake during their lives and relates to the context in which these take place. The more diverse the experience the richer the content of tacit knowledge; Nonaka (1994) and Nonaka and Takeuchi (1995) state that tacit knowledge involves cognitive structures, based on mental models that provide overall positive and normative perspective to actions and activities, as well as technical elements, based on know-how and practice under specific circumstances.

Tacit knowledge is the practical foundation of individual skills (Nelson and Winter 1982). Nonaka (1994) and Nonaka and Takeuchi (1995) add that individuals' intentionality or willingness to practice the search for meaning in their environment in order to understand and improve it, is critical to enhance individual knowledge. In their view, intention and freedom are major forces motivating individuals to expand their individual knowledge. Kim (1998) complements this view by pointing out that, in addition to motivation or, perhaps, a consequence of it, intensity of effort, or the 
amount of energy individuals use to solve problems, constitutes a major driver in the construction of meaning in organisations. In sum, individuals are the beginning and a major source of organisational knowledge and learning. Through exploring education and training, creative thinking, experiences and beliefs, expertise and relationships, intentions and freedoms and intensity of efforts, individuals contribute to learning and innovation in organisations. Building suitable working environments that nurture these processes is imperative for firms to succeed.

\subsubsection{Organisational learning}

Economics often depicts organisations as systems that process information in order to make the appropriate decision in light of uncertainty (Casson 1990; Nonaka 1994; Nonaka and Takeuchi 1995). Neoclassical theories of the firm see knowledge creation as an input-output problem-solving activity, which merely requires adequate processing to yield unambiguous solutions. However, Nonaka (1994) points out that this approach underestimates the nature of the activity at stake; it excludes the possibility of explaining the potential of firms to create new information and knowledge. To conceptualize organisations as information processing entities assumes uniformity of learning processes which is not the case. Organisations have cognitive structures and memories; over time, they develop behaviours and mental representations that perpetuate their social patterns. Nelson and Winter (1982) and Kay (2000) argue that organisational knowledge or competencies become embedded in organisational routines, which act as organisational memory. These mental representations, or routines, influence individuals' learning within the organisation and transmit organisational memory to new personnel. Organisations can possess less knowledge than that of its members if there is little or poor internal communication.

Kessler et.al, (2000), Bierly and Chakrabarti (1996) and Zack (1999) point out that organisational learning always involves choices regarding internal and external learning; firms often need to decide whether to develop their own knowledge or acquire and/or imitate that of others. The main reason to develop internal sources is to generate absorptive capacity (Cohen and Levinthal 1989). Absorptive capacity refers to the ability to evaluate and use outside knowledge. It is based on the level of related knowledge already available in firms, including basic skills as well as recent technological and scientific developments in specific fields. The rationale behind the notion of absorptive capacity is that the more objects, patterns and concepts stored in an organisation's memory, the more readily new information about these constructs can be acquired, and the easier it is to use them in new settings. This is because learning often takes place through association with patterns, situations or events already recorded in organisational memory. Absorptive capacity arises out of previous knowledge accumulation and the 
intensity of current learning efforts by firms and their members.

External sources of knowledge, in turn, bring fresh thinking and provide a benchmark for internal efforts. Sources of external knowledge are not limited to other organisations. They include external publications, universities, research institutes, government agencies, consultants and professional and personal networks. Kim (1998) and Kim and Cha (2000) developed an international dimension to this argument, by pointing out that external knowledge acquisition and imitation can function across and connect national systems of innovation.

\subsubsection{Learning strategies: exploration and exploitation}

From the discussion above two important questions emerge: (i) what is it that firms need to learn? And (ii) how can this be achieved? Multiple approaches can be used to analyze a firm's learning processes. Cumulative learning experiences involve several types of learning: (i) learning-by-doing, which supports efficiency gains in production routines; (ii) learning-by-using, which promotes increased efficiency in the use of complex systems; and (iii) learning-by-interacting, which involves userproducer interactions potentially leading to product innovations (Bell 1984; Lundvall 1992). If attention is given to final outcomes, firms seek knowledge that supports cost-reducing innovations in the form of new or improved manufacturing processes. Alternatively, knowledge for demand enhancing innovations include improvements to existing products or design new ones (Miravete and Pernias 2006). Knowledge can also underpin incremental or radical innovations, which help tailor specific technological content and the degree of novelty needed, whether in the case of firms, markets or the world (OECD 2005). Factors commonly found across these interpretations of learning relate to different perceptions of knowledge content, the distinct nature and goals of learning strategies. In the spirit of capacity building, as opposed to outcomes, Li et.al, (2008) recommend to address learning as a process whereby firms mobilise resources with a more or less clear goal in mind.

Cohen and Levinthal's $(1989,1990)$ treatment of the dual role of R\&D as a learning mechanism traces a link between management practices and $R \& D$. R\&D generates new information and knowledge underpinning searches for new market and technological opportunities through innovation. R\&D is equally relevant for assimilating and exploiting existing information and knowledge. In other words, it helps to build the absorptive capacity by tapping existing knowledge. Cohen and Levinthal $(1989,1990)$ stressed that the contribution of individuals' cognitive processes to accumulate absorptive capacity is contingent on prior knowledge and background. These elements impact an individual's capacity to absorb, assimilate, link, analyse and, eventually, create knowledge. The authors also highlighted the distinct outcomes expected from R\&D. In effect, firms can exploit their existing knowledge bases, or engage in exploration and expansion of knowledge bases. 
From a management perspective, the notions of knowledge exploitation and knowledge exploration, as central and distinguishable elements shaping organisational learning and capacity-building, are integrated in the so-called knowledge-based theory of the firm (March 1991). According to this literature, the primary role of firms, which is the basis of organisational capabilities, is to integrate specialised knowledge (Grant 1996b). The latter is often interpreted in tacit form, as know-how, skills and practical knowledge embedded within individuals considered to be core components of an organisation (Barney 1991).

Learning strategies differ in complexity, uncertainty and risk. They are shaped by the type of resources available and how firms mobilise them when seeking to accomplish specific goals. According to the knowledge-based theory of the firm, learning is a means to further exploit knowledge residing within its cognitive boundaries (Grant 1996b); the firm can gain in efficiency and productivity by refining, improving and reorganizing available resources. Alternatively, firms can engage in more risky and uncertain learning activities compelling them to explore outside their cognitive boundaries. This is through more systematic, costly and lengthy research and experimentation. That firms develop and use knowledge through either exploitation or exploration or both, is an indication of the heterogeneous, complex and distinct nature of the learning process.

In order for a firm to catch-up, learning approaches must be incorporated strategically and over a sufficient period of time. Short-term benefits from knowledge-sharing cannot sustain long-term expansion strategies without the creation of internal knowledge and absorptive capacity to support the acquisition of external knowledge (Cardinal and Hatfield 2000). The literature states that, in general, dynamic latecomer firms couple local searches, through internal learning efforts, with distant searches, knowledge diffusion and assimilation through, for instance, reverse engineering. Nelson and Winter (1982) argue that accumulated experiences eventually lead firms to develop routines that increase their efficiency and productivity in manufacturing and, in general, the management of their product portfolios. Improvements in products, processes, or both, are generally based on searches within a firm's accumulated knowledge. Conversely the more alien the intended innovation relative to what the firm knows, the larger the need to look beyond familiar cognitive boundaries. Management systems influence and play a mediatory role in these processes. Such systems influence the organisation and mobilization of individuals and their corresponding knowledge (Cohen and Levinthal 1989 and 1990; Barney 1991). Moreover they assist in the creation, transfer and integration of knowledge flows that enrich a firms' human capital, as a stock (Wright et al., 2001), in ways that are valuable, rare and inimitable (Grant, 1996).

Innovation scholars acknowledge the distinction of knowledge exploration and knowledge exploitation (Li et.al, 2008), particularly in relation to product innovation (Greve 2007; Rothaermel and Deeds 2004; Yalcinkaya et.al, 2006). Interpretations of 
the relevant concepts are heterogeneous (Li et.al, 2008). Exploitation refers to refining and efficiency, development projects, incremental innovation, strengthening existing market positions, deepening existing capacities and so on. Exploitation entails shorter perspectives, and more certainty and proximity with regard to potential benefits. By contrast exploration is linked with issues such as experimentation, research projects, radical innovation, market creation and the broadening of technological capabilities. It identifies searches for new knowledge, use of unfamiliar technologies, creation of products/services with unforeseen, or, at least, difficult to predict, demand (Greve 2007; March 1991). Exploration implies long-run thinking and greater uncertainty about future revenues and benefits.

From managerial and organisational perspectives, exploitation and exploration 'require different structures, processes, strategies, capabilities and cultures, and can have different impacts on an organization's performance' (Li et.al, 2008:107). Although the effects of exploration and exploitation on learning and capabilitybuilding can be complementary, they lead to competing resource allocation, and increased risks and tradeoffs in investment decisions. Finding the right balance is problematic; either strategy impacts the survival and prosperity of firms: “...Systems that engage in exploration to the exclusion of exploitation are likely to find that they suffer the costs of experimentation without gaining many of its benefits. They exhibit too many undeveloped new ideas and too little distinctive competence. Conversely, systems that engage in exploitation to the exclusion of exploration are likely to find themselves trapped in suboptimal stable equilibria" (March 1991:71).

For the purpose of this study, a practical interpretation of exploration and exploitation will be used based on the cognitive distance between the searched-for knowledge and a firm's existing knowledge base (Benner and Tushman 2002; Li et.al, 2008); in other words, the degree of familiarity between new knowledge and what the firm 'already knows'. This cognitive distinction between exploration and exploitation will be drawn upon to analyse innovation as a process, and as an activity involving learning efforts, behaviours, investment and strategies (Li et.al, 2008). Concepts such as absorptive capacity, technological capacity building and catching up become relevant for the analysis (Cohen and Levinthal 1989 and 1990).

The distinction made in the preceding paragraph is aligned with the view that knowledge and by extension, innovation are gradual and cumulative (Grant 1996a). Innovation can refer to the production of new knowledge, and of combining, in novel ways, already existing knowledge (Lundvall 1992). Innovation is rooted in various types of learning processes associated with the actions of many agents involved in ordinary economic activities. Such is the essence of potential complementary relationships between the two concepts (Levinthal and March 1993). R\&D and other technology acquisition activities can be approached from the points of view of either knowledge exploration or exploitation (Li et.al, 2008).

Another relevant concept to emerge from the theoretical discussion so far is 
that firms operate within a competitive ecology. This conditions ways in which learning occurs and knowledge is used. Firms compete for resources and market shares. However they can also engage in informal and formal, contract-based, interactions and many other kinds of cooperative learning behaviours with other agents in the environment (March 1991). Consequently a firm's boundaries often need to expand to allow internal and external knowledge searches and integration according to the goals of exploitation and/or exploration (Grant 1996a). Such searches frequently occur outside the physical, geographical and cognitive boundaries of the firm ( $\mathrm{Li}$ et.al, 2008); and condition the nature, success failure in learning through networks, mergers and acquisitions, contracted R\&D, technology alliances and so on (Gilsing 2006; Greve 2007; Rothaermel and Deeds 2004; Yalcinkaya et.al, 2006). The concept of knowledge flows indicates that firms are agents that can actively guide systems of innovation by launching searches within, and eventually nurture the stocks of knowledge outside their physical boundaries.

\section{Human resource management practices and learning for innovation in developing countries}

The discussion so far stressed the importance of understanding the role of the learning processes within organisations; in other words, how human resource management practices contribute to the development of a firm's innovative capabilities. This approach demonstrates the relevance of conducting research on human resource management and innovation, particularly from a development perspective. Empirical studies show the contribution that organisational practices, relating to $R \& D$ and innovation, have made toward assisting latecomer firms catch up to their competitors. Successful firms evolve as learners by assimilating and tapping into existing technologies, eventually developing capacities to generate proprietary technologies (Hobday et.al, 2004). Only when latecomer firms start to approach the technological frontier, does high quality basic research, more complex scientific techniques and instrumentation progressively gain importance to sustain productivity and competitiveness (Patel and Pavitt 1994). Transition from technology-follower status to that of technology-leader is neither linear nor automatic. Hobday et al. (2004) suggest that the transition requires, as complementary assets, gaining international brand recognition, strong marketing capabilities and control over foreign distribution channels, along with the ability to carry out the necessary organisational and structural changes.

Catching-up involves continuous efforts on the part of firms to mobilise and organise the resources they have at hand. In the case of Japan, for example, Odagiri (1998) highlighted the importance of building the absorptive capabilities, increasing efforts in training and entrepreneurship, and gaining a sound scientific and technological understanding, including mastering the production and management 
of skilled personnel. Hemmert (1998) further underscored such factors in his analysis of how Japanese firms have dealt with evolving and often adverse macroeconomic environments, and the challenges associated with business strategies posed by continuous technological innovation. Firms have had to constantly reorganise and restructure $R \& D$ in general and the management of R\&D personnel in particular. Continuous improvement in personnel management has underpinned innovative organisational practices to promote incentives, motivation and productivity and attract people into R\&D (Legewie et.al, 2000). Accordingly, Hemmert (1998) and more recently Michie and Sheehan (1999 and 2003) called for further investigation of the relationship between human resource management practices and firms' capacity to engage in R\&D.

As an interactive process of knowledge creation, diffusion and use, innovation implies the concurrence of a number of factors, internal and external to the firm, shaping the competencies or competitive ingredients that allow firms to differentiate in the market. This is coupled with the multiple directions in which information and knowledge feed back and forth across firms' departments (Lundvall 1988 and 1992). A firm's innovative capacity rests not only on a given set (endowment) of material resources, human skills and relevant knowledge, but on the way these are organised and co-ordinated in pursuit of the firm's strategic goals (Leonard-Barton 1992; Wilkens and Pawlowsky 1997). Positive effects expected from training, for example, can be enhanced if accompanied by appropriate human resource management interventions shaping incentive structures, and working conditions suitable for employees to implement newly acquired skills (OECD 1998).

White (2002) advocates the need to understand how management practices contribute to research and other technological capabilities in developing countries. In his view accumulated capabilities can erode because of inadequate or poor human resource management. This conclusion recalls Leonard-Barton's (1992:117) view of management as a double-edged sword for a firm's learning and innovation capacity. She asserted that by incorporating and organizing "unusual blends" of skills, and/or fostering beneficial behaviours not found elsewhere in competitive firms, managerial systems contribute to the development of innovation and other core capabilities. However such practices can turn into handicaps preventing firms to confront and overcome new challenges or carry out new projects.

Several studies document the challenges faced in defining and measuring innovation in developing countries (Forbes and Wield 2000; Lundvall et.al, 2002; Mytelka and Farinelli 2003). Conceptual ambiguities derive from the historical roots of the systems framework, centred on developed countries (Edquist 1997; Smith 2000). According to Edquist and Johnson (1997), who provide a bird's eye view of different definitions of innovation from a systems perspective, such ambiguity should not be problematic since definitions and analytical distinctions are neither right nor wrong. Depending on the objective, definitions can be 'good or bad; useful 
or not' (Edquist and Johnson 1997:10). In these authors' view, the systems literature is about technological innovation, organisational and institutional change. In a world where "the R\&D system was the source of innovation," ${ }^{13}$ it made sense to build an analytical framework based, almost exclusively, on R\&D inputs and outputs (Freeman 1995:10). However such a standardised procedure entails a rather limited interpretation of the sources and consequences of technical change. Formal education and R\&D are essential pillars for innovation, but there are several others. Technical change, productivity and ultimately, economic growth may depend more on efficient diffusion than on being first in the market (Freeman 1995). Innovation is rooted in various types of learning processes associated with the actions of many agents involved in ordinary economic activities (Lundvall 1992).

The former discussion provided an overview of the distinction between a narrow and a broad definition of systems of innovation (Freeman 2002; Lundvall 1992). Whereas a narrow definition "would include organisations and institutions involved in searching and exploring, such as R\&D departments, technological institutes and universities; "[a broader definition would entail more ample aspects of] the economic structure and the institutional set-up affecting learning as well as searching and exploring" (Lundvall 1992:12). Activities such as production, marketing, and finance become sub-systems where learning takes place and from which inputs to innovation flow back and forth (Lundvall 1992; Nelson 1991).

Recent studies agree that the broader definition of systems of innovation, wherein a system that creates and uses both innovation and competencies in pursuit of development goals, is best suited to analyse innovation in developing countries working behind the technological frontier (Forbes and Wield 2000; Lundvall et.al, 2002; Mytelka and Farinelli 2003). Such an extended definition allows for learning and innovation opportunities in SMEs and traditional industries, and searching for creative ways to reduce costs through design, management and production systems. Cassiolato et.al, (2003) assert that developing countries can be viewed as extended production and competence building systems linking education and labour markets to innovation. Technological modernization, the most common innovative exercise in developing countries, introduces new, more advanced machinery and equipment, or the adoption of enhanced manufacturing and managerial techniques. By contrast, formal R\&D leading to product/process innovation is less frequently used indicator (Cimoli and Constantino 2000; Corona 1997; Tecanhuey 2002).

Alternatively, developing countries are perceived as learning systems (Viotti 2002), where both modernisation through technical change and R\&D are potentially complementary activities (Hernández et.al, 2002). Based on the discussion in Chapter 1 , this interpretation is more valid where innovation is approached from the

\footnotetext{
${ }^{13}$ Stress in the original by the authors.
} 
perspective of processes, rather than in terms of outcomes (García and Calantone 2002; Li et.al, 2008). Moreover it calls for a careful appraisal of the nature of innovation and, more specifically, the contribution of R\&D to a firm's success. The literature shows that although the technological dynamism of firms from developing countries generally lags behind that of large multinationals, R\&D remains a major determinant of firms' sustainability and growth (Cardinal and Hatfield 2000; Cattozzella and Vivarelli 2007). Systematic R\&D efforts coupled with consistent business and technological strategies, and intensive use and development of human resources, have enabled some firms operating in developing countries to draw closer to their competitors in the developed world (Kim et.al, 1989; Maiti and Raghavendra 2007; Meyers 2006).

Based on Cohen and Levinthal (1989 and 1990), March's (1991), and recent work by Laursen and Foss (2003) and Hobday et.al, (2004), who examine how R\&D contributes to a firm's staying power, further research should shed light on determinants of business strategies and organisation around learning and innovation. This might enable for what Hemmert (1998) and Coriat and Weinstein (2002) qualified as a much needed firm-based 'systemic' theory of innovation. From this perspective firms would no longer be 'representative firms', 'passive black boxes' acted upon by the macro-social environment around them; rather, one would consider the diversity of organisational patterns at the firm, sector and national level. Within a systemic approach, there is room to explore how firms work, the choices they make during production, innovation and so on; how and why they take distinct forms, and how they develop over time (Coriat, 2002). 


\section{Chapter 2}

\section{Analytical framework and methodological ap- proaches to research on human resource} management practices for learning and innovation $^{1}$

\section{Introduction}

This thesis proposes the hypothesis that a firm's human resource management practices support innovation via the learning processes underpinning the latter activities. This chapter begins with a discussion of the main tenets of the analytical framework used in this thesis. The framework suggests the need to understand how organisational practices influence learning. It also stresses the importance of understanding the characteristics of the knowledge bases in which firms operate, and how these relate to the knowledge requirements of firms during the innovation process. Finally, the framework recognizes that firms do not operate in a vacuum. Learning and human resource management practices influence the relationships that firms establish with external sources of knowledge.

This chapter also presents some methodological approaches that have been applied or that could be applied in research on human resource management and performance at the firm level. Both the analytical framework and the methodology build on the management and innovation literature. Emphasis is placed on research linking human resource management, learning and innovation in both developed and developing countries. The discussion that follows presents the relevant variables that will be taken into account in subsequent chapters.

\section{Analytical framework}

The literature review in this thesis suggests that four interrelated factors shape a firm's innovative performance: (i) the characteristics of R\&D and innovation management, of which this thesis highlights human resource management practices. Such practices underpin individual learning inside the firm; (ii) a firm's

\footnotetext{
${ }^{1}$ This chapter benefited from comments by participants at the DRUID-DIME PhD Conference Academy Winter 2006, particularly Nicolai Foss and Abraham García; staff at the Research Division of the Faculty of Business Administration and Accounting, UNAM; and Javier Jasso.
} 
internal organisation, including routine production and innovative activities that support organisational learning; (iii) the industry or sectoral affiliation which conditions the nature of innovation processes and, relatedly, the kind of knowledge required, generated, acquired and used within firms; (iv) learning strategies including the complex and diverse sets of interactions between firms and other agents in their relevant environment, the national innovation system broadly defined. Figure 2.1 summarizes the four dimensions around learning and innovation.

Figure 2.1 Interactive dimensions condition a firm's learning and innovation activities

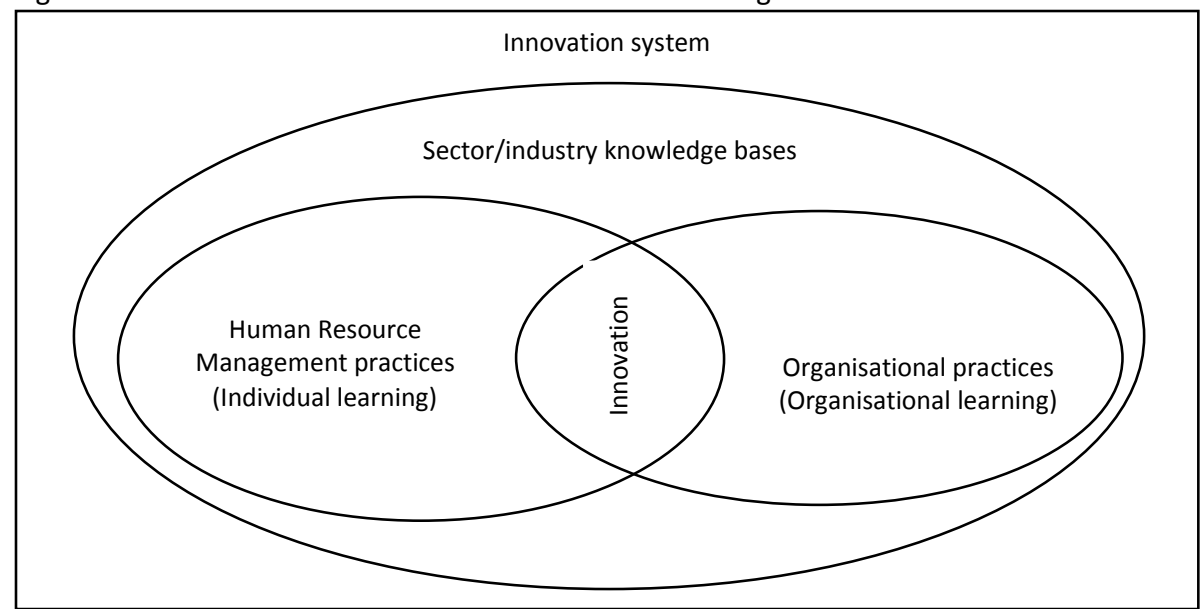

Source: Author

From a management perspective Amabile (1996:8-10) proposed a model wherein creativity and innovation are framed within a particular social context inside the firm: the organisational environment. The schematic representation in figure 2.1 takes this a step further, depicting that same organisation within the broader socio-economic environment. It proposes that knowledge bases shape and support the firm's learning, as well as its performance in terms of productivity and innovation. Moreover in figure 2.1 the notion of creativity, as a latent variable conditioning innovation, is replaced with that of learning. ${ }^{2}$ The elements of the framework are discussed below. Considering that the discussions in chapters 1 and 3 address more extensively the role of management practices, attention here centres on the remaining three instances, namely organisational practices, knowledge bases and the interactions of firms with other agents in the system of innovation.

\footnotetext{
${ }^{2}$ By replacing creativity for learning we do not imply these are substituting concepts; rather we suggest that at least these are two possible variables likely to explain linkages between human resource management practices and innovations.
} 


\subsection{Organisational practices}

Lundvall and Valeyre (2007) in the case of Europe, OECD (1998) for the OECD countries and Kaplinsky (1995) for developing countries document the interrelation between modern management practices and organisational strategies adopted by firms. Such strategies correspond to the type of management practices available for firms, and shape the environment in which learning takes place (Arundel et al., 2007). Effective organisational practices are often associated with the Japanese management style; they occur in heterogeneous backgrounds, adoption is prone to variety across firms and countries (Barton and Delbridge 2001; Kaplinsky 1995). Dynamic work practices involve adoption of new, improved and systematic organisational strategies such as Integrated Manufacturing (IM) and Total Quality Management (TQM). It also indicates the presence of human resource management practices to effectively capture, develop and use knowledge to compete in international markets. These activities include strategies to (i) expand and exploit markets for knowledge, (ii) adopt or develop new technologies requiring higher levels of skills, (iii) emphasize variety, service and quality rather than low cost (Doeringer et.al, 2003; OECD 1998).

Michie and Sheehan (1999 and 2003) reported that 'low road' management practices encouraged by labour market deregulation--short-term or part-time contracts, lack of labour union coverage and the unlikelihood of receiving workrelated training--, correlated negatively with R\&D levels and adoption of innovations. In contrast, flexibility based on 'high road' work practices--those involving high commitment to the success of the organisation, teamwork, job rotation, quality circles, TQM, high levels of training and innovative pay systems--, associated with increased investment and innovation. Dynamic human resource management practices linked strongly with the adoption of advanced organisational and manufacturing practices and technical change more broadly defined (Greenan 2003). Human resource management interventions need to be consistent with the principles guiding such organisational practices.

The literature about developing countries notes that the adoption of enhanced management and manufacturing practices tends to concentrate in large firms or those with clear export orientation. Incorporation of such techniques is heterogeneous across sectors and countries (Abramo 1997; Govinda 1998; Mertens 2005). Human resource management interventions are often fragmented and lack consistency with regard to modern organisational techniques. Organisational changes and modernisation frequently associate with defensive, survival strategies (Domínguez and Brown 1998; Gallart 2001; García 2002; Mertens 2005).

\subsection{Knowledge bases}


A firm's knowledge base denotes the technological inputs and underlying capabilities required to develop particular products; such requirements determine the simplicity or complexity of knowledge bases (Kale and Little 2007). In other words knowledge bases are highly localised and specific to product and process characteristics (Smith 2000). Production-specific knowledge bases are technically and socially shaped and concern the way technical processes fit into firms' routine activities (Lundvall 1988). The latter are associated with firms' skill-bases, production, training and management systems (Hemmert 1998; Smith 2000).

Based on the discussion in chapter 1 , exploitation of a knowledge base refers to local searches for familiar, mature, current or proximate knowledge; it builds on existing technological capabilities. By contrast, exploration of a knowledge base indicates searches for unfamiliar, distant knowledge. This interpretation of innovation draws attention to the learning process occurring inside the firm. It introduces flexibility to the analysis while capturing traditional views of innovation in terms of incremental and radical outcomes (Greve 2007). Whereas local searches may lead to incremental innovations, distant searches could lead to radical ones. Nevertheless, there is no reason for such a match between knowledge searches and innovation outcomes to always occur. Johnson and Lundvall (2003:163) indicate that firms need to adopt "new integrated competence building strateg(ies)"3 whereby they build internal competencies and management interventions.

Smith (2000) asserts that relevant economic knowledge adopts multiple forms:

- It can be highly specific, relative to factual information about specialised areas of expertise ('know-what');

- It implies basic scientific principles ('know-why') relevant to problem-solving during innovation; though there may not always be direct connection between scientific capabilities and innovative performance;

- It can be specific, selectively social when associated with certain personal relationships, access and/or contacts to key personnel and/or people ('know-who')

- It embodies practical skills and capabilities associated with aspects of production, marketing, and so on ('know-how')

Contingent on these different forms of knowledge, relevant technological knowledge bases may be informal and non-codified, in the form of skills specific to individuals or groups of individuals (Smith 2000). Moreover given the tacit nature and localized character of knowledge residing in the firm, no matter how competent individual firms are in a given area, competencies are bounded, and the ability to carry out search processes is limited. In other words, firms frequently face problems to perform innovations which require knowledge lying outside immediate areas of

\footnotetext{
${ }^{3}$ Stress in the original by the authors.
} 
expertise. In order to adopt and create new technologies, firms must be able to interact with and have access to other sources of knowledge. Returning to Smith (2000), knowledge bases are:

- Differentiated, multi-layered, involving the systemic integration of many different types of knowledge;

- Highly specific, organised around relatively limited sets of functions which firms know well. The system is thus bounded, in terms of both rationality and vision (Nelson and Winter 1982);

- Significantly tacit in their components, and embodied in the skills and backgrounds of engineers, R\&D staff, workers and managers;

- Cumulative, developed through time as firms gain experience dealing with particular technologies. Technological knowledge is path-, context-dependant (Grant 1996a);

- Costly as long as development of knowledge bases involve expensive processes of searching, learning and adaptation (March 1991);

- Internally systemic in the sense that knowledge bases are part of heterogeneous production and marketing systems (Cassiolato et.al, 2003);

- Externally systemic, knowledge bases involve and rely on interactions between firms and their environment. Reliance on knowledge infrastructure is also critical (Teubal et.al, 1996)

The notion of knowledge bases leads to an analytical model that considers the significance of firms' industry and sectoral affiliations; this is addressed more extensively in chapter 3 . It is important to understand regularities, probable differences in technological opportunities and consequently, distinct impacts of management practices on learning for innovation across industries or sectors (Laursen and Foss 2003; Pavitt 1984). This mirrors the distinction between knowledge exploitation and exploration to characterize knowledge flows associated with firm learning strategies. More importantly it brings to the forefront the discussion of what kind of learning and innovation activities developing countries are bound to perform.

\subsection{Interactions with external agents}

\subsubsection{Learning from external markets for knowledge}

An additional relevant dimension in our analytical framework refers to the interactions between firms and the complex set of agents within the system of innovation. Discussion of this particular dimension centres on the leading role of firms as agents inducing the dynamics and conditioning performance of such system 
over time (Nelson and Winter 1982). In other words, the analysis takes into account how innovative and learning activities carried out by firms in-house eventually give rise to the development and functioning of external markets for knowledge (Arora et.al, 2001).

Several factors shape external markets for knowledge, including: (1) the temporality of knowledge requirements, whether current or expected; (2) the means to transfer knowledge whether in embodied or disembodied form; and, (3) the means to acquire technology, whether by direct purchase or developed in collaboration with other agents (Arora et.al, 2001). In this regard, Santamaría et.al, (2009) indicate that in addition to joint or contracted R\&D, activities such as design, the use of advanced machinery and so on, contribute to innovation. The impact of those activities is especially important in low- and medium technology industries, particularly for the achievement of product innovations. Specific activities shaping external markets for knowledge include purchases and/or exchanges of technology and technological services, contracted and R\&D joint ventures, strategic alliances, licensing and cross-licensing, etc. (Arora et.al, 2001). Relevant partners include other firms, universities, research institutes, government agencies, consultants and personal networks.

The literature documents some of the factors that lead to the promotion of technology diffusion and the development of external markets for knowledge; these include: (1) the stance of a firm in relation to markets for knowledge, whether as supplier or buyer; (2) the importance of external knowledge for a firm's overall learning activities, and (3) the degree of a firm's technological attainment. These three factors combine in multiple ways in order to guide research. In this regard, a first line of enquiry assumes a division of labour in markets for knowledge; technology, in itself, becomes the item on sale (Arora et.al, 2001). This type of research sheds light on how and why firms become specialised technology suppliers. Attention centres on factors such as market structure, property rights regimes, competition, and other incentives and constraints for trading in technology. Relevant work in the field includes Arora et.al, (2001), Cantwell and Kosmopolou (2001) and von Zedtwitz and Gassmann (2002), among others. In sharp contrast to investigations involving large multinationals or firms from developed countries, research on the participation of technology suppliers from developing countries seems rare.

A second body of literature looks at some technologically dynamic, highly internationalized firms. These are buyers, or more generally users of technological capabilities developed abroad. These firms specialize in the creation of technology; at the same time, they actively search for external knowledge sources and associated new technological opportunities (Malerba and Orsenigo 2002; Patel and Vega 1999; Shiu-Wang and Ruei-Hung 2008). External knowledge complements internal efforts to develop and advance technology. Studies on global 
pharmaceutical firms illustrate this approach. They document that, in recent years, the industry has undergone an intense period of mergers and acquisitions, formation of joint ventures and so on (Jungmittag et.al, 2000a; Lane and Probert 2007; Staropoli 1998). Trends in the industry reveal a push towards outsourcing, and joint and contracted R\&D (Crossley 2004; Piachaud 2002). This has lead to strategies such as increasing speed and productivity in new drug development in the face of growing competition from generic manufacturers, and entering new business areas in fields such as biotechnology and genomics (Arora et.al, 2001; Tapon and Thong 1999). The activities of global pharmaceutical firms span developed and developing countries. They include exploitation of technological capabilities developed inhouse, and intense exploration for new technological opportunities (Gilsing 2006; Rothaermel and Deeds 2004). In general, studies in the field refer to dynamic multinationals from developed countries.

A third strand of literature characterises two types of firms. The first group relies, almost entirely, on externally acquired technologies; firms adopt a passive stance with regard to technology development. Notwithstanding some short-term gains in both productivity and competitiveness, the strategy may threaten a firm's viability or success (Kim et.al, 1989). Firms can lose some of their internally created technological capabilities while increasing their exposure to external technology suppliers (Bell 1984). The second group uses external knowledge as a complement to domestic technological efforts (Santamaría et.al, 2009). In this case firms need to develop the capacity to assimilate and use the new technology. This is, in essence, what (Cohen and Levinthal 1989 and 1990) identified as absorptive capacity. Studies in the field document the experiences of latecomer firms that start as followers, in terms of technological attainment and market position, but that eventually develop the capacity to generate and sell technology; in other words, R\&D and other learning activities gain in complexity over time (Dutrénit 2007; Hobday et.al, 2004). Dynamic latecomer firms perceive external knowledge as a source of both opportunities and challenges for their operation and sustainability in the market (Archibugi and Pietrobelli 2003; Reddy 1997; Singh 2007).

\subsubsection{Human resource management and external interactions}

Arora et.al, (2001) highlighted the importance of learning about differences in technology management derived from the development and operation of external markets for knowledge. In their view whenever technology converts into merchandise, distinct approaches are needed for the firm to manage its intellectual capital. The analysis needs to pay greater attention on tacit knowledge, strategic management, organisational structure and changing corporate strategies. Moreover human resources, and more specifically their management and organisation, are increasingly recognised as core components of the unique, difficult to imitate 
capabilities of the firm (Leonard-Barton 1992). Human resource management practices can enhance opportunities to learn and explore external knowledge sources in search of new ideas and technological opportunities (March 1991).

Zanko et.al, (1998) argue that new methodologies, techniques or approaches to management practices connect to and permeate across organisational membership. Interventions such as strategic hiring, sabbaticals, subcontracting and professional collaborations grant access to strategic sites, materials and, key people. Management practices influence the relationships with those individuals from external organisations that contribute to the performance of production or research teams, the implementation of training programmes, and so on (Florida and Goodnight 2005; Okada 2004). The reward to external agents contributing to inhouse R\&D or working on productive projects, the pressures and associated responses to customers/suppliers span organisational boundaries of a firm (Hemmert 1998; Zanko et.al, 1998).

The kind of organisations that firms interact with equally shapes the nature of the knowledge flows involved during the innovation process. Faulkner et.al, (1995) and Laursen and Salter (2004) maintain that meaningful interactions are not built from scratch; rather, firms guide and develop relationships based on specific knowledge requirements, which, in turn, are aligned with the goals set for specific projects or activities. Innovative firms proactively search for and evaluate both the sources and the types of knowledge obtained from external markets. Thus a firm connects with other firms, machinery suppliers, individual consultants, training centres and other intermediary agents attached to the industry. These agents provide technical and other kinds of knowledge they have acquired in the industry. They can be more familiar with productive activities and everyday operations of the firm. Alternatively, via universities and public research centres, firms can access knowledge on basic science, research techniques, and so on. Often the resulting knowledge flows may not fit with the common thinking structures or practices of firms. The distinction between partners and associated knowledge flows does not imply a hierarchy or specific advantage in linking with any specific partner.

Innovation is often constrained by the firm's bounded and incomplete knowledge base. Incompleteness leads firms to expand cognitive boundaries, and to engage in multiple interactions with external agents. Technology markets promote diffusion and more efficient use of scientific knowledge and existing technologies. Such markets underpin technological change and provide additional incentives for R\&D. Accordingly Arora et.al, (2001) call for research to inform corporate strategies, and provide guidance to managers on how to behave when external markets for technology are available. Nelson (1991) and Smith (2000) further emphasize that the effectiveness of interactive learning is conditioned by a firm's heterogeneous organisational structures, and the type and scale of communication and feedback with external agents. Distinct ways to organise and mobilise resources condition a 
firm's ability to access, assimilate, use and eventually transfer knowledge to and from the outside world (Leonard-Barton 1992).

\section{Internal, external, combined learning strategies}

Research on factors that contribute to a firm's learning and innovation strategies is often approached from the perspective of the boundaries of the firm. Two main streams of literature are identified here. Traditional transaction cost theory perceives choices of internal and external sources of technology as potentially mutually exclusive (Williamson 1975 and 1985). Organisational learning involves choices regarding internal and external learning efforts; firms need to decide whether to develop (make) their own knowledge or acquire and/or imitate (buy) that of others (Bierly and Chakrabarti 1996; Kessler et.al, 2000; Zack 1999). Finding the right balance between in-house development and the external acquisition of technology allows for optimum resource allocation to alternative learning activities (Nakamura and Odagiri 2005). The problem with this approach is that it only partially explains the perceived heterogeneity in firms' learning behaviours, or the characteristics of innovation processes in distinct industries or sectors (Arora and Gambardella 1990; Liyanage et.al, 1999), thus undervaluing the possibilities and importance of combined strategies (Cassiman and Veugelers 2006; Escribano et.al, 2009), particularly for latecomer firms (Du and Ai 2008; Kim et.al, 1989; Singh 2007).

An alternative approach arises in Penrose's seminal book on the growth of the firm (Penrose 1959), where she challenges the notion of "make" or "buy" by considering the decisions related to learning that stem from more complex processes inside the firm. Internal and external learning sources are not mutually exclusive; on the contrary there is great potential for complementary relationships among the two strategies. Penrose conceptualised firms as a "collection of resources bound together in an administrative framework, the boundaries of which are defined by the 'area of administrative coordination' and 'authoritative communication'" (Penrose 1997:xi). A firm's performance is determined, to a large extent, by its capacity to organise and mobilise resources. This involves dynamic processes whereby knowledge accumulates through incentives for further expansion and exploration of new and more productive ways to combine those resources. The notion of boundaries implies that firms are part of broader systems of agents and interactions. Such systems compose of informal and formal (market) transactions from which firms can obtain complementary cognitive and productive assets. Management plays a crucial role by identifying and mobilising available resources, while determining those that the firm leverages from outside.

Penrose's argument can easily extend to interpret learning, from both internal and external sources, along the dual perspective proposed by Cohen and Levinthal, in which learning implies both conscious capability building processes, and strategic 
searches for new technological and market opportunities. Building adequate absorptive capacity assists in the assimilation and use of external knowledge; it can give firms substantial bargaining powers in external markets for technology. Absorptive capacity builds on the level of related knowledge already available in firms, including basic skills as well as recent technological and scientific developments in specific fields. It arises out of previous knowledge accumulation and ongoing learning efforts by firms and their members. Some additional, albeit indirect, benefits of the efforts to build a strong technology base include the ability to: (i) search, choose and benefit from collaborative relationships; (ii) increase the capacity to sell technology and contribute to the technological base of the environment; (iii) detect environmental changes and capture new technological opportunities (Cardinal and Hatfield 2000). External sources of knowledge bring fresh thinking and provide benchmarks for internal learning efforts.

Kim (1998) developed an international dimension to this argument by pointing out that external knowledge acquisition and imitation can also function across and connect national systems of innovation. Recalling the notion of competitive ecology in chapter 1, adoption of mixed learning strategies leads firms to mobilise both internal and external resources, to expand physical and cognitive boundaries in order to accommodate internal and external knowledge searches. Knowledge integration proceeds according to the goals of exploitation- and/or explorationrelated innovations (March 1991). Recent research on complementary strategies is found in Beneito (2002), Cassiman and Veugelers (2006), Cattozzella and Vivarelli (2007), Lane and Probert (2007), Nakamura and Odagiri (2005), Piga and Vivarelli (2004), Shiu-Wang and Ruei-Hung (2008), Veugelers (1999). In the case of Mexico, Zúñiga et.al, (2007) applied a complementarity framework to study strategies for technology acquisition by pharmaceutical firms in the local market. Chapters 7 and 8 will deal with this in more detail, including the implications of the adoption of distinct learning strategies by firms in the presence of external knowledge sources.

\section{Human resource management practices and innovation: Methodological approaches}

This section will document that research on the linkages between human resource management practices and innovation is already well established in management studies. Some of the more common studies refer to R\&D personnel in developed countries. Scholars in the field assert that management interventions enhance attractiveness, motivation and, ultimately, people's capacity to carry out innovation (Amabile 1996; Katz 1988; Mumford 2000). Closed views on the conditions and functioning of individual managerial and organisational practices are useful to guide human resource management practitioners. Unfortunately this is insufficient to inform broader policy interventions particularly in light of more heterogeneous 
managerial approaches, distinct organisational and learning strategies, or the situated environment in which firms operate (Alic 1995; Lundvall et.al, 2002).

With regard to innovation studies, chapter 1 referred to the growing interest among scholars in the field in understanding the linkages between management practices and innovation performance. Recent work critiques traditional assumptions and conclusions about the Japanese and American models, which are considered, almost exclusively as the two alternatives in organizing R\&D personnel (Barton and Delbridge 2001; Joonmo 2004). Research seeks to understand the sources of heterogeneity and evolution of those models over time (Hemmert 1998; Legewie et.al, 2000); or how new and improved organisational practices shape dynamic workplaces and learning across firms, industries, and even countries (Arundel et.al, 2007; OECD 1998). This Section presents some of the main findings, lessons and challenges from the existing literature on management and innovation, and suggests some alternative, though not mutually exclusive approaches to research on management practices, learning and innovation. The discussion sheds light on some areas and issues missing from the literature.

\subsection{Six alternative, yet complementary approaches}

Based on a comprehensive literature review, this chapter proposes six approaches to analysing human resource management practices and their relationship with a firm's (innovation) performance. The approaches are neither mutually exclusive nor exhaustive, and they are both static and dynamic. In other words one can study the effects of human resource management practices on firms' performance at a given point in time or along a continuum, and/or under certain firm characteristics. In this manner, the analysis can focus on: (i) specific geographical, cultural and related contexts in which a firm operates (Type 1); (ii) particular management interventions or the characteristics of the personnel involved (Type 2); (iii) differences in management practices across a firm's departments (Type 3); (iv) the degree of innovativeness of the management interventions in themselves (Type 4); (v) the characterisation of management practices along different stages of the innovation cycle within a firm/industry (Type 5); and, (vi) the contribution of management strategies depending on the technological and productive profile of a firm (Type 6).

Type 1 approaches relate to management across cultures along the lines of Hofstede (1980) and subsequent studies. Research seeks to understand how crosscountry cultural differences influence adoption of or characterise local managerial approaches (Murphy 2006; Tello and Greene 1996). Alternatively, research refers to differences in management practices within multinational corporations in both the host and the parent countries (Flynn 1994; Forest 1994; Schuler et.al, 1996). Literature on Mexico seeks to provide foreign managers, often first-time visitors to the country, with knowledge about the 'do's' and 'dont's' of successfully managing 
an affiliate facility in the country (Martínez and Dorfman 1998). Several studies refer to management in 'maquiladoras'; they stress the obstacles that cultural differences impose in terms of the adoption of management practices promoting learning, wide participation and active involvement in innovation.

Work environments in Mexican firms are considered to be reflective of traditionally 'paternalistic', rigid and hierarchical social structures, where power is concentrated at the top. People are often assigned to high-ranking positions based on who they know (Forest 1994; Schuler et.al, 1996). These factors run against values and principles of dynamic work practices in developed countries, such as the United States, which emphasize meritocracy, individualism and trusting relationships between managers and employees, supportive, participative management, teamwork and other superior human resource management practices (Schuler et.al, 1996). Mexican workers are habituated to work environments where being submissive and loyal to people in positions of power is the norm, and where self-expression, initiative, and autonomy are discouraged (García 2002). Local culture is often unfavourable with regard to modern management practices (Tello and Greene 1996). However, in the case of Mexico, scholars agree that intensive training for both line workers and managers helps to overcome 'most cultural barriers' between Mexico and the US, thereby increasing the probability of successfully introducing US-type management practices in multinational affiliates operating in Mexico (Flynn 1994; Forest 1994).

There are some major flaws in this argument. In general, while scholars tend not to question the validity of the categories proposed by Hofstede's study, Dávila and Elvira (2007) suggest there is a need to reconsider the importance of cultural differences between Mexico and the US; interaction between the two countries might blur the differences, in terms of 'individualism' or 'attitudes toward achievement', that supposedly exist between the two societies (Rao and Teegen 2001). The authors call for a careful re-interpretation of the characteristics of Mexican workers, their resistance to interventions involving teamwork, pay-forperformance or when given the opportunity and incentives, to actively involve in participative management strategies (Dávila and Elvira 2007). Cultural differences may imply that things are different but not necessarily better in either context.

Type 1 approaches often tell little about the impact that cultural differences have on performance on either side of the Mexico-US border. They base their conclusions on small samples of firms; rely strongly on interviews with managers or key experts, but seldom with workers themselves. In addition, the approaches lack consideration of possible differences derived from distinct sectoral affiliations, even locations of firms (Hise et.al, 2003; Islas 2003; Lenartowicz et.al, 2003; Rao and Teegen 2001), or the tendency towards general prescriptions (Hope Pelled and Xin 1997; Muller and Rowell 1997; Reza et.al, 1998) all weaken their results.

Type 2 approaches, referred to as specific human resource management 
practices, are management studies centred on particular management interventions, namely teamwork, training, use of dual professional ladders, communication and so on. Studies in the field seek to understand how management practices underpin learning, job satisfaction, and so on (Ball 1998; Banker et.al, 1996; Cordero et.al, 1998; Debackere et.al, 1997; Florida and Goodnight 2005; Kim and Cha 2000; Livesay et.al, 1996; Lovett et.al, 2004). Unfortunately several of these studies suffer from a strong inclination towards description and prescription without critically evaluating the contexts and conditions within which management practices shape a firm's performance (Nelson 1991). Hence we learn about how specific management practices operate in R\&D, for instance, but not necessarily how implementation of such practice differs in manufacturing units within the same firm. In addition an analysis of concrete performance indicators or how managerial variables respond to influences from the environment is limited (Nelson 1991).

Researchers in the field look for best-practices, or taxonomies of, for example, leader's or inventors' personality traits, in order to derive pertinent recommendations for human resource management practitioners. With regard to developing countries, much of the research focuses on some of the most dynamic South East Asian economies, and on very specific aspects of the management and motivation of R\&D personnel (Kim and Cha 2000; Ta-Cheng 1997). The large number of management interventions and performance indicators being studied makes it difficult to draw general conclusions about individual practices. ${ }^{4}$ Nevertheless scholars stress that distinct social contexts result in heterogeneous managerial approaches within firms; transposing models built on the experience of developed countries or large multinationals does not necessarily fit developing countries (Kim and Cha 2000). Additional problems arise when scholars fail to consider how working environments in the departments under investigation influence connections to and interactions with the remaining areas of the firm.

Type 3 approaches, termed department specific, are subdivided in two groups. The first includes organisational studies dealing with management of R\&D personnel. Here attention is given to practices influencing creativity, attractiveness, motivation and productivity of individuals and groups in R\&D (Allen 1988; Amabile 1996; Amabile et.al, 2002; Badawy 1988; Gupta and Singhal 1993; James 2002; Mumford 2000). These studies claim that human resource management practices influence people's capacity to conduct R\&D; they shape incentives and rewards, opportunities to socialise within specific communities, or to develop and put creativity and knowledge at work.

A second strand of literature comprises the bulk of innovation studies; these concentrate on firms in developed countries and in industries such as

\footnotetext{
${ }^{4}$ For a more detailed discussion on some specific human resource management practices and how they impact on a firm's learning activities see chapter 3 in this thesis.
} 
Pharmaceuticals. Consideration of human resource management interventions is often secondary to the analysis of variables such as scale and nature of projects, and research productivity in terms of patents or publications (Cockburn and Henderson 2001; Cockburn et al., 1999a; Henderson and Cockburn 1994). Communication via publication, teamwork, and decision-making related to risktaking and the exploration of new ideas, access to advanced equipment, among other management interventions, are found to sustain $R \& D$, innovation in general.

In the case of developing countries, studies about R\&D personnel are constrained by the lack of a critical mass of R\&D departments operated by firms in such countries. Instead the work centres on the conditions and determinants of the diffusion of Japanese-style management practices (Kaplinsky 1995) and the impact of such practices on adoption of quality programs, training provision, or knowledge transfer across firms (Bae and Rowley 2004; Okada 2004). Further research is needed to shed light on the conditions at the upper levels of the skill-ladder (e.g. engineers, staff and managers), and in order to obtain comprehensive views of the firm as a more complex entity integrating production, marketing and R\&D.

Taking Mexico as an example, studies following the logic mentioned above, show bias towards analyses in the areas of skills and education attainment within the labour force, and real wage levels, particularly at lower-ends of the skill-ladder in manufacturing and so on (Abramo 1997; Weller 2000). Research here also addresses assembly processes within large firms, maquiladoras or other multinationals (Carrillo and Ramírez 1997; Dussel 2003 and 2004). The contribution of maquiladoras to technological capability building in specific sectors or the economy as a whole attracts great attention as well. In such environments, creativity, initiative and independent thought are hardly assets firms seek to promote (Luthans et.al, 1997; Samstad and Pipkin 2005). Weller (2000) asserts that maquiladoras exemplify how precariousness of employment becomes institutionalised. Although workers possess formal contracts and social protection, lack of security derives from low wages, the duration of shifts, and lack of workers' involvement in decision making. All of these factors accompany business strategies with very low emphasis on local technology development; thus, limited interest in technological learning, capability building and innovation.

Type 4 is one of the first approaches where the notion of time becomes potentially important for the analysis. It includes analyses of firms' technological and innovative profiles based on human resource management practices. Recent contributions along these lines include Ichniowski et.al, (1997), Michie and Sheehan (1999 and 2003), Laursen and Foss (2003). The approach focuses on the technological profile and corresponding performance of firms across sectors of economic activity. Definition of a production or innovation function links to a ranking of firms according to different combinations of management practices, from most conservative to most dynamic. Studies build on the notion of 
complementarities among management practices. Although individual interventions can enhance performance, and function interdependently, they are more likely to impact positively on performance when implemented in bundles as part of coherent incentive systems (Ichniowski et.al, 1997; Michie and Sheehan 1999). In line with the work of Milgrom and Roberts (1990) the hypothesis is that "If firms adopt work practices in a complementary fashion, then empirical tests should consider the impacts of groups of practices rather than simply the effects of individual practices" (Ichniowski et.al, 1997:295). Clusters of dynamic practices vary in number and range from most traditional to most innovative. Firms incorporating the latter activities are expected to outperform those featuring more traditional approaches (Michie and Sheehan 1999 and 2003). In practice Laursen and Foss (2003) find that this is contingent on some technological differences at the sectoral level.

Approach type 4 also refers to presumed regularities and the characteristics of management practices that depend on a firm's industry or sectoral affiliation. It is not obvious why firms with different innovation strategies and operating in completely different sectors should gain, equally, from the adoption of comparable management practices (Laursen and Foss 2003; Laursen and Mahnke 2001). This raises issues for further research; for instance exploring why the identification of relevant clusters of management practices is problematic. Clusters span and constitute a large number of practices along several categories of human resource management practices. Clusters can overlap since no firm necessarily implements similar bundles of dynamic management practices. Moreover, since alternative relationships are possible among such interventions (Delery 1998), identification of systems of practices leading to particular firm performance is problematic.

In line with the time dimension incorporated in type 4 approach to research, Lorenz and Wilkinson (2003:240) criticise these studies for their almost universal ranking of enterprises 'on a one-dimensional scale going from traditional Taylorist organisations to modern flexible organisations, based on the penetration rates of the stylised set of practices making up the high-involvement model'. In other words, heterogeneity in management models is limited by the assumption that as firms gain in technological complexity they move from traditional to dynamic management systems as well.

Type 5, labelled product life cycle, offers interesting avenues for research. Studies by Kidder (1982), Henderson and Cockburn (1994) and Omta et.al, (1997), among others, suggest different kinds of people, with distinct skills, professional backgrounds and professional orientations involve, either sequentially or simultaneously, along and according to the requirements of different development stages of a given product or technology. From a management perspective, specialisation means that firms can transfer a great share of the labour responsibility onto partner organisations. In the case of the pharmaceutical industry for example, the literature proposes differences in managerial approaches 
supporting drug discovery on the one hand, and drug development on the other. Research characterises by unpredictable timing, informality in the structure of work, modes of expenditure and uncertain results. By contrast, development features more predictable timing for the conclusion of tasks, formality in the organisation and the way activities are carried out, and considerably larger expenditure and planned results (Chiesa 1996; Datta et.al, 2003).

Frequently, the split between research and development occurs both at the organisational level, and in terms of physical infrastructure; hence, Chiesa (1996) indicated that management of each stage differs in terms of culture, organisation and types of people involved. People differ in goals, procedures, organisational requirements and incentive structures (Hullman 2000). Whereas the key in research is "creativity", the main tenet in development is "organisation" (Chiesa 1996). Researchers conducting basic research can hardly be obliged to look for economic success; cooperation and leadership are skills of paramount importance. By contrast, as an applied research process, development requires a hierarchical structure, a more exact definition of instructions about the functions and probable effects of medicines, the requirements of the health authorities and estimations of success of the new or improved drug (Hullman 2000:74). Accordingly, rewards, organisation, hiring, orientation and attitudes towards research, and recognition and promotion preferences differ between firms at different stages of the technological ladder. Comparative research on the management of human resources along different stages of the innovation cycle seems scarce, even nonexistent in the case of developing countries.

Type 6 approaches derive from literature on learning and technological capability building in latecomer firms. The approach suggests opportunities to incorporate, more explicitly, the human resource management dimension into current studies of how firms build capacity to carry out increasingly complex processes of learning, technological change and R\&D (Dutrénit 2000; Figueiredo 2003). Differences in learning processes support the construction and accumulation of distinct technological profiles; thus, the ability to carry out formal R\&D implies a need for advanced capabilities (Hobday et.al, 2004). Still missing are more detailed accounts of how progression of technological complexity feeds back and forth to changes in professional profiles and organisational practices. Evidence remains anecdotal, and scattered throughout case studies. Interest lies in the changing nature and complexity of the processes that firms are able to perform over time, but seldom on the work environments in which people perform such activities. A considerable gap remains in our knowledge about ways in which firms in developing countries organise R\&D personnel. Furthermore, what remains to be address is what distinguishes management strategies in innovative and non-innovative firms?

Related to the above, Kim and Cha (2000) and Laursen and Foss (2003) contend that firms with different technological profiles require and mobilise resources 
differently. This supports the view that more heterogeneous organisational models, as compared with those in mainstream literature, are possible. Dávila and Elvira (2007) for instance, stress culture, context and history as inducing a different, yet functional, form of employer-employee interactions. Equally important is the increasing emphasis on the character of innovation and the frequent lack of formal R\&D units within latecomer firms (Santamaría et.al, 2009). All this widens the gap between traditional studies on management practices in manufacturing and those on formal R\&D departments.

The pharmaceutical industry is illustrative of the type 6 approaches to research. Pharmaceuticals are highly R\&D intensive; the capacity to perform R\&D determines a firm's viability and prospects to grow in the market. R\&D intertwines with the capacity to exploit and explore technological and market opportunities. At a basic level of technological capabilities, R\&D supports the accumulation of some knowledge and experience needed to progressively generate more sophisticated drugs. Recent studies in India support this argument. Based on a capability building model, Kale and Little (2007) argue that "reverse engineering R\&D capability -the ability to develop products by copying the process-is categorised as a basic capability. Generics R\&D involves incremental change representing intermediate capability while new chemical entity research involves creating new drugs and innovative therapies representing advanced capabilities" (p.594).

Building on the experience of Indian pharmaceutical firms, Kale and Little illustrate how each stage of capability accumulation draws from a firm's knowledge base. Over time, local firms use, acquire and accumulate different types of knowledge inputs for innovation with increasing degrees of novelty. Progress in technology ladder has accompanied the expansion of learning activities outside familiar cognitive boundaries, where knowledge searches have become increasingly exploratory. Knowledge exploitation, however, remains relevant particularly for firms whose business strategies are still based on the extension of life-cycles of existing pharmaceutical products. This experience, together with those presented by Cardinal and Hatfield (2000) and Kim (1997) for example, show that although the technological dynamism of firms focused on catching up to their competitors generally lags behind that of large multinationals, R\&D remains a core ingredient for their success. The major difference is that, in most cases, R\&D in developing countries leads to incremental innovations.

From a management viewpoint rapid technological change and market dynamics in the pharmaceutical industry have had and are expected to continue having interesting implications in terms of labour characteristics and organisational practices (Jones 1996). Cockburn et al, (1999a) assert that novel technologies for new drug discovery require changes to managerial practices in order to better organise and motivate researchers; professionalise personnel and administrative management, while keeping the balance between these two activities. Accordingly, 
as noted under type 5, differences in managerial approaches supporting drug discovery on the one hand, and drug development on the other, have been proposed elsewhere in the literature.

A similar logic supports the need for research on catching-up countries. The technological progress that such countries are striving to achieve brings new opportunities but also new challenges in terms of personnel requirements and management in the local markets. As innovation activities gain in complexity, firms need to incorporate new skills, and adopt novel ways to organise, mobilise and retain staff. This is one area where bridging the literature on capability building and management studies becomes more apparent. Competition in the labour market can likewise increase as the new skills required would not necessarily be readily available. Unfortunately we still know little about management practices around $R \& D$ in pharmaceutical firms in developing countries.

Figure 2.2 illustrates the six approaches to research on human resource management, learning and innovation described thus far. This thesis draws from these distinct approaches, particularly Types 2, 4 and 6, in somewhat modified form. The focus is on the contribution of human resource management to firm's performance; in this case learning through distinct learning strategies. By incorporating explicitly such dimension as performance indicator, this thesis contributes to the literature in this field. The discussion progressively gains in complexity and incorporates in-house R\&D and other means to learn from external knowledge sources. Although the analysis does not address complementarities among human resource management practices, the latter are introduced in bundles. In other words, the study reflects on the effects of adoption of specific sets of human resource management practices, rather than individual practices.

The approach likewise assumes that firms conduct learning and innovation activities according to their specialisation within the overall industry's innovation processes. Such specialisation reflects the firm's learning strategy and complexity of its technological attainment. It also reflects how firms respond to the general conditions of the environment, e.g. quality of research infrastructure, availability of human resources and so on. The environment equally provides the background to understand which human resource management practices matter for the analysis; how and why they do so? A more detailed discussion is presented in Chapter 3. 
Figure 2.2: Approaches to research on human resource management practices and firms' performance

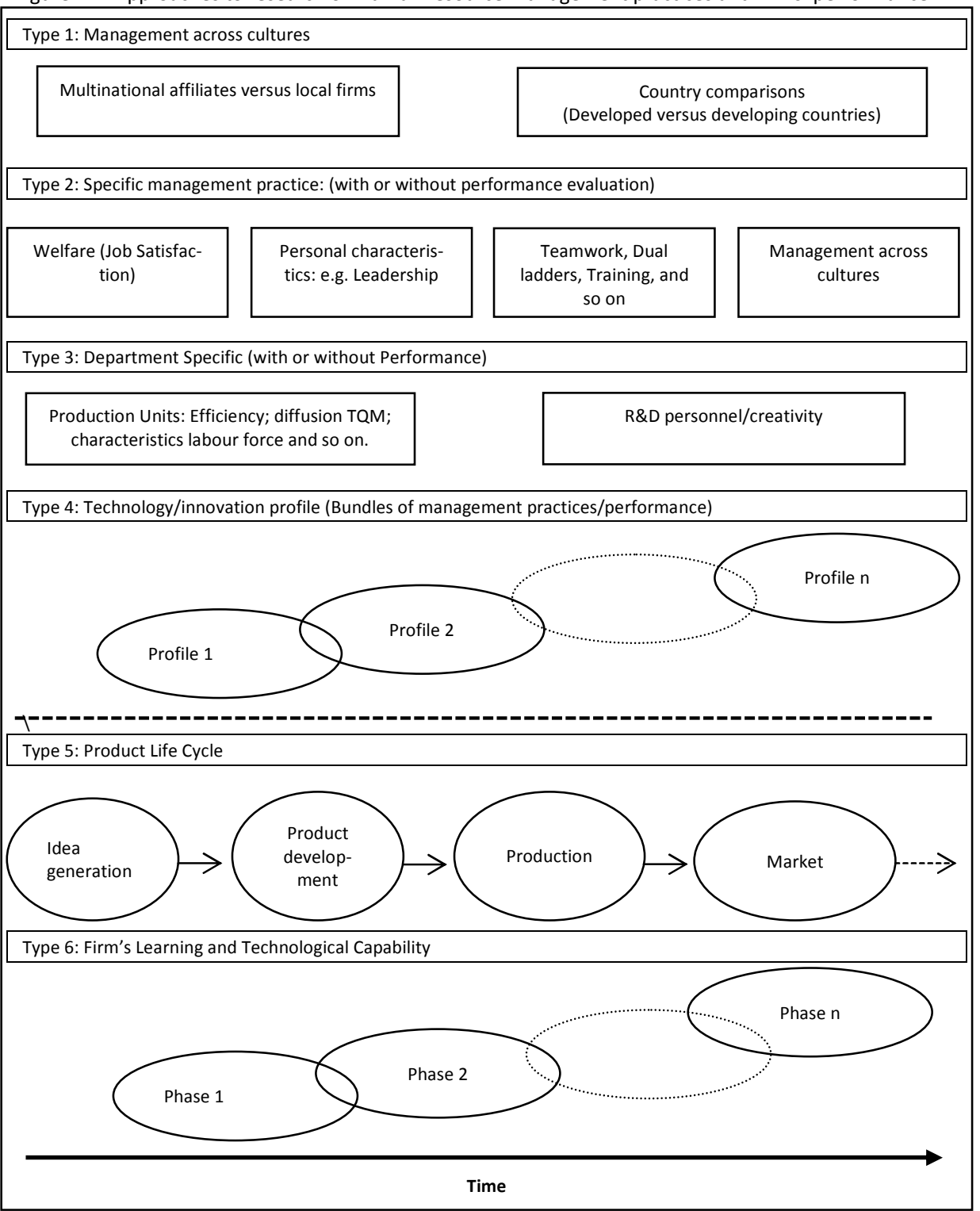

Source: Author 



\section{Chapter 3}

\section{Research hypothesis, variable definition, data and data sources in this thesis}

\section{Introduction}

Explaining how and why human resource management practices underpin innovation introduce innovation scholars into the more ample debate of how and why such practices influence firms' performance more generally. The task is complex, Boseli et.al, (2005) and Combs et.al, (2006) assert that huge challenges stem from the diversity in the number and possible definitions of indicators on human resource management practices, together with the distinct multidisciplinary approaches to research. In light of such complexity defining a comprehensive and concrete checklist of practices based on a widely accepted theoretical rationale is complex; Boseli et.al, (2005) and Combs et.al, (2006) advise pragmatism. Enhanced organisational practices often associate with Japanese management style. Hemmert (1998) for example, noted that practices that target R\&D personnel include: scouting, hiring and firing, job rotation and continuity and compensation systems.

Building on previous work on complementarities among human resource management practices, and actual interventions in steel production lines, Ichniowski et.al, (1997) identified systems of complementary human resource management interventions explaining distinct productive performance of steel finishing lines. These systems spanned seven different personnel management areas: incentive and compensation plans, recruiting and selection, work teams, employment security, flexible job assignments, training, and labour-management communication, together with two labour relations indicators: union status and grievance rates. Subsequent studies have investigated the effects of these and related variables on firm's innovation performance across industries (Laursen and Foss 2003; Lorenz and Valeyre 2004). These studies show that innovative practices occur in heterogeneous backgrounds; they vary significantly across firms and countries (Cardon and Stevens 2004; Vinding 2004). Table 3.1 presents some relevant management variables distributed according to seven categories found in the literature.

In the case of developing countries, relevant human resource management practices are associated with adoption of modern organisational techniques, such as TQM or JIT, by the firm. The study of factors determining adoption of such techniques has received great attention by innovation scholars. Modern 
organisational approaches include the provision of training, worker's empowerment, payment and staff promotion (Islas 2003; Mertens 2005; Vargas 2004). Previous research suggests that relative to innovative companies, noninnovative firms feature larger turn-over rates, and stronger influence by the owner/founder on the way businesses run. Poor innovation performers rely more on numerical flexibility as opposed to functional flexibility.

Table 3.1: Enhanced human resource management practices and Firm's (innovation) performance

\begin{tabular}{|c|c|c|c|c|c|}
\hline & $\begin{array}{l}\text { Ichniowski } \\
\text { et.al, (1997) }\end{array}$ & $\begin{array}{l}\text { Michie and } \\
\text { Sheehan } \\
(1999,2003)\end{array}$ & $\begin{array}{l}\text { Laursen and } \\
\text { Mahnke } \\
(2001)\end{array}$ & $\begin{array}{l}\text { Laursen } \\
(2002)\end{array}$ & \begin{tabular}{|l|} 
Laursen and \\
Foss (2003)
\end{tabular} \\
\hline $\begin{array}{l}\text { Staffing practices } \\
\text { Strategic hiring } \\
\text { External market+* } \\
\text { Internal market+* }\end{array}$ & $\checkmark$ & $\begin{array}{l}\checkmark \\
\checkmark \\
\checkmark\end{array}$ & & & \\
\hline \begin{tabular}{|l|} 
Goal-setting, performance \\
appraisal and rewards \\
Goal-setting* \\
Performance evaluation \\
Reward for performance \\
\end{tabular} & $\checkmark$ & $\checkmark$ & $\checkmark$ & $\checkmark$ & $\checkmark$ \\
\hline \begin{tabular}{|l} 
Team-based organisation \\
Teamwork practice \\
Group Structure Leadership*
\end{tabular} & $\checkmark$ & $\checkmark$ & $\checkmark$ & $\checkmark$ & $\checkmark$ \\
\hline $\begin{array}{l}\text { Integration to the organisation } \\
\text { Induction Programmes } \\
\text { Empowerment/politics++ } \\
\end{array}$ & & $\checkmark$ & $\checkmark$ & $v$ & 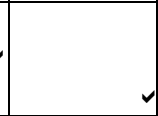 \\
\hline \begin{tabular}{|l} 
Flexibility \\
Rotation assignments \\
Internal \\
External \\
\end{tabular} & $\checkmark$ & $\begin{array}{l}\checkmark \\
\checkmark \\
\checkmark\end{array}$ & $\checkmark$ & $\checkmark$ & $\checkmark$ \\
\hline \begin{tabular}{|l|} 
Industrial relations \\
Employment security \\
Communication manager- \\
employee \\
Unionisation
\end{tabular} & $\checkmark$ & $\checkmark$ & $\checkmark$ & & \\
\hline \begin{tabular}{|l} 
Training \\
Low+++ \\
High+++ \\
On-the-job \\
Off-the-job
\end{tabular} & $\checkmark$ & $\checkmark$ & $\checkmark$ & & $\checkmark$ \\
\hline
\end{tabular}

*Mentioned in management literature but not formally addressed in innovation studies; + Refers to whether firms rely on internal promotion or external labour markets to staff their activities; ++ Includes supervisor-employee relationships, workers participation in decision making about working conditions, goal-setting, and so on; +++ indicates the share of employees participating in training. Source: Author based on literature review

Similar to Ichniowski et.al, (1997), the choice of relevant variables in this thesis was validated through exploratory interviews with representatives of 
pharmaceutical companies located in Mexico City-see section 3.2. This thesis explores the effects on learning associated with four out of seven categories of human resource management practices in table 3.1: the provision of training, remuneration for performance, staff hiring and worker's participation in decision making about the work place.

\section{Human resource management practices relevant for learning and innovation}

\subsection{Training}

Training assists development of technical and managerial skills among people, who are repositories of the tacit knowledge of an organisation (Johnson et.al, 1996). Tacit knowledge supports organisational structures, as well as the productive and innovation capabilities of a firm. Training improves the capacity of workers to operate new equipment, adopt new techniques and, in general, to appropriate knowledge available in the environment. In such a way firms can enrich the knowledge base of the organisation as a whole. Skills and knowledge tend to be very specific, in line with technical requirements of productive and, eventually, innovative processes (Bell 1984; Okada 2004). In practice, training goes beyond formal knowledge acquisition, it includes reflection on learning and learning through problem-solving (Gray et.al, 2004). Training can contribute to strategies to promote motivation and reward; it can help addressing motivational problems affecting blue-collar workers facing extremely low levels of education and limited development opportunities (Colmenares 1992; García 2002).

Training takes, at least, two complementary forms: on-the-job and off-the-job. The former is the most common, frequently provided by staff within the organisation; it supports learning of routine operations and an understanding of basic concepts of internal work processes. The second is usually available for key personnel, provided through formal external, classroom, education and linkages to external knowledge-producer organisations. External training contributes to enhancing the intellectual capital and skills by capturing existing knowledge, that is, latest developments in specific knowledge fields, research techniques and so on (Hara 2003). These two approaches condition how and how quickly, new knowledge and skills are diffused within the firm (Laursen and Salter 2004; Okada 2004).

Training is one of the main reasons to linking firms with universities and public research centres (Casas 2001). Interactions and resulting knowledge flows respond to the goals and specific requirements of firms (Laursen and Salter 2004). Relationships with external knowledge-producers can grant access to new scientific knowledge, improved understanding of specific processes, research techniques and so on (Nakamura and Odagiri 2005). Similarly, partnerships with firms and other relevant organisations within the industry can provide technologies and other more 
technical and industry-specific knowledge (Bell 1984; Casas 2001). Likewise Casas (2005) points out that a central aspect to study processes of network construction between academic organisations and firms is the knowledge that is exchanged and how this is assimilated to nurture a firm's knowledge base. Such knowledge is expected to help in the improvement or generation of new products and/or processes, in the creation of new technologies or the promotion of innovative activities. Training is a relevant mechanism to mobilise scientific and/or technological knowledge for problem solving in the production sector, as well as for the formation of human resources according to a firm's knowledge requirements (Kuruvilla et.al, 2002; Labarca 1999a).

Gray et.al, (2004) warn that the influence of training depends on the creation of an environment where sufficient returns on investment in such activity can be expected. In other words, training needs to be accompanied by pertinent incentives and working conditions so that improved skills are adequately used (Laursen and Foss 2003). Frequent problems result from poor formalisation of training structures, mismatches between training and career development perspectives, independence, enhanced authority and responsibility (Domínguez and Brown 1998; Samstad and Pipkin 2005). This is accompanied by weak incentives to training, incompatibility with work schedules, inappropriate conditions to implement the new skills and high turn-over (Carrillo and Ramírez 1997; García 2002; Islas 2003).

Pharmaceuticals firms are strongly inclined to train personnel across operations (BLS-USLD 2007). Training requirements range from a few hours of on-the-job training to years of formal education, including job experience. Training includes development of general skills, together with those needed to carry out specific projects, develop particular processes, conduct specific analyses, handling specialised equipment and so on. Firms frequently train in safety, environmental and quality control and technological advances. Training in marketing and sales is expected to increase the market success of a product. From the above we formulate the following hypotheses:

H1: Training influences positively the likelihood that firms carry out learning activities.

$\mathrm{H} 2$ : The nature of training and its impact on learning differs depending on the nature of the activities carried out by the firm.

H3: The influence of training varies according to the agent with which a firm interacts.

\subsection{Remuneration}

Management literature contends that the type of incentives firms provide and how they are administered condition diverse motivational styles and, whereby, staff attitudes towards work (Badawy 1988; Florida and Goodnight 2005). The correct 
appreciation of individual and professional aspirations promotes commitment towards an organisation (Quinn and Rubb 2006). Mumford (2000) contends that effective reward systems encourage employees to take risks, pursue the development of new products and continuously generate ideas that can be realized. Adequate remunerations contribute to skill development cycles by organizing, recognizing and rewarding people for their skills, background, expertise and intuition (Samstad and Pipkin 2005). Creativity can be encouraged if freedom, financial rewards, promotion and other forms of recognition exist (Amabile 1997). The literature recommends provision of a mix of intrinsic rewards--such as greater autonomy, additional developmental opportunities and public recognition-and extrinsic ones--such as pay increases and promotion opportunities (James 2002; Mumford 2000).

Wages and other compensations respond to the balance between internal and external labour market conditions. When firms prioritize the former market, wages may be determined internally, somewhat freely of market pressure (Lazear and Oyer 2004). Offering attractive compensation packages supports strategies aiming to increase a firm's human capital. Remunerations help to strategically attract talent from outside; thus minimizing costs of internal development (Labarca 1999b). In such a way firms save time and other resources in personnel development programs. In the presence of external labour markets however, wages are determined by some aggregate process independently of the control of the firms. This is particularly relevant in developing countries where critical masses of welltrained and experience personnel are often scarce. Firms in developing countries face strong competition for and high mobility of qualified labour. Sectoral and industry differences also reflect distinct dynamics and prospects for specific economic activities within and across countries.

The contribution of remuneration to strategies aiming to retain human capital is also important; it prevents the loss or fragmentation of a firm's knowledge base. For example, studies about the maquiladora industry in Mexico show that high turnover rates for people at different hierarchy levels constitute major obstacles to improved firm performance (Forest 1994; Sargent and Matthews 1997). Compensation mechanisms become instrumental to attract, motivate and retain personnel (Dussel 2003; Stephens and Greer 1995). In Mexico monthly remuneration is the usual practice, with compensation packages usually including something more than nominal salaries (Samstad and Pipkin 2005). Non-pecuniary 'status enhancing' perks are highly appreciated particularly at higher levels of responsibility and skills (Stephens and Greer 1995; Tello and Greene 1996).

Setting adequate remuneration systems is complex; creative individuals can prefer a challenging and innovation-driven environment over high salaries. For instance, Terziovski and Morgan (2006) argue that in science-based industries, such as biotechnology, performance-linked rewards might not be as attractive and 
stimulating as compared to access to sophisticated scientific equipment and instruments. The later enable researchers to work while increasing their intellectual capital. In the context of developing countries, the use of remunerations as a rewarding mechanism finds additional limits. They characterize by tight markets for skilled-labour and reliance on wage contention policies to underpin industrial competitiveness. These considerations lead to formulate the following hypothesis:

H4: Adequate compensation and reward for performance positively and significantly impact learning activities by firms.

H5: The influence from remunerations depends on the nature of knowledge requirements of the firm.

H6: The influence of remunerations depends on the type of learning strategy of the firm, whether internal or external, or a combination of both those strategies.

\subsection{Empowerment}

Notable among innovative human resource management practices is decentralisation of both decision-making and problem solving rights (Zanko et.al, 1998). Self-esteem--the feeling of power--is an important determinant of employee performance (Gupta and Singhal 1993). Bartlett et.al, (2002) stress that in highperformance work systems people should be given the opportunity and means to tackle new problems, to gain varied experiences, and to be prepared to take on more challenging tasks. People may participate in the definition of personal objectives or the time they spend at work. Employees can voluntarily request to become involved in assignments promoting skills development, or in the establishment and management of effective mentoring relationships; in such ways firms can foster discovery activities (Mumford 2000).

Empowerment means opportunities for workers to understand, manipulate and master newly acquired technologies (Dutrénit 2000 and 2007). Morgan and Zeffane (2003) highlight the positive contribution of direct consultation between employees and managers in major change processes at the firm. By empowering employees, managers can minimize conflict and resistance to projects involving technical change and, consequently, alteration of customary working conditions or labour relationships. Successful empowerment often accompanies teamwork and the provision of training (Carrillo and Ramírez 1997; García 2002). Bartlett et al. (2002) warn that mismatches between increased responsibility, and means and skills to perform the job can render empowerment meaningless, even counterproductive.

In contexts where labour relations are highly hierarchical, power flows topdown, based on paternalism, links of trust and loyalty between workers and immediate supervisors, delegation of responsibility is limited to particular tasks, goes without decision-making authority and resistance to follow-up and control (Martínez and Dorfman 1998;Schuler et.al, 1996). Such environments, considered as 
running against learning and innovation, would be frequently found in developing countries. This is said to be the case in Mexico and other Latin American countries (García 2002; Muller and Rowell 1997). In addition to poor qualification levels, workers face trouble to assume higher responsibilities, to participate actively in organisational or technical change (Abramo 1997). Nevertheless, as training and education attainment increases, workers, notably those working for multinational affiliates or high-standard local companies, are less inclined to traditional work styles (Flynn 1994). Particularly at managerial levels, people show strong work ethics and openness to work long journeys, and assume extraordinary responsibilities (Dávila and Elvira 2007; Murphy 2006).

In science-based organisations such as pharmaceuticals, an adequate management of the tension between professional autonomy and organisational goals is crucial to minimise potential conflict between professionals and their organisations (Randle, Keith 1996; Styhre and Sundgren 2003). For exploratory activities autonomy involves capacity to determine working schedules, often beyond the time stipulated in contracts or outside normal working hours. It implies capacity to join projects and run experiments without or minimum management control, or to be able to take leaves from time to time -e.g. sabbaticals, attend congresses (Chiesa 1996; Hemmert 1998). By contrast, in drug development settings things may be less relaxed. Chiesa (1996) and Hara (2003) noted that drug development involves clear definition of authority and responsibilities, together with milestones and timeframes to meet the required objectives. First-line managers may receive increased autonomy and responsibility regarding management of his/her subordinates including recruitment, appraisal, and rewarding.

Working conditions in the pharmaceutical industry tend to be among the best throughout manufacturing (BLS-USLD 2007). As described in chapter 4, manufacturing processes and operations, in general, must comply with strict sanitary and quality requirements, manufacturing practices and other industry standards, and work closely with regulatory authorities. This leads to working environments where cleanliness and safety compare positively with other industries. As science-based organisations education requirements tend to be high, this often traduces in better remuneration packages, even in developing countries. Consequently it is customary to find pharmaceuticals firms ranking among the best places to work throughout the world, and Mexico is not an exception (GPWI).

Nonetheless one must acknowledged that, at a global scale, strict regulations faced by the pharmaceuticals industry effectively reduce opportunities to modify working conditions. Any modification to the drugs and corresponding manufacturing processes can lead to burdensome requirements for (re)certification, supervision and control by regulatory agencies. In regards to $R \& D$, the literature documents that drug development activities, such as those underpinning the formulation of generic drugs, are more structured and defined in terms of timing, nature of tasks, formality 
in the organisation, conduction of activities, and so on. This could be the situation in Mexico were the bulk of R\&D leads to obtaining generic products (chapter 6). Based on the conflicting evidence from above, one can derive the following research hypotheses about worker's empowerment:

H7: The influence of empowerment on learning is constrained by the nature of the knowledge pursued by the firm.

H8: The more exploratory nature of the learning activities, the more important should worker's empowerment be.

\subsection{Strategic hiring}

Strategic hiring, ways to staff the organisation, team building or training programmes are means for firms to accumulate technological and other types of capabilities. March (1991) identified turnover and staff replacement as mechanisms introducing variability in organisations and whereby, renewed opportunities for organisational learning. New comers reduce levels of socialization within the firm, relative to more experienced staff; consequently, by bringing them in to the organisation, firms can induce increased opportunities to exploration and knowledge accumulation. In line with this idea Du and Ai (2008) argue that flexible hiring facilitates inter-organisational knowledge sharing. It also enables firms to overcome the constraints of internalised knowledge searches during the innovation processes. A mix of experience and skills, but also clear intention to keep consistency with in-house innovation or production teams, with short- and longterm knowledge requirements constitute relevant criteria to hire new staff (Du and Ai 2008; Santamaría et.al, 2009).

Potential benefits from hiring new staff stem however, from the introduction of increased diversity in individual knowledge, rather than on an intrinsic superiority in the skills and knowledge of new employees. Organisations can improve innovation performance through flexible hiring interventions, by strategically incorporating mobile scientists and engineers, specialised consultants, even by capturing the expertise residing in a geographically dispersed organisation. Santamaría et.al, (2009) stress the importance of external knowledge sources such as the use of consultants, the hiring of personnel, collaboration agreements and external R\&D. Firms can capture and benefit from such knowledge without having to create it from scratch (Bell 1984; Lacetera et.al, 2004). Based on these considerations, the working hypotheses associated with strategic hiring read as follows:

H9: Staff hiring supports acquisition of externally generated knowledge.

$\mathrm{H} 10$ : The influence of staff hiring on learning is constrained by the nature of the knowledge pursued by the firm.

Hypotheses $\mathrm{H} 1$ through $\mathrm{H} 10$ inform the empirical analyses in Chapters 7 through 9. 


\section{The data in this thesis}

This thesis builds on two kinds of data: quantitative and qualitative from both primary and secondary sources. The combination of these two methodological strategies for data collection makes the analysis much stronger than mere survey based research or case studies (Creswell 2003); this is a major departure from available literature in the field. Results from the quantitative analyses were contrasted with qualitative information about the agents in the pharmaceutical industry; hence one can better understand their behaviour in relation to the topics under investigation. The main source of primary data for the quantitative study was a survey conducted by the Mexican government as described in Section 3.1. The anecdotic information was gathered through in-depth interviews with people from the pharmaceutical industry and related public and private organisations. Secondary data came from extensive searches on archival and other documentary sources, attendance to specialised seminars, presentations, Internet and so on.

\subsection{Primary Data}

\subsubsection{Quantitative Data}

The core of the empirical discussion in this thesis is presented in chapters 6-8. The econometric analyses in those chapters built on data from a survey carried out by the Mexican government: the Encuesta Nacional de Empleo, Salarios, Tecnología y Capacitación (ENESTYC) ${ }^{1}$. ENESTYC is a survey carried out by the Instituto Nacional de Estadística, Geografía e Informática (INEGI) ${ }^{2}$ on behalf of the Secretaría del Trabajo y Previsión Social (STPS), Mexico. ${ }^{3}$ ENESTYC's geographical coverage is at national level; hence, it is representative for the whole of the Mexican manufacturing sector. Manufacturing is split into non- and maquiladora activities. Our focus was on non-maquiladora firms. Classification of manufacturing activities is based on the North American Industrial Classification System (NASCl). The manufacturing establishment is the unit of analysis. The survey builds on a stratified sample based on the establishment's size as measured by total employment: Large 251+; medium: 101-250; small: $10-100$ and micro: 0-5. ENESTYC follows a probabilistic stratification. As for sampling procedures, manufacturing establishments with 100 or more employees are all included plus a random sample of those with less than 100 employees. Total population is 9,920 non-maquiladora manufacturing units. Confidence level is 95 per cent with a relative error of 10

\footnotetext{
${ }^{1}$ National Survey of Employment, Salaries, Technology and Training

${ }^{2}$ National Institute for Statistics, Geography and Informatics

${ }^{3}$ Department of Labour, Mexico
} 
percent. Estimated non-response is 10 percent. There are no fixed time frames to run the survey with new questions being incorporated over subsequent waves. The latest publicly available edition of ENESTYC corresponds to the event 2001. Nevertheless, with a previous commitment to observe all pertinent confidentiality requirements by INEGI, personnel from such Institute processed for us preliminary data from the event 2005. Information corresponds to 2004.

This thesis used the module for the pharmaceutical industry (NASCl code 3254) which, in practice, constitutes a census of the industry. The module includes 141 data points with information representative for a total of 388 establishments. Our effective working sample, without missing values, is 112 data points. Some firms may own more than one establishment; however it is impossible to match data points with specific firms. Given the size of the pharmaceutical industry and the sampling procedure, staff at INEGI preferred not to merge those establishments belonging to a single firm. Consequently the remaining of this thesis uses indistinctly the term establishment and firm.

\subsubsection{Data on learning strategies of pharmaceutical firms}

In ENESTYC information about manufacturing units in Mexico include: technological and organisational profiles; employment and remuneration levels; some general human resource management practices and the provision of training. As for the technological performance, ENESTYC contains data on in-house R\&D. The variable is identified in two manners: first, firms can be classified depending on whether they carry out $R \& D$ or not. Second, R\&D is captured according to the objectives pursued by the firm, whether for new/improved process or product innovation. This thesis broadly interprets in-house R\&D as an internal source of learning.

ENESTYC also contains information about the participation of pharmaceutical firms in external markets for technology. This is through indicators such as technology licensing, acquisition of machinery and equipment, performance of joint $R \& D$, contracting consultant firms, reading specialised literature and so on. Interactive activities underpinning learning from external technology sources are also captured through two indicators: One such indicator denotes collaboration among firms and exchange of information about the economic and technical conditions of the industry. A second variable indicates joint acquisition of technology and equipment. These variables are broadly interpreted as learning from external sources of knowledge.

For comprehensiveness of the analysis, indicators on internal and external learning efforts are described in greater detail in Chapters 7 and 8, respectively. Correlation analyses are also conveniently provided in those chapters. 


\subsubsection{Controls on firms' characteristics}

In line with the framework in figure 2.1, the econometric analyses here control for variables such as the adoption of modern organisational practices by the firm, the firm's size, the presence of foreign capital ownership and exports. Table 3.2 presents the control variables used in this thesis; written in bold are indicators created based on the ENESTYC dataset.

Table 3.2: Control variables about pharmaceutical firms in Mexico

\begin{tabular}{|c|c|c|c|c|c|}
\hline & Mean & S.D. & Min & Max & Description \\
\hline $\begin{array}{l}\text { impor- } \\
\text { tance_totalq }\end{array}$ & 1.741 & 1.849 & 0 & 8 & $\begin{array}{l}\text { Ranking of the use of total quality } \\
\text { management (TQM) practices by a firm, } \\
\text { from } 1 \text { very important through } 8 \text { not } \\
\text { important; } 0 \text { if the firm does not use TQM }\end{array}$ \\
\hline $\begin{array}{l}\text { impor- } \\
\text { tance_justinti } \\
\text { me }\end{array}$ & 1.786 & 2.689 & 0 & 8 & $\begin{array}{l}\text { Ranking of the use of just-in-time (JIT) } \\
\text { practices by a firm, from } 1 \text { very important, } \\
\text { through } 8 \text { not important; } 0 \text { if the firm does } \\
\text { not use JIT }\end{array}$ \\
\hline $\begin{array}{l}\text { use_justintim } \\
\text { e }\end{array}$ & 0.348 & --- & 0 & 1 & $\begin{array}{l}1 \text { if the firm reports the use of just-in-time } \\
\text { organisational practices irrespective of } \\
\text { importance; } 0 \text { otherwise }\end{array}$ \\
\hline use_totalq & 0.634 & --- & 0 & 1 & $\begin{array}{l}1 \text { if the firm reports the use of total quality } \\
\text { management organisational practices } \\
\text { irrespective of importance; } 0 \text { otherwise }\end{array}$ \\
\hline $\begin{array}{l}\text { mod- } \\
\text { ern_practice }\end{array}$ & 0.670 & --- & 0 & 1 & $\begin{array}{l}1 \text { if the firm reports the use of total quality } \\
\text { management and/or just-in-time organisa- } \\
\text { tional practices irrespective of actual impor- } \\
\text { tance; } 0 \text { otherwise }\end{array}$ \\
\hline Size & 1.884 & 0.888 & 1 & 4 & $\begin{array}{l}\text { Size of the firm 1=Large, 2=Medium, } \\
3=\text { Small, } 4=\text { Micro }\end{array}$ \\
\hline size_firm & 1.589 & 0.494 & 1 & 2 & $\begin{array}{l}\text { Recode of size; hence it is more intuitive to } \\
\text { see the size of the firm: } 1=\text { Medium, small } \\
\text { and micro, } 2=\text { Large }\end{array}$ \\
\hline exports* & 72.9 & 340.9 & 0 & 3499.4 & Total exports in 2004 \\
\hline $\begin{array}{l}\text { ex- } \\
\text { port_dummy }\end{array}$ & 0.536 & ---- & 0 & 1 & 1 if the firm reports exports; 0 otherwise \\
\hline fdi & 0.313 & --- & 0 & 1 & $\begin{array}{l}\text { Share of foreign ownership within a firm's } \\
\text { total social capital structure }\end{array}$ \\
\hline foreign_share & 25.768 & 41.922 & 0 & 100 & $\begin{array}{l}1 \text { if the firm has some foreign ownership } \\
\text { within its total social capital structure; } 0 \\
\text { otherwise }\end{array}$ \\
\hline
\end{tabular}

Notes: Information for the 112 data points in our working sample; * Million Mexican pesos

Source: Author with information from ENESTYC, 2005; INEGI, Mexico

Organisational environment: Based on the discussion in chapter 2, the econometric analyses control for the characteristics of the organisational environment inside a firm. This is through a variable denoting the use of modern organisational practices such as JIT and TQM. Although ENESTYC captures this two variables individually, they were highly correlated with explanatory variables such as worker's empowerment-see below. The use of a new variable, modern_practice, 
helped to avoid potential multicollinearity problems. This is consistent with the view that pharmaceutical firms customarily introduce advanced organisational practices as a means to meet strict product safety and quality requirements-chapter 5 .

Participation in export markets: Arora et.al's (2001) study on external markets for knowledge found that competition in markets for goods is an incentive to license technology. Kim et.al, (1989) equally highlights export orientation as a competitionrelated factor conditioning a firm's technological behaviour. These considerations lead to control for the firm's participation in export markets. Exposure to external competition is expected to positively influence learning from external markets.

Foreign ownership: Capital ownership conditions decisions on investment in technology in developing countries. This is closely tied to how affiliates contribute to the overall innovative strategy of the parent firm. In the case of developing countries, the concentration of decision making in the parent company suggests that foreign ownership can have negative effects on learning from external markets. This is particularly so in the case of activities such as R\&D for knowledge exploration (Nakamura and Odagiri 2005). By contrast foreign ownership is expected to impact positively and significantly on learning from external markets in activities other than $R \& D$; multinationals invest heavily in plant modernisation in host countries.

ENESTYC provides information on both the share of foreign capital in the firm's total social capital, and on export behaviour. In order to reduce some collinearity problems, while avoiding trouble in the computation of logarithms for entries set at zero, the two variables were converted into dummy variables.

Size: Controlling for scale effects associated with the size of a firm is standard in the literature; the pharmaceutical industry is no exception. Large firms are expected to show more positive technological behaviours, as compared to smaller businesses. More specifically, large firms report enhanced capacity to systematically invest in R\&D and other innovation-related activities (Cockburn 2004). Such firms can spread the risk among a greater number of projects, even across geographical boundaries (Cockburn and Henderson 2001). In the context of the pharmaceutical industry, Kim et.al, (1989) stressed that the scale of operations may condition, either negatively or positively, learning performance of firms in catching up contexts. Size is an important factor in Mexico and other developing countries were large multinationals often dominate the most dynamic segments of the market-see chapter 6 . In this regard, by combining scale effects with the variable on worker's remuneration it was possible to eliminate some high and positive correlation between the variable on remunerations, fdi and exports.

\subsubsection{Indicators on management practices}

Table 3.3 presents the variables on human resource management practices in ENESTYC, 2005. Based on Delery's (1998) proposition, we used alternative 
constructs about management variables; indicators in bold are those that were created based on the information in the ENESTYC dataset. For comprehensiveness, correlations for variables in table 3.3 are provided in chapters 6 through 8 .

Table 3.3 Variables on human resource management practices in Mexican manufacturing and available through ENESTYC, 2005

\begin{tabular}{|c|c|c|c|}
\hline & Min & Max & Description \\
\hline \multicolumn{4}{|c|}{ Human resource management practices } \\
\hline train04 & 0 & 1 & $\begin{array}{l}1 \text { if the firm provided training to its employees in 2004; } 0 \\
\text { otherwise }\end{array}$ \\
\hline training_internal & 0 & 1 & 1 if training is provided by colleagues in-house; 0 otherwise \\
\hline training_pubuniv & 0 & 1 & $\begin{array}{l}1 \text { if external training was provided by a public university; } 0 \\
\text { otherwise }\end{array}$ \\
\hline training_priuniv & 0 & 1 & $\begin{array}{l}1 \text { if external training was provided by a private university; } 0 \\
\text { otherwise }\end{array}$ \\
\hline training_firm & 0 & 1 & $\begin{array}{l}1 \text { if external training was provided by another firm; } 0 \\
\text { otherwise }\end{array}$ \\
\hline training_tradeorg & 0 & 1 & $\begin{array}{l}1 \text { if external training was provided through a training centre } \\
\text { of a trade organisation; } 0 \text { otherwise }\end{array}$ \\
\hline training_freelance & 0 & 1 & $\begin{array}{l}1 \text { if external training was provided by an individual } \\
\text { consultant; } 0 \text { otherwise }\end{array}$ \\
\hline $\begin{array}{l}\text { training_sup_mac } \\
\text { h }\end{array}$ & 0 & 1 & $\begin{array}{l}1 \text { if external training was provided by a supplier of machinery } \\
\& \text { equipment. } 0 \text { otherwise }\end{array}$ \\
\hline external_training & 0 & 1 & $\begin{array}{l}1 \text { if the firm provides training through external providers } \\
\text { (specialised public job training centres, public universities, } \\
\text { private universities, other firms, consultants or the industry's } \\
\text { trade organisation); } 0 \text { otherwise }\end{array}$ \\
\hline $\begin{array}{l}\text { internal_external } \\
\text {-tr }\end{array}$ & 0 & 1 & $\begin{array}{l}1 \text { if the firm provides training both in-house and externally; } 0 \\
\text { otherwise. This is an interaction term between } \\
\text { training_internal and external_training }\end{array}$ \\
\hline In_avg_rem & 2.67 & 5.75 & $\begin{array}{l}\text { Natural logarithm of the average remuneration per worker: } \\
\text { total remuneration (salaries and benefits) paid in } 2004 \\
\text { divided by total number of employees in the same year }\end{array}$ \\
\hline $\begin{array}{l}\text { impor- } \\
\text { tance_empower }\end{array}$ & 1 & 8 & $\begin{array}{l}\text { Ranking set by the firm about importance of workers partici- } \\
\text { pation in decision-making about the workplace; } 1 \text { very impor- } \\
\text { tant through } 8 \text { not important; } 0 \text { if the firm workers do not } \\
\text { participate in decision-making }\end{array}$ \\
\hline $\begin{array}{l}\text { imp_empowerme } \\
\text { nt }\end{array}$ & 0 & 2 & $\begin{array}{l}1 \text { if workers participate in decision making and the firm } \\
\text { declares that such practice is important; } 2 \text { not important; } 0 \\
\text { workers do not participate }\end{array}$ \\
\hline \multicolumn{4}{|c|}{ Human resource management policies } \\
\hline $\begin{array}{l}\text { hire_permwork_c } \\
\text { c }\end{array}$ & 0 & 1 & $\begin{array}{l}1 \text { if the firm reports that it governs hiring practices through } \\
\text { collective contracts; } 0 \text { otherwise }\end{array}$ \\
\hline hire_permwork_ir & 0 & 1 & $\begin{array}{l}1 \text { if the firm reports an internal regulation, other than collec- } \\
\text { tive contracts, to govern hiring practices; } 0 \text { otherwise }\end{array}$ \\
\hline rule_hiring & 0 & 1 & $\begin{array}{l}1 \text { if the firm regulates hiring staff through either collective } \\
\text { contracts or other internal negotiations; } 0 \text { otherwise }\end{array}$ \\
\hline
\end{tabular}

Notes: Working sample: 112 data points; Variables in bold denote indicators created by the authors.

Source: Author with information from ENESTYC, 2005; INEGI, Mexico

ENESTYC contains data on management practices relevant for learning and innovation. These include the provision of training, the use of rotation assignments 
and worker's participation in decision making. In addition, there are some questions on the regulation of practices such as staff hiring, staff promotion, remunerations and so on. In this regard, Boseli et.al, (2005:74) acknowledged three forms to measure human resource management variables: "by its presence (i.e. a dichotomous scale for whether it is actually in effect 'yes' or 'no'), by its coverage (i.e. a continuous scale for the proportion of the workforce covered by it) or by its intensity (i.e. a continuous scale for the degree to which an individual employee is exposed to the practice or policy). The overwhelming majority [of studies rely] only on measures of presence." To a large extent, ENESTYC allows performance of the latter type of analysis, as in general, variables are measured in terms of adoption by the firm. Although this facilitates data collection and analysis, it is possible that managers and employee representatives can disagree on the presence and, more importantly, the effectiveness of a given practice (Boseli et.al, 2005; Ichniowski et.al, 1996). Only a few but relevant variables in the ENESTYC dataset reflect intensity of practices. A notable example is the indicator on workers' participation in decisionmaking processes; it shows the perceived importance of delegation from the perspective of the employer.

Wright et.al, (2003) and Boseli et.al, (2005) equally warn about the differences resulting from the measurement of management variables in terms of either policies or practices. Whereas the former reflects an organisation's stated intentions regarding management activities; the latter are the actual, functioning, observable activities, as experienced by employees. Written policies concerning management practices will only lead to performance as individuals perceive them as important for organizational well-being. This distinction is clear in the literature on developing countries where distinctions are made between stated management styles, and how actual management interventions take place (Abramo 1997; Dutrénit 2000).

ENESTYC contains variables on regulations applicable to management policies; however, information about how such rules translate into actual management interventions is missing. Consequently, our use of such variables limits to those indicators for which our interviews-see section 3.1.2.1- provided some more concise information. Hence it was possible to learn about the implementation of the relevant practices as necessary condition for effectiveness (Boseli et.al, 2005). This was the case of regulations governing the hiring of new staff.

The empirical analysis in this thesis incorporates variables such as the provision of internal and external training, remuneration for performance, staff hiring and worker's participation in decision making about the conditions of the work place. The goal is to learn how they contribute to learning by pharmaceutical firms in Mexico. In this regard, the variable on external training was split in order to identify some specific training providers for which ENESTYC provides information: individual consultants, private and public universities, public research centres, machinery suppliers and, training centres linked to local trade organisations of the 
pharmaceutical industry.

\subsubsection{Qualitative Data}

Collection of primary qualitative data through in-depth interviews informed about the environment in which pharmaceutical firms operate in Mexico and abroad. The interviews captured the characteristics of the firm, the type of R\&D and other innovation activities it carries out in Mexico, if at all, and some factors explaining why firms do or do not do R\&D in Mexico. Moreover, the interviews explored the different areas shaping pharmaceutical innovation: basic research, clinical trials and manufacturing-see chapter 4. An additional set of questions targeted the human resource management strategy of the firm. Based on Henderson and Cockburn (1994) and Ichniowski et.al, (1997), the information thus obtained helped to interpret both the ways and contexts in which human resource management practices intervene in processes underpinning learning for pharmaceutical innovation in Mexico.

\subsubsection{The interviews}

The design of the interview guide, in the form of a survey type questionnaire Annex 1-, built on the literature review in chapters 1 and 2, and a series of exploratory interviews conducted in Mexico and abroad. The interviews took place at three different points in time. Exploratory meetings were held in January (Spain) and June (Mexico), 2006. Afterwards two rounds of field work took place in Mexico during February-August 2007 and October-December, 2007. Additional interviews were held in late 2008. The pilot of the interview instrument included several sources, namely: the head of the human resource management department and a technician from the development unit at a generics drugs manufacturer in Pamplona, Spain. Two telephone interviews conducted with people at a European multinational with operations in Mexico. Finally, two interviews were carried out at a Mexican firm, and one at a US affiliate. The Mexican firm and a contact person at the National Trade Organisation of the Pharmaceutical Industry in Mexico (CANIFARMA for its name in Spanish) helped to validate the final version of the interview instrument. Useful observations, comments and contacts were obtained from researchers at the National Autonomous University of Mexico (UNAM for its name in Spanish) and the Metropolitan Autonomous University (UAM for its name in Spanish).

Seizing the pharmaceutical industry in Mexico involved extensive searches through several public and private data sources; distinct sources provided different numbers of firms shaping the local pharmaceutical industry. The focus was on firms 
producing drugs and other pharmaceutical products for human consumption. ${ }^{4}$ The basic reference was Secretaría de Salud (2005a), ${ }^{5}$ which reported that, in 2005, 200 pharmaceutical firms were located in Mexico, including 49 multinational affiliates, and operated 226 manufacturing plants. Unfortunately, since the document did not identify firms by name, additional searches were conducted within the Mexican Pharmacopeia ${ }^{6}$, the Hoovers Database, and the websites of the main local trade organisations: CANIFARMA, Association of the Industry of Pharmaceutical Research (AMIIF for its name in Spanish) and National Association of Drug Manufacturers in Mexico (ANAFAM for its name in Spanish). ${ }^{7}$ Snow-bowling and access to a telephone directory of the industry identified some additional firms. These search strategies allowed identification of 193 pharmaceutical firms, of which 140 were effectively approached, most of them through CANIFARMA -Annex $2 .^{8}$

CANIFARMA distributed the interview guide via email among its affiliates in June 2007; a reminder followed in October 2007. Follow up was conducted by the author of this thesis and some research assistants from the UNAM. A total of 40 firms-for a response of 28.6 percent- replied to our request for information, but only 26 agreed to participate. Participation was through interviews but, in some cases, the firms simply returned the interview instrument together with some comments. For reasons of an explicit commitment to confidentiality, identity of informants in each participating firm remains anonymous. Table 3.4 presents more details about the interviewees.

The interviews were semi-structured, took an hour long on average and, in most cases, were audio-taped and fully transcribed afterwards. Previous to the meeting, interviewees were given specific guidance about the objectives and scope of the study. Some introductory letters were sent reconfirming the information about the study, together with the interview instrument. Normally the initial contact was the general director's office or that of the manufacturing head. Sometimes these persons granted the interview, some others they directed us to either the human resources, or the development department. In general it was possible to adjust the flow of the conversation as interviewees prompted issues worth to explore further. Interviews were conducted in Spanish and only occasionally, in English. In addition to General Directors, Medical directors, Human

\footnotetext{
${ }^{4}$ Additional items include API manufacturing, veterinary products and health auxiliary devices.

${ }^{5}$ Secretaría de Salud (2005a) is the most recent and comprehensive publication by the Mexican Health authorities about the characteristics and operation of the pharmaceutical industry. The document sets the general bases of a renewed public policy approach to the local industry.

${ }^{6}$ The pharmacopeia is a public record of pharmaceutical products officially authorized for sale in a given country; in this case, Mexico.

${ }^{7}$ CANIFARMA, AMIIF and ANAFAM represent the largest share of pharmaceutical firms in Mexico, with affiliation overlapping across the three organisms. Nevertheless CANIFARMA is the largest of the three; membership accounts for the bulk of the Mexican pharmaceutical industry in terms of value, employment and sales, ( 80 percent or more).

${ }^{8}$ CANIFARMA denied access to the directory of firms arguing confidentiality reasons.
} 
resource managers, $R \& D$ Heads or Development analysts, interviews were conducted at CANIFARMA and AMIIF. People from the local regulatory agency, Comisión Federal para la Protección Riesgos Sanitarios (COFEPRIS), the Instituto Mexicano del Seguro Social (IMSS) ${ }^{9}$ and the coordinating body of the public healthcare and health research centres (CCINSHAE) ${ }^{10}$ were also interviewed. In total 40 interviews were conducted, 34 of which correspond to 22 firms.

Several reasons explain unwillingness of firms to take part in this study. The majority of them argued internal policies, ethical reasons or difficulties to provide confidential information. Other firms insisted that an official request from the local regulatory authority had to be submitted with details about the information needed. And yet some other firms qualified themselves as too small, hence considered that they could provide limited information, barely useful for our purposes. Reticence to participate frequently resulted from strict confidentiality agreements signed by the employees with the company. Particularly for large firms, a policy of fragmenting information across departments and functions complicated access to data. This suggests that future studies may need to run in steps following the logic of for example, studies type 3 as described in chapter 2; data can be gathered for individual departments and then integrated and analysed in the light of the broader operation of firms.

\subsection{Secondary data sources}

Secondary data sources assisted in the overall characterisation of the pharmaceutical industry in Mexico, including market structure and dynamics, regulatory aspects, employment, sales, exports, R\&D expenditure and overall recent innovation performance. Important supplements of data were in the form of archival searches in the national press, reference texts, academic and medical literature, reports by consultant firms and other specialised sources of information about the industry, regulatory agencies and the Internet. These sources assisted in better understanding operation of the industry at a global scale and in Mexico. Additional data stem from attendance to specialised seminars about the industry.

\footnotetext{
${ }^{9}$ IMSS and ISSSTE are the two largest public healthcare organizations. They count with 61 million affiliates, roughly 58 percent of Mexico's total population.

${ }^{10}$ A total of twelve Institutos Nacionales de Salud are in place. These are high speciality hospitals that provide health-assistance and training across 12 different therapeutic areas. The fundamental mission however, is to perform high quality clinical and some basic research.
} 
Table 3.4: General description of interviews carried out as part of this study

\begin{tabular}{|c|c|c|c|c|c|c|c|}
\hline Firm & Origin $^{1 /}$ & $\begin{array}{l}\text { Employ- } \\
\text { ploy- } \\
\text { ment }\end{array}$ & Sales $^{/ 2}$ & Years $^{13}$ & Date & Contact & Duration $^{/ 4}$ \\
\hline 01 & $\mathrm{~F}$ & 210 & 360000 & $<3$ & 25/Jun/07 & Director general & 63 \\
\hline \multirow[t]{3}{*}{02} & $\mathrm{~F}$ & 1100 & 3119745 & $>50$ & 11/Jul/07 & Plant manager & \\
\hline & & & & & 20/Mar/07 & Supervisor Manufacturing & 75 \\
\hline & & & & & 26/Mar/07 & Staff Manufacturing & 60 \\
\hline \multirow[t]{3}{*}{03} & $\mathrm{M}$ & n.a. & 281775 & $>50$ & 17/Jul/07 & Plant manager & 104 \\
\hline & & & & & 17/Jul/07 & Development manager & 81 \\
\hline & & & & & 17/Jul/07 & Research director & 88 \\
\hline 04 & $M$ & 421 & n.a. & $\sim 30$ & 02/Jul/07 & CEO & 31 \\
\hline \multirow[t]{2}{*}{05} & $M$ & 343 & 450000 & $\sim 40$ & 11/Jun/07 & CEO & 92 \\
\hline & & & & & 19/Jun/07 & Plant manager & 109 \\
\hline \multirow[t]{2}{*}{06} & M & n.a. & 416394 & $\sim 40$ & 07/May/07 & $\begin{array}{l}\text { Director General } \\
\text { Development manager }\end{array}$ & 110 \\
\hline & & & & & 04/Jul/07 & $\begin{array}{l}\text { Development manager \& } \\
\text { two staff members }\end{array}$ & 140 \\
\hline \multirow[t]{3}{*}{07} & $\mathrm{~F}$ & 808 & 2228675 & $\sim 40$ & 02/Apr/07 & Director General & 34 \\
\hline & & & & & 10/Apr/07 & Communications manager & 55 \\
\hline & & & & & 16/Apr/07 & $\begin{array}{l}\text { Medical and regulatory } \\
\text { affairs manager }\end{array}$ & 32 \\
\hline \multirow[t]{3}{*}{08} & $\mathrm{~F}$ & 1100 & n.a. & $>50$ & $16 /$ Feb/07 & \multirow{2}{*}{$\begin{array}{l}\text { Latin America, Human } \\
\text { resource management } \\
\text { affairs }\end{array}$} & 120 \\
\hline & & & & & 13/Mar/07 & & 90 \\
\hline & & & & & 16/Mar/07 & Technical operations & 75 \\
\hline 09 & $\mathrm{M}$ & n.a. & n.a. & $>50$ & 09/Mar/07 & Former CEO assistant & 60 \\
\hline \multirow[t]{2}{*}{10} & $M$ & n.a. & n.a. & $>50$ & 07/Dec/07 & Former Director General & 76 \\
\hline & & & & & 16/Jul/07 & Head R\&D department & 89 \\
\hline 11 & M & 770 & 600000 & +30 & $\begin{array}{l}27 / \mathrm{Jul} / 06 \\
27 / \mathrm{Feb} / 07\end{array}$ & Operations director & $\begin{array}{c}120 \\
75\end{array}$ \\
\hline 12 & $\mathrm{~F}$ & n.a. & n.a. & $<4$ & 11/Jul/07 & Director General & 19 \\
\hline \multirow[t]{2}{*}{13} & $\mathrm{~F}$ & $>1000$ & n.a. & $>50$ & $30 / \mathrm{Jul} / 07$ & R\&D director & 47 \\
\hline & & & & & $30 / \mathrm{Apr} / 07$ & Development manager & 31 \\
\hline 14 & $\mathrm{M}$ & $>1000$ & n.a. & $>50$ & 23/Nov/07 & $R \& D$ director & 71 \\
\hline 15 & $\mathrm{~F}$ & $>1000$ & 4583905 & $>40$ & 26/Jul/06 & Human resource technician & 60 \\
\hline $16^{5 /}$ & $\mathrm{M}$ & $>30$ & n.a. & $>20$ & $19 / 10 / 07$ & Director general & --- \\
\hline $17^{5 /}$ & $\mathrm{F}$ & $>1000$ & n.a. & $>30$ & 14/Aug/07 & Medical director & --- \\
\hline $18^{5 /}$ & $\mathrm{F}$ & $>1000$ & n.a. & $>50$ & 19/Aug/07 & Communication director & --- \\
\hline $19^{5 /}$ & $M$ & $>30$ & 11000 & $>70$ & 14/Aug/07 & Director general & --- \\
\hline $20^{5 /}$ & $\mathrm{F}$ & 90 & n.a. & 3 & 14/Aug/07 & Operations director & --- \\
\hline $21^{5 /}$ & $\mathrm{F}$ & $>350$ & n.a. & $>70$ & 14/Aug/07 & Medical director & --- \\
\hline $22^{5 /}$ & $M$ & $>40$ & n.a. & 4 & $14 /$ Nov/07 & Director general & --- \\
\hline Trade1 & --- & --- & --- & --- & 26/Mar/07 & Director research & 100 \\
\hline Trade2 & --- & -- & -- & --- & 03/May/07 & Director communications & 52 \\
\hline InsH1 & --- & --- & --- & --- & 12/Jul/07 & Coordination & 23 \\
\hline $\mathrm{InsH} 2$ & --- & --- & --- & --- & 09/Oct/08 & Research coordination & 90 \\
\hline InsH3 & --- & $\begin{array}{c}-- \\
\end{array}$ & --- & --- & 18/Apr/07 & Director & 35 \\
\hline CRO & --- & --- & --- & --- & 04/Apr/07 & Clinical research monitor & 60 \\
\hline
\end{tabular}

Notes: $1 / \mathrm{M}=$ Mexican, $\mathrm{F}=$ foreign; $2 /$ thousand Mexican pesos; 3/ years of operation in Mexico; 4/ in minutes; 5 / correspond to firms that returned the interview instrument together with some comments; TradeX: Trade organisation; InsHX: National Health Institute; IMSS or Regulatory body; CRO: Contract research organisation; n.a. Not available because the firm denied the information or provided only the share of products/markets.

Source: Author based on interviews 


\section{Chapter 4}

\section{Understanding innovation in pharmaceuticals: Processes, knowledge bases and trends}

\section{Introduction}

The global pharmaceutical industry stands out for its dynamic growth rate, socioeconomic, health and ethical implications. Intensive R\&D efforts characterize it as a highly science-based industry. Pharmaceuticals systematically rank among the top R\&D expending sectors throughout the developed world (NSF 2008). Continuous exploration for technological opportunities and innovation is vital for competitiveness and success of firms. The industry deserves considerable attention from alternative research perspectives including, systems of innovation (Cockburn 2004; McKelvey et.al, 2004) and capability building (Kim 1997; Singh 2007).

The literature addresses the factors determining innovation and overall performance of the global pharmaceutical industry. This includes the strengthening of IPR's and associated welfare implications as in Arundel and Kabla (1998) and Angell (2004); regulatory and competitive issues shaping dynamics of the industry at local and global levels; ${ }^{1}$ availability, costs and access to medicines for the poor; ${ }^{2}$ or, ethical considerations related to pharmaceutical R\&D and patenting activities. ${ }^{3}$ Research aims to understand recent changes in the processes, technologies and knowledge bases supporting $R \& D ;{ }^{4} R \& D$ productivity, skills requirements and so on. ${ }^{5}$ These strands of literature approach pharmaceutical innovation from different historical, technical, health and socioeconomic perspectives.

Gaudillière (2004) offers an interesting integrative approach to understand pharmaceutical innovation. The author proposes that such activity is simultaneously scientific, technical, organisational, institutional and judicial. The process can be approached from two distinct but complementary perspectives: that of health and medical sciences professionals on the one hand, and that of economists on the other. In the first case innovation refers to introduction of new or improved

\footnotetext{
${ }^{1}$ (Dijkema et.al, 2006; DiMasi 2001a and b; DiMasi et.al, 2003; Reichert 2003)

2 (Grace 2004; Molina and Rivas 1998)

${ }^{3}$ (BHSP 2006; Drennan 2001; Sharma 2004; Santiago 2009)

${ }^{4}$ (Butcher et.al, 2004; Cardinal 2001; Ginsburg and McCarthy 2001; Ulrich and Friend 2002; Walker 2004)

${ }^{5}$ (Beret et.al, 2003; Cockburn et.al, 1999b; Henderson and Cockburn 1994)
} 
substances, ${ }^{6}$ medicines, capable of healing or at least, improving conditions of people affected by disease. As such innovation comprises two dimensions: capacity to discover and create new molecules; and finding clinical applications for them. Each of these dimensions can be associated with two types of research activities: that of chemists and that of medical doctors (Gaudillière 2004). Accordingly, the therapeutic revolution of the last 50-60 years results from the articulation of processes such as (i) screening of "libraries" of molecules owned by pharmaceutical companies, and (ii) conduction of the required therapeutic tests and studies to ensure healing power and safety of new drugs. These processes endure strict regulatory controls and legal requirements, particularly to govern interactions between firms and medical doctors (Jungmittag et.al, 2000a).

Gaudillière (2004) asserts that from economics viewpoint the notion of innovation has different connotations. At first sight it corresponds to introduction into the market of new goods and their corresponding impact on profits, firms' growth or foreign trade dynamics. Factors conditioning innovation are at least, twofold: (i) a firm's structure, its internal organisation and functional divisions; and (ii) the regulatory and administrative frameworks framing firm's performance. Pharmaceutical innovation is a process leading to the transformation of medicines in merchandise, their adaptation to mass production and commercialization. Bearing Gaudillière's (2004) ideas in mind, this chapter describes the different phases of pharmaceutical innovation. It sheds light on the technological processes and recent trends conditioning productivity, efficiency and speed of pharmaceutical innovation.

\section{Pharmaceutical innovation}

New Chemical Entities (NCEs) are potentially new drugs which in general represent significant therapeutic advances. They are defined as "those products representing new chemical structures never previously available to treat particular disease" (Reichert 2003). But how do innovative drugs get into the market? Pharmaceutical innovation can be summarised in four major and often overlapping phases as shown in figure 4.1 (placed at the end of this chapter). The length and sequence of these four phases are determined by legal requirements and scientific and economic necessities (Jungmittag et.al, 2000b). In general it takes 10 to 15 years to pass through all four stages and bring a new drug into market. The first stage includes discovery or basic research leading to identification of new molecular targets or NCEs, followed by performance of pre-clinical studies. Second, there is the long phase of development, when clinical studies are carried out. The latter constitute

\footnotetext{
${ }^{6}$ Gaudillière (2004) considered only new products in his definition of innovation. To be consistent with the literature on developing countries, I included the idea of incremental innovation in the sense of product/process improvements.
} 
the largest share of the time needed to bring new drugs into the market; they represent a third or more of the USD\$800-900 million estimated investment in the entire pharmaceutical innovation process (Boggs et.al, 1999; Maiti and Raghavendra 2007).

A third area captures the regulatory processes of evaluation and eventual approval/rejection of applications for drug testing, development and marketing. In fact this third dimension determines much of what happens throughout the pharmaceutical innovation process. DiMasi (2001a and b) and Kaitin and Healy (2000) document some of the debate on the extent regulatory evaluation and approval impacts on productivity in pharmaceutical innovation. ${ }^{7}$ Public regulation introduces the principles and acceptable practices to conduct new drug-related R\&D, from the physical movement of chemical and biological substances, to ensuring that research involving human beings meets strict requirements of protection of the populations involved.

Secretaría de Salud (2005a) asserts that regulatory interventions should consider: (i) the epidemiological profile of the country and the goals of the national pharmaceutical policy; (ii) the goal of ensuring safe, effective and quality medicines; (iii) the need to secure access to medicines; and, (iv) the strategies to promote innovation and competitiveness of the pharmaceutical industry. Public policy should link a process that starts with the detection of particular health problems; follows with the search for suitable products to address such need and, hopefully, obtaining and manufacturing a new medicine. Last but not least there is the commercialisation and surveillance for long-term effects of the drug on consumers. Figure 4.2 illustrates these elements.

Frequently, innovation scholars restrict their work to understanding the aforementioned stages of discovery, clinical research and regulation. However, what we know is that for a new or improved product, service or process to become an innovation, it still has to prove successful in the market. A last stage in the process comprises drug manufacturing, marketing and product life-cycle support (Styhre and Sundgren 2003). This is congruent with normal regulatory requirements whereby (innovative) drugs are subject to continuous surveillance to prevent potential health and other sanitary risks. With some notable exceptions of firms in India who start to participate, either via joint ventures or by directly performing them, in drug discovery activities (Reddy 1997; Singh 2007), the contribution of developing countries concentrates in manufacturing. This is via development of generic drugs, enhancements or improvements of drugs by combining existing molecules, new dosage forms, new indications, and formula changes; and new drug delivery systems (DDS).

\footnotetext{
${ }^{7}$ FDA (2004b) reports an average of 16.9 months for the FDA to review and approve new drugs in 2003. The share of rejected applications has remained constant at about 10-15 per cent.
} 
Figure 4.2: Public policy process in Pharmaceuticals

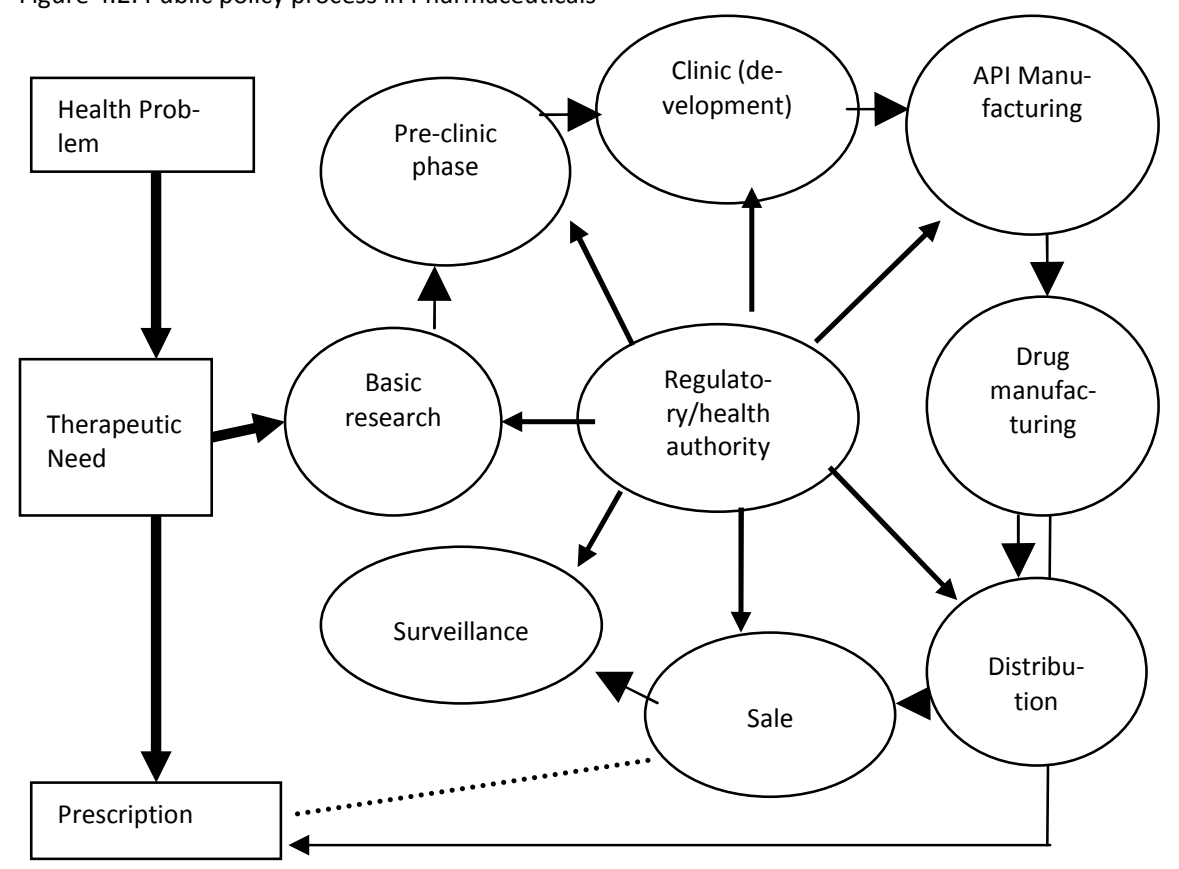

Source: Adapted and translated from Secretaría de Salud (2005a)

The following paragraphs characterise further each instance of pharmaceutical innovation. For comprehensiveness with the rest of the thesis, we focus on R\&D and manufacturing; regulatory issues are introduced throughout the discussion.

\subsection{Drug discovery and pre-clinical tests}

\subsubsection{Drug discovery}

The discovery phase aims to identify specific targets, new molecules with desirable properties and effects on particular disease; that is to say, promising prospects for new medicines. To find a target, literally thousands of compounds, either natural or chemically or genetically engineered, must be screened in a series of test tube experiments called "assays": compounds are added one at a time to enzymes, cell cultures, or cellular substances grown in the laboratory. The goal is to find combinations with desired pharmacological effects. Assays lead to the generation of lead compounds which in turn, must be modified to increase activity or minimize undesirable side effects, a process called lead optimization (Bush 2004; DHHS et.al, 1998; FDA). From a historical perspective one can distinguish two main innovation re- 
gimes, systems of practices, to carry out the screening and identification of potentially new pharmaceutical products (Gaudillière 2004).

In the early years the knowledge and experience of pharmacists supported drug innovation, namely: preparation, isolation and concentration of active ingredients. The process included the isolation and combination of substances according to the characteristics of both the substance itself and the disease it intended to treat (Gaudillière 2004). Roots of this regime go back to the office pharmacists and publication of pharmacopoeias, far from manipulation of living beings (Gaudillière 2004). Back then drug discovery depended on experimental protocols guided by researchers' informed curiosity and trial-and-error approaches. Compounds synthesized by medicinal chemists were tested in experimental animals hoping to obtain some desired biological activity and to separate it from unwanted effects by further chemical manipulation of the lead structure (Kuhlman 1997). With time, this regime eventually gave way to a second one involving the screening and chemical synthesis of compounds (Gaudillière 2004).

In line with literature on technology diffusion, for some time the two innovation regimes coexisted in the industry but, eventually, the second one gained dominance thanks to developments in the chemical and more precisely, the dye industry at the end of the XIX Century (Gaudillière 2004). The new regime built up from the development of selective chemotherapies based on anti-bacterial properties of some dye products, systematic use of intellectual property rights to protect and capture monopolistic rents from new products (Gaudillière 2004). Early in the development of the new regime, new drugs were generated based on random, serendipitous chemical processes but increasingly from interactions between biologists and chemists. These two groups of professionals increasingly seek to understand the biochemical mechanisms of action, the biological structures and function of novel chemical structures (Drews 2000).

Drug discovery is perhaps the area of pharmaceutical innovation where many of the most interesting changes in technologies, processes and knowledge bases have occurred and are currently taking place. This has been guided by developments in combinatorial chemistry, ${ }^{8}$ pharmacology, microbiology and biochemistry, molecular biology, let alone better understanding of the bases of disease, knowledge of the human genome and notably, biotechnology (Malerba and Orsenigo 2002; Zucker and Darby 1997). These factors are expected to shape the future course of drug discovery (Cockburn 2004; Drews 2000). Great expectations result from the prospects of advancing towards personalized medicine, a dreamed appli-

\footnotetext{
${ }^{8}$ Combinatorial chemistry refers to "The synthesis of a substantial number of structurally distinct compounds using similar reaction conditions. The process encompasses systematic molecular design either by linking separate building blocks or by adding substitutes to a core structure" (Kuhlman 1997). Years of experimentation have lead to creation of libraries of molecules, synthesis techniques, physiochemical properties and so on.
} 
cation for the new technologies (Butcher et.al, 2004; Daar and Singer 2005; Ginsburg and McCarthy 2001; Myers and Baker 2001). New screening methods are under development including, computer-aided molecular modelling systems, and other systems biology tools enabling systematic and simultaneous combination of literally hundreds of thousands of molecules. ${ }^{9}$

Today the search for new drugs starts by understanding how the body works, both normally and abnormally, at its most basic levels. Hence it is possible to determine how a drug might be used to prevent, cure, or treat disease or medical conditions (FDA 2003). Automation through computer-controlled robotic systems and the use of combinatorial chemistry accelerates screening of large numbers of novel compounds. As scale advantages diminish, small biotech firms are taking the lead as a supplier industry in robotics/automation, information technologies, genomics, combinatorial chemistry and so on (Jungmittag et.al, 2000a; Malerba and Orsenigo 2002).

Unfortunately, the impact of new technologies on productivity of pharmaceutical innovation remains disappointing (Cockburn 2004; Drews 2000). Further research is needed to explain factors hindering progress; (Drews 2000) argued that new screening techniques and processes still need to be optimized. For instance, although (ultra) high throughput screening systems make possible to identify thousands of new promising compounds --200-300 compounds per year (Kuhlman 1997); only a minor fraction can be chemically synthesised (Butcher et.al, 2004). The bio-chemical, pharmaceutical, toxicological and other properties of thousands of targets need to be known before entering the development stage (Ulrich and Friend 2002). Complexity in knowledge requirements and lack of experience in new drugrelated basic research limits strongly the ability of developing countries to participate in drug discovery activities.

\subsubsection{Pre-clinical tests}

Following identification of suitable drug candidates, lead compounds enter a period of years of recurrent scientific, regulatory and economic testing and validation. Previous to tests in humans, pre-clinical testing through laboratory (in vitro) and animal (in vivo) studies evaluate safety and biological activity of new compounds. This can take anywhere from 3-6 years. Core tests include pharmacokinetics, meaning how active ingredients behave in living organisms via processes such as absorption, distribution, metabolism and excretion. ${ }^{10}$ The tests ensure that substances

\footnotetext{
${ }^{9}$ Butcher et.al, (2004) offer a more ample discussion on this topic

${ }^{10}$ Choices of animal species, mode of administration, dose and dosing interval, and duration of administration are chosen so that results can be interpreted in connection to pharmacological and toxicological investigations. Methodologies employed include high-pressure liquid chromatography, gas chromatography, mass spectrometry analysis and radio- or enzyme-immunoassays (Kuhlman 1997)
} 
reach intended targets, that pass through and that are properly excreted from the body (DHHS et.al, 1998). Safety tests continue after the start of clinical trials with the intention to determine any possible long-term adverse effects associated with the new compounds.

In addition to biological tests, a number of chemical studies establish the compound's purity, stability and shelf life. Manufacturing tests identify potential to mass produce the prospective medicine. Pharmaceutical development studies explore optimum dosage, packaging and formulation--e.g. pills, inhalers and injections; for the new drug (DHHS et.al, 1998). Pre-clinical tests provide the information that a firm compulsory needs to submit when filing for a human investigational new drug (IND) (FDA). ${ }^{11}$ Such applications must include data about the compound's chemical structure, how it is expected to work in the body; any side effects in animals, and how compounds are manufactured (FDA 2001). Applicants must detail plans of how, where and by whom clinical trials will be conducted (DHHS et.al, 1998).

\subsection{Clinical trials}

Notwithstanding progress in drug discovery, boost to pharmaceutical innovation remains limited. Of an estimated 250 compounds entering preclinical testing only about five will make it to clinical trials (DHHS et.al, 1998). Development of lead compounds asks about the potential of the new substance to become more effective than current therapies, if at all existent; feasibility to mass produce the new drug and so on (Bush 2004;DHHS et.al, 1998). ${ }^{12}$ Blinded $^{13}$, random ${ }^{14}$, controlled clinical trials are the best designed instrument to determine if the drug is both safe for people and an effective treatment for the disease in question (Sheiner 1997; Thompson and Vega 2001; Zivin 2000). Tests of manufacturing potential run in parallel as successive phases of trials require substantial amounts of the new substance to be administered to study subjects. They also inform appropriate methods for large scale manufacturing and formulation. The latter may take up to 5 years to develop (Styhre and Sundgren 2003). Clinical-pharmacology and biometric studies support the planning and evaluation of each individual study (Kuhlman 1997). Clini-

\footnotetext{
${ }^{11}$ The IND is a requested exemption from regulations prohibiting that unapproved drugs are shipped and moved across a desired location to conduct clinical trials (FDA)

${ }_{12}$ Molecules can have properties that complicate optimal therapy and administration, including low bioavailability, chemical instability or low solubility. In addition, there are marketing- and other demands in terms of the user-friendliness, design and frequency of administration, including drug delivery technologies (Styhre and Sundgren 2003)

${ }^{13}$ Ideally neither voluntary participants nor physicians conducting clinical tests should know which subject is part of either treatment or control groups; whether the test drug is being administered and to whom (Zivin 2000)

${ }^{14}$ INDs are exceptionally provided to very ill patients (DHHS et.al, 1998). Normally, participants are randomly allocated among control and test groups (Zivin 2000)
} 
cal research involves epidemic studies, life-style modifications, prognostic studies, health records and tests of non-pharmacology related therapies. However, clinical research on new drugs is the most abundant. Trials split as follows:

Phase I: The compound is tested in a small group (10-100) of healthy volunteers, often in a hospital setting, to determine safety profile, including safe dosage range (DHHS et.al, 1998). To minimize risks of major negative reactions in the participants, initial doses are typically very low compared to those administered during animal and non-animal tests; however, these are escalated closer and closer to the expected optimum dosage ${ }^{15}$. Similar to the pre-clinical stage, pharmacokinetic studies examine drug absorption, distribution, metabolization and excretion, and duration of its action in the human body. Phase I studies last from six months to one year and cost about US\$10 million (Zivin 2000).

Phase II: Non- or placebo-controlled Phase II trials involve approximately 100 to 500 volunteer patients with the target disease. Beyond the mere testing of effectiveness of a medicine prospect, Phase II informs about the characteristics, number of study subjects required, dosage and estimated duration of treatment, and other experimental conditions for the larger and more complex Phase III tests. This includes definition of end points, "unambiguous results that indicate exactly what the treatment can do" ${ }^{16}$ (Zivin 2000). Researchers continue to evaluate safety and possible side effects, determine optimal dose and intake schedules. Phase II studies go from six months to two years and cost about US\$20 million.

Phase III: The compound is tested in a significantly larger number of volunteers, from some hundreds to several thousands, in hospitals, clinics and/or physician offices. This renders statistically significant data about safety and efficacy of potential new drugs. By this point, at least one group of patients should render meaningful information about how they benefited and the best way to administer treatment (Zivin 2000). Phase III can provide authoritative confirmation that a drug works. According to Zivin (2000) if analyses prove that the drug candidate is potentially and significantly more effective than the control treatment, the trial is called pivotal. If a regulatory agency is satisfied with the evidence it may issue new drug marketing approval; in practice several trials are needed to inform decision making ${ }^{17}$ (DiMasi 2000; Peck, Carl 1997). Phase III can take from 1-4 years depending on the disease, length of the study, and the number of volunteers; cost may be in excess of US\$45 million (Zivin 2000).

\footnotetext{
${ }^{15}$ If chances are that the new compound will render extremely serious side effects, Phase I tests may be conducted in patients with the medical condition intended to treat; hence potential risks are balanced by potential benefits. These are considered "compassion" tests (DHHS et.al, 1998)

${ }^{16}$ End points signal changes in the condition of the patient from healing to a reduction in the progression of the disease, or whether dead rates have fallen, and by how much (Zivin 2000)

${ }^{17}$ Peck (1997) documented that out of 12 clinical trials, some 25 per cent of all new drug applications in the US in 1994-1995, the least number of clinical studies in an approved NDA was 23, while the maximum exceeded 150 .
} 
Clinical trials are cumbersomely long, costly and highly uncertain even if expected results are more or less known beforehand. Ability to undertake quick, rulegoverned, reasonably low-cost, and credible clinical studies is a major asset and source of sustainable competitive advantage in the pharmaceutical industry (Styhre and Sundgren 2003). These factors help to reduce time-to-market, increase profits and enhance product quality. Each day saved in the process, particularly in Phase III, brings substantial gains in expected revenues. ${ }^{18}$ Accordingly, outsourcing and offshoring of clinical trials has been an increasingly common strategy adopted by pharmaceutical firms to try and speed innovation up. As a result clinical trials are increasingly run at numerous sites around the world. Pharmaceutical multinationals leverage scientific and technical capabilities and other country-specific characteristics in relevant markets while protecting, enhancing or complementing the core knowledge developed at corporate level (Kuemmerle 1999; Le Bas and Sierra 2002; Patel and Vega 1999). Regulatory changes taking place in relevant markets underpin internationalisation of pharmaceutical R\&D. In the US for example, the FDA accepts data from clinical trials performed abroad to support any new drug application (FDA 2001). Similarly, firms take advantage of host countries that are able to comply with strict international standards on good clinical practices (GCP) and good laboratory practices (GLP) respectively, ${ }^{19}$ as this is required to ensure quality and integrity of data and more importantly, to safeguard wellbeing of study subjects.

Developing countries emerge as relevant sites for clinical research. India and China appear as preferred destinations, but good prospects are also available for Brazil, South Africa and Mexico for example. In addition to large domestic markets, such countries have consolidated regional manufacturing and export bases for foreign-owned subsidiaries as well as for some domestic firms. Emerging economies feature some country specific conditions shaping their attractiveness as investigative sites. For instance Santiago (2009) mentions heterogeneous and growing populations, high prevalence of targeted diseases and lower research costs-even for similar labour force quality and research conditions relative to developed countries; ${ }^{20}$ let alone the presence of fairly strong public healthcare systems with large population coverage.

Although firms can benefit from off-shoring clinical trials into developing countries, this strategy rises strong debate around potential ethical and health implica-

\footnotetext{
${ }^{18}$ Boggs et.al, (1999) indicate that each day a successful drug reaches the market earlier may earn up to US\$200,000 for a company.

${ }^{19}$ Adoption of GCPs in the post-II World War period responded to the need to protect integrity of subjects participating in clinical trials; key practices include informed consent and observance of ethical aspects of tests in humans. GLPs in turn, refer to systems of management controls conditioning work in laboratories and research organizations ensuring quality, consistency, validity and reliability of test data (FDA/ORA)

${ }^{20}$ Maiti and Raghavendra (2007) for example report savings of 30 to 50 per cent in India for comparable clinical trials carried out in Europe or the US.
} 
tions, particularly for local populations. As Santiago (2009 and 2010) document, subject to research is the extent to which study subjects are aware of and sufficiently protected against inherent risks of participation in drug testing; or, the capacity of public policy organisations to minimize risks and increase opportunities of host countries to benefit from clinical trials. This field is open for research and policy analysis.

\subsection{Drug manufacturing}

Medicines contain two basic elements. On the one hand the active pharmaceutical ingredient (API) also known as the chemical entity, or the active molecule or principal ingredient. APIs are the ultimate outcome of the ten years or more of basic research and clinical development. APIs are the substances responsible for specific therapeutic actions: they provide relief to the patient. In physical terms APIs make up only a small proportion of the final medicine, but constitute the most expensive part of the product. On the other hand, the excipients, inactive substances, serve as vehicles or media for a drug or any other active substance. Excipients give shape and stability to the medicine. Raw materials of the medicine include both these elements, together with the materials and substances employed in manufacturing but not contained in the final product.

\subsubsection{Good Manufacturing Practice}

Ensuring effectiveness and safety of pharmaceutical products leads to the careful structuring of manufacturing activities so as to avoid any health risks resulting from impurities, variations in the amount of active substance or for instance, the dissolution pattern of a pill (Seiter 2005). In most countries the health authorities tackle these issues by implementing comprehensive safeguards and procedures of obligatory observance by drug manufacturers. These procedures are termed Good Manufacturing Practice (GMP) which, in simple words, indicates the rules/practices to manufacture a drug (Seiter 2005). ${ }^{21}$ GMPs cover layout and functionality of buildings, qualification and training of personnel, cleanliness and sanitation, monitoring, supervision and many other aspects, from beginning to the end, of drug manufacturing (Seiter 2005). GMPs are constantly reviewed and adjusted according to scientific and technological advances; hence, the frequent denomination of "current" or cGMPs (FDA 2004b; Seiter 2005). cGMP compliance requires great investment ef-

\footnotetext{
${ }^{21}$ In Mexico for example, cGMP's are regulated by specific national norms issued by the Secretary of Health, (Secretaría de Salud. 1998a, b)
} 
forts and operating costs. ${ }^{22}$ More importantly, as we discuss latter, cGMPs can condition opportunities for innovation in drug manufacturing.

\subsubsection{Manufacturing process ${ }^{23}$}

Drug manufacturing can be decomposed into: (i) Primary manufacture or making of APIs; and, (ii) Secondary manufacture where formulation of the medicine takes place. Drug manufacturing is lot-based; raw materials subsequently pass from one process step to the next. Manufacturing processes require complex and fairly advanced technologies: distillation reactors, systems to recover solvents and dust emissions, confined spaces, tablet machinery, and for packaging and labelling, among others. Each step processes and transforms the inputs incrementally.

Primary manufacture: The first stage of making medicines is manufacturing of APIs. Two main ways are possible to do so: (i) pharmochemical technology and, (ii) biotechnology. Medicines can combine both processes (Dussel 1999). APIs can be contained in herbs or homeopathic products. Regarding pharmochemical technology, primary manufacture involves chemical reactions to create molecules or chemical compounds. Figure 4.3 illustrates the many possible stages to these reactions. Groups of chemists isolate and purify the API from other products using variety of techniques. Several processes are needed to produce a completely pure sample of the API.

Figure 4.3: Schematic representation of the primary manufacturing process for biopharmaceuticals

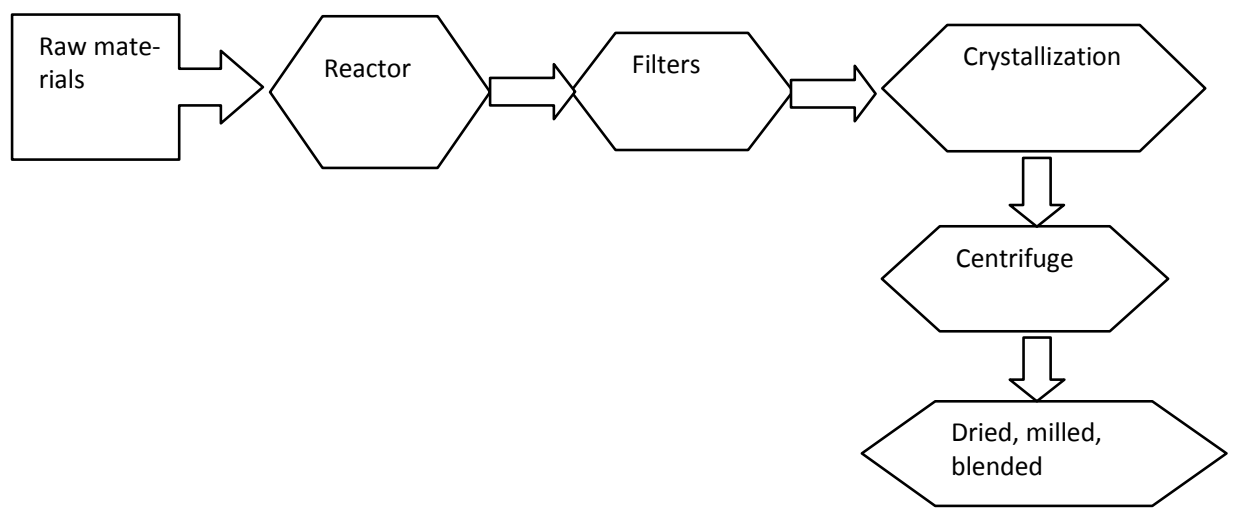

Source: Taken from ABPI (2006)

\footnotetext{
${ }^{22}$ Additional items relevant in the cost structure of a pharmaceutical firm include labour costs, cost of capital, construction costs, taxes and tariffs, costs for environmental safeguards, insurance, licensing, utilities and costs of externally procured goods and services (Seiter 2005)

${ }^{23}$ This section draws heavily from ABPI (2006)
} 
In the case of biotechnology, living beings intervene in API manufacturing. Recent techniques, such as genetic engineering, have been adopted to modify the genes of bacteria so that they can produce useful proteins or monoclonal antibodies (ABPI 2006). Genetic engineering allows scientists to introduce new genes for useful proteins into a cell's DNA, for example bacteria, fungi or cultures of animal cells. The modified cells are subsequently grown on a large scale to produce proteins called biopharmaceuticals. They can be vaccines, hormones, enzymes or monoclonal antibodies. Production of biopharmaceuticals is similar to the primary manufacture sequence in figure 4.3. Nevertheless, the nature of raw materials is different, the cells or micro-organisms and the culture medium in which they grow. The reactor is usually a fermenter. The product is extracted using a series of filters and centrifuges and purified by chromatography. The API is customarily provided in vials as a solution or as a frozen dried powder, ready for formulation in secondary manufacture.

Secondary manufacture: In this stage the API is processed in order to make it suitable for administration to a patient. During this phase firms follow strict codes of good manufacturing practice (Secretaría de Salud 1998a and b). APIs are turned into medicines by mixing with other substances, excipients. Although the latter make up most of the volume of medicines, they have no active role in curing a patient. Excipients shape medicines, such as tablets or capsules, liquids, topical medicines, inhalers or syrups, and give stability to the API (ABPI 2006). Secondary manufacturing entails a series of systematic steps and system technologies, including: (i) the manufacturing system; (ii) the tracking system; (iii) information technology systems; (iv) delivery systems; (v) control systems; and, (vi) technological systems (ABPI 2006).

The manufacturing system: The manufacturing system considers the process of bringing a (new) medicine to the market; it can break down in terms of inputs, processes and outputs.

Inputs: New drug development starts with learning about a particular disease, specifications for new potential medicines and a series of resources including financing, energy, equipment, raw materials and knowledge and expertise of employees, together with the regulatory framework determining and setting the limits to what is feasible in the process of developing and manufacturing a (new) drug (ABPI 2006). The quality of the raw materials is of paramount importance for success in manufacturing processes. Raw materials are carefully evaluated for the identity and purity of the chemical entity; certificates of compliance with cGMP are issued by the appropriate health or regulatory authority of the country of origin.

The processes: Important aspects include the manufacturing cycle itself; the production systems (layout and how equipment is grouped and linked); the checking system to ensure that medicines meet proper specifications; the scale and the pace of production (whether products are manufactured continuously, or in small 
or large batches); the organisation of the company; and quality controls. Meeting strict safety and quality principles require full time personnel in such functions (BLSUSLD 2007).

The outputs: In addition to medicines, there are by-products as waste and the means of storing and transporting the medicines to distribution channels.

The tracking system: As an integral part of the manufacturing system, the tracking system seeks to ensure that medicines are manufactured safely. A strategy is to make medicines in batches; hence, it is easier and possible to identify when and where particular samples were made. A number of tests carried out at each stage guarantees that each batch complies with the specifications in the manufacturing licence issued by the regulatory authorities-see discussion on sanitary registration below. The tests include physical and biochemical characteristics of the product. Tests and quality insurance span the entire supply-buyer chain (ABPI 2006). Keeping batch registries makes it easier to trace back any problems arising at later dates. Strong safety and environmental concerns, both within and off-line are characteristic of the industry.

Information Technology (IT) systems: The IT systems help in the management, handling and retrieval of data needed for daily operation of pharmaceutical firms.

Control systems: Controls are introduced throughout the manufacturing process; these may be automated or based on human actions.

Technological systems: Technological systems comprise mechanical, electrical, microelectronic, hydraulic and pneumatic components to control and automate the processes. Production operations characterize by high degree of automation.

Working Conditions: Compared to most other manufacturing plants, working conditions in pharmaceutical shops are better. Strong emphasis is placed on keeping equipment and work areas clean because of the danger of contamination of both the product and personnel. Plants usually are air-conditioned, well lighted, and quiet. Ventilation systems protect workers from dust, fumes, and disagreeable odours. Special precautions are taken to protect employees working with infectious cultures and poisonous chemicals. With the exception of work performed by material handlers and maintenance workers most jobs require little physical effort (BLSUSLD 2007).

\subsubsection{Innovation in drug manufacturing}

The literature frequently privileges the study of innovation and learning processes taking place during the R\&D phases of pharmaceutical innovation. This is understandable considering the impressive technological and organisational changes taking place in those activities. Scientific, technological and organisational challenges seeking increased productivity in drug discovery and development are significant. By contrast, considerably less attention is granted to innovation practices 
at advanced levels of the drug innovation cycle. In particular, innovation in manufacturing activities has received very little consideration in the literature. Some good reasons support the omission; notably, the strong standardization and controls imposed by sanitary and related regulations on drug manufacturing processes. Conventional drug manufacturing proceeds using batch processing with laboratory testing conducted on collected samples to evaluate quality. The need to keep consistency and traceability makes difficult to modify manufacturing processes once they have been validated and approved by regulatory agencies. Firms may need to "carry out a large number of studies to certify that any modification [to the process] has no significant impact on the quality of the product" (Interview at trade1). Otherwise firms need to have the new manufacturing process recertified and authorised for use by the regulatory agency. Recertification is cumbersome and costly. Regulatory uncertainty reduces incentives to introduce innovative systems into drug manufacturing (FDA 2004a).

From the above, regulatory authorities such as the FDA in the US acknowledge that significant opportunities exist "for improving pharmaceutical development, manufacturing, and quality assurance through innovation in product and process development, process analysis, and process control" (FDA 2004b:2). According to the FDA, from a public health perspective, strategies to promote innovation in drug manufacturing should be promoted. They would contribute to the availability of safe, effective, and affordable medicines. With these goals in mind, the FDA has promoted the increased use of an integrated systems approach based on science and engineering principles for assessing and mitigating risks related to poor product and process quality (FDA 2004a and b). Since 2003, the FDA supports adoption of "a system for designing, analyzing, and controlling manufacturing through timely measurements (i.e., during processing) of critical quality and performance attributes of raw and in-process materials and processes, with the goal of ensuring final product quality" under the name of Process Analytical Technology (PAT). The term is comprehensive and includes chemical, physical, microbiological, mathematical, and risk analysis conducted in an integrated manner. A core principle is that "quality cannot be tested into products; it should be built-in or should be by design" (FDA 2004b:4). ${ }^{24}$

The PAT framework is expected to reduce production cycle times and human errors by enhancing automation, prevent deviations from the approved process and consequently, the risk of product rejects by sanitary authorities. The framework should also diminish scrap and reprocessing of materials, while increasing workers safety (Albano 2008). Intensive use of information to monitor and process control is also notable (Macher and Nicherson 2006). Notwithstanding its newness, some evaluations have been undertaken already on the PATs (Macher and Nicherson

\footnotetext{
${ }^{24}$ Bolds included in the original.
} 
2006). Although initial results tend not to support PAT adoption, ${ }^{25}$ further research should document whether this is because the new tools are ineffective, or because they still require some time to be assimilated and positively exploited by firms. It seems pertinent to study the evolution of the PATs framework. On the one hand, to shed light on the implications of government driven innovation in the most important pharmaceutical market in the world, the US. On the other hand because the PATs are already diffusing into developing countries via affiliates of US firms. What the implications for the industries in the host countries are? To what extent governments in developing countries may promote innovation via modernization in drug manufacturing? Chaturvedi et.al, (2007) suggest that in India government intervention has been key for innovation in pharmaceutical manufacturing.

Patent expiration and low pipeline productivity hinder financial sustainability of innovative pharmaceutical firms. Keeping new drug innovation up and running calls for significant investment in terms of time and other resources. It is pertinent to take a careful look at complementary strategies implemented by innovative firms in the development of generic products; hence we can learn about pharmaceutical innovation beyond frontier R\&D. The approach is pertinent from a catching up perspective. Recent empirical experiences of technological capability building in India, for example, suggest that the seeds for successful catching up build up at the shopfloor of generics and API manufacturers (Joshi 2003; Kale and Little 2007; Reddy 1997; Singh 2007). By systematically linking R\&D and drug manufacturing a firm sets the bases for the eventual development of stronger capacities to perform research, chemical synthesis and formulation; these capacities underpin subsequent stages of drug innovation.

As this thesis documents there is room to investigate how systematic searches for increased efficiency and productivity by pharmaceutical firms contribute to human resource development processes. For instance, interviews at firms 02 and 08 , respectively, showed that the search for continuous improvement in manufacturing processes leads firms to invest heavily in training, coaching and promotion of cooperative activities. Firms promote team-based strategies aimed at reducing cost, lower waste, increase safety and protection of both workers and the environment. Innovations with more social, rather than purely economic content are frequently found in drug manufacturing activities.

\subsubsection{Learning through generic drugs}

\footnotetext{
${ }^{25}$ Macher and Nicherson (2006) found that process analytic tools correspond with increases in the number of batches failed, increases in raw material deviations and product and process parameter deviations. The authors call for a careful interpretation of results as they do not necessarily indicate causality from PAT adoption to actual performance of firms.
} 
It is possible to characterize pharmaceutical firms according to the type of intellectual property rights they rely on. There are: (i) "innovator companies", firms specialised in the development and manufacturing of innovator products, protected by patents; (ii) generic manufacturers, firms that produce drugs whose patent has already expired; and (iii) firms that participate in both markets. In all these cases firms have to ensure that products are manufactured in controlled and consistent manners in terms of cGMPs, raw materials, processes and validation and so on. Regulatory agencies keep a close watch on manufacturers, including physical inspection of productive facilities; they require strong capacity to enforce strict sanitary regulations. Firms from developing countries specialize in manufacturing and at a lesser extent, export of generic drugs.

A generic drug is a product comparable to an innovative drug, frequently one for which a patent has already expired (DHHS et.al, 1998). Generics emulate the innovative drug regarding dosage form, strength, route of administration, quality, performance characteristics and intended use. A main characteristic of generics is that applications for marketing approval do not demand clinical data on safety and efficacy, as these parameters have already been established by the innovative drug. Development of generics starts a few years before patent expiry of the innovator product. Firms have to reproduce the knowledge needed to manufacture it while ensuring bioequivalence and bioavailability, thus supporting its characteristic as a generic interchangeable drug. ${ }^{26}$ Speed is necessary, to the extent that first movers can gain and retain relevant market shares (Caves et.al, 1991; Hollis 2002). In most cases, the choice of products is linked to current product portfolios; what firms already know. Nevertheless, expected benefits increase if firms are able to enhance the characteristics of the innovator drug. Quality enhancement includes relatively simple improvements in product packaging, reformulation or recombination of existing molecules. New products, in turn, include new applications of existing drugs, often in different therapeutic areas. The search for new knowledge may relate more to the methods and techniques used to synthesize the components--biotechnology techniques, for instance---than to the characteristics of the drug itself (Kale and Little 2007).

In the words of the operations manager at a Mexican manufacturer: "Replication of the knowledge underpinning manufacturing of generic drugs may not require as costly and advanced infrastructure, scientific equipment, research centres and so on; yet there is a fair degree of complexity involved. Firms need be attentive to the expiry date of patents. Some 4-5 years previous to expiration a company may begin investing in the technologies and infrastructure needed to produce the drug. During such period firms have to learn how to manufacture the product, so that by

\footnotetext{
${ }^{26}$ Generic interchangeable (GI) denomination indicates that the reaction to a generic drug in the human body is exactly the same as that of an innovator drug.
} 
the expiry date, it is ready to launch the new generic" (Interview at firm 11). Based on these considerations, the perception is that whereas generic manufacturers base competitiveness solely on prices, innovators do so based on differentiation (Dussel 1999). Yet generics may not be mere copies of branded innovative products. Quite the contrary, the former frequently introduce some improvements to the latter. Competition is fierce; manufacturers should differentiate and enhance product quality. Improvements in drug absorption, more friendly dosages and drug delivery systems, reformulation or means to minimize possible side-effects of the original product are examples of innovative features added to generic drugs. Licensing is possible to manufacture generic drugs, yet this frequently implies technological dependence on the licensor firm.

\subsection{Ongoing Studies and product life-cycle support}

Pharmaceutical innovation does not end with marketing approval of new drugs. A period of surveillance and monitoring of long-term effects ensues; this is known as pharmacovigilance. During this period regulatory agencies can ask companies to conduct additional research, Phase IV or post-marketing clinical studies, to evaluate long-term safety and generate more data about how the medicine affects particular groups of patients (Becerril 2006; DHHS et.al, 1998; Styhre and Sundgren 2003).

Product life-cycle support brings opportunities to continue innovating around a specific product, or to extend the commercial value of such products. In other words companies tap post-marketing studies to submit new marketing applications related to incremental innovations. Hence it is possible to see how drugs change in the form of administration, in daily dosages, reduce pernicious side effects while exploring ways to maximise positive ones. Aspirin ${ }^{\circledR}$, active ingredient acetylsalicylic acid, is a good example of product-life cycle innovations. In more than hundred years of existence the product has moved from initial use in pain-relieve and antiinflammatory and fever-fighting to applications in heart-related diseases such as heart attacks, recurrent heart attacks or angina, stroke prevention and so on.

\section{Final comments}

This chapter presented the main characteristics of the pharmaceutical innovation processes. In so doing it described the heterogeneity of both the stages and the corresponding learning, organisational and investment processes involved. The dynamics of technological developments, high risk levels and new scientific knowledge content usually attracts significant attention to drug discovery. Drug manufacturing features high standardization and routines; this limits interest in research about innovation and learning occurring in such activities. We have learned however, that while all phases of the process are interconnected, significant technologi- 
cal progress in drug discovery has so far not being accompanied by corresponding improvements in subsequent stages. Drug testing and development remains a major bottleneck to speed drug innovation up. Firms face more complex and challenging scenarios to remain profitable, to face growing competition in the market. Government regulation and supervision continues to play important roles in guiding behaviour and performance of pharmaceutical firms. Opportunities for further work remain significant. The search for increased efficiency, reduced cost, let alone product safety and quality calls for careful reappraisal of the value of innovation in drug manufacturing. 


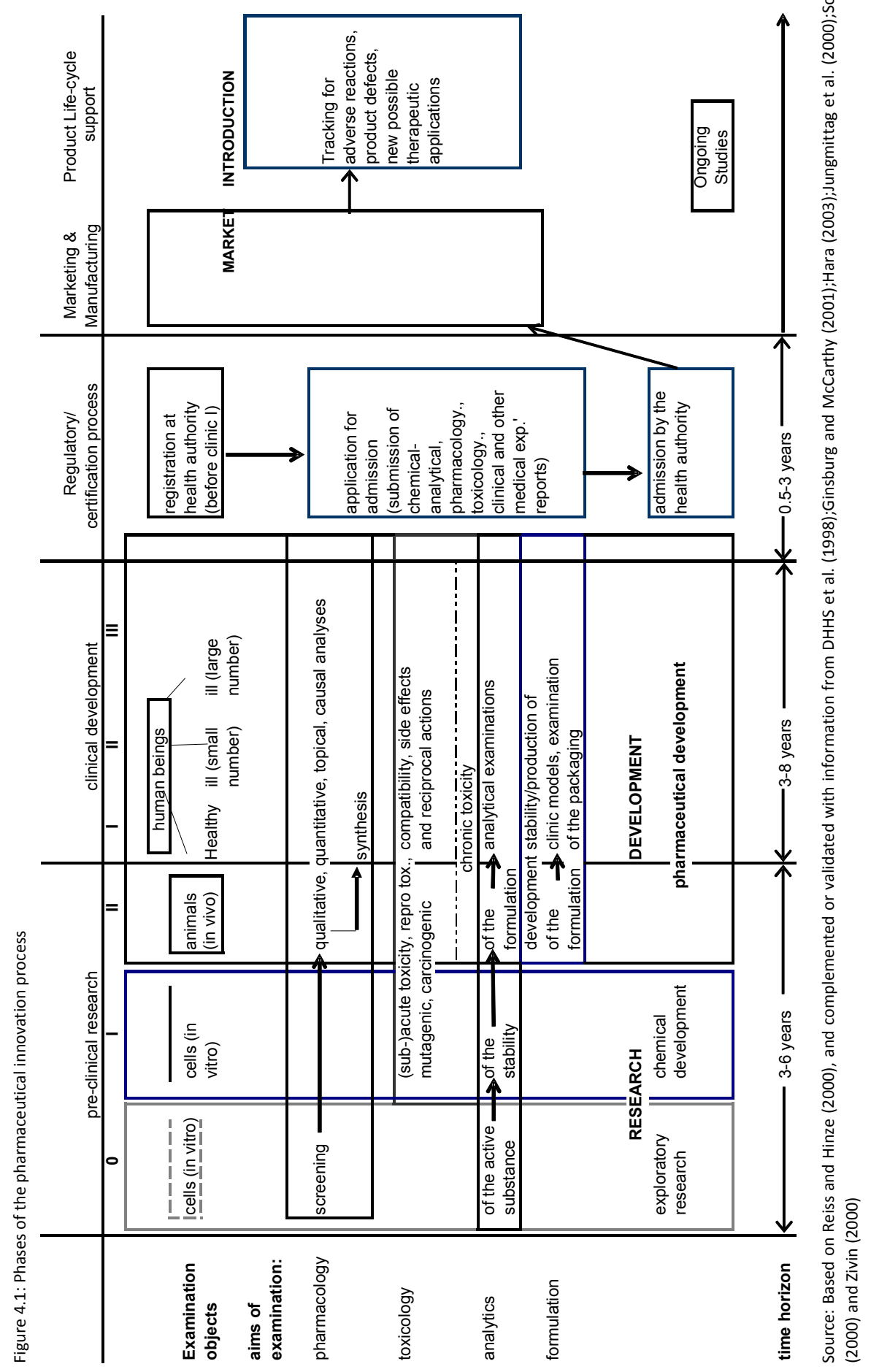





\section{Chapter 5}

\section{Pharmaceuticals in Mexico}

\section{Introduction}

Emerging markets are expected to significantly influence future developments within the global pharmaceutical industry. By the year 2020 they are predicted to contribute to more than 50 percent of worldwide pharmaceutical market growth, up from just 13 percent in 2001 (IMS-Health). In 2009 China, Brazil, India, South Korea, Mexico, Turkey and Russia were expected to grow at a combined rate of 1415 percent to reach a collective market worth of US\$105-\$115 billion. However, the expansion of the Latin American region in 2007/2008, as shown in table 5.1, increased 9.0 per cent, which is significantly higher than that of some developed countries. Among the (IMS-Health 2009a) factors being cited to explain the growth rates in developing countries are greater government spending on healthcare, broader public and private funding, and demand for innovative medicines.

Table 5.1 also shows that Mexico is the world's 10th largest pharmaceutical market, and the second largest in Latin America. Together with Brazil, Argentina and Venezuela, the country accounts for more than $80 \%$ of total sales in the Latin American region (Secretaría de Salud 2005a). At the end of 2008 retail sales in the Mexican pharmaceutical industry amounted to US\$8.6 billion, a figure equivalent to a $2 \%$ increase from 2007. In Mexico, local infrastructure for manufacturing pharmaceutical products is among the most modern in the world, in many cases complying with the US-FDA standards; and it provides significant growth potential for the industry (Andre 2005a and d). The country has real, albeit poorly exploited resources to imitate and to generate innovative pharmaceutical products (Guzmán 2005). Pharmaceutical firms invest some US\$150 million per annum in plant modernization, technological upgrading and clinical research (AMIIF).

This Chapter examines the structure, recent performance and trends observed in the Mexican pharmaceutical market. A discussion of some of the factors shaping learning and innovation in the local pharmaceutical industry will help build a framework for the subsequent econometric analyses in chapters 6-8. The reader will note that this chapter poses more questions than it can answer, given its scope and the data available. The discussion is based on a thorough review of the literature, as well as information collected through in-depth interviews conducted with representatives of the industry. The rest of the chapter is organised into sections, as follows: Section 2 presents a historical account of the development of the pharma- 
ceutical industry in Mexico, which helps shape the framework that will be used to analyse the current structure of the industry in section 3. Section 4 examines the innovative performance of the industry; followed by a concluding discussion in Section 5.

Table 5.1: Pharmaceutical industry: Main global markets, 2008

(Sales through retail pharmacies)

\begin{tabular}{|l|c|c|}
\hline US\$ billion & November, 2008 & \% Growth/Nov-07 \\
\hline North America & 225.5 & 2.0 \\
\hline USA & 208.7 & 6.0 \\
\hline Canada & 16.8 & 1.0 \\
\hline Europe (Top 5) & 114.6 & 4.0 \\
\hline Germany & 35.2 & 1.0 \\
\hline France & 30.7 & 2.0 \\
\hline Italy & 17.2 & 1.0 \\
\hline United Kingdom & 16.0 & 4.0 \\
\hline Spain & 15.3 & 2.0 \\
\hline Japan (including hospital) & 66.7 & 9.0 \\
\hline Latin America (Top 3) & 24.4 & 11.0 \\
\hline Brazil & 12.5 & 2.0 \\
\hline Mexico & 8.6 & 22.0 \\
\hline Argentina & 3.2 & 10 \\
\hline Australia/New Zealand & 7.9 & \\
\hline
\end{tabular}

Source: IMS-Health (2009b)

\section{Historical account of the Mexican pharmaceutical industry}

Origins of the pharmaceutical industry in Mexico trace back to the 1940s, marking the beginning of the exploitation of Barbasco (Sc. Name: Wild Yam), a plant containing phyto (plant-derived) estrogens, in particular the chemical diosgenin, used in the preparation of estrogens to replace female hormones and produce contraceptives (Dussel 1999). The firm Syntex (1943) was one of the main processors of Barbasco and, in Mexico, Laboratorios Senosiain, part of a pharmaceutical chain of the same name, became the first pharmaceutical laboratory in the country (Dussel 1999). During World War II the halt of supplies from multinationals to Mexican affiliates, some of them dating from the $1920 \mathrm{~s},{ }^{1}$ led them to replace imports and start manufacturing facilities in the country. From some 60 pharmaceutical firms in the 1940s, they grew rapidly up to 200 firms by the 1980s (Brodovsky 1997; Dussel 1999). By 1977 about $35 \%$ of all APIs needed by the country were produced locally. The number of APIs produced locally rose from 6 in the 1960s, to around 90 during the 1990's (Dussel 1999).

Historically public policy has considerably influenced the development of the pharmaceutical industry in Mexico. In the post-Second World War period, the government imposed restrictions on imports of any locally produced pharmochemical.

\footnotetext{
${ }^{1}$ In this earlier period foreign firms conducted mostly commercial and distribution activities.
} 
In addition, the foreign capital ownership of any firm located in Mexico was restricted to 49 percent maximum. As for public procurement, this required consolidated tenders and was based on purchases of generic products according to a specific listing of basic drugs: cuadro básico (henceforth basic drugs scheme), for use of public healthcare. $^{2}$

The government promoted price controls through the public healthcare system, privileged local manufacturers and high local integration (Dussel 1999). Price controls were the main instrument to promote the pharmaceutical and pharmochemical industries (Brodovsky 1997; Dussel 1999). Controls aimed to limit benefits accrued by firms; however they had induced negative incentives to invest in capital goods and R\&D (Brodovsky 1997). The controls led to market distortions, as maximum prices were often fixed based more on people's ability to lobby policy makers, than on the actual technical and economic merits of the products (Brodovsky 1997). In the context of a protected market, with fairly ambitious public healthcare programmes and strict price controls, the pharmaceutical and pharmochemical industries flourished. In the early 1980s Mexico manufactured most of the medicines within its borders. While exports of pharmaceutical products were negligible, imports of pharmochemical accounted for up to $50 \%$ of local consumption (Dussel 1999).

Then regulatory and macroeconomic environments changed drastically as a result of the 1982 Mexican economic crisis. A notable shift was the adoption, in 1984, of an integral plan for the development of the pharmaceutical and pharmochemical industries (SECOFI 1984). The Bill for the Promotion and Regulation of the Pharmaceutical Industry set among its goals ensuring self-sufficiency in API manufacturing; it also aimed toward national integration of the production of both pharmochemicals and medicines. The intention was to deepen import substitution, increase local content of pharmaceutical products, and promote decentralization away from the Mexico City area (Dussel 1999). This notwithstanding, it was possible then to import medicines provided as part of the basic drugs scheme, and for high-incidence diseases. In 1987 there were 94 pharmochemical firms producing 259 APIs, roughly 67 percent of the national consumption of these raw materials. The sector enjoyed trade surpluses of up to US\$40 million. Incentives from public procurement remained important for local producers; up until 1989 public tenders granted five more percentage points to participants using locally produced APIs.

A new shift in the macroeconomic environment resulted from the introduction of economic reforms at the end of the 1980's. In 1986, accession of Mexico to the General Agreement on Tariff and Trade (GATT) led to a generalized and unilateral reduction in import duties on purchases of non-locally produced raw materials and

\footnotetext{
${ }^{2}$ Creation of Cuadro Básico, presidential decree of $9^{\text {th }}$ April 1975, homogenized drug supplies to the public health sector. The use of generic codes, rather than brand names, intends to promote scale economies and reduce unitary prices by raising volumes of purchases (Villaseñor 2006)
} 
APIs. This was accompanied by a programmed reduction in duties paid on imports of inputs produced locally. Authorities levied restriction on imports provided importers had production facilities in Mexico. ${ }^{3}$ Nevertheless, imports of some intermediate products led to the entry of certain duty-taxes into the country (Secretaría de Salud 2005a). Up until the early 1980's, manufacturing processes accounted for 40 percent of total value added in the industry. High standardization in this area demonstrated that cost differentials among firms resulted from distinct production scales (Dussel 1999).

By the end of the 1990's major transformations were underway, with liberalization of the industry, and the subsequent reduction in the protection firms had previously enjoyed in the local market. Price controls have since been relaxed, yet mechanisms to set prices, such as the principle of "precio máximo de venta al público" (maximum retail price), remain in place today. ${ }^{4}$ Notwithstanding some government attempts to eliminate VAT exemptions on medicines, the rule of zero tax rate persists. Public procurement procedures changed, and since the 1990s, rather than consolidated purchases, individual tenders are held by each healthcare institution and Federal State government-section 3.3 below. In addition to lower scale requirements, firms faced increased administrative costs (Dussel 1999).

The liberalization programme posed additional challenges to the local industry. The sector was no longer considered strategic, effectively opening it up to the broader participation of foreign capital and greater exposure to competition. Rapid and almost generalized reduction in import taxes, the reclassification of several product classes under direct control, and elimination of import permits were significant (Brodovsky 1997; Dussel 1999). Enactment of NAFTA further deepened the liberalization programme. From 1994 onward, import taxes on all products not produced in Mexico were eliminated, with programmed cuts instituted over a period of ten years. Effectively from 2004, both pharmaceutical and pharmochemical products could be imported from within the NAFTA region at a zero tax-rate. Additionally, new rules of origin, and changed mechanisms for public procurement, were also introduced. ${ }^{5}$

The industry downsized as a result of both reorganisation and changes in the regulatory framework. Between 1987 and 1998 some 59 pharmochemical firms went out of business, roughly half of those operating in the early 1980s. By 1994 the

\footnotetext{
${ }^{3}$ The net effect of the lower restrictions was increased production capacity and reduction in imports of pharmaceutical products. Distributors, wholesalers and retail pharmacies cannot import such products (ACHEMAMERICA 2005)

${ }^{4}$ The mechanism of maximum retail price allows manufacturers, in coordination with the Ministry of Economy, to propose a maximum price to consumers thereby factually setting a price-cap in the market. Distributors and retail pharmacies negotiate profit "margins" by setting a pharmacy price which varies according to volumes and time for payment. Commercialization margins, the gap between prices from the manufacturer to the distributor, range between 4-15 percent, a high level relative to international standards (Secretaría de Salud. 2005a). The margin for the pharmacies is around 21 percent.

${ }^{5}$ For a further discussion on the topics see Dussel (1999)
} 
number of APIs produced in the country had fallen to 129, accounting for about 55 percent of the market. By 2005 there were only 20 companies affiliated with the National Chamber for the Manufacturing Industry (CANACINTRA for its name in Spanish), and the National Association of the Chemical Industry (ANIQ for its name in Spanish). There were also nine firms integrating all stages of production from the sourcing of the pharmochemical to its manufacture, and at least another two that produced biopharmochemicals in the process (Secretaría de Salud 2005a). The reduction in the number of APIs produced locally occurred alongside the centralization of the industry in areas like Mexico City, Estado de México, Puebla, Morelos and Jalisco (KPMG 2004). Self-reliance in medicine production fell from 60 percent in 1988 to about 35 percent in 1994 (Brodovsky 1997). Over recent years prices and public procurement have seldom been used as mechanisms to promote the local industry.

\section{The industry today}

Mirroring the typical structure of the industry worldwide, pharmaceuticals in Mexico comprise four main activities: (i) the pharmochemical segment including manufacturers of substances or compounds containing the APIs responsible for the pharmacological or therapeutic effects; (ii) the manufacture of medicines for human consumption; (iii) production of veterinary medicines, and (iv) production of healthcare auxiliary products, such as medical and chirurgic equipment and materials, dentistry and toiletries, diagnosis materials, and others. This chapter focuses on the first two activities mentioned.

The value chain of the local industry comprises a complex network of backward and forward linkages with other sectors of the economy (Dussel 1999). It integrates 12 sectors ranging from the manufacturing of APIs and other pharmochemical ingredients, to packaging, manufacturing and distributing pharmaceutical products through both private and public markets, figure 5.1.

In this context, according to the Encuesta Industrial Anual (EIA 2004) (Annual Industry Survey) ${ }^{6}$, in 2003 there were 480 pharmaceutical establishments, of which 92.9 percent, or 446 units, were drug manufacturers, (see table 5.2). This figure represented 0.1 percent of total manufacturing establishments in the country. Gross output was 3.7 percent of the total manufacturing output, and 1.7 percent of Mexico's total GDP. As for direct employment, this stood at 50,780, of which 47,172 , (92.9 percent), corresponded to pharmaceutical manufacturing and the

\footnotetext{
${ }^{6}$ The econometric analyses in this thesis build on data from the Encuesta Nacional de Empleo, Salarios, Tecnología y Capacitación (ENESTYC) (Chapter 3), while analysis in this chapter presents information from the EIA. This is because, unlike ENESTYC, the EIA distinguishes between Pharmochemical and Pharmaceutical manufacturers. Considering that the methodology supporting the ENESTYC is similar to that of the EIA, the data are comparable.
} 
remaining 3,608, 7.1 percent, to the pharmochemical segment. Within the former segment, there has been as a rate increase of 2.4 percent per annum since 1994. Today employment in pharmaceuticals accounts for 1.3 percent of the total labour market in the area of manufacturing. As for the distribution of employment, EIA indicates that some 53.4 percent of staff is in management and sales, 46.0 percent in production and the remaining 0.6 percent in other functions. The industry requires high specialisation and skills; on average, salaries and remunerations were approximately 2.4 times higher than those in other manufacturing industries.

Figure 5.1 Mexico: Structure of the Pharmaceutical industry

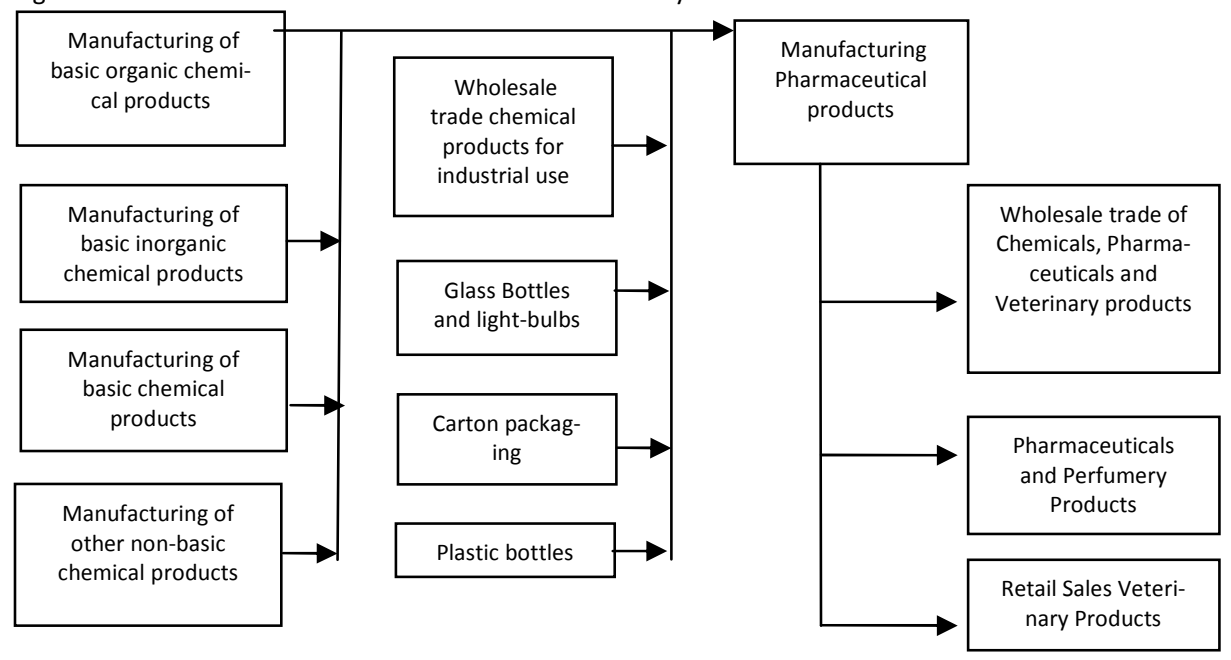

Source: Adapted from Dussel (1999)

Table 5.2: Characteristics of the Mexican pharmaceutical industry 2003.

As a share of total manufacturing

\begin{tabular}{|c|r|r|r|r|r|}
\hline & \multicolumn{1}{|c|}{ Units $^{1}$} & Gross output & \multicolumn{1}{|c|}{ Sales } & Employment & Avg wage/Month $^{2 /}$ \\
\hline Pharmaceutical Industry & 0.1 & 3.7 & 3.9 & 1.3 & 1588.7 \\
\hline Raw materials & 0.0 & 0.2 & 0.2 & 0.1 & 1355.4 \\
\hline Pharmaceutical products & 0.1 & 3.5 & 3.7 & 1.2 & 1606.7 \\
\hline
\end{tabular}

Notes: ${ }^{1 /}$ Number of manufacturing establishments; ${ }^{2 /}$ US\$ dollars per month per person; average exchange rate 10.7953

Mexican pesos per US dollar. This corresponds to the exchange rate used to process foreign currency denominated operations (FIX).

Source: Author based on information from INEGI and Banxico

Today, the pharmaceutical industry in Mexico is strong; it currently fulfils about 86 percent of local demand, up from the 35 percent figure from 1994. This is achieved mainly through the formulation and manufacturing of imported APIs, and via imports for the remaining 14.0 percent. The processes used to extract APIs and pharmochemicals are fermentation and purification, or by synthesis of chemical compounds, as in biotechnology. Seiter (2005) suggests this is typically the most complex and value adding part of the process. Mexico produces mainly steroids, fermented and semi-synthetic antibiotics, other anti-infectious medicines, non- 
steroidal anti-inflammation, anti-carcinogenic, anti-ulcer, vitamins and biopharmaceuticals (faboterapeutic, interferon, eritroproyetine). Although accurate figures are not available, the estimated usage of manufacturing capacity stands at some 63 percent; firms have considerable margins whereby they can increase production in case of need (Secretaría de Salud 2005a). According to Secretaría de Salud (2005a) some challenges that influence the long term performance of the industry include: (i) increased competition from abroad, particularly Asia; (ii) high investment costs; (iii) low availability of intermediate chemical products needed to manufacture medicines; (iv) limited technological development and very rigid and disadvantageous contracts for technology transfer; (vi) low incentives for and interest among local producers to search for new products and, (vii) low integration of the supply chain.

\subsection{The local market}

In Mexico drugs are defined as the single substance or combination of substances whether natural or synthetic, with therapeutic, preventive or rehabilitative effects. These descriptions arise from the characteristics of their pharmacological, physical, chemical and biological activity. For instance, food supplements, which are considered drugs as they include vitamins, minerals, electrolytes or amino acids in concentrations greater than those found in nature, are sold in pharmaceutical form and have therapeutic, preventive or rehabilitative effects as indicated on the packaging (Secretaría de Salud 1984). Approximately 7,000 different types of drugs, presented in 19,000 different packages are marketed in the country. Predominant product classes are: Alimentary and Metabolism; Anti-infective, Central Nervous System (CNS); Respiratory and Cardiovascular, among others (figure 5.2).

In Mexico the market for drugs shows a dual structure in terms of both quality of products and access by the population. The two segments are well defined and independent of each other. On the one hand, there is the "institutional" or public sector characterized by demand for mostly generic and technologically mature products. On the other hand there is the private market dominated by commercial trademarks and innovative products (Secretaría de Salud 2005a). Whereas unit sales tend to favour the public sector; in terms of value the private sector, which buys the more expensive patented brands, takes the lead. Spending in the latter is almost seven times greater than that in the public sector, which purchases mostly cheap, locally produced generic drugs (O'Boyle 2002), figure 5.3. In 2002 sales in the Mexican pharmaceutical market reached 2,270 million units. 


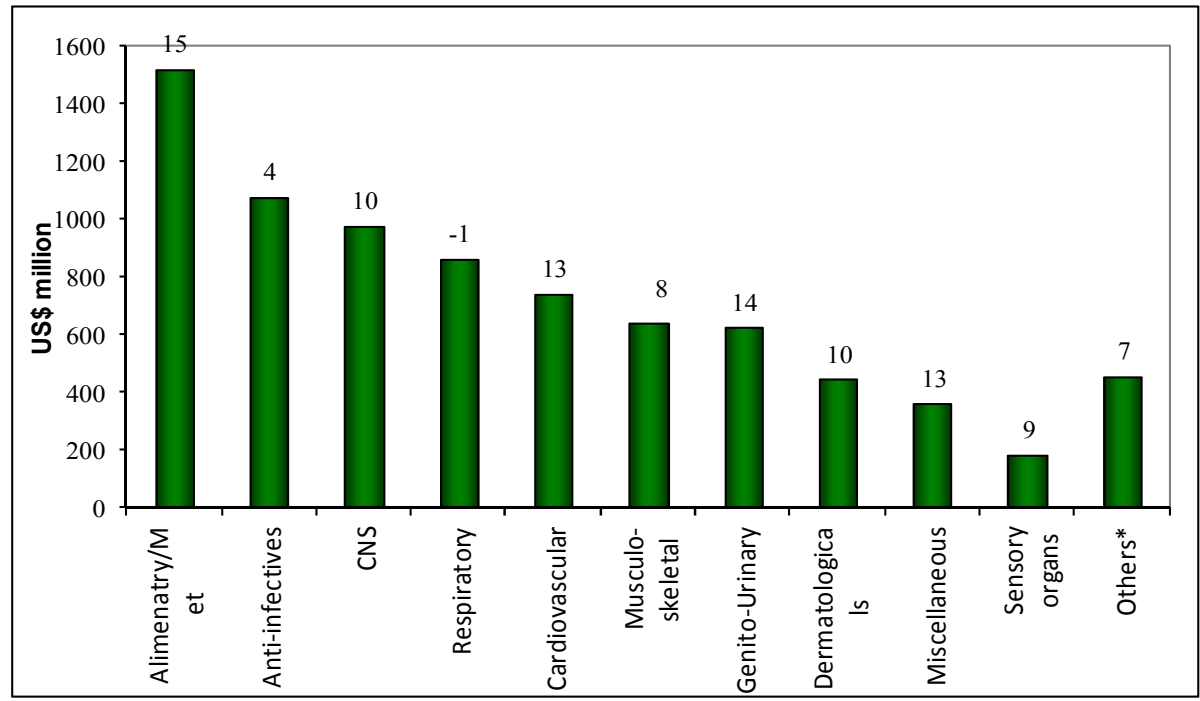

Notes: CNS: Central Nervous System; *Systemic hormones, Blood agents, Parasitological, Cytostatics, Diagnostic Agents, and Hospital Solutions. Figures on top of each bar indicate the annual rate of growth relative to July, 2005 and in constant dollar terms.

Source: IMS-Health (2006)

Figure 5.3: Distribution of volumes and values of sales in the Mexican pharmaceuticals by type of market. Million units and US\$ million

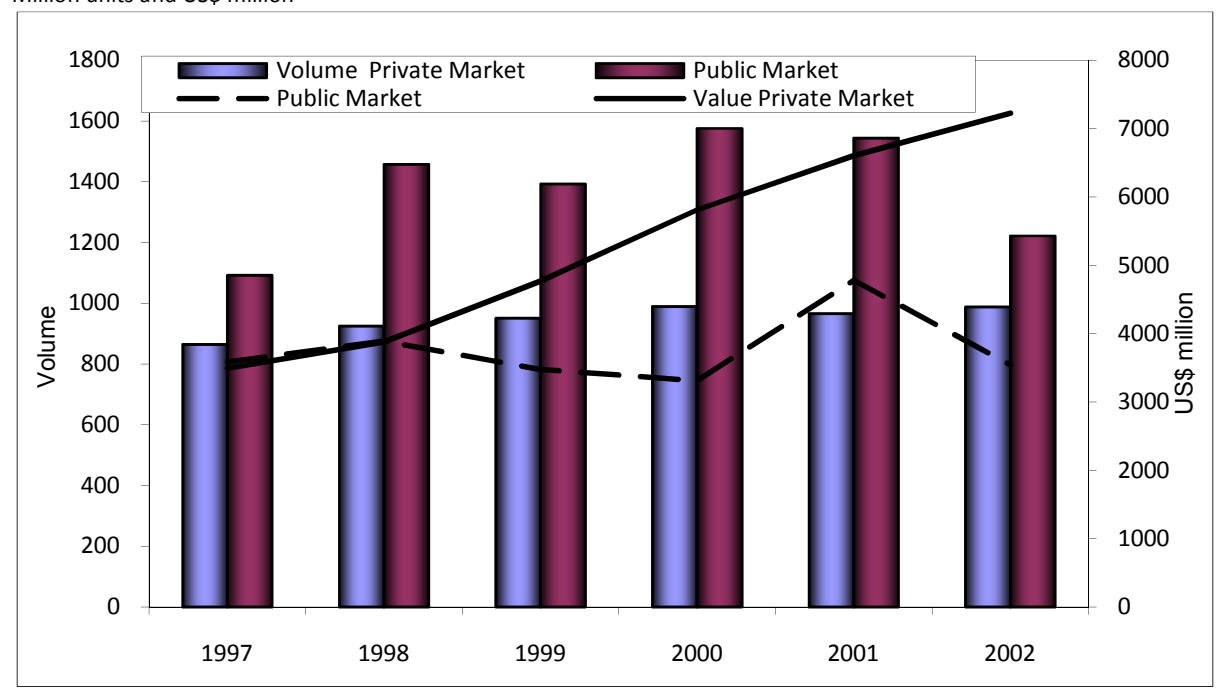

Source: Andre (2005a)

The generic drugs segment of the private market is expanding rapidly. Factors driving this phenomenon include cheaper prices and recent regulatory changes intended to increase supply of compounds with the same APIs as branded drugs, but for a fraction of the cost. This segment has been the most dynamic over the 
past years (Dussel 1999), and yet accounts for only three percent or less of total sales in the Mexican market. Equally important has been the development of an "impulse" market which, in simple terms, results from the exploitation of some regulatory voids (Box 1). Consequently, firms can sell copy drugs which contain the same API as the innovator drug, but not necessarily in the same concentrations, and which have not been proven to work in the same way (O'Boyle 2002). In other words, such drugs have never passed tests for bioequivalence and bioavailability ensuring interchangeability with the innovator drug. These low-cost medicines are sold in dedicated or exclusive pharmacies, or through other informal, often illegal channels (Secretaría de Salud 2005a). Recent efforts to reorganise and improve governance of the generics market have been constrained by an insufficient capacity to enforce regulatory reforms. In fact counterfeiting continues to distort the local market (Interviews with firm 06).

\section{Box 1: Promotion and regulation of generic drugs in Mexico}

Health authorities around the world are faced with the challenge of rising costs of medicines, the responsibility of keeping overall healthcare expenditure in check, and the need for adequate developments in both the manufacture of generic and innovative drugs. Mexico is no exception. Mexican health authorities face many problems in trying to ensure adequate provision of healthcare services, and improve the quality and reduce the costs of products in the basic drugs scheme. This is, compounded by shortcomings in the supply and distribution capacity of public health institutions which, in turn, derive from poor logistics, administration, costly and inefficient procurement systems (Secretaría de Salud 2005a). Problems are aggravated by poor enforcement capacity of eventual regulatory reforms. Next we illustrate some of these issues.

In Mexico marketing of pharmaceutical products requires Sanitary Registration (Registro Sanitario). This document, issued by the local regulatory agency, Comisión Federal para la Protección contra Risgos Sanitarios (COFEPRIS), certifies that the firm meets strict requirements of safety, efficacy and quality. It describes and validates API manufacturing processes performed both in-house and at supplier firms. It also defines quality standards for raw materials, manufacturing and distribution processes from the beginning to the end, tests to corroborate stabilities and therapeutic power of drugs, and so on. These are the equivalent to New Drug certificates granted by the FDA for sales of pharmaceutical products in the US. In the past the customary practice in Mexico was to grant Sanitary Registries and thereby drug marketing authorization, for indefinite periods of time. This eventually led to the presence of outdated registrations for products that may fail to comply with current sanitary and related legislations (Andre 2005d). The regulation was such that firms could hold sanitary registrations for products they no longer sell in the market. More importantly, this regulatory void promoted development of copy drugs with suspected deficiencies in quality and safety. 


\section{Box 1: Promotion and regulation of generic drugs in Mexico (Continued)}

To address some problems related to quality and availability of drugs, in 1997 a Bill was passed requiring that only drugs meeting strict bioavailability and bioequivalence tests could be registered and labelled Genéricos Intercambiables, GI (interchangeable generics) (Andre 2005d). The new provision, effective $1^{\text {st }}$ January 1998, required medical doctors at public organizations to prescribe based on active ingredient rather than on brand names (Hayden 2005).

In 2002 a new provision was passed requiring that public health organizations should only buy GI-denominated products. Yet again in 2005 amendments to Article 376 of the Health Bill strengthened impulses to the GI market (Secretaría de Salud 2005a). According to the new provision by the year 2010 all non-patented pharmaceutical products registered and marketed in Mexico should be GI (Luhnow 2005). During the five year transition period firms should renovate or regulate Sanitary Registrations backing their product portfolio. The task is complex considering that out of some 40,000 products registered in Mexico up to September 2005, about 7,000 were commercialized and only about 3,109 were GI.

A core component of this strategy has been the creation of some independent laboratories, Terceros autorizados, responsible for performing the required interchangeability tests (Secretaría de Salud 1998b;1999). In principle, Secretaría de Salud (2005a) indicated that some 40 laboratories or authorized third parties were needed to conduct all the tests required over the five year transition period. However creation of the laboratories has proceeded at a slow pace, and to date only 30 are in place, including firms, public laboratories, universities and other public organizations (COFEPRIS). The response from the pharmaceutical firms has also been slow (Anonimous, La Jornada 2009). By February 2009, about 55.5 percent of the total products in need of certification (aproximately 10,500) had concluded the procedure; 23.3 percent were under way and the remaining 21.2 percent had not even started the process. The deadline to conclude the recertification process was February 2010.

As for some likely reasons behind the perceived slow response of firms in complying with the new regulation for the manufacturing of drugs, exploratory interviews with Mexican manufacturers revealed some complaints about inconsistency in terms of regulation with the normal operation of firms. About a year after the start of the transition period, the representative of a Mexican firm, a pioneer in the conduction of local R\&D activities, commented that the new rules meant they would be "unable to perform the necessary quality controls on their own products; testing safety and efficacy is a core component of any drug development process underpinning eventual product registration." Although the government could increase transparency in the tests by taking them away from firms, the latter considered this a hindrance to the development of quality control and other research capacities. As we discuss in section 4.3 in this chapter, people systematicaly involved in quality control often provide the seeds for the development of more formal R\&D activities. 


\section{Box 1: Promotion and regulation of generic drugs in Mexico (Continued)}

More interesting is to ask what will happen once the period allotted to carrying out tests of interchangeability expires? What will be the implications associated with the creation of the third party independent laboratories for the industry? To what extent will these laboratories eventually help in building some additional research capacity in the country? (Lijima and Tachiki 1994), (Kuruvilla et.al., 2002) and (Sanz-Menéndez and CruzCastro 2005) document the significant contribution that publicly promoted programmes may have on the construction of technological capabilities for firms, particularly by transferring capacity built within public organizations to private firms.

Source: Author

\subsection{Prices}

In Mexico the price of medicine for consumers has continued to rise over the last decade or so; increases have surpassed the country's general inflation (Secretaría de Salud 2005a). In 2003 private expenditure in medicines per capita was the highest it had been in more than a decade. On average, a Mexican expended US\$70.10 in medicines in the private market, nearly doubling that of the rest of Latin America, totalling US\$36.50 (Secretaría de Salud 2005a). Regarding specific products, consumer prices benefit innovative drugs. We can see this by comparing prices of "old" drugs, those that have been around for 15 years or more; and "new" medicines, those that have existed for 10 years or less; in table 5.3. The price gap for each drug type is considerable, particularly in the case of antibiotics and immune-suppressors (Villaseñor 2006).

Table 5.3 Mexico: Average drug prices to the final consumer for old ( $>15$ years) and new medicines ( $<10$ years); Mexican pesos

\begin{tabular}{|l|c|c|c|}
\hline Type of medicine & Old & New & \% increase* \\
\hline Immune-suppressors & 271.1 & 4375.0 & 1514.0 \\
\hline Antibiotics & 51.1 & 602.5 & 1078.6 \\
\hline Oral Hypoglycaemic & 71.9 & 250.2 & 247.9 \\
\hline Anti-osteoporosis & 214.2 & 642.1 & 199.8 \\
\hline Anti-depressors & 75.7 & 218.8 & 189.0 \\
\hline Blood agents & 101.3 & 272.3 & 168.8 \\
\hline Anti-inflammation & 97.0 & 222.2 & 129.0 \\
\hline Hypolipemiants & 213.0 & 410.7 & 92.9 \\
\hline Insulin & 197.9 & 342.6 & 73.1 \\
\hline Antihypertensive & 113.6 & 177.0 & 55.8 \\
\hline
\end{tabular}

*Variation in prices between new and old products

Source: Modified and translated from Secretaría de Salud (2005a)

Rising prices have led to a situation in which, although with regard to volume the Mexican market has remained constant (the average growth rate between 1997 and 2002 was only 1.1 per cent), in terms of value it increased by about 11 per cent per annum (Secretaría de Salud 2005a). Performance of prices in the private market 
illustrates this finding. During the period of 1999-2002, prices increased by an average of 10.0 percent, reaching some US\$7.31 per unit in 2003 (Secretaría de Salud 2005a). Price hikes have nurtured some positive dynamics in the private market, yet some concerns exist concerning long term sustainability, as individual income for many Mexicans remains very low (Guzmán 2005). Prices in the private market contrast sharply with those of the public sector. Approximately half of the medicines, in units, are bought and subsequently distributed by public institutions at a third of their price in the private market. Domestic firms supply the public sector mostly with generic drugs, at very low unit costs. However, such drugs may not necessarily have passed through bioequivalence tests (Secretaría de Salud 2005a). Taking into account these differentials in quality, Secretaría de Salud (2005a) states that the price of medicines in Mexico can fall to about 64 per cent of what they're sold for in the private market: e.g. from US\$7.3 per unit, to a global US\$4.6 per unit.

\subsection{Public procurement}

In Mexico, government procurement plays an important role in guiding market developments in the drug industry, particularly in generics. Procurement is based on public tenders according to a basic drugs scheme for first level healthcare (general practice, family doctors), and by ingredient listings in the second (regional and national hospitals, intermediate care) and third levels of attention (high speciality care). Tenders take place around a single event, with prices being the most important criteria in terms of granting contracts. The focus on pricing, without further consideration of product quality, the use of locally sourced ingredients, or market risks faced by suppliers is considered to distort the market (Villaseñor 2006). It induces pernicious competitive practices as firms can bid really low unitary prices in order to acquire contracts that ultimately they will be unable to fulfil in time (Interviews with trade 1 and firms 03 and 06 ). In order to meet volume requirements, public institutions may purchase products that do not comply with the GI criteria (Villaseñor 2006). Insufficient transparency and limited participation of the industry in the definition of prices for products in the basic scheme further complicates the scenario (firms 02 and 06).

Domestic firms usually complain about the way in which public tenders are carried out. This is understandable considering that their sales structure relies strongly on the public market. In such an uncertain environment, incentives to conduct R\&D are really low (interviews at firms 05 and 06). Survival strategies are based more on the capacity to provide large volumes of generic products; in this case the firm privileges modernization and large manufacturing capacity with significant margins remaining idle (interview at firm 03). Excess capacity allows firms to respond to unexpected requests from the government, for example when a firm is unable to meet the terms of a contract. By contrast, multinationals face a rather unique predica- 
ment. On the one hand they may be unwilling or unable to compete against large volumes and significantly low unit prices bid by some domestic generic manufactures (interviews at firms 02); on the other hand, they exploit their capacity to offer innovative patent-protected products, therefore displacing competitors (interviews at firms 01 and 05). In any case, for foreign affiliates the share of sales in the public sector is rather modest compared to that of Mexican manufacturers.

\subsection{Presence of multinational affiliates}

Mexico hosts affiliates of large firms from countries with long traditions in pharmaceutical innovation, including the US, Germany, Switzerland and France. Increasingly however, the country attracts affiliates from new players such as Spain and notably, India. Operations range from marketing and distribution to large scale manufacturing, even some limited R\&D efforts with varying degrees of sophistication. Affiliates of big multinationals remain the main players in the Mexican pharmaceutical market. Investment, technological and research performance differ significantly between local and multinational firms, with the latter being the most dynamic (Guzmán 2005). Affiliates produce and export finished products with quality and safety standards comparable to those of developed countries. They centre marketing efforts on the lucrative private retail market where they take the lead in terms of total sales; Novartis and Pfizer are the market leaders. Competition remains strong nonetheless with companies holding maximum market shares of around 8.0-9.0 percent, table 5.4. Frequently multinationals enter into commercial agreements with local firms, the latter are responsible for the import, handling, safety and security of products according to local regulations (Secretaría de Salud 2005a).

Table 5.4: Mexico, leading foreign companies, 2005

\begin{tabular}{|l|c|c|c|c|l|}
\hline Company & Origin & Sales $^{1 / 2 /}$ & Share $^{3 /}$ & Founded & \multicolumn{1}{c|}{ Relevant notes } \\
\hline $\begin{array}{l}\text { Far- } \\
\text { macéutica }\end{array}$ & Swiss & 450 & 9 & 1996 & $\begin{array}{l}\text {-Active in pharmaceuticals and consumer health } \\
\text {-Promotion of local generic markets is expected } \\
\text { to benefit operation of Sandoz, its mature } \\
\text { product division }\end{array}$ \\
\hline Pfizer & US & 250 & 8.5 & 1951 & $\begin{array}{l}\text {-Pfizer's main office for Northern Latin America } \\
\text { (1997) } \\
\text {-Controls operations in Central America }\end{array}$ \\
\hline $\begin{array}{l}\text { GlaxoS- } \\
\text { mith } \\
\text { Kline (GSK) }\end{array}$ & UK & 250 & $8.5 e$ & 1964 & $\begin{array}{l}\text {-Local subsidiary exports to 12 other Latin } \\
\text { American countries, over US\$30million per } \\
\text { annum } \\
\text {-Domestic sales represent 25-30 percent of the } \\
\text { firm's major's total regional sales }\end{array}$ \\
\hline $\begin{array}{l}\text { Boe- } \\
\text { hringer- } \\
\text { Ingelheim } \\
\text { Promeco }\end{array}$ & German & 350 & 8 & 1953 & $\begin{array}{l}\text {-Exports account for about 24\% of total sales } \\
\text {-Exports to the US were in excess of } \\
\text { US\$200million (2004) } \\
\text {-In June 2005 announced investment for some } \\
\text { US\$2million in R\&D in Mexico }\end{array}$ \\
\hline
\end{tabular}




\begin{tabular}{|c|c|c|c|c|c|}
\hline Company & Origin & Sales $^{1 / 2 /}$ & Share $^{3 /}$ & Founded & Relevant notes \\
\hline $\begin{array}{l}\text { Sanofi- } \\
\text { Aventis }\end{array}$ & French & 600 & $7 e$ & 1973 & $\begin{array}{l}\text {-Integration between Sanofi-Synthelabo and } \\
\text { Aventis - begun 2004- is complete in Mexico } \\
\text {-The two companies merged local clinical } \\
\text { research operations }\end{array}$ \\
\hline $\begin{array}{l}\text { Merck } \\
\text { KGaA }\end{array}$ & German & 250 & 5 & 1930 & $\begin{array}{l}\text {-Exports some } 30 \text { percent of production to Latin } \\
\text { America } \\
\text {-Local affiliate is the firm's fourth-highest } \\
\text { earning overseas unit }\end{array}$ \\
\hline $\begin{array}{l}\text { Roche- } \\
\text { Syntex }\end{array}$ & Swiss & 120 & 4 & 1948 & $\begin{array}{l}\text {-November 2005, Indian generics maker } \mathrm{Dr} \\
\text { Reddy's acquired Roche's APIs business in } \\
\text { Mexico (US\$59million) }\end{array}$ \\
\hline Eli Lilly & US & --- & $3 e$ & 1943 & $\begin{array}{l}\text {-Local turnover increased above market growth, } \\
\text { at some } 12 \% \text { per annum } \\
\text {-Exports from Mexico to over } 54 \text { countries } \\
\text { (chiefly Latin America) } \\
\text {-Faces several problems associated with coun- } \\
\text { terfeit copies of its products }\end{array}$ \\
\hline $\begin{array}{l}\text { Bristol- } \\
\text { Myers } \\
\text { Squibb }\end{array}$ & US & 200 & $6 e$ & 1947 & $\begin{array}{l}\text {-Recent years have seen heavy investments in } \\
\text { the expansion of local operations, including new } \\
\text { manufacturing facilities }\end{array}$ \\
\hline Bayer & German & 700 & 3 & 1939 & $\begin{array}{l}\text {-Local sales account for around } 24 \text { percent of } \\
\text { Bayer total regional turnover } \\
\text {-Mexico is the company's second-largest market } \\
\text { in Latin America } \\
\text {-Aspirin and Naproxen, have made Bayer the } \\
\text { leading consumer-care business in the country }\end{array}$ \\
\hline
\end{tabular}

Notes: 1/In US\$ million;2/ Figures may appear inconsistent with market shares. Although not explained in the original source, this may be due to differences in information reported by firms. Whereas some provide data on sales for the human line only, for others data corresponds to sales from all products sold in Mexico; 3/ Market share as percentage of total sales in the Mexican market; e. estimate

Source: Author with information from BMI (2006).

Mexico attracts pharmaceutical companies targeting the local market while simultaneously servicing other countries in Latin America. For instance, companies such as Boehringer-Ingelheim, through its affiliate Boehringer-Ingelheim Promeco, expected Mexico to become a major production hub to serve the US and Canadian markets (Andre 2005b). Roche-Syntex Mexico has turned into one of Roche's five largest subsidiaries worldwide and one of the largest selling companies in Mexico, table 5.4. A large share of the company's income stems from primary care products but is expected to shift slowly towards speciality care such as oncology. Pfizer's subsidiary is the largest in Latin America (Andre 2005c).

\subsection{Foreign Trade}

Mexico represents some 0.27 percent of the worlds' total export of pharmaceutical products (Secretaría de Salud 2005a). Mexican exports target mainly the US and the EU; the primary markets in Latin America are Venezuela and Colombia. Limited local production of APIs makes Mexico strongly dependent on the import of raw materials, of which more than 50 percent comes from outside the country. Main suppliers include the US, Germany, Switzerland, England, France and Italy. By contrast, im- 
ports of final products represent only 8 percent of local consumption (Guzmán 2005). The US is the leading source, followed by England, Switzerland, Germany, France and Italy (KPMG 2004). As for the trade balance, exports have increased at a higher rate than imports, 2.8 percent vs. 1.6 percent, respectively, during the last decade. In spite of this, Mexico recorded an increase of 1.3 percent in the trade deficit over the same period (Secretaría de Salud 2005a). Imports of pharmaceutical products amounted to US\$1,288 million in 2003. Exports, in turn, reached US\$890 million, equalling a deficit of US\$398 million. Purchases of innovative medicines fuel the expansion of imports (Secretaría de Salud 2005a).

The studies by Hikino and Amsdem (1994), Hobday (1995) and Kim (1997) reveal that adopting a decisive export orientation was a key strategy by some of the dynamic South East Asian economies in terms of catching up to their competitors. This approach is also effective for pharmaceutical firms; see for example Kim et.al's (1989) study about South Korean firms. Over the years some Mexican firms have managed to adapt to and resist the changing macroeconomic and regulatory environments, while still being able to expand their operations. To a large extent, survival strategies have been associated with export orientations, coupled with technological, financial and managerial restructuring (Brodovsky 1997). In some cases this has accompanied some incipient but decisive R\&D efforts, as well as investment in technological development (Interviews with firms 05 and 10). Nevertheless, export opportunities, particularly to the large US market, remain insufficiently exploited, thus limiting Mexico's ability to strategically support technological progress by local pharmaceutical firms (Interviews with firms 03, 06, 12 and 14). The high cost of obtaining marketing licenses in the US, ${ }^{7}$ absence of a large enough manufacturing capacity, let alone the limited power available to generate a constant flow of new products based on in-house R\&D, were prompted by Mexican manufacturers. In some other cases, inexperience or insufficient understanding of market regulations, in Europe for example, hinder a more active export strategy (Interview with firm 06).

The limited export of Mexican pharmaceuticals contrasts significantly with the strategies of some of the larger Indian firms. As stressed by the director of an affiliate of Indian origin in Mexico: "...the US market is such that you have to continuously keep launching the products to be able to compete and to retain your place in the market. You cannot launch four products and then sleep for the next year, you have to continuously launch 10, 15 new products in a year. It requires a whole lot of commitment of resources, but also the company has to be geared towards servicing the market. And the Mexican companies so far, you know, they are pretty comfortable in Mexico; and to be able to service the more dynamic US generic market, I

\footnotetext{
${ }^{7}$ Licenses to manufacture drug in the US are costly, costs vary depending on whether the product is innovator or generic; in other cases bails and insurances on compliance can be involved (Secretaría de Salud. 2005a). Rights to manufacture effectively serve as entry barriers.
} 
don't think they have the mindset yet" (Interview with firm 12). Chapters 6-8 review the importance of exposure to external competition, through exports, in terms of driving learning in the local industry.

\subsection{The competitive environment}

Traditionally, Mexican authorities required firms interested in marketing pharmaceutical products in the local market to set up properly authorized manufacturing, laboratory and related facilities in Mexico. This was not exclusive to Mexico as several countries in Europe and Latin America have similar provisions. As mentioned in section 3.4 above, multinationals without local facilities could overcome this regulatory requirement by entering into commercial agreements with local manufacturers. A central element of the regulation was the figure of the Responsable Sanitario, a designated representative of a pharmaceutical firm legally established and authorised to sell drugs in Mexico. Irrespective of where the drugs were manufactured, the Responsable Sanitario is responsible for ensuring the quality, stability and safety of the products. In the unfortunate event of a negative side effect arising from the consumption of a particular drug in Mexico, the Responsable Sanitario is liable to any resulting legal or civil sanctions (López 2006; Secretaría de Salud 2005b).

The requirement of a Responsable Sanitario promoted expansion of manufacturing facilities in Mexico. However, on March $30^{\text {th }}, 2007$, the local regulatory agency, COFEPRIS, presented a reform to remove this requirement. The initiative followed the loss of a trade dispute with El Salvador, Honduras and Guatemala. Those countries claimed that the figure of the Responsable Sanitario was effectively an unfair non-tariff barrier blocking imports of pharmaceutical products into Mexico. The requirement was finally abolished by Presidential decree on August $5^{\text {th }}$, 2008, a decision which, after a six month transitory period, entered into force on February $2^{\text {nd }}, 2009$. Thus the Mexican government effectively opened up the market to imports of vitamins, vaccines, hormonal products of biological origin, and homeopathic drugs, among other products. Liberalization of imports of patented drugs and medical devices will follow in August 2010. The mechanism is expected to induce significant price cuts, particularly in specialty drugs such as those used to treat HIV-AIDS.

It is expected that consumers, particularly the largest share served by the public sector, will benefit from cheaper and more readily available drug supplies. This notwithstanding, the perception among some segments of the Mexican society is that elimination of the Responsable Sanitario entails potentially serious threats to sanitation. Major concerns result from COFEPRIS' failure to ensure that imported drugs comply with required sanitary standards (Interview with firm 05). "Unlike the US and other countries, where local regulatory agencies conduct exhaustive audits and inspection visits to manufacturing facilities at the countries of origin, the Mexi- 
can agency is unable to perform such monitoring and certification activities. It simply lacks the human, material and financial resources to do so" (Interview with firm 05). Such concerns were shared by some affiliates with manufacturing facilities in Mexico (Interview with firm 02). Third party authorized laboratories at Mexican public universities and healthcare organisations will assist in the monitoring and certification of imported drugs.

Increased competition is expected as cheaper drugs enter freely into the Mexican market. This point was raised during interviews with directors of multinationals operating manufacturing facilities in Mexico; interviewees expressed that it is unlikely they will withdraw from the country (Interviews with firms 02 and 07). Nevertheless, those with what are so far purely commercial operations, expressed intentions to reconsider future investment in green-field facilities in Mexico (Interviews with firms 01 and 12). They claimed that the large manufacturing capacity at the parent sites would be enough to service the market. It will be interesting to observe the extent to which Mexico is able to support a strong pharmaceutical industry based on factors such as market size, epidemic profile, capacity to offer a sound legal environment and so on. As suggested by Chaturvedi et.al,'s (2007) study about India, the challenge for Mexican pharmaceutical firms is to turn increased market turbulence, created by public policy, into opportunities to expand and build new technology, knowledge and market capabilities. In tackling such challenges the authors stressed the value of business strategies that combine research, marketing and internationalization.

\subsection{Property rights}

Patent and trademark protection on chemical products and processes in Mexico has recorded cycles of lax and strong protection. The 1976 Patent Law established that chemical products and chemical pharmaceutical products were not patentable; they could only be protected by means of certificates of invention ${ }^{8}$ (Lorca and Schmidt 1994). Patents and certificates of invention were granted for a maximum of 10 years from the date of issue. The intention of the 1976 Law was to promote R\&D activities, the overall development of the pharmaceutical and pharmochemical industries, together with import substitution in the field (Dussel 1999). However, according to Lorca and Schmidt (1994) the 1976 Patent Law led many foreign pharmaceutical companies to cease filing patent applications in Mexico. By 1987, amendments to the 1976 Law extended the duration of both patents and certificates of invention up to 14 years from when they were granted. More

\footnotetext{
8 "The most important difference between a patent and a certificate of invention was that the owner of a patent had an exclusive right to the patented invention, while the owner of a certificate of invention indeed had the right to work the invention himself but was also under an obligation to grant a nonexclusive licence to any third party who wished to use the invention" (Lorca and Schmidt 1994)
} 
importantly, they opened the door for patent on previously non-patentable activities including: (i) processes for obtaining, modifying or applying chemical products or mixtures of them, with the exception of biotechnological process; and (ii) processes for obtaining alloys, pharmaceutical products, medicines, in general, foods and beverages for animal consumption, fertilizers, pesticides, herbicides or fungicides (Lorca and Schmidt 1994). In principle a transition period of 10 years was established, rendering patentability effective as of 1997 (Dussel 1999).

At that time the local legislation was considered already more advanced than most other countries in Latin American (Allende 2000); and yet Mexico was the first country in the region to adjust local IPR legislation according to current international standards. The first occurred in 1991 with the granting of patents for up to 20 years counted from the date of application. Certificates of invention were removed, further extending patenting to include (i) some plant varieties; (ii) inventions relating to microorganisms, such as those involving their use, those applied to microorganisms or inventions that result from them, covering all types of microorganisms: bacteria, fungi, algae, viruses, mycroplasm protozoa and, in general, cells that reproduce asexually; (iii) pharmaceuticals, chemicals, medicines in general, foods and beverages for human or animal consumption, fertilizers, pesticides, herbicides, fungicides or products with biological activity, such as vaccines and hormones; and (iv) biotechnological processes for obtaining any of the preceding products (Lorca and Schmidt 1994). Pipeline protection was granted to inventions already patented elsewhere even if they were not produced in or imported to Mexico (Uríbe 2005).

Considered a rather controversial decision with unfortunate consequences for the local industry, the new 1991 Law eliminated, retroactively, the 10 years transition period stipulation set by the 1987 amendments, and patentability became enforced immediately. The 1991 legislation was subsequently reformed in 1994 in order to comply with some provisions of TRIPS and NAFTA. Some of these provisions required non-discrimination principles in regards to: (i) the field of technology; (ii) the place within the NAFTA area where the invention originates ${ }^{9}$ and, (iii) whether products are imported or locally produced (Lorca and Schmidt 1994). A major issue was the effective enforcement of patents by prohibiting product imitation, even if the manufacturing process is different. This was considered detrimental for the local industry as it seriously constrained the scope of R\&D activities (Uríbe 2005). For instance, under this policy, firms would be forced to enter unfavourable technology transfer agreements or licensing contracts (Dussel 1999). Important shortcomings in the legislation persist in the areas of non-disclosed information and parallel imports (Allende 2000; interview with firm 03). Insufficient funding and

\footnotetext{
${ }^{9}$ Under NAFTA the parties involved most recognise patents granted to pharmaceutical products by each member country. They also should grant local protection for a period equal to the remnant validity period of such patent in the other countries (Dussel 1999)
} 
frequently understaffed operations have also been major constraints for the operation of patent authorities (Wagner 1998).

In Mexico, the bulk of patent applications and patents granted correspond to products developed abroad. With the aim of increasing congruence between patent registration and the compulsory sanitary registration, recently some adjustments were made to the regulatory environment, including:

- The possibility to patent new chemical entities with the intention to obtain sanitary registration;

- Authorization of necessary R\&D processes supporting application for sanitary registration three years before patent expiry. This is known as "Cláusula Bolar" (Bolar clause) and prevents artificial extension of protection. Generic manufacturers may carry out the bureaucratic procedures and investment needed well before the patent expires;

- Arbitrage introduced as a dispute mechanism to solve conflicts;

- Creation of a public listing of patents of innovative molecules with the goal of making it coincident with the sanitary registration (Secretaría de Salud 2005a).

Pending challenges include the persistence of entry barriers to generic drug markets. There are no established mechanisms to file complaints in relation to the granting of patents. Whenever third parties are subject to damage after the granting of a patent, there is little room and few mechanisms to dispute such a patent (Secretaría de Salud 2005a). Also missing are rules for Data Protection. "In the US such rules are already in place and, in Canada, have recently been introduced. Protection varies from 3-6 years depending on the country. [By contrast, absence of such procedures in Mexico implies that] you can now file a patent application using own data, arguing that they are already in the public domain (...) There should be an additional period of protection from the date of patent expiry" (Interview with firm 02). Currently firms protect themselves by means of internal control systems such as confidentiality agreements and by fragmenting information; or by entering into specific agreements and codes of practice negotiated through trade organisations such as CANIFARMA and AMIIF. Partner research organisations, for instance public hospitals conducting clinical research, should adhere to such principles and procedures (Interview with firms 01, 05, 11 and Trade2, Insh1 and InsH2).

\section{Learning and innovation}

As noted in Chapter 4 learning and innovation are core ingredients for the sustainability and eventual success of global pharmaceutical firms. Firms in developing countries are not exception to this. Major differences result in the kind of innovative activities that pharmaceutical firms carry out in either develop or developing 
countries. Learning in developing countries aims mainly to the development and manufacturing of generics drugs. Based on the Mexican experience, the following sections document that such specialisation results from a mix of firm's strategic decisions and the influence of factors external to the firm.

\subsection{General environment around R\&D}

Guzmán (2005) and Secretaría de Salud (2005a) maintain that considerations such as the size of the local pharmaceutical market, and its integration into the international market, imply Mexico's potential as an important centre for innovation. Unfortunately, to date this potential remains largely unrealized. The dynamism of the industry seldom translates into significant R\&D efforts (Dussel 1999; Secretaría de Salud 2005a). Major challenges include an unsuitable environment in which to carry out $R \& D$, weaknesses in health and sanitary regulations, and dated legislation in the area of health research (Santiago 2009; Secretaría de Salud 2005a). Equally challenging is the low support to R\&D and interactivity within the system of innovation. Moreover, effective plans to promote the development of the industry are missing (Interviews with firms 05, 06 and 11 and Trade1). These factors worsen the effects of the high cost of basic infrastructure, including energy (Secretaría de Salud 2005a), and the tight price controls, macroeconomic risks and uncertainty about public policy.

In Mexico, the overall macroeconomic environment around S\&T activities remains a source of concern. In 2005, the country's total R\&D expenditure represented 0.46 per cent of GDP; just below the 0.88 percent recorded by Brazil, the largest economy and pharmaceutical market in Latin America (CONACYT 2007). Public investment in S\&T in turn, comprised 0.36 per cent of GDP, with 6.2 percent allocated to the area of health. More important is the slow pace of growth in overall expenditure in S\&T and in particular, R\&D-table 5.5. Despite this, prospects for the health sector look better than in other areas. The average growth rate of public expenditure in health-related S\&T has been the most dynamic over the last eight years or so. Unfortunately, stagnant total public expenditure results in trade-offs between expanding investment in health and reducing support to other sectors. ${ }^{10}$ Encouraging though are the recent dynamics of private expenditure in R\&D. Since 1997 private investment has increased at a pace of 19.0 percent per annum. From a share of 16.9 percent in 1997, it reached 41.5 percent of total R\&D in 2005 (CONACYT 2007).

Major efforts are needed to improve the contribution from within the country's human resource base as well. Secretaría de Salud (2005b) reports that the proportion of researchers in the field of health per 1000 inhabitants is considerably below

\footnotetext{
${ }^{10}$ FCCT (2006) presents a more ample discussion about the expenditure in S\&T in Mexico.
} 
that of developed countries; in fact, only 20 percent of health research-related personnel are employed full-time in this area. ${ }^{11}$ In Mexico there is debate concerning the adequacy of incentives for researchers to work towards applied research, to take patents or develop new products (AMC-FCCT 2005). Researchers may ignore the potential benefits of participating in applied research (Interview with firm 05 and Trade2). Those benefiting from public programmes such as the National System of Researchers (NSR), ${ }^{12}$ regard publication and being cited in international scientific journals, as core curricular activities (AMC-FCCT 2005). Nevertheless, some recent measures in the fields of medical and health sciences grant increased importance to technological developments as criteria for promotion. Valid performance evaluation criteria in relation to technological developments include patents, prototypes, specialised software, technical reports, industrial secrets, copyrights, and so on; and supporting new technologies and applications in the health and biomedicine fields (Secretaría de Salud 2005a).

Table 5.5: Mexico: Expenditure in Science and Technology activities by selected sectors, 1997-2005

\begin{tabular}{|l|c|}
\hline FES\&T $^{2 /}$ & Average Growth $^{1 /}$ \\
Public Education & 1.5 \\
Energy & -3.9 \\
Health & -5.4 \\
Agriculture & 13.7 \\
Other & (1) \\
GERD & 0.3 \\
Private & 3.3 \\
Public & 6.7 \\
\hline
\end{tabular}

${ }^{1 /}$ at constant prices of 2006; FES\&T: Federal expenditure in S\&T; GERD: Gross expenditure in R\&D; ${ }^{2 /}$ the ordering of the components of FES\&T indicate the relative importance of each item within total public investment; ${ }^{3 /}$ includes the Secretaries of Economy, Environment, Navy, Communications, Justice, Social Development and others not specified in the source.

Source: Author with information from CONACYT (2007)

Noteworthy is that a small but world class research community already in Mexico. About half of the total national scientific production is related to clinical disciplines, in particular immunology and neurosciences (Secretaría de Salud 2005a). Medical publications have been growing and gaining credibility during the last 15 years (de la Fuente et.al, 2004); Mexican publications in pharmacology, for example, represented some 0.9 per cent of world scientific publications in the field during

\footnotetext{
${ }^{11}$ de la Fuente et.al, (2004) argue that figures may underestimate the actual number of researchers in health, as they exclude people that classify themselves in areas other than medical research but that carry out activities related to health, for instance, physiology and biochemistry.

${ }^{12}$ The National System of Researchers (SNI for its name in Spanish) is one of the instruments supporting S\&T activities with the longest tradition in Mexico. Since inception in 1984, the SNI promotes the formation, development and consolidation of a critical mass of researchers at the highest level, mostly within the public system of higher education and research. Member researchers receive both pecuniary (a monthly compensation) and non-pecuniary stimulus (status and recognition) based on the productivity and quality of their research.
} 
2002-2006 (CONACYT 2007). Mexico faces opportunities to decentralize research capacities; currently such capacities concentrate in the main universities and public hospitals located in Mexico City (FCCT 2006).

The pharmaceutical industry has gradually gained recognition within total R\&D in Mexican manufacturing. CONACYT (2007) states that pharmaceutical R\&D grew at an average rate of 43.9 percent between 2000 and 2005 (see table 5.6). This is greater than that of total manufacturing $R \& D$ (27.5 percent); or those from other industries relevant for the Mexican economy: Motor vehicles, (2.8 percent); Electronic devices such as televisions, radio and telecommunications equipment, (26.9); and Petrol related products, (22.2 percent). In the same period the share of pharmaceutical $R \& D$, relative to total $R \& D$ in manufacturing, went from 5.8 percent to 10.7 percent. As a share of gross national expenditure in $R \& D$, pharmaceutical $R \& D$ went from 3 percent in 2000, to 8.6 percent in 2005.

\subsection{Drivers of pharmaceutical R\&D in Mexico}

Under Mexican law companies can file an application for a new Registro Sanitario and start development of a new generic drug three years before patent expiration. Hence by the time protection ends, the firm should be ready to launch the new generic product (KPMG 2004). Although this action was expected to further support development of the local generics market, the process is much more complex as a large number of complementary assets are needed. For instance Kim et.al, (1989) and Hobday et.al, (2004) agree on the need to understand the strategic orientation of firms and, more specifically, the role played by learning strategies based on inhouse R\&D. According to interviews with firms 03, 06, 10 and 11, incentives for Mexican pharmaceutical firms to invest in R\&D are twofold: On the one hand there is the desire to gain independence from suppliers of raw materials; and, on the other, the desire to address eventual market opportunities, specifically with regard to generics within the private sector. Regarding the former, firms intend to reduce costs as import prices of raw materials increase. Alternatively, they try to shake-off some unfavourable conditions imposed by suppliers via contracts, or marketing restrictions with regard to final products outside Mexico. Local firms try to strengthen vertical integration by incorporating manufacturing of APIs and to a lesser extent, other raw materials and inputs.

As noted earlier, strengthening vertical integration is a strategy similar to that employed by firms in India and China where integration and control of API manufacturing facilitate technology developments: "Entrepreneurship, you know, you have to constantly keep launching the products, 10 to 15 products, NDA's, which require a lot of in-house support from $R \& D$, backup studies have to be done, data have to be collected, backward integration of API has to be there. All that in Mexico is.... [not really going on]. Whereas in India and China it is possible because you have a lot of 
API manufacturers also; so getting access is easier. And companies like Ranbaxy, Dr. Reddy, SipLab; they also have a lot of API manufacturing of their own. So they're back in control of their own APIs" (Interview with firm 12).

Table 5.6: Mexico: Gross Expenditure in R\&D by main industry, 2000-2005

\begin{tabular}{|c|c|c|c|}
\hline Industry field & 2000 & 2005 & $2005 / 2000^{/ 1}$ \\
\hline Agriculture & 0.0 & 0.0 & --- \\
\hline Mining & 0.8 & 0.4 & 1.5 \\
\hline Manufacturing & 50.5 & 80.8 & 27.5 \\
\hline -Food, beverages and tobacco & 6.4 & 15.5 & 38.7 \\
\hline Food and beverages & 6.4 & 15.5 & 38.7 \\
\hline -Textiles, apparel and leather products & 3.8 & 5.1 & 22.8 \\
\hline Textiles & 3.6 & 1.6 & -1.7 \\
\hline Apparel and leather & 0.0 & 2.3 & 224.8 \\
\hline Leather and footwear manufacturing & 0.2 & 1.2 & 64.8 \\
\hline - Wood products, paper, and printing & 0.6 & 1.3 & 35.9 \\
\hline - Petroleum and coal, nuclear energy, chemicals, rubber and plastic & 11.5 & 26.5 & 37.1 \\
\hline Petroleum and coal products manufacturing, and nuclear energy & 0.2 & 0.2 & 22.2 \\
\hline Chemical manufacturing & 10.0 & 18.1 & 30.6 \\
\hline Chemical products (except pharmaceuticals) & 7.1 & 9.5 & 23.0 \\
\hline Pharmaceuticals & 3.0 & 8.6 & 43.9 \\
\hline Rubber and plastic products & 1.3 & 8.2 & 66.7 \\
\hline - Non-metallic mineral product manufacturing & 1.9 & 4.6 & 38.0 \\
\hline - Basic metals & 1.0 & 1.5 & 26.2 \\
\hline - Metal manufacturing (except machinery and equipment) & 0.8 & 6.6 & 77.4 \\
\hline -Machinery and equipment including transport & 20.1 & 19.3 & 15.1 \\
\hline Computer, electronic, office and accounting product manufacturing & 0.0 & 2.2 & --- \\
\hline Electrical equipment manufacturing & 0.8 & 3.2 & 54.8 \\
\hline Electronic equipment (radio, TV. and communications) & 0.1 & 0.6 & 58.0 \\
\hline Motor vehicles & 17.4 & 9.5 & 2.8 \\
\hline - Furniture and Related Product Manufacturing & 4.3 & 0.4 & -100.0 \\
\hline - Electricity, gas and water (public utilities) & 2.0 & 0.5 & -13.0 \\
\hline Construction & 0.3 & 0.0 & -40.8 \\
\hline Services & 46.3 & 18.2 & -3.7 \\
\hline -Communications & 14.2 & 1.6 & -25.1 \\
\hline Telecommunications & 14.0 & 1.6 & -25.0 \\
\hline - Financial and insurance services & 6.7 & 3.6 & 2.4 \\
\hline - Real Estate and Rental and Leasing & 0.0 & 0.1 & 53.9 \\
\hline - Community, social and personal services & 16.7 & 9.0 & 2.6 \\
\hline Total & 100 & 100 & 16.1 \\
\hline
\end{tabular}

Note: Totals may not add up due to rounding; *Constant MX Pesos, 2006=100; /1 Avg Growth.

Source: Author with information from INEGI-Conacyt, Encuestas sobre Investigación y Desarrollo Tecnológico 2002, 2004 y 2006.

With regard to the second strategy, firms literally try to escape from the government's monopsonistic power (Interviews with firms 05 and 06). They seek to capture some of the benefits accruing from the generic segment of the private market. To a lesser extent, firms have targeted the generic market in the US, or have looked at the market for so-called 'Orphan' drugs (Interview with firm 09). ${ }^{13}$ Per-

\footnotetext{
${ }^{13}$ Orphan drugs are products that treat a rare disease or condition affecting some relatively small group of consumer. In the US for example, these refer to diseases affecting fewer than 200,000 Americans (FDA. 2001)
} 
ceived dynamics of prices, and demand and revenues from these markets make investment in more formal and systematic R\&D more attractive.

Business strategies based on more systematic in-house R\&D are far from easy to implement. As suggested by Kim et.al, (1989), and more recently by Forbes and Wield (2000) and Hobday et.al, (2004), major strategic changes are needed in the mindset and organisation of activities within latecomer firms. Interviews revealed that some Mexican pharmaceutical firms begin this sort of transition by shifting the balance of power between development activities on the one hand, and manufacturing and quality control on the other (Interviews with firms 03, 06, 10 and 11). Indeed, development and eventually, R\&D departments, need flexibility and autonomy within the organisation. Furthermore, they need to be empowered with the time and resources to carry out their activities. It is difficult to progress when development, manufacturing and quality control compete for infrastructure inside the firm (Interviews with firms 05, 06, 10 and 11). For instance, Firms 05 and 06 mentioned that although development staff needs to perform tests on compression and other properties of a new tablet, in order to access the required machinery they have to stand in the line until it becomes available.

As R\&D gains momentum, further advancements will depend upon the effective development of human resources, in clinical research for instance, -if only for the testing of new applications and reformulations (Interviews with firms 06 and 11). However limited, performance of clinical research compels firms to complement sound understanding of the physics and biochemistry of compounds, with knowledge about medical conditions and the intricacies of drug testing in humans. In practice, this means that skilled and knowledgeable staff with sufficient understanding and experience in clinical research should be hired. At the same time, organisational practices need to change in order to accommodate the needs of personnel with diverse profiles and interests. Interviews with Mexican generic manufacturers revealed that firms are not always ready to undertake these tasks.

\subsection{R\&D performance}

Chapter 2 discussed alternative definitions of innovation in the context of developing countries. On the one hand, technological modernization denotes introduction of new, more advanced machinery and equipment, or adoption of enhanced manufacturing and managerial techniques. This is considered the most common innovation exercise in such countries. On the other hand, studies document formal R\&D efforts leading to successful adoption of product/process innovations with different degrees of novelty. In 2005, total expenditure in innovation-related activities in the Mexican pharmaceutical industry was US\$132-148 million; figure 5.4. Machinery and equipment, and R\&D represented the areas with the largest investment with combined shares of 80 per cent of total expenditure. Nevertheless, R\&D represents 
the largest component of innovation-related expenditure. Investment in industrial design or prototype plants is also an area of considerable interest for pharmaceutical firms. By contrast, acquisition of software and other external technologies represent a larger share of investment by manufacturing firms. Expenditure on innovation-related training is negligible in terms of investment in technology acquisition.

Figure 5.4: Mexico, distribution of investment in innovation activities by manufacturing firms, 2005

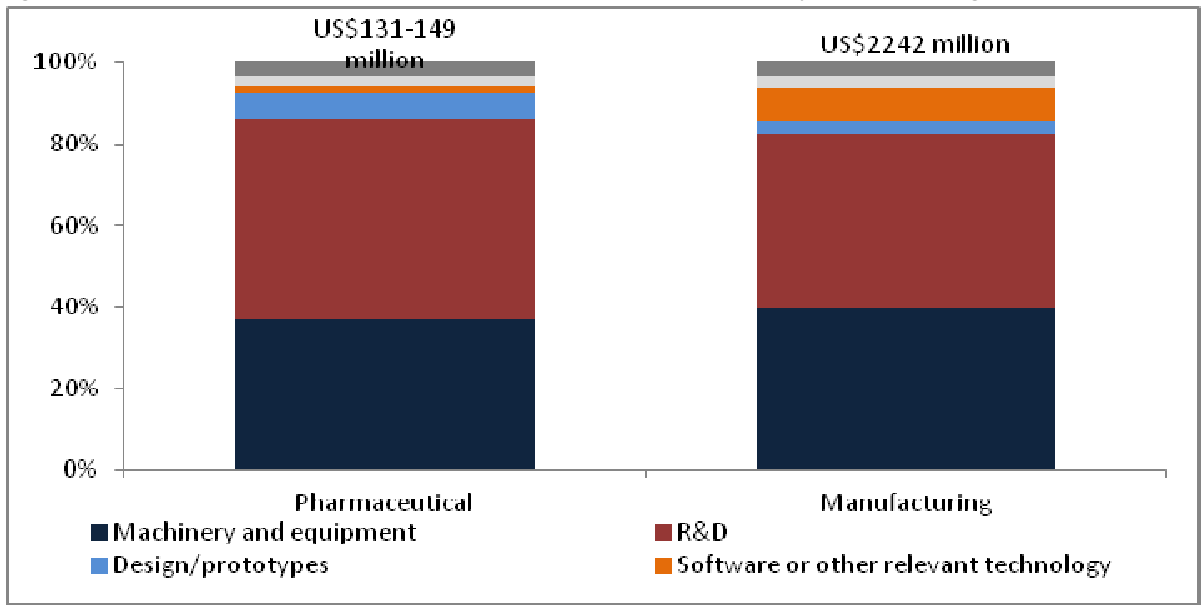

Notes: Average exchange rate 10.8939 Mexican pesos per US dollar. This corresponds to the exchange rate used to process foreign currency denominated operations (FIX).

Source: CONACYT (2007) and Banxico.

Figure 5.5 depicts the share of investment taken up by distinct activities shaping global pharamaceutical innovation. It distinguishes the different instances where Mexico participates more actively. Some 30 percent of total investment corresponds to drug discovery and preclinical studies up to the stage of toxicity testing. These are areas where Mexico makes little or, in effect, no contribution at all. As documented in Chapter 4, the most expensive and longest component of pharmaceutical innovation corresponds to clinical trials, with something more than 40 percent of total investment. Chapter 4 equally noted that dosage, formulation and stability, together with drug manufacturing development are the activities most frequently carried out by developing countries. These items capture 7.3 and 8.3 per cent, respectively, of total investment in pharmaceutical innovation.

Figure 5.5 shows that Mexico characterises by limited performance of research underpinning drug discovery. The country's contribution to global pharmaceutical innovation begins with galenic development and sustainability of active ingredients. As discussed later, in line with global trends of the pharmaceutical industry, clinical research is growing in the country. Most technological contributions remain in the manufacturing or post-marketing stage of the pharmaceutical innovation cycle. This is through incremental innovations with degrees of technological complexity rang- 
ing from limited to moderate (Interview at Trade1 and firms 04 and 05). Innovative activities are geared mostly to pharmaceutical development including, analytic methods, new drug delivery systems, new applications or reformulations of existing molecules, development of new dosage forms, and generics; firms may also create new or new combinations of excipients (Interview at firm 05).

Figure 5.5: Distribution of R\&D investment among the different phases of the development of a new drug: where does Mexico stand?

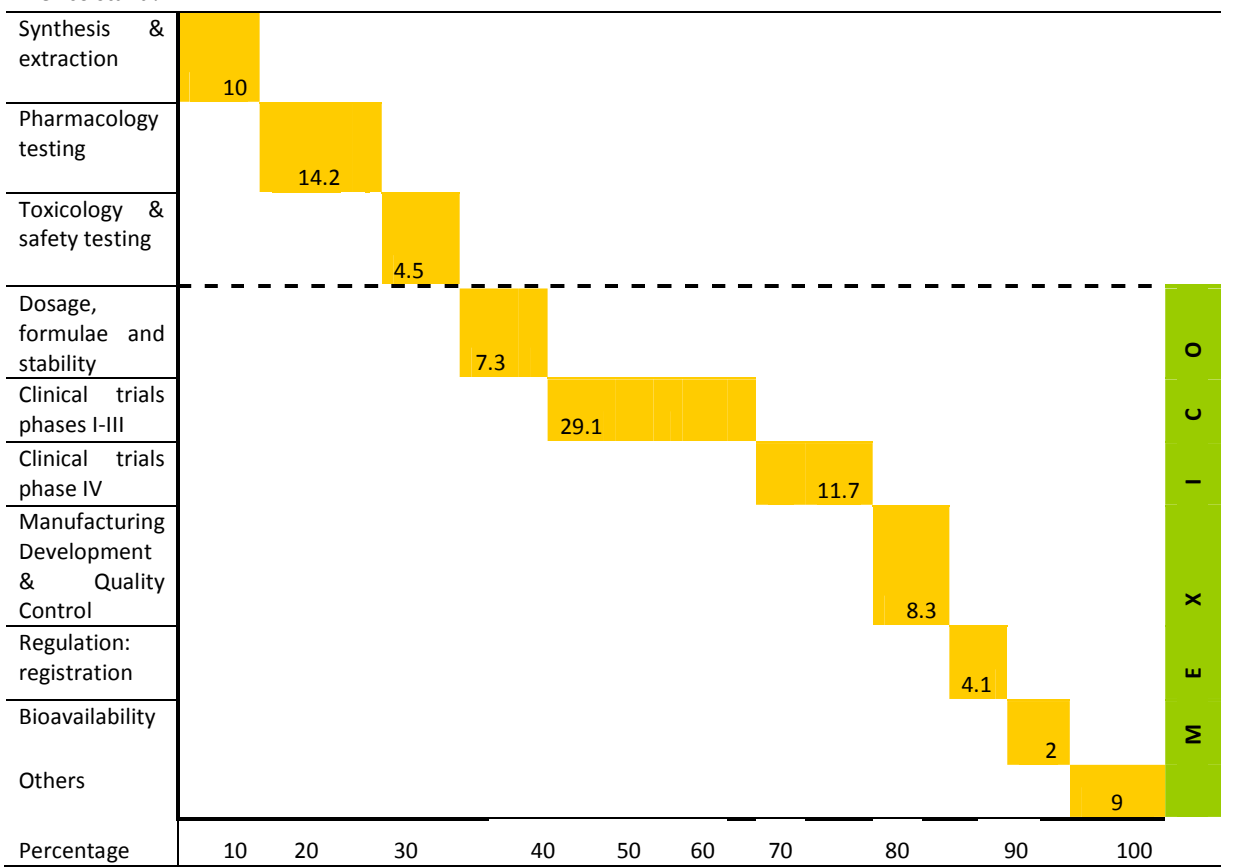

Notes: For construction purposes, the columns and rows may differ in width; however, the scale remains the same. Source: AMIIF, 2005

Drug development takes two main forms. First, firms replicate existing drug manufacturing processes in order to obtain marketing approval by Mexican authorities. Secondly, efforts are made to enhance product quality and performance. Domestic firms are quite active in these latter activities. There are in addition, firms such as Silanes, Probiomed and Alpharma, which have a capacity to explore some NCEs based mostly on biotechnology tools and relatively closer interaction with public and private research organisations in Mexico and abroad. Domestic manufacturers perceive biotechnology as a viable though still expensive and demanding way to start building formal R\&D efforts (Interviews with firms 03, 06 and 10).

As for the contribution of multinationals to technological activities in Mexico, the picture is rather mixed, depending on where such investment occurs. To a large extent multinationals are responsible for the highest levels of modernization and automation of the local industry. US affiliates for example, are already introducing some of the advanced monitoring and manufacturing techniques under the PAT 
framework-see chapter 4. Hence, compared to local firms, multinationals tend to take the lead when it comes to technology. In terms of R\&D the conclusion is somewhat different. Firms such as Schering-Plough have established fully-fledged R\&D facilities in support of their global innovation strategies, with a somewhat limited capacity to perform original research. ${ }^{14}$ In general however, R\&D by multinationals remains concentrated in the formulation of new applications or niche products tailored to the Mexican market (Interviews with firms 07 and 13). Merck KGaA in Mexico for example, developed a vitamin supplement tailored specifically for the large diabetic population. The product has rapidly diffused to other markets worldwide. Alternatively, multinationals increasingly carry out clinical research in partnership with local research organisations, mainly public hospitals (Interview with Trade2).

Zúñiga and Combe (2002) argue that it is difficult to expect significant increases in R\&D expenditure by multinationals in developing countries. This is complicated even following patent reforms, considering the nature of the pharmaceutical industry, with a traditional concentration of corporate R\&D laboratories in the countries of origin. Other factors are needed for multinationals to relocate R\&D facilities, including: (i) more coherent science and technology policies; (ii) linking better academic and industry R\&D efforts, and (iii) direct promotion of stronger R\&D activities in the pharmaceutical industry.

\section{4. $R \& D$ outcomes}

According to the latest Community Innovation Survey 2006 (CONACYT 2007), some 59.1 percent of pharmaceutical firms in Mexico performed in house R\&D, the majority of which, 94.8 percent, obtained some kind of result, table 5.7. Mirroring global trends in the industry, pharmaceutical firms in Mexico have a larger propensity to invest in R\&D than the rest of the manufacturing sector. In terms of outcomes, product innovations are the most frequent; almost all firms performing inhouse R\&D obtained such innovations. Firms performing R\&D and obtaining some kind of results (181) introduced, on average, 16.8 new or improved pharmaceutical products between 2004 and 2005. The number of firms introducing new or improved processes is considerably lower (75); yet, on average firms introduced some 15.7 process innovations.

In line with the discussion in Chapter 1, the incremental nature of pharmaceutical R\&D in Mexico is reflected in the large number of innovations that are new to the country and, to a lesser extent, the firm. Local firms mostly tap into available knowledge in order to adapt products and/or processes to the local market. Despite this, some firms operating in Mexico have managed to obtain some radical innovations in the sense that they are completely new to the world. However, sales revenue makes little distinction between new and improved products; though new products represent about 53.0 percent of total sales. The figure differs significantly

\footnotetext{
${ }^{14}$ It is uncertain what will happen with those R\&D facilities after the merger of Schering-Plough and Merck, Co.
} 
with those for the whole of the manufacturing sector. Although pharmaceutical firms report a larger R\&D focus in terms of sales, expected sales revenue from the new or improved products is lower than those from R\&D in the manufacturing industry.

Table 5.7: Innovative performance of the Mexican pharmaceutical industry, 2004-2005

\begin{tabular}{|c|c|c|c|c|c|}
\hline & Pharmaceuticals & Manufacturing & & Pharmaceuticals & Manufacturing \\
\hline Total firms & 323 & 16398 & \multicolumn{3}{|c|}{ Distribution of sales by novelty of product (\%) } \\
\hline \multicolumn{3}{|c|}{ Carried out $R \& D^{1 /}$} & New & 24.2 & 31.8 \\
\hline Yes & 191 & 4,090 & Improved & 28.8 & 36.4 \\
\hline With results & 181 & 4,040 & No change & 47.0 & 31.8 \\
\hline No & 132 & 12,307 & Total & 100 & 100 \\
\hline \multicolumn{3}{|c|}{ Results from R\&D } & \multicolumn{3}{|c|}{ Patents } \\
\hline Products & 3,043 & 35,471 & & Applied & Granted \\
\hline Yes $^{1 /}$ & 181 & 3,891 & Mexico & 64 & 22 \\
\hline$\%$ of total firms & 56.3 & 23.7 & Abroad & 56 & 11 \\
\hline Processes & 1,178 & 9,444 & Total & 119 & 33 \\
\hline Yes $^{1 /}$ & 75 & 2,001 & \multicolumn{3}{|c|}{ Linkage activity in pharmaceuticals $^{1 /}$} \\
\hline$\%$ of total firms & 23.2 & 12.2 & \multirow{3}{*}{$\begin{array}{l}\text { In house } \\
\text { Research } \\
\text { Centres }\end{array}$} & Product/Services & Process \\
\hline \multicolumn{3}{|c|}{ Innovations by degree of novelty (per cent) } & & 138 & 69 \\
\hline Firm & Country & World & & 10 & 4 \\
\hline \multirow[t]{3}{*}{21.4} & 77.6 & 1.0 & Universities & 15 & 0 \\
\hline & & & Other firm & 18 & 2 \\
\hline & & & Total & 181 & 75 \\
\hline
\end{tabular}

Notes: ${ }^{1 /}$ Number of firms

Source: Author with information from CONACYT (2007)

Chapters 7 and 8 offer a more extensive analysis of the propensity of pharmaceutical firms in Mexico to acquire technological knowledge from external markets; licensing in particular, is among the mechanisms preferred by firms. This situation can partly explain the larger number of patents established in Mexico by multinational, compared to domestic firms. By applying for patents in Mexico, multinationals support the marketing of innovative drugs, particularly to the benefit of private market. In such a way those firms capitalize on the improved local environment around IPRs following Mexico's endorsement of the TRIPS agreement. By contrast, the low patenting activity of local agents reflects the limited learning activities they carry out. In effect Guzmán (2005) reports that the bulk of pharmaceutical patents by Mexican agents correspond to individuals or research organisations; only a minor share are proposed by domestic firms and transformed into marketable products. The few patents that Mexican firms file abroad concentrate in the European Union.

The literature stresses that one of the more disquieting features of the Mexican system of innovation is that low levels of $R \& D$ are accompanied by limited or poor interactions among agents shaping such systems (Cimoli 2000; Cimoli and Constantino 2000). Casas (2001) asserts that firms rely almost exclusively on internal learning efforts to fulfil knowledge requirements. This situation is exemplified by the Mexican pharmaceutical industry. Nearly three quarters of firms that introduced product innovations did so without interacting with other agents. The lack of connection is even more evident in the case of process innovation. 
Recent efforts to promote interactivity in the system by CONACYT, the agency responsible for S\&T policy in Mexico, have achieved some modest results. Over the last years, CONACYT has funded projects carried out jointly by firms and other organisations. In 2006, investment in such projects added up to MX\$3,999.8 million, roughly US\$366.9 million, (table 5.8). Some 481 firms were involved, carrying out 1,616 projects; the two latter figures more than tripled compared to those observed in 2001. The presence of pharmaceutical firms increased considerably between 2001 and 2006, but the figures suggest some inconsistency in terms of resource allocation. More detailed information about the number of applicants and corresponding funding requirements is missing. Nevertheless, one can see that although the number of both pharmaceutical firms and projects has increased, investment per project has not. The number of pharmaceutical firms supported by CONACYT is a minor fraction of those that could potentially participate, table 5.8.

Table 5.8: Conacyt's investment in projects involving interactions of firms and other agents, 2001-2006

\begin{tabular}{|c|c|c|c|c|c|c|}
\hline & 2001 & 2002 & 2003 & 2004 & 2005 & 2006 \\
\hline \multicolumn{7}{|c|}{ Pharmaceutical industry } \\
\hline Firms $^{1 /}$ & 9 & 16 & 27 & 35 & 50 & 48 \\
\hline Projects $^{1 /}$ & 31 & 95 & 132 & 202 & 278 & 273 \\
\hline Investment $^{2 /}$ & 3.1 & 3.2 & 5.7 & 11.6 & 17.9 & 29.0 \\
\hline Inv/project ${ }^{3 /}$ & 100.8 & 33.2 & 43.1 & 57.2 & 64.3 & 106.1 \\
\hline \multicolumn{7}{|c|}{ Share in total } \\
\hline Firms $^{1 /}$ & 6.3 & 7.4 & 11.4 & 9.8 & 8.2 & 10.0 \\
\hline Projects $^{1 /}$ & 6.1 & 11.5 & 15.1 & 15.4 & 13.3 & 16.9 \\
\hline Investment $^{2 /}$ & 6.5 & 5.0 & 10.1 & 9.5 & 6.2 & 7.9 \\
\hline \multicolumn{7}{|l|}{ Total } \\
\hline Firms $^{1 /}$ & 142 & 216 & 236 & 357 & 608 & 481 \\
\hline Projects $^{1 /}$ & 506 & 824 & 873 & 1308 & 2083 & 1616 \\
\hline Inv/project ${ }^{3 /}$ & 95.2 & 76.1 & 64.8 & 93.0 & 137.4 & 227.1 \\
\hline
\end{tabular}

Notes: ${ }^{1 /}$ Number; ${ }^{2 /}$ US\$ million, 2006 $=100 ;{ }^{3 /}$ US\$ Thousand

Source: Author with information from CONACYT

\subsection{Basic research}

Mexico has facilities to perform new drug-related research; yet activity in such areas is only in its early stages. Basic research happens mostly at universities and public research centres with limited links to the industry. Nevertheless BMI (2006) reports that GSKs Rotarix, a novel, orally administered two-dose vaccine for rotavirus infection in infants, was one of the first drug discoveries to be made in Mexico; and the product was partly developed at the local affiliate. ${ }^{15}$

One of the main questions of this chapter, is why firms, particularly multinationals, do not conduct basic research in Mexico? Interviews with firm representatives revealed that there are several reasons to explain this. In line with literature on internationalization of R\&D (von Zedtwitz and Gassmann 2002), the most frequent answer was that from a business strategy point of view, Mexico is mostly a

\footnotetext{
${ }^{15}$ In July 2004 GSK announced that COFEPRIS had approved Rotarix. Therefore the product was launched in Mexico even before obtaining approvals from the US or European authorities. The drug is expected to generate annual sales of up to US\$1.8 billion, and royalty payments of US\$1-2 million. More importantly, Mexico became the starting point for a promising new business for GSK (BMI 2006)
} 
manufacturing location and consumer market, but not a major R\&D centre. This was the case even for affiliates of Indian origin.

Mexico lacks the technical infrastructure, an attractive and conducive research environment, and a sufficiently experienced human resource base. A few public research centres meet world-class standards and possess adequate research methodologies and procedures. However, they lack sufficient equipment, both in terms of the quantity and degree of sophistication required to carry out the massive amount of biological and chemical tests underpinning new drug discovery. "Tests should often run simultaneously and at considerable precision and speed. [Mexican researchers have little or no experience in] conducting lead discovery projects, understanding of the physicochemical structure of the processes under research; for instance, to test for systemic or crossed effects of lead targets, particularly when processes of hypothesis testing involve combinations or simultaneous analysis of different molecules or substances" (Interview with firm 13). Whereas the bulk of local R\&D activities currently focus on inter-changeability tests, multinationals are a few steps ahead "exploring, testing and solving new hypotheses" (Interview with firm 13).

An important question to pose, considering, most new drug-related basic research happens at universities, limited though it may be, is why firms do not capitalise on those activities. Efforts to bridge the gap between firms and academic institutions have rendered limited results; the two agents operate according to different incentives and motivations, where 'publish or perish' clashes with 'time to market' incentives and rewards (Interview with firms 05, 06 and 11). This classic dichotomy is widely documented in the literature (Pavitt 1998; Stephan 1996; Stephan and Audrestsch 2000). Additional obstacles stem from inadequate handling of IPRs within academic organisations, which hinders access to research with potential pharmaceutical use. It is problematic to negotiate technology transfer or joint development projects when no one owns the technology (Interview with firms 06 and 13).

In some other cases, researchers disregard or fail to appreciate the many procedures required by law to test, develop, improve, manufacture and market new drugs. These require time, advanced facilities, laboratories, pilot plants and personnel -resources that are not readily and widely available at Mexican public research organisations. Failure to value potential technologies would be an additional obstacle. Limited interactivity occurs not only between firms and research organisations but among the latter, and between these and government institutions. For instance, the leader of the R\&D department at firm 13 commented that, "Although diabetes is one of the most prevalent diseases in Mexico, so far there are no specific mechanisms whereby public health and S\&T organisms, healthcare institutions, research organisations and firms may join forces to develop new drugs or other products for such population. Everybody is working on his/her own agenda without proper assessment of how research results may be applied and translated into new products".

The business environment is also an area of concern (Secretaría de Salud 2005). In a best case scenario, firms sponsor research projects at universities or research 
centres; alternatively firms award prizes and recognition to interesting basic research projects in the areas of health, medicine and pharmacology, through organisations such as CANIFARMA. In general though, such projects never make it to the development stage; researchers are either not interested in pursuing further development, applicability in the real world is not immediately obvious, or linkages to the industry are weak (Firms 05, 11 and Trade1). According to Trade1 between 2000 and 2006 some 160 projects competed for the CANIFARMA Award in health- and pharmaceutical-related research, but only around eight projects were successful. of those successful projects no more than two have been made into usable products. Pharmaceutical innovation is a matter of creating critical masses of projects, mobilizing resources, cultivating an environment of collaboration between different research organisations, including the sharing of assets; Mexico is still weak in all of these areas.

Uncertainties regarding whether large manufacturers of innovative products will be willing to commercialise molecules developed by local API manufacturers may also help explain the lack of appeal related to basic R\&D (Secretaría de Salud 2005a and Interview with firm 06). This is compounded further by factors such as the absence of linkages between health problems and R\&D; inadequate regulation preventing public research organisations from receiving funding and equipment from private organisations; few linkages between public scholarship programmes and the on-the-ground needs of industry in terms of human resources; insufficient funding for $R \& D$, and the enduring uncertainty surrounding pharmaceutical research (Secretaría de Salud 2005a).

In the case of biotechnology, Bolívar (1997) reported that a major obstacle to develop industrial applications has been the strong teaching or research orientation of graduate programmes in the field; they have little or no connection at all with industry needs. Such problems are aggravated by "the inadequate interpretation of the concept of biotechnology by Mexican policy makers. Because authorities take it as a generic sector, they tend to ignore differences in the development of applications for agriculture, food and pharmaceutical industries" (Interview with firm 05).

\subsection{Clinical research}

Countries such as Mexico are increasingly being considered as potential sites for drug development activities, mostly via the off-shoring of clinical research by multinational firms. Santiago (2009) maintains that multinationals benefit from the presence of effective and sufficiently equipped healthcare organisations with experience and well established procedures to deal with patients and regulations. Equally important are factors such as the presence of a large pool of experienced clinical researchers; an effective ethics committee, and superior evaluation and supervisory mechanisms to ensure that research protocols occur in a relatively efficient, transparent and speedy manner. Mexico is an attractive site as it fulfils many of these requirements (Santiago 2009). It complies with principles established by the International Conference on Harmonisation (ICH) on Good Clinical Practices. The country has positioned itself as one of the leading sites for clinical trials in Latin America 
with research protocols in more than 20 therapeutic areas and more than 1,000 institutions and 43,000 patients involved in 2005 alone (AMIIF). Despite this, there are some factors hindering success, such as regulatory shortcomings in, for instance, authorization and supervision of trials by both ethics committees and COFEPRIS (Interviews with trade2, Insh2, Insh3 and CRO); and the lack of experienced researchers to conduct clinical research (Secretaría de Salud 2005a).

\section{Concluding remarks}

The introductory section to this chapter argued that the climate surrounding the pharmaceutical industry in Mexico discourages learning and innovation, particularly by domestic firms. A number of factors stand out from the analysis. Historically, public policy seems to struggle finding the middle ground between strict protectionism and extreme liberalisation. In either case government intervention has been somewhat ineffective in setting the stage for the advancement of the local industry. Rather public policy tends to nurture cautious behaviour by domestic firms; firms reluctantly seek business strategies based on more ambitious plans to develop proprietary technologies. Studies on Korea and India show that strategies based on intensive domestic learning require long-term approaches; hence it is possible to more systematically undertake uncertain and risky R\&D activities (Kim et al, 1989; Kale and Little 2007).

Incentives to invest in innovation and learning derived from traditional market mechanisms, such as prices, are equally hindered by conflicting policy goals. When it comes to public procurement of basic drugs, consumer protection and reduction of healthcare costs result in price structures that privilege low cost over quality and novelty. In such a context market specialisation of domestic and multinational firms places the former in precarious positions; they depend strongly on the low profit, large volume public market. Most domestic firms concern more about survival than growing market shares via increased in-house technological efforts. Their capacity to tackle the more profitable private sector is limited by low R\&D performance.

The analyses in chapter 6-8 reinforce the perception that strategies to develop the pharmaceutical industry based on capturing knowledge from foreign firms are also questionable. Mexico still ranks very low as suitable location for multinational firms to carry out some of their more advanced R\&D activities. Reform and increased market orientation have been poorly conducive for the development of the local pharmaceutical industry. Such efforts seldom accompany more decisive actions to strengthen whatever technological base is in place in the domestic industry. Moreover, the agents in the relevant system of innovation are unable to complement each other's efforts, or to support more rapid and sustained construction of technological capabilities by domestic firms.

The pernicious macroeconomic context around pharmaceutical innovation in Mexico accompanies an equally limited learning environment inside pharmaceutical firms. The econometric analyses in Chapters 6-8 documents the limited influence that organisational arrangements and related human resource management practices have on learning performance of pharmaceutical firms in Mexico. 


\section{Chapter 6}

\section{Human resource management practices for learning through in-house R\&D: pharmaceuticals in Mexico ${ }^{1}$}

\section{Introduction}

This chapter contributes to the literature on human resource management practices and learning for innovation in the context of developing countries. In-house R\&D is broadly interpreted as learning at firm level. Based on the notions of knowledge exploitation, and knowledge exploration, the research hypotheses here is that the influence of human resource management interventions on learning depends on two factors: first, the nature of the knowledge required; and second, the expected goals from the learning activities carried out by the firm-see chapters 1 and 3 . The underlying logic is that human resource management practices influence innovation by stimulating, first, learning and capacity-building through in-house R\&D.

To the best of our knowledge, this is one of the first systematic analyses of the sway of human resource management over learning through R\&D in developing countries. Focus on the Mexican pharmaceutical industry illustrates the importance of carefully considering the contexts in which management practices work. Overall macroeconomic conditions and the social environment around R\&D conditions what can be expected from human resource management interventions. In particular, the effects of such practices on performance depend on how countries get involved and contribute to global innovation processes in specific industries.

From a methodological perspective, the chapter illustrates the potential benefits of research on the latent processes linking human resource management practices to innovation, in this case, learning. This kind of approach is quite familiar for management scholars interested in comprehending how management practices affect creativity and creative thinking for example. In this manner this chapter paves the way towards better understanding how human factors and their organisation

\footnotetext{
${ }^{1}$ Earlier versions benefited from comments by Gabriela Dutrénit; Nobuya Haraguchi; Wilfred Dolfsma, Branka Urem, Jojo Jacob and members of the research group on Innovation, global business strategies and host country development at UNU-MERIT; Leonel Corona, Javier Jasso and staff of the División de Investigación, Facultad de Contaduría, Administración e Informática of the National Autonomous University, Mexico. Suggestions by Martin Shrolec and other participants at the $7^{\text {th }}$ Annual conference of the Globelics network are appreciated. Maria Fermie helped in editing and correcting previous versions. A paper based on this chapter is currently under review by the Journal Structural Change and Economic Dynamics; this will be a special issue with contributions to the $7^{\text {th }}$ Globelics conference. I appreciate comments by two anonymous referees to the journal.
} 
inside firms contribute to the building and operation of systems of innovation. The chapter proceeds as follows: Section 2 defines the dependent variables and research strategy used in this chapter; they denote different types of in-house R\&D performed by pharmaceutical firms in Mexico. Section 3 provides results. Finally, section 4 presents some discussion and conclusions.

\section{Variable definition}

Data used in this chapter were extracted from the ENESTYC dataset--chapter 3.

\subsection{Dependent variables}

ENESTYC includes detailed questions on the R\&D activities performed by pharmaceuticals firms in Mexico. To begin with, ENESTYC enquires if firms perform R\&D, at all. This is captured by the variable rd_inhouse, item (1) in table 6.1. A novel feature of this study is the identification of the objectives pursued by the firm through R\&D. ENESTYC identifies R\&D supporting cost-reducing innovations through: (2) improvements in existing drug manufacturing processes (rd_improve_process); (3) improvement or design of new machinery and equipment for the firm's own use (rd_design_meq). This second is interpreted as R\&D for new process innovation. Other R\&D variables capture demand-enhancing innovations including: (4) quality improvements on existing pharmaceutical products (rd_drug_improvement); and (5) design of new pharmaceutical products (rd_drug_design). The novelty of the $R \& D$ outcomes is defined taking the firm as reference; innovations may be new to the firm but not necessarily to the Mexican market or the world.

Table 6.1: Indicators on in-house R\&D performance by pharmaceutical firms in Mexico

Table 6.1: Indicators on in-house R\&D performance by pharmaceutical firms in Mexico
\begin{tabular}{|l|l|l|}
\hline & Variable & Definition \\
\hline$(1)$ & rd_inhouse & The firm carries out R\&D in-house \\
\hline$(2)$ & rd_improve_process & The goal of R\&D is to improve existing manufacturing processes \\
\hline$(3)$ & rd_design_meq & $\begin{array}{l}\text { The goal of R\&D is to improve or design new machinery and equipment for } \\
\text { the firm's own use }\end{array}$ \\
\hline$(4)$ & rd_drug_improvement & The goal of R\&D is to improve existing pharmaceutical products \\
\hline$(5)$ & rd_drug_design & The goal of R\&D is to design new pharmaceutical products \\
\hline$(6)$ & rd_exploit & The firm performs R\&D for knowledge exploitation \\
\hline$(7)$ & rd_explore & The firm performs R\&D for knowledge exploration \\
\hline
\end{tabular}

Source: Author with information from ENESTYC, 2005

Items (2) and (4) in table 6.1 identify knowledge exploitation activities; improvement in pharmaceutical products and/or processes leads to searches within the firm's familiar knowledge bases. By contrast, the introduction of some new manufacturing processes or new drugs, indicators (3) and (5), relate to knowledge searches outside familiar cognitive, including physical and geographical, boundaries of the firm. ${ }^{2}$ This distinction coincides with Kale and Little's (2007) differentiation of pharmaceutical firms, based on their accumulated technological capabilities. Based

\footnotetext{
${ }^{2}$ Similar interpretations in the context of biotechnology and pharmaceuticals are found in Rothaermel and Deeds (2004), Gilsing (2006) and Kettler and Modi (2001)
} 
on the logic of exploitation and exploration, variables (2)-(5) were combined to generate two new indicators on R\&D. By combining (2) and (4) a variable on $R \& D$ for knowledge exploitation, rd_exploit, is obtained. Likewise, by combining (3) and (5) the variable on R\&D for knowledge exploration, rd_explore, is obtained.

Chapter 5 documented that, in general, firms in Mexico pursue imitative, incremental innovations based on the exploitation of knowledge already available in-house. Quality enhancements of pharmaceutical products denote changes in formulations so that the products meet the requirements of bioequivalence and bioavailability of the API. Firms may also improve product packaging. New products, in turn, include new vaccines, development of new applications of existing drugs by combining excipients, reformulating or recombining existing molecules--often in a different therapeutic area; and designing novel medical devices. Some of the more dynamic local firms have capacity to developed new generics and excipients based on the use of biotechnology.

Correlation analysis in table 6.2 lends support to some of the previous arguments; it reveals that knowledge exploitation, particularly for the improvement of drugs already in a firm's product portfolio, is what drives R\&D of pharmaceutical firms in Mexico. ${ }^{3}$ There is high and statistically significant correlation between variables on R\&D for knowledge exploitation. By contrast, the weakest correlations relate to R\&D for the design and improvement of machinery and equipment for the firm's own use.

\subsection{Explanatory and control variables}

Table 6.2 presents the explanatory and control variables used in this paper. Sections 2 and 3.1.1 in Chapter 3 discussed the theoretical underpinnings and the construction of the variables based on the ENESTYC dataset, respectively. The chapter highlighted the difficulties to identify, based on concrete theoretical grounds, the human resource management practices that matter the most for firm performance. The decision was to include some practices adopted by both innovation scholars, and available studies on human resource management practices in Mexico. Thus the analysis includes distinct forms of remunerations, training and worker's participation in decision making -variables 8-14 in Table 6.2. Likewise we control for firm's characteristics such as adoption of organisational practices, exports, foreign ownership-variables 8-14 in Table 6.2. Scale effects are captured in interaction with remunerations to personnel.

\subsection{Research strategy}

\footnotetext{
${ }^{3}$ To further identify factors driving pharmaceutical R\&D in Mexico exploratory factor analysis was conducted including rd_process_improvement, rd_design_meq, rd_drug_improvement and rd_drug_design; from the analysis one single factor was retained. Within such factor, rd_drug_improvement had the largest factor loading, albeit somewhat close to those for rd_drug_improvement and rd_drug_design. For the sake of simplicity of the analysis this chapter reports only results from the correlation analysis.
} 
This chapter explores the likelihood that a pharmaceutical firm carries out different types of in-house R\&D. A suitable approach for studying this type of binary decision variables is a probability model, such as binary probit regression (Greene 2003). The dependent variable can be expressed as:

$y=\left\{\begin{array}{l}1, \text { if } y^{*}>0 \\ 0, \text { otherwise }\end{array}\right.$

The function linking the vector of dependent variables $Y$ and the explanatory variables $x$ 's can be represented as:

$$
E(Y)=\mu=\sum_{k=1}^{K} \beta_{k} x_{k}+\varepsilon
$$

Given the binary nature of $Y$, one can express the linkage function between $Y$ and $\mathrm{X}$ in a more general fashion as $\eta$. Hence, a probit model is a generalised linear model with a probit link:

$$
\eta=\Phi^{-1} \mu
$$

Where $\Phi$ is the standard normal cumulative density function (CDF) in the form of a standardized variable or Z score, expressed in probability terms (Liao 1994). Probit analysis assumes a binomial distribution of the dependent variable and a normal distribution in the errors term, $\varepsilon$.

The analysis started with the construction of a basic model that explores the extent to which the variables in the analysis explain the likelihood that a firm performs in-house R\&D. ${ }^{4}$ Then, the definition of the dependent variable was iteratively changed. ${ }^{5}$ As for variables in the right hand side of the equation, normalizing the log of remunerations with respect to firm's size (rem_size) corrected problems of high and positive correlations between In_rem_avg and the variables on fdi and exports, respectively (table 6.2). It also captured some scale

\footnotetext{
${ }^{4}$ Several checks were performed to ensure accuracy and robustness of results. Models were included, first where each dependent variable was regressed on the explanatory human resource management variables only; then compared to full specification models; and second, full specification models. Equations were also run including only those explanatory and control variables that revealed some statistical significance, at 5 per cent or less, in the full specification model. The results from such models were consistent with those reported here.

${ }^{5}$ Note a minor difference in the definition of training used in models with rd_design_meq as the dependent variable. The majority of pharmaceutical firms reported to have provided training during 2004. Consequently, models with train04 had problems to converge, the variable predicted perfectly the probability that a firm performs such type of R\&D (Long and Freese 2006). The choice was for the alternative, internal_external_tr, which denotes interactions between internal and external training. As section 4 reports, individual effects of internal and external training, respectively, were tested on the remaining definitions of $R \& D$.
} 
effects associated with firm size (Cockburn 2004). A similar situation occurred in the case of the variable on adoption of JIT techniques. The use of the variable modern_practice eliminated high correlation with the indicator on worker's empowerment. Results from models including only the TQM were similar to those presented here.

\section{Empirical results}

\subsection{Learning behaviour of pharmaceutical firms in Mexico}

Table 6.3 summarizes the learning behaviour of pharmaceutical firms in Mexico. It shows that 74.1 per cent of firms performed R\&D in 2004, with some 63.4 per cent and 70.5 per cent focusing on process and product innovations, respectively. Of those conducting R\&D for process innovation, 25.3 per cent did so to improve or design machinery for their own use, while some 63.4 per cent to improve productive processes. As for demand-enhancing innovations, some 61.1 per cent of firms pursued new products, and some 66.1 per cent focused on improvements in existing drugs. In this context, indicators such as sales and employment show that, on average, R\&D performers slightly outperform those reporting no R\&D. For instance, average employment, total sales and sales per employee are, respectively, 1.4, 1.6 and 1.1 times larger in firms with active learning strategies.

Indicators on capital origin and export orientation tend to favour non-R\&D performers. Some 70 per cent of firms carried out either knowledge exploitation or exploration. The corresponding figures on employment, sales and so on, are very close among each group, yet with a slight advantage for active learners. Some 60 per cent of firms in the sample participated in export markets. However, since the average share of exports in total sales of the industry is rather modest, one can argue that pharmaceutical firms are oriented to serving the local market. In line with the cGMPs requirement, ENESTYC reports an extensive adoption of modern manufacturing practices in the pharmaceutical industry.

Table 6.4 presents the independent and control variables used in this chapter by type of learning strategy selected by the firms in our sample. The table shows the great propensity of pharmaceutical firms in Mexico to provide training to employees. Note also that training is more frequently provided by firms with R\&D for knowledge exploitation, and by those pursuing drug improvements. Firms make use of combinations of both internal and external sources of training, whereby documenting the search for synergistic effects between the two types of training. The pharmaceutical industry in Mexico restrains worker's participation in decision making about working conditions. Even in those occasions where workers have a voice, the practice is reported as having little importance for the company. Interviews with several Mexican manufacturers revealed that R\&D staff frequently subordinates to the needs of manufacturing and quality control units.

\subsection{Human resource management and learning through in-house R\&D}




\subsubsection{Knowledge exploitation or exploration}

This chapter contends that knowledge exploration, in the sense of research, experimentation and technological capability-building; associates with stronger exigencies on human resource management practices. This section explores this hypothesis. Table 6.5 presents estimates from the econometric analysis. Model (1) corresponds to in-house R\&D, irrespective of the goal pursued by the firm. Model (2) captures R\&D for knowledge exploitation (rd_exploit) and finally, model (3) identifies R\&D for knowledge exploration (rd_explore). Each model in the table splits in four sections: models with human resource management variables only, and then those with the full set of explanatory and control variables. In order to ensure that correlation between fdi and export_dummy does not cause major problems, a third column includes models with an interaction term between such variables (fdi_expt). ${ }^{6}$ Finally, the computation of marginal effects for the model with the full set of explanatory variables is presented. The Wald tests for the value of $X^{2}$, which is different from zero, confirm that the models are statistically significant at standard confidence levels. The count $\mathrm{R}^{2}$ for each of the models shows that, in general, their individual predictive power is acceptable (Liao 1994). Similarly, the values of the Cragg-Uhler $\mathrm{R}^{2}$ suggest that the models adequately explain the probability that a firm does R\&D.

Individual estimates reveal that training has the strongest and most significant effect on learning through $R \& D$. This is indicated in models with human resource management variables only. In terms of the specific dependent variable, the effect looks stronger for knowledge exploitation than for knowledge exploration. Remunerations in turn, show positive impact on rd_explore but the effect seems not to be robust. Export participation and foreign ownership in turn, report relevant influences on R\&D performance. The effects, however, run in opposite directions. Whereas export participation induces learning, foreign ownership inhibits it. In fact, the influence of capital ownership is stronger than that of exports. This is evident by looking at models with fdi_expt as explanatory variable. Scale effects are also captured by the variable on remunerations, as it is normalized by the firm's size. Adoption of modern_practice and worker's empowerment do not reveal any specific effect on learning. Overall, the estimates suggest a passive learning behaviour of the pharmaceutical industry in Mexico. The constant term is consistently negative and statistically significant. If all right-hand side coefficients were set at zero, the probability that a firm carries out R\&D is rather low.

A complementary way to look at results from probit models is to compute the marginal effects derived from modifications in the value of a given explanatory

\footnotetext{
${ }^{6}$ We evaluated performance of models in Tables 6.5 and 6.6, respectively, with and without the interaction term fdi_export without leaving out any of the control variables. Unfortunately estimations including all three variables, fdi, export_dummy and fdi_expt, were problematic as they tended to predict perfectly the learnimg behavior of firms. Based on Long and Freese (2006) we corrected by droping the observations creating problems. But then considering the relatively small size of the working sample, colinearity problems increased. In STATA the practical solution to colinearity is to automatically drop the redundant variable from the equation, in this case fdi_expt. The chapter report models with and withouth fdi_expt.
} 
variable (Christofides et.al, 1997; Christofides et.al, 2000). A fourth column for each model in table 6.5 presents the marginal and discrete probability changes for the variables in the full specification models. Estimates confirm that the provision of training has the largest positive and statistically significant impacts on learning. If all remaining variables in the equation are left constant, in this case at the mean value, the shift from non- to provision of training increases, by some 48 per cent, the probability that a firm carries out in-house R\&D. Once the notions of knowledge exploitation and exploration are taken into account, stronger effects of training are associated with knowledge exploitation than with R\&D for knowledge exploration. Contrary to our research hypothesis, so far the findings in table 6.5 suggest that the influence of management practices on the likelihood that a pharmaceutical firm does R\&D is rather limited. Moreover, it is difficult to perceive how distinct types of learning activities associate with different management practices adopted by a firm. Based on the discussion in section 2.1, in what follows a further distinction is made on the expected innovation outcomes from the R\&D carried out by the firm.

\subsubsection{Learning through different kinds of R\&D}

Table 6.6 presents the results from models that incorporate the distinct goals pursued through in-house R\&D. Models (1) and (2) include cost-reducing R\&D, while models (3) and (4) relate to demand-enhancing R\&D. For convenience of the analysis, the table excludes the computation of marginal effects; these are presented in table 6.7. Customary indicators on goodness of fit corroborate the adequacy of the models. As expected, the more detailed definitions of R\&D provide better information on the distinct contribution of human resource management practices on learning. Relevant practices vary both in number and strength of the perceived effect. This supports the idea that firms with dissimilar learning and innovation strategies should gain differently from adoption of even comparable human resource management practices (Laursen and Foss 2003; Laursen and Mahnke 2001).

Estimates for individual practices indicate that the provision of training remains the most significant practice across learning activities; the strongest contribution corresponds to new drug designs. Variables on remunerations and worker's empowerment also gain in statistical significance. Remunerations are important for exploratory R\&D supporting new manufacturing process or new drug designs. Worker's empowerment has positive effects on R\&D for the design or improvement of machinery and equipment. Export_dummy and fdi continue to play relevant roles, albeit with effects running in opposite directions, for rd_design.

Table 6.7 presents the computation of marginal effects for the variables in the basic models of table 6.6. Unlike the analysis in table 6.5 this new exercise is much more detailed. Estimates confirm training as the intervention with the largest positive and statistically significant impact on the likelihood that a firm performs R\&D. In fact, the largest effect of training is on rd_drug_design, 43.7 per cent. By contrast, the lowest influence, some nine percent, is in the case of rd_design_meq. The latter variable is also the one where worker's empowerment has perceptible and positive contributions to learning. Marginal increases in remunerations have 
positive and statistically significant influence on knowledge exploration. This result lends support to the expectation that as firm grow, so does their capacity to carry out $R \& D$, and to pay more attractive remunerations to personnel in such activities.

Interpretation of discrete probability changes should be handled with care, as they are meaningful only for variables spanning over a sufficiently large range of values (Long and Freese 2006). A pertinent case is that of remunerations. Column (1) in table 6.7 reveals that a change in the log of remunerations, equivalent to an increase from minimum to maximum, raises the likelihood that a firm conducts rd_drug_design by some 0.341 . Changes in remunerations are stronger for demandenhancing R\&D than for cost- reducing activities. Similarly, the impact from changes of half a standard deviation in the log of remunerations, column (4), are larger for rd_design than for any other type of process R\&D. Interestingly, except for rd_design_meq, worker's participation in decision-making seems to impact negatively the likelihood of R\&D performance. We come back to this in section 4 .

\subsection{Effects from different types of training}

The analysis so far documents that the provision of training has positive and robust influences on the likelihood that a firm does R\&D. In order to extract some more meaningful conclusions, more disaggregated measures on the actual nature of training were introduced. Chapter 3 identified two complementary forms: internal (on-the-job) and external (off-the-job). The former was expected to support knowledge diffusion and sharing within the organisation, as it would be more closely related to exploitation strategies. By contrast, external training would support the expansion of knowledge bases through interaction with other knowledge producers (Casas 2005). In order to explore this dual nature of training, two additional variables, namely, training_internal and external_training, were brought into the analysis. Table 6.8 contains estimates for models where train04 is replaced by the two new variables. ${ }^{7}$ The Wald tests show that, with the exception of rd_drug_improvement, the remaining models are statistically significant at conventional confidence levels. ${ }^{8}$ Estimates in table 6.8 confirm that the provision of internal training is more closely related to knowledge exploitation. By contrast, the training provided via interactions with external agents impacts more directly on knowledge exploration, particularly rd_drug_design. Note that remunerations and worker's empowerment lose the explanatory power found in tables 6.5 and 6.6. Exposure to competition through participation in export markets stimulates learning, particularly for (new) product innovation.

\footnotetext{
${ }^{7}$ The analysis excluded the variable on rd_design_meq because training_internal tended to predict perfectly the probability that a firm performs this specific activity. In the presence of perfect prediction STATA drops the problematic variables out from the equation (Long and Freese, 2006).

${ }^{8}$ Although not included in table 7.8 , we also ran models where the variables fdi and export_dummy where replaced by the interaction term, fdi_expt. Results from such models corroborate the conclusions presented here.
} 


\section{Discussion and concluding remarks}

Chapter 1 in this thesis established that a consistent theory on the relationship between human resource management practices and innovation performance at firm level is at an early stage, since the linkages between those variables are yet to be comprehended. This chapter investigated the influence of human resource management practices on the likelihood that a firm performs in-house R\&D. In the context of the pharmaceutical industry in Mexico, R\&D was broadly interpreted as conscious learning activity promoting and supporting technology capability building processes in latecomer firms. The literature recognizes this as absorptive capacity building.

Based on the notions of knowledge exploitation and knowledge exploration, respectively, the analysis considered distinct definitions of in-house $R \& D$, each of them implying distinct knowledge requirements that firms need to fulfil in order to innovate. Firms carry out in-house R\&D with at least two clear goals in mind: they can exploit their existing knowledge base, or enter more complex explorations for knowledge residing outside it. Different knowledge requirements, in turn, relate to specific R\&D outcomes along the different stages of the innovation process characteristic of an industry, even a country. In this case, our discussion in chapter 5 indicated that Mexican pharmaceuticals concentrate in the segment of generic drugs. R\&D therefore needs to be interpreted in terms of incremental innovations on existing drugs, pharmaceutical products more broadly defined.

The empirical analysis revealed some positive linkages between human resource management practices and learning at firm level. Differences in the nature of R\&D lead to distinct knowledge requirements and consequently, demands and roles for the human resources shaping an organisation. The number of relevant practices and their corresponding influence diverged contingent on both the novelty of the knowledge required by the firm, and the expected outcomes from $R \& D$. In line with the literature on human resource management and new product development, R\&D for new drug designs was positively associated with training and remunerations (Christensen and Lundvall 2004). Those studies stress that in the context of new product development, human resource management approaches condition creativity, risk taking and exploration. Such approaches assist in channelling and enhancing knowledge and skills of the personnel involved.

In addition to the above, this chapter disclosed some positive impacts of human resource management practices on $R \& D$ for new process innovation, technical change more broadly defined (Greenan 2003). The provision of training, worker's remuneration and incorporation of workers into decision making supported R\&D for the design or improvement of machinery for the firm's own use. To the best of our knowledge, this is one of the first studies documenting this issue in the context of developing countries. The structure of our data prevented further investigation into this finding; nevertheless, it is relevant considering that process innovations enjoy a significant share of innovations in developing countries. Even in contexts where most innovation activities are perceived as incremental, management strategies can contribute to learning and capability building. 
As for the specific personnel management interventions, and in light of the hypotheses presented in chapter 3 , some relevant findings are as follows: The provision of training systematically exerts positive effects on the likelihood that a firm pursues R\&D; hence hypothesis $\mathrm{H} 1$ is confirmed. This result was robust to changes in either the construction of the variable on training, or on the model specification. The finding supports Domínguez and Brown's (1998) and Samstad and Pipkin's (2005) views on that training and general qualifications of the labour force dictate the type of management practices that are needed and that can be implemented in countries such as Mexico. Raising skill levels facilitates adoption of advanced management systems by Mexican firms. The empirical results equally support the pertinence of promoting interactions between firms and other external agents, at least for the provision of R\&D-relevant training. External provision of training is a relevant mean for firms to acquire new knowledge and expand existing knowledge bases. Further research should shed light on the nature of the knowledge flows being actually involved. However, the interviews conducted among Mexican firms suggest that interactions are broad; they include learning about new excipients and formulations, to methodologies for the synthesis of chemical ingredients (Interviews with firms 06). For some firms however, external training increasingly provides understanding of advanced research methodologies and applications, particularly in areas such as biotechnology (Interviews with firms 03 and 10). Overall, hypothesis $\mathrm{H} 2$ was confirmed.

The literature review in the first part of chapter 3 highlighted that adequate compensation and reward for performance are core ingredients of strategies promoting enhanced performance. Estimates in this chapter revealed that raising remunerations increases the probabilities that a firm does R\&D, particularly for knowledge exploration; however, the effect was not robust. Consequently, whereas hypothesis H3 is only partially supported, hypothesis $\mathrm{H} 4$ seems more plausible. Remunerations underpin learning but only under certain conditions and for specific types of R\&D. However difficult to corroborate based on data used here, a possible explanation results from the frequent limits imposed on pecuniary remunerations, more specifically wages, in countries such as Mexico. Interviewees at both Mexican and multinational pharmaceutical firms expressed that beyond certain threshold, subsequent wage increases for an individual can alter the overall compensation structure of the firm. The local environment contributes to wage stickiness; the pharmaceutical industry in Mexico is already one of the industries with the best wages and overall compensation.

Factors such as enhanced training and/or promotion opportunities become equally or even more relevant as reward mechanisms. This is in either foreign affiliates or Mexican pharmaceutical firms. Some firms accept to sponsor specialised postgraduate training, for up to a year in private universities, for key personnel (Interviews with firms 08 and 11). In other cases, remunerations act more as mechanisms determining labour mobility within the pharmaceutical industry; thus promoting a continuous transfer of research capabilities, however limited, within the industry (Interviews with firms 05, 10 and 13). In the aggregate, the positive effects on the firm attracting the employee cancel out by the negative impact on 
the one loosing him/her.

Somewhat inconclusive results were drawn in the case of worker's empowerment. The practice was positive only in the case of exploration-related $R \& D$ underpinning adoption of new drug manufacturing processes. This is at odds with previous literature where delegation of decision-making capacity is key ingredient for new product development; empowering people fosters creativity and discovery (Mumford 2000). A possible explanation relates to the traditional perception that paternalistic work environments, rigid and hierarchical organisational structures, such as those generally found in Mexico and other similar countries, hinder good performance.

Nevertheless, as stressed in chapter 4, the nature of drug manufacturing processes introduces some limits to a worker's capacity to influence the way R\&D is pursued. Concerns over product quality and safety lead to close scrutiny and approval, by sanitary authorities, of practically every step of the drug manufacturing process. Sanitary regulations limit the capacity to change both existing drugs and the corresponding manufacturing processes. Any alteration in either of them can lead to additional reviews and need to obtain approval by regulatory authorities. FDA (2004a, b) recognizes that this can be cumbersome for the firm; and a major barrier for process innovation in the pharmaceutical industry. In the context of countries specialised in the manufacturing of generic drugs, development of such products is restricted by the need to comply with specific parameters and qualities set by the drug innovator. If firms are required only to reproduce the knowledge behind such products, it makes little sense to empower workers and allow them to play around with the technology.

Some final comments in relation to the control variables are noteworthy. The findings here contradict the usual perception that foreign firms are more technologically dynamic than domestic firms. After all, the literature documents the frantic behaviour of global pharmaceutical firms regarding technology acquisition and new drug development. However, the choice of the relevant performance indicators is important. In terms of $R \& D$, a careful reflection points to the position that developing countries, such as Mexico, occupy within overall business and innovation strategies of multinationals. Affiliates maintain a low profile; rather they assist in the exploitation of knowledge generated at the parent location or elsewhere in the developed world (von Zedtwitz and Gassmann 2002). The new knowledge demanding R\&D activities are seldom carried out in developing countries. Affiliates in developing countries maintain a low, indeed modest, profile when it comes to R\&D performance.

By contrast, exposure to external competition and larger market opportunities was found to increase the likelihood that domestic firms pursue R\&D. The strongest effect was associated with new drug designs. In line with Kale and Little's (2007)'s findings in the case of India, the managing director of an affiliate of Indian origin in Mexico stressed the significant boost that Indian firms have received from their decisive export orientation. He argued that "Success requires strong commitment of financial and human resources, particularly in research. The goal is to develop a portfolio of products to be launched in export markets over a significant time 
horizon". In the case of Mexican pharmaceutical firms, strong reliance on the local pharmaceutical market inhibits incentives to innovate; human resource management strategies aim largely to increase productivity and efficiency. In other words, adoption of modern organisational practices simply contributes to the making of what Cimoli (2002) identifies as a "global modern manufacturing centre".

The analysis presented in this chapter is only a partial one. As documented in Chapters 4 and 5, respectively, innovation in the pharmaceutical industry is highly globalised; firms cannot afford to rely, exclusively, on internal technological efforts. Rather, firms increasingly interact with and attract knowledge from external sources. These observations raise questions about the extent to which the results in this chapter remain once firms are allowed to participate in external markets for knowledge. Chapter 7 and 8 address this question. The analysis is as follows: first chapter 7 looks at the extreme case in which firms transfer responsibility for technology development to external agents; firms assume a passive stance vis-à-vis learning and innovation. Then, chapter 8 introduces further reality by bringing together internal and external learning strategies adopted by pharmaceutical firms in Mexico. Against these alternative backgrounds we examine the contribution of human resource management variables. 


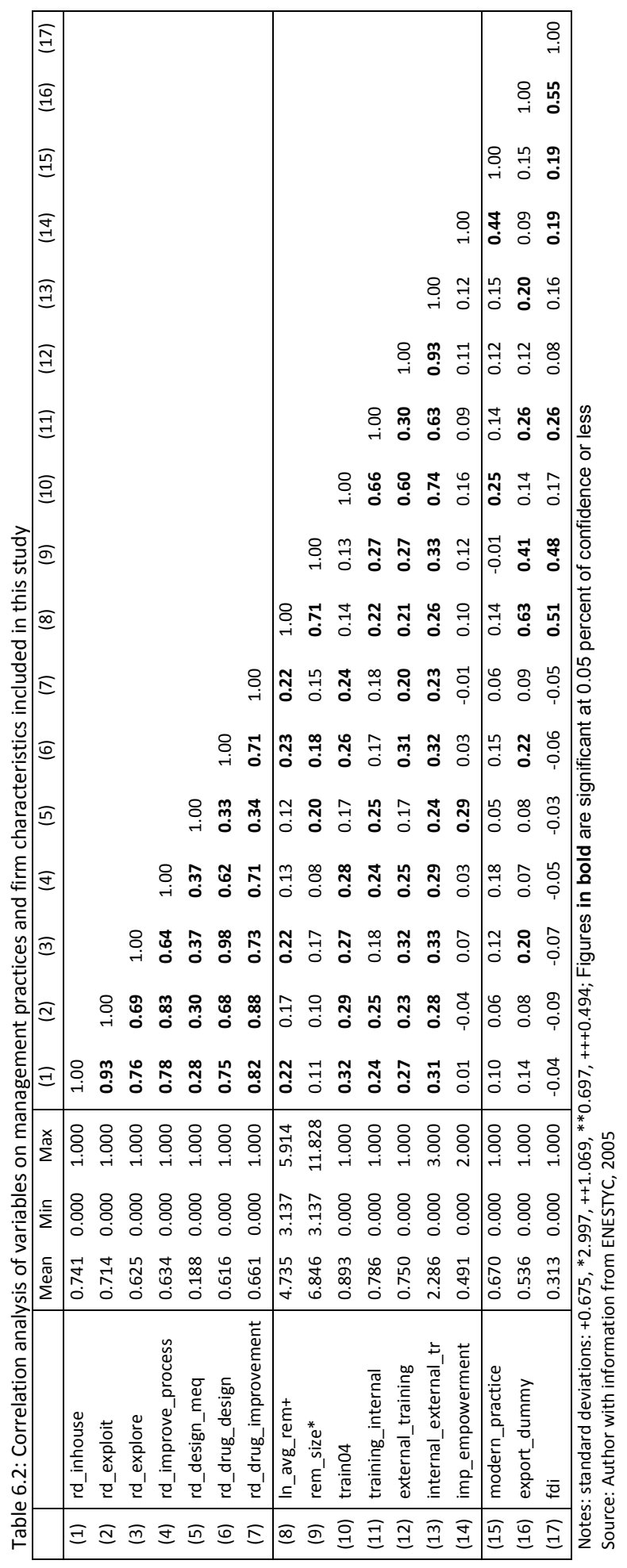


Table 6.3: Summary statistics for the Pharmaceutical industry in Mexico, 2004

\begin{tabular}{|c|c|c|c|c|c|c|c|c|c|}
\hline \multirow{3}{*}{$\begin{array}{l}\text { R\&D in- } \\
\text { house }\end{array}$} & \multicolumn{3}{|c|}{ Mean } & \multicolumn{2}{|c|}{ Std Dev } & \multicolumn{2}{|c|}{ Min } & \multicolumn{2}{|c|}{ Max } \\
\hline & $R \& D^{3}$ & No $R \& D^{4}$ & & & & & & & \\
\hline & (I) & (II) & (I)/(II) & (I) & (II) & (I) & (II) & (I) & (II) \\
\hline Employment & 475.7 & 331.2 & 1.4 & 555.2 & 259.1 & 1.1 & 63 & 3391.5 & 1158.4 \\
\hline Total sales $^{1}$ & 694.1 & 433.0 & 1.6 & 1270.9 & 694.9 & 2.4 & 12.1 & 6958.0 & 2297.0 \\
\hline $\begin{array}{l}\text { Domestic } \\
\text { sales }\end{array}$ & 609 & 394.5 & 1.5 & 1055.3 & 634.7 & 2.4 & 0 & 6334.5 & 2069.8 \\
\hline Export share & .07 & .08 & 0.9 & .13 & .20 & 0 & 0 & .69 & 1 \\
\hline Share of FDI & .30 & .34 & 0.9 & .46 & .48 & 0 & 0 & 1 & 1 \\
\hline $\mathrm{Age}^{2}$ & 33.2 & 27.5 & 1.2 & 19.4 & 16.6 & 1 & 0 & 74 & 70 \\
\hline rd_improve_process & $R \& D^{5}$ & No $R \& D^{6}$ & $(\mathrm{I}) /(\mathrm{II})$ & (I) & (II) & (I) & (II) & (I) & (II) \\
\hline Employment & 492.5 & 344.3 & 1.4 & 589.2 & 261.3 & 1.1 & 63.0 & 3391.5 & 1158.4 \\
\hline Total sales $^{1}$ & 7414.9 & 427.5 & 1.7 & 1354. & 641.4 & 2.4 & 12.1 & 6958.0 & 2297.0 \\
\hline Domestic sales & 656.7 & 375.3 & 1.8 & 1120.7 & 583.4 & 2.4 & 0.0 & 6334.5 & 2069.8 \\
\hline Export share & 0.1 & 0.1 & 0.6 & 0.1 & 0.2 & 0.0 & 0.0 & 0.6 & 1.0 \\
\hline Share of FDI & 0.3 & 0.3 & 0.9 & 0.5 & 0.5 & 0.0 & 0.0 & 1.0 & 1.0 \\
\hline $\mathrm{Age}^{2}$ & 33.2 & 29.2 & 1.1 & 20.6 & 15.1 & 1.0 & 0.0 & 74.0 & 70.0 \\
\hline rd_design_meq & $R \& D^{7}$ & No $R \& D^{8}$ & (I)/(II) & (I) & (II) & (I) & (II) & (I) & (II) \\
\hline Employment & 655.0 & 388.3 & 1.7 & 804.2 & 386.7 & 2.2 & 1.1 & 3391.5 & 2852.9 \\
\hline Total sales $^{1}$ & 1140.1 & 508.0 & 2.2 & 1808.1 & 914.3 & 31.9 & 2.4 & 695.8 & 6772.2 \\
\hline Domestic sales & 919.5 & 469.3 & 2.0 & 1307.2 & 856.1 & 31.9 & 0.0 & 4359.9 & 6334.6 \\
\hline Export share & 0.1 & 0.1 & 1.4 & 0.2 & 0.1 & 0.0 & 0.0 & 0.6 & 1.0 \\
\hline Share of FDI & 0.3 & 0.3 & 0.9 & 0.5 & 0.5 & 0.0 & 0.0 & 1.0 & 1.0 \\
\hline $\mathrm{Age}^{2}$ & 39.2 & 30.0 & 1.3 & 17.7 & 18.7 & 16.0 & 0.0 & 74.0 & 72.0 \\
\hline $\begin{array}{l}\text { rd_drug_improveme } \\
\text { nt }\end{array}$ & $R \& D^{9}$ & No $R \& D^{10}$ & $(\mathrm{I}) /(\mathrm{II})$ & (I) & (II) & (I) & (II) & (I) & (II) \\
\hline Employment & 496.6 & 324.7 & 1.5 & 577.4 & 261.5 & 1.1 & 63.0 & 3391.5 & 1158.4 \\
\hline Total sales $^{1}$ & 738.0 & 409.4 & 1.8 & 1328.8 & 653.9 & 2.4 & 7.8 & 6958.0 & 2297.0 \\
\hline Domestic sales & 654.1 & 358.1 & 1.8 & 1101.8 & 587.8 & 2.4 & 0.0 & 6334.5 & 2069.8 \\
\hline Export share & 0.1 & 0.1 & 0.6 & 0.1 & 0.2 & 0.0 & 0.0 & 1.0 & 1.0 \\
\hline Share of FDI & 0.3 & 0.3 & 0.9 & 0.5 & 0.5 & 0.0 & 0.0 & 1.0 & 1.0 \\
\hline $\mathrm{Age}^{2}$ & 34.2 & 26.8 & 1.3 & 19.8 & 15.9 & 1.0 & 0.0 & 74.0 & 70.0 \\
\hline rd_drug_design & $R \& D^{11}$ & No $R \& D^{12}$ & (I)/(II) & (I) & (II) & (I) & (II) & (I) & (II) \\
\hline Employment & 526.1 & 297.4 & 1.8 & 592.1 & 238.0 & 2.2 & 1.1 & 3391.5 & 1158.4 \\
\hline Total sales $^{1}$ & 765.7 & 403.3 & 1.9 & 136.8 & 631.2 & 2.4 & 7.8 & 695.8 & 2297.0 \\
\hline Domestic sales & 676.5 & 356.6 & 1.9 & 1134.4 & 564.4 & 2.4 & 0.0 & 6334.5 & 2069.8 \\
\hline Export share & 0.1 & 0.1 & 0.7 & 0.1 & 0.2 & 0.0 & 0.0 & 0.7 & 1.0 \\
\hline Share of FDI & 0.3 & 0.3 & 0.8 & 0.5 & 0.5 & 0.0 & 0.0 & 1.0 & 1.0 \\
\hline $\mathrm{Age}^{2}$ & 34.6 & 27.1 & 1.3 & 19.9 & 16.2 & 1.0 & 0.0 & 74.0 & 70.0 \\
\hline R\&D_exploitation & $R \& D^{13}$ & No $R \& D^{14}$ & $(\mathrm{I}) /(\mathrm{II})$ & (I) & (II) & (I) & (II) & (I) & (II) \\
\hline Employment & 475.9 & 344.3 & 1.4 & 560.7 & 276.6 & 1.12 & $\begin{array}{c}63 \\
12 .\end{array}$ & 3391.5 & 1158.4 \\
\hline Total sales1 & 708.4 & 421.9 & 1.7 & 1291.8 & 665.5 & 2.4 & 1 & 695.8 & 2297.0 \\
\hline Domestic sales & 626.2 & 372. & 1.7 & 107.1 & 607.8 & 2.4 & 0 & 6334.5 & 2069.8 \\
\hline Export share & .1 & .1 & 1 & .1 & .2 & 0 & 0 & .6 & 1 \\
\hline Share of FDI & .3 & .4 & 0.7 & .4 & .5 & 0 & 0 & 1 & 1 \\
\hline $\mathrm{Age}^{2}$ & 33.3 & 27.7 & 1.2 & 19.7 & 16.1 & 1 & 0 & 74 & 70 \\
\hline R\&D-exploration & $R \& D^{15}$ & No $R \& D^{16}$ & $(\mathrm{I}) /(\mathrm{II})$ & (I) & (II) & (I) & (II) & (I) & (II) \\
\hline Employment & 488.1 & 319.0 & 1.5 & 565.6 & 249.1 & 1.12 & 63 & 3391.5 & 1158.4 \\
\hline Total sales1 & 705.5 & 437.6 & 1.6 & 1292.8 & 693.5 & 2.4 & 7.7 & 6958.0 & 2297.0 \\
\hline Domestic sales & 620.6 & 393.4 & 1.6 & 1073.9 & 623.6 & 2.4 & 0 & 6334.5 & 2069.8 \\
\hline Export share & .1 & .1 & 1 & .1 & .2 & 0 & 0 & .7 & 1 \\
\hline Share of FDI & .3 & .3 & 1 & .5 & .5 & 0 & 0 & 1 & 1 \\
\hline $\mathrm{Age}^{2}$ & 33.6 & 27.2 & 1.2 & 19.4 & 16.7 & 1 & 0 & 74 & 70 \\
\hline
\end{tabular}

Firms in sample: $112 ; 1$. Million Mexican pesos; 2 . difference between the year in which a firm started operations in current business and the year of the survey, 2004; Number of firms: 3. (83); 4. (29); 5. (71); 6. (41); 7. (21); 8. (91); 9. (74); 10. (38); 11. (69); 12. (43); 13. (80); 14. (32); 15. (79); 16. (33). Source: Author with information from ENESTYC 2005, INEGI 
Table 6.4: Frequency analysis of the explanatory and control variables included in the analysis

\begin{tabular}{|c|c|c|c|c|c|c|c|c|c|c|c|c|c|c|}
\hline \multirow[b]{2}{*}{ train04 } & \multicolumn{2}{|c|}{ rd_inhouse } & \multicolumn{2}{|c|}{$\begin{array}{c}\text { rd_design } \\
\text { meq }\end{array}$} & \multicolumn{2}{|c|}{$\begin{array}{c}\text { rd_improve } \\
\text { _process }\end{array}$} & \multicolumn{2}{|c|}{$\begin{array}{l}\text { rd_drug } \\
\text { _design }\end{array}$} & \multicolumn{2}{|c|}{$\begin{array}{c}\text { rd_drug_impro } \\
\text { vement }\end{array}$} & \multicolumn{2}{|c|}{$\begin{array}{c}\text { rd_exploi } \\
t\end{array}$} & \multicolumn{2}{|c|}{$\begin{array}{c}\text { rd_explor } \\
\text { e }\end{array}$} \\
\hline & no & yes & no & yes & no & yes & & & no & yes & no & & no & \\
\hline No & 8 & 4 & 12 & 0 & 9 & 3 & 9 & 3 & 8 & 4 & 8 & 4 & 9 & 3 \\
\hline $\begin{array}{l}\text { Yes } \\
\text { inter- } \\
\text { nal_external_tr }\end{array}$ & 21 & 79 & 79 & 21 & 32 & 68 & 34 & 66 & 30 & 70 & 24 & 76 & 33 & 67 \\
\hline No & 8 & 4 & 12 & 0 & 9 & 3 & 9 & 3 & 8 & 4 & 8 & 4 & 9 & 3 \\
\hline Internal & 5 & 11 & 14 & 2 & 7 & 9 & 9 & 7 & 6 & 10 & 5 & 11 & 9 & 7 \\
\hline External & 3 & 9 & 12 & 0 & 5 & 7 & 4 & 8 & 4 & 8 & 4 & 8 & 4 & 8 \\
\hline $\begin{array}{l}\text { Both } \\
\text { imp_empowerm } \\
\text { ent }\end{array}$ & 13 & 59 & 53 & 19 & 20 & 52 & 21 & 51 & 20 & 52 & 15 & 57 & 20 & 52 \\
\hline Not implemented & 20 & 50 & 63 & 7 & 29 & 41 & 30 & 40 & 25 & 45 & 21 & 49 & 30 & 40 \\
\hline Very important & 5 & 8 & 8 & 5 & 7 & 6 & 7 & 6 & 6 & 7 & 6 & 7 & 6 & 7 \\
\hline Not important & 4 & 25 & 20 & 9 & 5 & 24 & 6 & 23 & 7 & 22 & 5 & 24 & 6 & 23 \\
\hline In_avg_rem & 4.5 & 4.8 & 4.7 & 4.9 & 4.6 & 4.8 & 4.5 & 4.9 & 4.5 & 4.8 & 4.6 & 4.8 & 4.5 & 4.8 \\
\hline $\begin{array}{l}\text { rem_size } \\
\text { modern_practice }\end{array}$ & 6.31 & 7.03 & 6.6 & 8.1 & 6.5 & 7.0 & 6.1 & 7.3 & 6.2 & 7.2 & 6.4 & 7.0 & 6.2 & 7.2 \\
\hline No & 12 & 25 & 31 & 6 & 18 & 19 & 18 & 19 & 14 & 23 & 12 & 25 & 17 & 20 \\
\hline $\begin{array}{l}\text { Yes } \\
\text { export_dummy }\end{array}$ & 17 & 58 & 60 & 15 & 23 & 52 & 25 & 50 & 24 & 51 & 20 & 55 & 25 & 50 \\
\hline No & 17 & 35 & 44 & 8 & 21 & 31 & 26 & 26 & 20 & 32 & 17 & 35 & 25 & 27 \\
\hline $\begin{array}{l}\text { Yes } \\
\text { fdi }\end{array}$ & 12 & 48 & 47 & 13 & 20 & 40 & 17 & 43 & 18 & 42 & 15 & 45 & 17 & 43 \\
\hline No & 19 & 58 & 62 & 15 & 27 & 50 & 28 & 49 & 25 & 52 & 20 & 57 & 27 & 50 \\
\hline Yes & 10 & 25 & 29 & 6 & 14 & 21 & 15 & 20 & 13 & 22 & 12 & 23 & 15 & 20 \\
\hline Total & 29 & 83 & 91 & 21 & 41 & 71 & 43 & 69 & 38 & 74 & 32 & 80 & 42 & 70 \\
\hline
\end{tabular}

Source: Author with information from ENESTYC, 2005; INEGI 


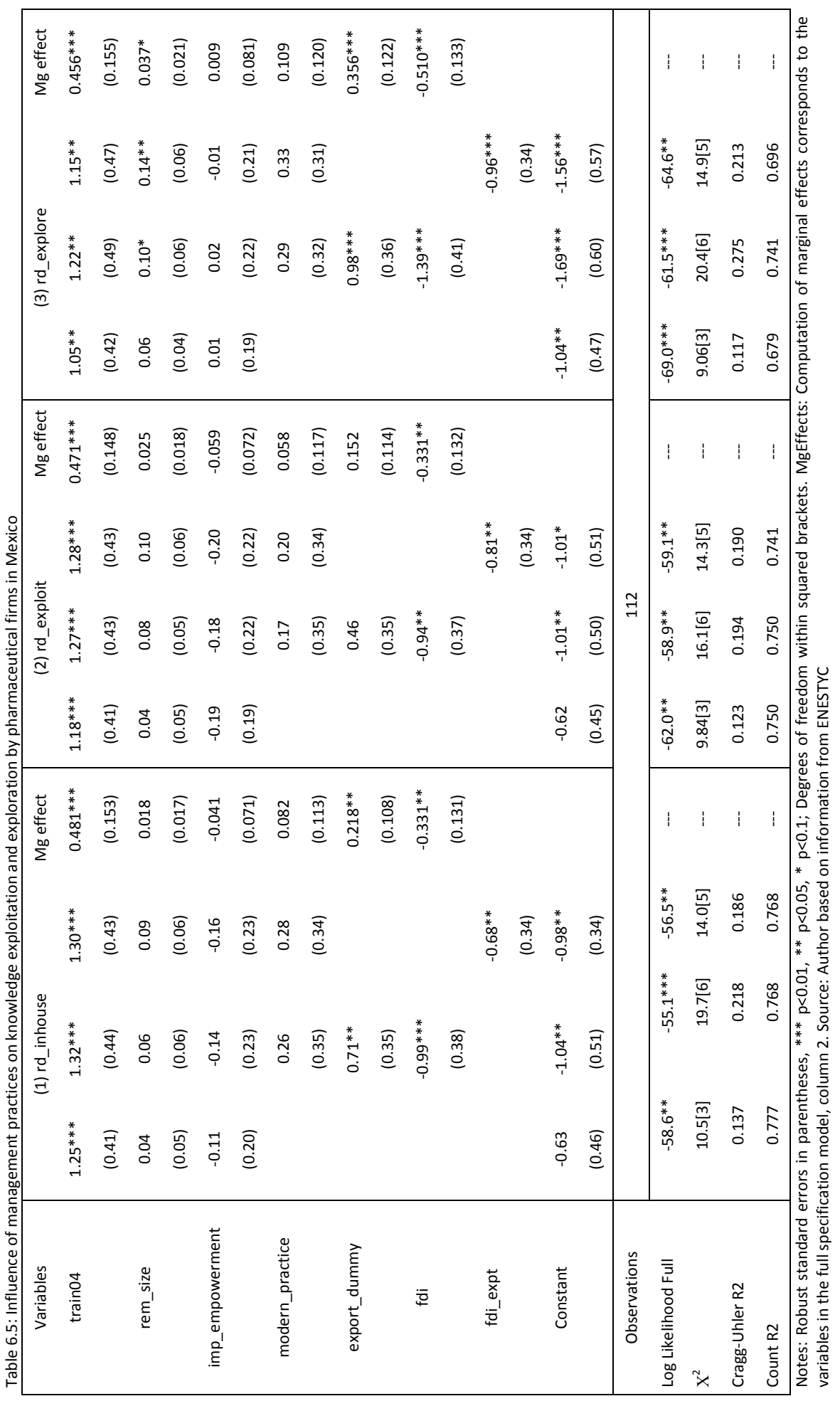




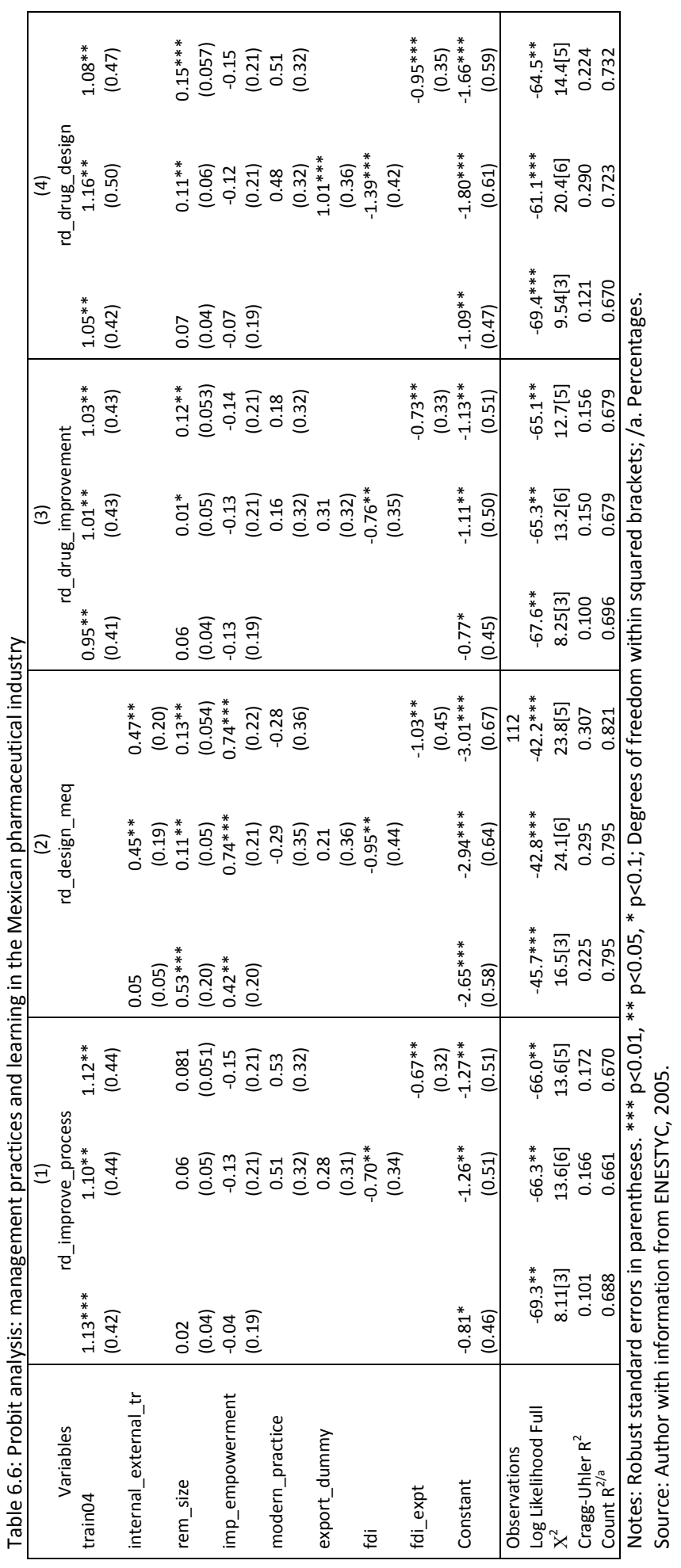


Table 6.7: Changes in probabilities and marginal effects for models in Table 6.6

\begin{tabular}{|c|c|c|c|c|c|c|}
\hline & (1) $\min ->\max$ & (2) $0->1$ & (3) $-+1 / 2$ & (4) $-+s d / 2$ & (5) MargEfct ${ }^{1}$ & (6) MargEfct ${ }^{2, a}$ \\
\hline rd_impr_proc & & & & & & 0.642 \\
\hline train04 & 0.418 & 0.418 & 0.394 & 0.127 & 0.412 & $0.418(0.146)^{* * *}$ \\
\hline rem_size & 0.199 & 0.025 & 0.024 & 0.070 & 0.024 & $0.024(0.019)$ \\
\hline imp_empowerment & -0.101 & -0.050 & -0.050 & -0.035 & -0.050 & $-0.050(0.080)$ \\
\hline modern_practice & 0.192 & 0.192 & 0.187 & 0.089 & 0.189 & $0.192(0.123)$ \\
\hline export_dummy & 0.103 & 0.103 & 0.103 & 0.052 & 0.103 & $0.103(0.117)$ \\
\hline $\mathrm{fdi}$ & -0.265 & -0.265 & -0.255 & -0.120 & -0.260 & $-0.265(0.128)^{* *}$ \\
\hline rd_design_meq & & & & & & 0.124 \\
\hline Internal_external_tr & 0.188 & 0.027 & 0.093 & 0.099 & 0.092 & $0.092(0.035)^{* * *}$ \\
\hline rem_size & 0.218 & 0.008 & 0.023 & 0.069 & 0.023 & $0.023(0.011)^{* *}$ \\
\hline imp_empowerment & 0.420 & 0.154 & 0.152 & 0.106 & 0.151 & $0.151(0.050)^{* * *}$ \\
\hline modern_practice & -0.062 & -0.062 & -0.059 & -0.028 & -0.059 & $-0.062(0.081)$ \\
\hline export_dummy & 0.042 & 0.042 & 0.042 & 0.021 & 0.042 & $0.0420 .071)$ \\
\hline $\mathrm{fdi}$ & -0.160 & -0.160 & -0.197 & -0.091 & -0.195 & $-0.1600 .062)^{* *}$ \\
\hline rd_drug_imp & & & & & & 0.672 \\
\hline train04 & 0.387 & 0.387 & 0.354 & 0.113 & 0.366 & $0.387(0.152)^{* *}$ \\
\hline rem_size & 0.295 & 0.039 & 0.036 & 0.107 & 0.036 & $0.036(0.019)^{*}$ \\
\hline imp_empowerment & -0.093 & -0.045 & -0.045 & -0.032 & -0.045 & $-0.045(0.076)$ \\
\hline modern_practice & 0.057 & 0.057 & 0.057 & 0.027 & 0.057 & $0.057(0.119)$ \\
\hline export_dummy & 0.112 & 0.112 & 0.111 & 0.056 & 0.111 & $0.111(0.117)$ \\
\hline $\mathrm{fdi}$ & -0.283 & -0.283 & -0.269 & -0.127 & -0.274 & $-0.283(0.132)^{* *}$ \\
\hline rd_design & & & & & & 0.642 \\
\hline train04 & 0.437 & 0.437 & 0.413 & 0.134 & 0.433 & $0.437(0.161)^{* * *}$ \\
\hline rem_size & 0.341 & 0.042 & 0.042 & 0.124 & 0.042 & $0.042(0.021)^{* *}$ \\
\hline imp_empowerment & -0.092 & -0.045 & -0.045 & -0.032 & -0.045 & $-0.045(0.079)$ \\
\hline modern_practice & 0.181 & 0.181 & 0.176 & 0.084 & 0.177 & $0.180(0.121)$ \\
\hline export_dummy & 0.368 & 0.368 & 0.364 & 0.187 & 0.377 & $0.368(0.123)^{* * *}$ \\
\hline fdi & -0.510 & -0.510 & -0.484 & -0.238 & -0.518 & $-0.510(0.136)^{* * *}$ \\
\hline
\end{tabular}

Min->Max: change in predicted probability as $x$ changes from minimum to maximum; $0->1$ : change in predicted probability as $x$ changes from 0 to $1 ;-+1 / 2$ : change in predicted probability as $x$ changes from $1 / 2$ unit below base value to $1 / 2$ unit above; -+sd/2: change in predicted probability as $x$ changes from $1 / 2$ standard deviation below base to $1 / 2$ standard deviation above; MargEfect: partial derivative of the predicted probability/rate with respect to a given independent variable. 1. Computed based on the method of discrete changes; 2 . Computed based on the method of marginal changes; robust standard errors in parentheses; $* * *, * *, *$ denote significance at the $1 \%, 5 \%$ and $10 \%$ levels, respectively; ${ }^{a}$ changes for binary variables from 0 to 1.

Source: Author based on information from ENESTYC, 2005. 
Table 6.8: Testing the influence of internal and external training on performance of in-house R\&D

\begin{tabular}{|c|c|c|c|c|c|c|}
\hline Variable & rd_inhouse & rd_exploit & rd_explore & $\begin{array}{c}\text { rd_improve } \\
\text { _process }\end{array}$ & $\begin{array}{l}\text { rd_drug } \\
\text { _design }\end{array}$ & $\begin{array}{c}\text { rd_drug } \\
\text { improvement }\end{array}$ \\
\hline \multirow[t]{2}{*}{ training_internal } & $0.58^{*}$ & $0.70^{* *}$ & 0.31 & $0.59 *$ & 0.24 & 0.40 \\
\hline & $(0.33)$ & $(0.32)$ & $(0.33)$ & $(0.32)$ & (0.33) & $(0.32)$ \\
\hline \multirow[t]{2}{*}{ external_training } & $0.63^{* *}$ & 0.46 & $0.79 * *$ & $0.50 *$ & $0.75^{* *}$ & 0.35 \\
\hline & $(0.31)$ & $(0.31)$ & $(0.32)$ & $(0.31)$ & $(0.32)$ & $(0.31)$ \\
\hline \multirow[t]{2}{*}{ rem_size } & 0.020 & 0.043 & 0.061 & 0.030 & 0.075 & 0.076 \\
\hline & $(0.060)$ & $(0.057)$ & $(0.058)$ & $(0.053)$ & $(0.058)$ & $(0.055)$ \\
\hline \multirow[t]{2}{*}{ imp_empowerment } & -0.11 & -0.15 & 0.035 & -0.12 & -0.11 & -0.11 \\
\hline & $(0.24)$ & $(0.23)$ & $(0.22)$ & $(0.22)$ & $(0.22)$ & $(0.21)$ \\
\hline \multirow[t]{2}{*}{ modern_practice } & 0.31 & 0.22 & 0.34 & $0.54^{*}$ & $0.52 *$ & 0.21 \\
\hline & $(0.35)$ & $(0.34)$ & $(0.31)$ & $(0.32)$ & $(0.32)$ & $(0.32)$ \\
\hline \multirow[t]{2}{*}{ export_dummy } & $0.71 * *$ & 0.42 & $0.99 * * *$ & 0.23 & $1.01 * * *$ & 0.28 \\
\hline & $(0.33)$ & $(0.34)$ & $(0.33)$ & $(0.32)$ & $(0.33)$ & $(0.31)$ \\
\hline \multirow[t]{2}{*}{ fdi } & $-0.94 * *$ & $-0.89 * *$ & $-1.31 * * *$ & $-0.63 *$ & $-1.29 * * *$ & $-0.69 *$ \\
\hline & $(0.38)$ & $(0.38)$ & $(0.40)$ & $(0.35)$ & $(0.41)$ & $(0.36)$ \\
\hline \multirow[t]{2}{*}{ Constant } & -0.56 & -0.57 & $-1.21 * * *$ & $-0.90 * *$ & $-1.32 * * *$ & $-0.68 *$ \\
\hline & $(0.44)$ & $(0.43)$ & $(0.44)$ & $(0.42)$ & $(0.45)$ & $(0.41)$ \\
\hline Observations & \multicolumn{6}{|c|}{112} \\
\hline Log Likelihood Full & -55.5 & -59.3 & -60.9 & -65.9 & -60.9 & -66.4 \\
\hline$X^{2}[7]$ & $23.2^{* * *}$ & $15.6^{* *}$ & $30.1 * * *$ & $14.1^{* * *}$ & $29.3^{* * *}$ & 11.5 \\
\hline Cragg-Uhler $\mathrm{R}^{2}$ & 0.207 & 0.185 & 0.287 & 0.135 & 0.295 & 0.127 \\
\hline Count $\mathrm{R}^{2}$ & 0.777 & 0.741 & 0.696 & 0.705 & 0.723 & 0.688 \\
\hline
\end{tabular}

Notes: Robust standard errors in parentheses, ${ }^{* * *} p<0.01,{ }^{* *} p<0.05,{ }^{*} p<0.1$; Degrees of freedom within squared brackets.

Source: Author with information from ENESTYC, 2005. 


\section{Chapter 7}

\section{Learning from external markets for technology: Is there a role for human resource management practices?}

\section{Introduction}

Chapter 3 argued that learning and innovation are interactive dimensions spanning both the physical and cognitive boundaries of a firm. It is therefore not surprising to find scholars being interested in exploring how firms, including those in developing countries, respond to both the challenges and opportunities associated with external markets for technology (Arora et al. 2001; Archibugi and Pietrobelli 2003). The task is complex, as interactions differ in nature--they range from cooperation to purely market based transactions--and imply different degrees of commitment by the firm. Distinct relationships require the mobilization of different kinds of resources by the firm.

From the above, this chapter addresses the questions of whether human resource management practices contribute to learning from external markets for technology, and how they do so. Based on the discussion in chapter 1 , the research hypothesis is that human resource management practices support innovation by conditioning, first, the way it learns from external knowledge sources; hence the pertinence to look at a firm's interactions with external knowledge sources. In the spirit of chapter 6 , relevant human resource management interventions are expected to vary depending on the type of knowledge pursued by the firm. This is one of the first systematic efforts to investigate this topic, particularly by adopting the perspective of developing countries (Chung-Jen, and Jing-Wen, 2009).

The empirical analysis here abstracts from any formal learning efforts carried out in-house by the firm; it focuses exclusively on learning from external markets. In other words, as discussed in chapter 3, this chapter addresses the extreme case in which firms rely exclusively on external sources of technology. ${ }^{1}$ The remainder of the chapter proceeds as follows: Section 2 presents the data, the variables definitions and the research strategy. Section 3 contains the empirical results. Empirical evidence refers to the pharmaceutical industry in Mexico. The

\footnotetext{
${ }^{1}$ The case when markets for technology are perceived as sources of supplementary knowledge inputs for a firm's internal learning efforts is the subject matter of chapter 8 .
} 
presentation is split into two sections. First, some descriptive statistics are provided about the pharmaceutical firms in Mexico based on two criteria: on the one hand, the table presents characteristics such as size, sales, employment and so on. On the other hand, the table identifies the type of human resource management practices adopted by firms. A second section contains the results from the econometric analysis. Section 4 discusses the results and presents the conclusions.

\section{Variable definitions and research strategy}

\subsection{Dependent variables}

Data used in this paper come from the ENESTYC dataset described in chapter 3 . The dependent variables, as originally defined in ENESTYC, are presented in table 7.1, part A. Based on Cassiman and Veugelers (2000 and 2006) some such variables were subsequently combined to generate three new generic indicators on external markets for knowledge- table 7.1, part B. Criteria for the aggregation was the form in which technology is acquired, whether embodied in physical artefacts or in a nonphysical form.

Table 7.1: Means for technology acquisition from external markets: pharmaceutical firms in Mexico

\begin{tabular}{|c|c|}
\hline Variable & Definition \\
\hline \multicolumn{2}{|c|}{ Part A:Variables in ENESTYC, 2005} \\
\hline 1. extrel_rd & Firms carry out R\&D in collaboration with other agents \\
\hline 2. licensing & Firms license technology \\
\hline 3. tech_package & Firms acquire technology packages \\
\hline 4. tech_consultant_firm & Firms hire consultant firms as a source of technology \\
\hline 5. tech_literature & Firms consult literature as a source of knowledge \\
\hline 6. extrel_learn_inds & $\begin{array}{l}\text { Firms collaborate with other firms to learn about the conditions of the business envi- } \\
\text { ronment and other characteristics of the industry }\end{array}$ \\
\hline 7. extrel_acq_machin & Firms acquire machinery and equipment in collaboration with other firms in the industry \\
\hline \multicolumn{2}{|r|}{ Part B: Redefinition of variables for the econometric analysis } \\
\hline 8. external_mkt & Firms acquire technology through at least one of the items 1-7 in Part A \\
\hline 9. embodied & Firms acquire technology in an embodied form; includes items 3,4 and 7 \\
\hline 10. disembodied & Firms acquire technology in a disembodied form; includes items 1,2,5 and 6 \\
\hline
\end{tabular}

Source: Author based on information from ENESTYC, 2005

External R\&D: Innovation scholars pay considerable attention to contracted or joint performance of R\&D as learning mechanism. This is the best proxy for what Arora et.al, (2001) and DOJ-FTC (6th April 1995) term the market for future technology, the market for innovations. In this context, the literature documents some trend towards off-shoring of R\&D activities by global pharmaceutical firms (Crossley 
2004); internationalization is increasingly in the form of clinical research (Piachaud 2002; Santiago 2009). Mexico and other developing countries face opportunities to participate mostly as investigative sites hosting clinical research (Interviews with trade2 and Insh3). As discussed in chapter 4 although clinical research is carried out mostly by foreign affiliates, some firms in host countries have also the capacity to do some such activities in connection with local hospitals and other specialised research organisations. Last but not least, and even if this remains rather limited, some joint R\&D is carried out between local companies and research institutions in connection to development or improvement of generic drugs and other pharmaceutical products. The variable extrel_rd captures the performance of joint R\&D by pharmaceutical firms in Mexico. Unfortunately, it does not specify the specific type of R\&D the firm carries out with external agents.

Technology licensing: Technology licensing, particularly of patents, is among the most common means to acquire technology. Depending on the conditions of the negotiation between the licensee and the licensor, the new knowledge can be used as input for further technological developments. Development however is conditioned by the relative distance between the new piece of knowledge and the licensee's technological capabilities (Leone and Reichstein 2009). In other cases contracts limit the use of the new technology, effectively prohibit any modification by the licensee. Taking into account the importance of patents and licensing of technologies for the pharmaceutical industry (Nakamura and Odagiri 2005), analysis in this chapter introduces licensing as dependent variable. This is interpreted as a component of the market for existing knowledge (Arora et.al, 2001; DOJ-FTC 6th April 1995).

Other external markets: Part A of table 7.1 includes some additional indicators on external markets. In general, the variables denote the acquisition of packaged technologies, tech_package; or the purchase of machinery in collaboration with other firms, extrel_acq_machin. The table also includes variables denoting the hiring of consultancy firms, tech_consutant_firm; access to specialised literature, tech_literature; and some collaborative learning activities among firms in the industry, extrel_learn_inds, for example via participation or in partnership with trade organisations.

Generic variable on external markets: Merging both extrel_rd and licensing with the rest of indicators in Part A of table 7.1, generates a new variable, external_mkt, which denotes the participation of a firm in external knowledge markets. The variable takes the value of one if the firm carries out at least one of the activities 1-7 in table 7.1. Otherwise, the variable is set to zero. The new variable indicates that the firm seeks to tap knowledge from external markets (Cassiman and Veugelers 2000 and 2006).

(Dis)embodied technologies: A frequent definition of technology acquisition considers its mode of transfer, whether in physical or 'virtual' form. In other words, whether the knowledge is incorporated in a tangible artefact, or separated from the 
thing itself (Cassiman and Veugelers 2000). In the first case, we talk about embodied technologies; in the second, of disembodied technologies. Embodied technologies come in the shape of products, instruments, machinery and equipment, software or prototypes. Disembodied technologies, in turn, reflect trading of intangibles such as intellectual property rights. These allow the use of blueprints, designs, formulas, or contracted R\&D. Depending on the nature of contracts disembodied technologies can sustain either the mere replication of whatever knowledge is obtained, or the mobilisation of resources to develop the technology further. Based on these considerations, the analysis in this chapter includes two new variables created using the information from the ENESTYC: embodied and disembodied (Cassiman and Veugelers 2000). The first variable merges items 3, 4 and 7 in table 7.1, and denotes acquisition of technologies in physical form. The second variable captures the acquisition of knowledge in disembodied form, items 1, 2, 5 and 6 in the same table.

\subsection{Independent variables}

Human resource management variables: This chapter explores the effects on learning from external markets associated with management practices such as the provision of training, remuneration for performance, worker's participation in decision making about the work place, and the hiring of new staff. The definition of these variables and how they can impact on learning are described in chapter 3 in this thesis. Section 3.2 in chapter 3 explains variable constructions.

Control variables: This Chapter controls for some firm characteristics including: the adoption of modern management practices; capital ownership, participation in export markets and size.

\subsection{Research Strategy}

The dependent variables used in this chapter are binary; they identify some means for pharmaceutical firms in Mexico to tap external knowledge. A suitable econometric approach to study this type of decision variables is probit regression (Greene 2003; Liao 1994). The analysis proceeded as follows: a basic model specification was identified using external_mkt as dependent variable. This is the reference to compare results from models including other variables on learning from external sources. Similar to the analysis in chapter 6 , we then iteratively changed the definition of the dependent variable. Considering the importance that the literature grants to R\&D, licensing and the acquisition of embodied and disembodied technologies, the empirical analysis incorporates these variables.

As for variables in the right hand side of the equation, similar to Michie and Sheehan (1999) and Laursen and Foss (2003), our analysis considered whether the provision of training was carried out by a staff member in-house (internal training), 
or by linking to some external provider (external_training). This alternative was preferred to using a general indicator on training, train04, as it rendered some finer information about the characteristics of the training provided. Nevertheless, introducing train04 in the regressions rendered similar results to those reported in section 3. Finally, a series of models enquired about the influence of human resource management interventions once we distinguish the specific partner assisting the firm in the provision of external training. This chapter reports models where external training is provided by individual consultants, private and public universities, public research centres, machinery suppliers, and training centres linked to local trade organisations of the pharmaceutical industry. Each of these variables was combined with internal_training. The exercise served two goals. First, it suggested the kind of knowledge flows obtained through external training. Second, it shed light on the robustness of results.

This chapter also reports the computation of marginal effects for the models in the analysis. Additional checks were performed to ensure accuracy and robustness of results. First, each dependent variable was regressed on the human resource management variables only; this tested the extent to which such variables capture the learning behaviour of pharmaceutical firms in Mexico. Likewise, we ran models including only the explanatory and control variables showing some statistical significance, at a maximum 5 per cent confidence level, in the basic model for each dependent variable. ${ }^{2}$

\section{Empirical results}

\subsection{Participation in external markets for knowledge}

Table 7.2 presents the learning behaviour of pharmaceutical firms in Mexico. The industry shows a fairly diversified use of external sources of knowledge. In 2004 some 60.7 percent of firms participated in such markets. However, the most frequent learning mechanism was technology acquisition in disembodied form. Within this, the most important item was consulting specialised literature with about a third of firms reporting that activity. After specialised literature, performance of joint R\&D and technology licensing ranked second and third as sources of disembodied knowledge, with some 25.9 and 18.8 percent of firms, respectively. Limited joint R\&D and licensing indicate the low efforts aimed at building learning capacities by pharmaceutical firms in Mexico. In fact collaboration, particularly for the performance of R\&D, is rather low in the local industry. The latter characterises by

\footnotetext{
${ }^{2}$ For reasons of space, the results from models including variables with significance at the 5 percent level or lower are omitted from presentation. However, estimates were similar to those reported here.
} 
limited interactions underpinning the capacity to generate future knowledge flows and potential innovations. This finding coincides with the discussion in Chapter 6.

As for the acquisition of embodied technology, this was carried out by some 35.6 percent of firms in the sample. In this case, the most important type was the purchase of packaged technology, 26.8 percent of firms. Hiring consultant firms and acquisition of machinery and equipment through collaborative relations followed. Some 25.0 percent and 13.4 percent of firms, respectively, made use of these mechanisms.

Table 7.2 also identifies pharmaceutical firms based on indicators such as employment, sales, exports, foreign ownership, size and age. Moreover, firms are classified by type of external market. Larger firms, in terms of both size and sales, participate actively in markets for technology. Sales per employee for this group of firms are 1.2 times larger than those corresponding to firms reporting no external technology acquisition at all. The bulk of sales for both groups of firms stem from the domestic market.

Table 7.2 suggests that exports are of little relevance as factor motivating learning from external markets; sales of pharmaceutical firms are directed mostly to the Mexican market. Exports are equal to only 10 percent of total sales. This notwithstanding, one should remember that the econometric analysis in Chapter 6 revealed that exports stimulate knowledge exploration-particularly for new drugs; through in-house R\&D. Would exports condition learning from external markets in particular ways?

Table 7.2 suggests that foreign capital ownership conditions negatively learning activities in the pharmaceutical industry in Mexico. In general, the share of foreign capital is larger for firms reporting no learning activities, about 40 percent. Notable exception is learning via licensing where foreign owned firms are more active. Chapter 5 suggested commercial reasons as being among the main drivers for technology licensing; foreign affiliates take patents that back sales of innovative drugs in the Mexican market. The strengthening of IPRs following endorsement of the TRIPS Agreement by Mexico, may have increased the cost of licensing, affecting negatively incentives for investment in R\&D and productive capacity by domestic firms (Guzmán et.al, 2005). Firms that license technology reported sales which are considerably larger relative to those of firms that do not license technology at all. Unfortunately, neither the ENESTYC nor the interviews provided evidence about the characteristics of licensing contracts established by pharmaceutical firms in Mexico. Hence, it is difficult to conclude anything about how likely are firms in the local industry to subsequently enhance the licensed technology.

Table 7.3 presents the correlation analysis of the variables on external markets used in this chapter. The table corroborates the perceived importance of disembodied technologies for pharmaceutical firms in Mexico. Reading of specialised literature accounts for most of the learning in disembodied form. Joint 
$R \& D$ and licensing come second and third within this specific kind of learning strategy. Overall, table 7.3 shows that the different sources of external technology are poorly correlated among themselves. The strongest correlation is observed between the acquisition of packaged technologies and the hiring of consultant firms. This finding suggests that interactions between pharmaceutical firms and technology suppliers in Mexico occur mostly via market transactions. Purchases of technology require specialised assistance to install and ready the new machinery and equipment. Joint R\&D is poorly connected to the rest of technological activities in the local industry.

\subsection{Human resource management practices by source of external knowledge}

Table 7.4 presents the independent and control variables used in this chapter arranged according to the distribution of firms among types of external learning strategies. The table corroborates the high frequency with which pharmaceutical firms in Mexico provide training to staff. The likelihood that training takes place by means of both internal and external knowledge providers is high as well. Internal knowledge diffusion is supplemented with external knowledge through training. Interviewees at firm 03 and 06 suggested that suppliers of APIs and other raw materials contribute significantly to learning; they provide knowledge about new substances, possible combinations and how they can be used to expand development and formulation opportunities. This is together with knowledge about new machinery and equipment.

Chapter 1 argued that by capturing part of the supply of human resources available in the market, firms influence developments in S\&T-related labour markets. Table 7.4 reveals that firms that participate in external technology markets tend to adopt some specific regulation to govern hiring practices. Interviews with firms in the industry showed that as firms grow larger and particularly for positions requiring higher skill levels, staffing processes become more systematic and carefully conducted (Interviews with firms 08 and 15). Prospective employees undergo long and strict selection processes, some time spanning several months and entailing several interviews with different people within the hiring organisation. One can also perceive that acquisition of disembodied technologies coincides with the largest frequency of firms that have specific regulations to guide staffing practices. At the same time, firms performing joint R\&D or technology licensing report some of the lowest propensity to regulate staffing practices. These observations do not imply causality between these variables.

Table 7.4 shows that adoption of modern organisational practices is frequent for firms that use external sources for knowledge. The largest frequency corresponds to firms that incorporate disembodied technologies. Note that there is no evident difference in the distribution of firms, by size, according to export 
behaviour. Nevertheless, firms that both export and carry out some kind of learning activity are relatively fewer in number.

\subsection{Econometric results}

Table 7.5 presents the findings from the econometric analysis. The Wald tests for the value of $X^{2}$ different from zero confirm that the models are statistically significant at standard confidence levels. The values of the count $R^{2}$ scalar, which is a brief indication of the predicting power of the models, are also adequate (Long and Freese 2006). As a final indication on the goodness of fit, the values of the CraggUhler $\mathrm{R}^{2}$ suggest that the models with the full set of explanatory variables sufficiently explain the learning behaviour of firms (Long and Freese 2006). The exception is the models for acquisition of technologies in embodied form; those models failed to provide statistically meaningful information about the learning behaviour of pharmaceutical firms.

Model (1) in table 7.5 shows the isolated effects of the human resource management variables on external acquisition of technology. Workers' empowerment and adoption of specific rules to govern staff hiring, respectively, seem to influence learning. By contrast, none of the training indicators provides meaningful information about their influence of learning. Incorporation of the full set of variables, model (2), results in the control variables taking the explanatory power. Estimates for individual management variables indicate that neither has perceptible effects on learning. This holds even in the case of the provision of training. These results fail to support the expectation-see chapter 3--; that human resource management practices will positively and significantly affect learning. Computation of marginal effects for the full specification model leads to similar conclusions. Notwithstanding these disappointing results, by looking at the more detailed definitions of markets for technology, the findings become somewhat more revealing. This is presented in the next paragraphs.

\subsubsection{Embodied and disembodied knowledge acquisition}

Table 7.5 presents the results for models including technology acquisition in either embodied or disembodied forms. Since the models including embodied technologies obtained non-statistically significant results, the discussion focuses on the estimates for models with acquisition of disembodied technologies as dependent variable. The Models are statistically significant at the one percent level; their predictive power is also acceptable (Cassiman and Veugelers 2006). These results reflect the previous finding that incorporation of disembodied technologies is the preferred external source of knowledge of pharmaceutical firms in Mexico.

Individual estimates show that both adoption of modern organisational 
practices and exports impact positively on learning from external sources. By contrast, foreign ownership reduces the probability that a firm learns by means of disembodied knowledge. Estimates for the variables on human resource management practices indicate that rule_hiring is the single variable with statistically significant effects on learning. Adoption of formal procedures to regulate staffing practices increases the likelihood that a pharmaceutical firm incorporates disembodied technologies. Unfortunately, none of the remaining management practices reported statistically significant effects; computation of marginal effects corroborates these conclusions. We explored further these findings by looking at the indicators on joint R\&D and technology licensing.

\subsubsection{Markets for innovation: joint R\&D}

Table 7.5 contains the results for models with joint R\&D as dependent variable. The models reveal a good explanatory power across the alternative model specifications. In line with the notion of knowledge exploitation, estimates for individual variables indicate that foreign ownership influences negatively the propensity to learn via engagement in collaborative R\&D. R\&D in general, and collaboration for R\&D are not relevant components of business strategies of multinational affiliates in Mexico. Neither exports nor the adoption of modern organisational practices provided some statistically meaningful information. By contrast, regulation of staffing practices revealed some positive and statistically significant effects on joint R\&D. Computation of marginal effects corroborates these results.

\subsubsection{Markets for technology: licensing}

Models (9) and (10) in table 7.5 present results for models with licensing as dependent variable. Estimates show that adoption of modern organisational practices has no perceptible effect on licensing. Surprisingly, and contrary to our expectations, the control for capital ownership rendered no statistically significant information. By contrast, exports reported positive and significant impacts on licensing. The variables on human resource management variables indicate that remunerations and staff hiring mechanisms are the most influential on learning. The effect however, is no robust to inclusion of the control variables; when the latter enter the equation, the variables on human resource management report no perceptible influence on learning from external markets. The computation of marginal effects confirmed these findings. The enquiry of the extent to which technology licensing is accompanied by internal learning efforts is postponed to chapter 8 .

The analysis so far reveals that human resource management variables have limited influence on the learning from external knowledge sources by 
pharmaceutical firms in Mexico. We observe that the variables denoting a firm's characteristics seem to explain learning from external markets. Particularly intriguing is the lack of statistical significance of variables such as the provision of external training. In the innovation literature, including that about Mexico, external training usually stands out as the main reasons for manufacturing firms to collaborate with education and research institutions. In order to explore further this issue, the variable on external training was split into some different training providers a firm can associate with. Results are presented in the following section.

\subsubsection{Learning from distinct training providers}

This section explores the effects of the linkages of pharmaceuticals with organisations such as universities, public research centres, other firms, and individual consultants. The analysis focuses in the provision of R\&D-relevant training. ${ }^{3}$ The results from these models are presented in tables 7.6-7.9 at the end of the chapter. In general the models turned out statistically significant at customary confidence levels; nevertheless, those where acquisition of embodied technologies was used as dependent variable failed to provide meaningful results. ${ }^{4}$ Consequently, the following comments concentrate on the former group of models.

Models with external_mkt as independent variable (table 7.6), revealed that the variables on adoption of modern organisational practices and foreign ownership systematically influence learning from external markets. However, the corresponding individual effects show opposite signs. Regarding management practices, rule_hiring was positive and statistically significant whenever training is provided in connection with centres attached to local trade organisations. The marginal effects associated with adoption of the latter variable were also relevant. Strikingly, none of the training variables identifying traditional knowledge producers, universities and research centres, provided statistically meaningful information to explain learning by firms. By contrast, the hiring of individual consultants supported learning from external markets.

Models using the variable on acquisition of disembodied technologies, table 7.7, corroborated some of the results presented in section 3.3.1. Both the adoption of modern organisational practices and exposure to external competition through exports motivate firms to acquire technology. The opposite effect is observed in the case of foreign ownership. Among the variables on human resource management, rule_hiring and training in connection with individual consultants were the only variable with some statistically significant effects on learning.

Turning to joint performance of $R \& D$, the models showed that management

\footnotetext{
${ }^{3}$ During the analysis two distinct sets of models were run; the main difference was the presence or absence of internal training provision. Results were similar to those reported here.

${ }^{4}$ Full results are available from the author upon request.
} 
practices have really poor explanatory power, with the exception of rules governing hiring practices-table 7.8. Foreign ownership revealed negative and statistically significant effect on the likelihood that a firm performs external R\&D.

In the case of technology licensing -table 7.9, the estimates revealed that whereas foreign ownership lost the statistical significance observed in previous models, exposure to competition through exports gained relevance to explain licensing by pharmaceutical firms in Mexico. From a management perspective, regulations applicable to hiring practices increase the likelihood of technology licensing. Regarding the provision of training, none of the variables used in the analysis turned out statistically significant.

\section{Discussion and concluding remarks}

Firms face difficulties to internalise all the resources and efforts needed to produce and commercialize new technology. A firm's innovative capacity is constrained by its ability to interact with external organisations offering some complementary assets. Thus the interest in learning about factors conditioning the development and functioning of external markets for knowledge. Previous research documents the complexities involved in setting straight boundaries between different types of, transmission channels and ways to appropriate knowledge. External markets are heterogeneous; they include activities with different degrees of technological content and proprietary rights, from specialised literature and acquisition of modern machinery and equipment, to technology licensing. Firms can perform R\&D to jointly explore new markets, tackle promising technological and business opportunities, or develop new knowledge underpinning innovation. Cooperative and purely market-based interactions mediate knowledge exchanges within and across systems of innovation.

External markets for knowledge involve firms with different levels of technological capabilities. Considerable attention focuses on firms that act as both producers and consumers in external markets for knowledge. Such firms tap into existing knowledge stocks while contributing to advancement of the technological frontier in specific sectors or industries. To a large extent, available studies involve large multinationals in high-technology industries such as electronics, pharmaceuticals and biotechnology. However the literature documents that in alternative contexts, firms can also benefit from technology markets. Arguably, those markets open windows of opportunities for improved performance and growth of firms in catching up modes. External markets provide complementary assets for latecomer firms facing more limited technological capabilities and learning efforts (Santamaría et.al, 2009).

In this context, this chapter documented that during 2004 approximately two thirds of pharmaceutical firms in Mexico made use of external technology markets. 
Whereas this seems positive, a careful look at individual activities revealed that the complexity of learning activities of the local pharmaceutical industry is relatively limited. Most activities involve knowledge exploitation; firms learn by replicating existing knowledge, or by adapting and incorporating technologies developed elsewhere into everyday processes. External markets support searches for shortterm efficiency gains with limited demands and incentives to expand a firm's customary knowledge base (March 1991).

Learning by pharmaceutical firms in Mexico usually takes place through the reading of specialised literature. In such a way development staff gets acquainted with new ways to synthesize and replicate knowledge supporting manufacturing of a given drug (Interview with firms 05 and 06). Particularly in the case of off-patent drugs, consulting professional journals, blue-prints and other specialised literature grants knowledge about analytical methodologies, the pharmochemical and biological properties of the compound-- parameters such as dissolution, absorption and excretion curves--; the characteristics of excipients and other raw materials required to (re)formulate the drug. This strategy often leads companies to build libraries in-house, subscribe to specialised journals or to actively promote Internet usage. In such context, personnel characteristics such as experience and educational background constitute key ingredients to adequately perform learning activities.

In line with traditional transaction cost theory, this chapter assumed firms to adopt external learning strategies independently of domestic technological efforts; firms avoid the risks and costs involved in developing new technologies. Next we enquired about the contribution of management practices to learning. The results from the econometric analysis indicated both the limited explanatory power of the models, and the difficulties to conclude on the influence of management practices on learning. In fact, firm characteristics had a stronger explanatory power. This notwithstanding, it is possible to draw some conclusions from the analysis.

Based on the literature, the expectation is that firms with stronger learning behaviours should perform better than those revealing more passive stances. Our analysis suggests this needs a careful interpretation. Pharmaceutical firms that participated in technology markets tended to perform better, in terms of sales and employment, than those with no learning activities; nevertheless, the advantage was modest. Major differences corresponded to firms reporting the use of technology licensing as learning mechanism. In those cases, total sales, and more specifically those leveraged from the local market, were nearly three times larger than those recorded by firms that do not license technology. It seems that it all depends on the kind of learning activities and how these are carried out by the firm. Bell (1984) for example, distinguished two possible ways for individuals and organisations to learn. Learning can involve dynamic processes of acquisition and accumulation of technical knowledge and skills, firms constantly nurture their knowledge bases. Alternatively, learning can reflect "patterns of change in the 
performance of production activities" ${ }^{5}$ (p. 187). (Increased) efficiency in task performance, productivity gains and so on, indicate that learning in the first sense is occurring. However Bell (1984) qualified this conclusion as potentially misleading. Observed improvements may arise out of knowledge accumulation taking place elsewhere along the supply chain; good performance occurs without enrichment of a firm's knowledge base. Technology acquisition can lead to short-term efficiency and productivity gains, while masking processes of slow disarticulation of technological capabilities in the local industry (Kim et.al, 1989). Such processes potentially hinder future development prospects of the industry; by giving up internal learning efforts, firms preclude future capacity to explore and tackle technological and business opportunities.

We also found that foreign ownership systematically and negatively influences learning by pharmaceutical firms in Mexico. The exception was the case of learning through technology licensing where fdi provided no statistical significance. In principle, this is an intriguing result considering the weight of multinationals in the Mexican pharmaceutical market. However, the information in table 7.4 showed that only a limited number of firms reporting FDI licensed technology.

The positive effects of exports on the propensity to license technology are more important. However limited as a share of total sales of pharmaceutical products, estimates in table 7.5 showed that export behaviour explains better the propensity of a firm to license technology. Kim et.al, (1989) documented a similar situation in the case of Korea; a firm's size induced positive effects on learning, particularly through licensing, when combined with export behaviour. Arora et.al, (2001) in turn, pointed out that competition in markets for goods can positively drive licensing. The finding is interesting as table 7.4 documents that licensing is not strongly connected to exports in Mexico, only a small number of firms reported participation in both those activities.

The analysis in this chapter built on the notion that learning from different types of external markets requires distinct ways to mobilise a firm's resources. Among the latter, the organisation of human resources was stressed as an area deserving more attention than is common in the literature. Accordingly, the discussion of results pertaining to variables on firms' characteristics provided some context to interpret findings for those on human resource management. The analysis of the latter variables showed the relatively limited power they have to explain learning by pharmaceutical firms.

In regard to individual variables, the regulations applicable to new staff hiring were the sole factor with a positive and statistically significant contribution to external learning. The finding is intuitive because hiring new staff normally assumes movements of knowledge embodied in people; in itself staff hiring is a mechanism

\footnotetext{
${ }^{5}$ Stress in the original by the author.
} 
to acquire knowledge from external sources. The limited size of the Mexican market for skilled labour leads to strong competition for talent in the industry; firms frequently complained about the high labour mobility across firms. Introducing adequate and well defined guidelines to incorporate new staff becomes sort of prerequisite to learn from external sources (Interviews with trade2, firms 03, 05, 11 and 13). By incorporating some sufficiently skilled and knowledgeable people firms can access, assimilate and implement new knowledge. There might be a lag between the moment of hiring and that in which actual organisational learning takes place. Based on the previous considerations, we positively confirm the research hypotheses $\mathrm{H} 9-\mathrm{H} 10$.

As for the provision of training, it is intriguing the lack of statistical significance that, in general, was obtained from this variable. Literature on skill bias indicates that technical change frequently motivates training interventions in order to accommodate newly acquired technologies. This of course frequently implies some conscious learning efforts carried out internally by the firm. This is a dimension that chapter 8 will further explore; hence some more concrete conclusions are expected from the analysis there.

Equally relevant from tables 7.6-7.9 was the dearth of a perceptible contribution of training from universities and research centres. As FCCT (2006) documents, those organisations carry out most research and technologically related activities in Mexico; some such knowledge can be transferred to firms via the provision of training (Casas 2005). Based on our interviews, we suggest some possible interpretations for these findings. A mismatch in orientation of both firms and public universities is frequently involved. Particularly in the case of public universities, bureaucratic burdens hinder flexibility and ability to respond to training requirements, especially when these do not necessarily lead to academic degrees (Interview with firms 05 and 06). In extreme cases, the mismatch reflects what Ruíz (2004) identified as a low esteem, even reticence of some major Mexican public universities to design study programmes by contacting and gaining feedback from the productive sector.

By contrast, the findings point out that, under certain conditions, training provided by independent consultants, or through specialised centres related to some trade organisations, reported some positive results. This is symptomatic of the incremental nature of learning activities of pharmaceutical firms in Mexico; they obtain relevant knowledge by interacting with agents more directly connected to the industry. This was frequently found during our interviews. Firms prefer to interact with agents that are able to understand the nature of processes and development activities carried out in the industry (Interviews with Trade1, firms 03, 05 and 15). Theoretical or more abstract contents are seldom relevant for training programmes in the industry. Overall, these results confirmed only partially hypotheses $\mathrm{H} 1-\mathrm{H} 3$. 
The effects on learning associated with worker's empowerment were also difficult to perceive in the statistical analysis. This is of concern as it prevents to meaningfully conclude on the importance of granting workers increased capacity to participate in decision making. This is something suggested in the literature. For example, Dutrénit (2000) and Dutrénit (2007) documented the positive effects on learning whenever firms grant workers the opportunity to manipulate and 'play around' with newly acquired technologies. Conclusions related to hypotheses $\mathrm{H} 7-\mathrm{H} 8$ need further exploration; this is done in chapter 8.

The lack of statistical significance of variables such as remunerations and worker's empowerment suggests the lack of reinforcing effects among management practices as well. Perhaps this explains the high mobility among personnel within the industry. The dynamism of organisational practices is limited by the strategic orientation towards strong reliance and transfer of responsibility to perform technological efforts onto parent companies, or supplier firms. Whenever incentives to acquire new, increasingly more complex knowledge are low, the potential contribution of human resource management practices is also limited. The capacity of the industry to sway over the functioning of labour markets underpinning technological development looks pretty low. Chapter 8 explores further some of these issues. 
Table 7.2: Learning from external markets: Pharmaceutical industry in Mexico, 2004

\begin{tabular}{|c|c|c|c|c|c|c|c|c|c|}
\hline & \multicolumn{3}{|c|}{ Mean } & \multicolumn{2}{|c|}{$\mathrm{SD}^{1}$} & \multicolumn{2}{|c|}{ Min } & \multicolumn{2}{|c|}{ Max } \\
\hline External_mkt & $\mathrm{nal}^{4}$ & (II) $\mathrm{No}^{5}$ & (I)/ (II) & (I) & (II) & (I) & (II) & (I) & (II) \\
\hline Employment & 467.2 & 393.6 & 1.2 & 525.4 & 456.7 & 1.1 & 63.0 & 3391.5 & 2852.9 \\
\hline $\begin{array}{c}\text { Total sales }^{2} \\
\text { Domestic }\end{array}$ & 720.9 & 480.8 & 1.5 & 1.2 & 1074.8 & 2.4 & 7.7 & 6958.0 & 6772.2 \\
\hline sales & 631.2 & 433.9 & 1.5 & 937.1 & 1008.4 & 2.4 & 0.0 & 4359.9 & 6334.5 \\
\hline Export share & 0.1 & 0.1 & 1.0 & 0.1 & 0.2 & 0.0 & 0.0 & 0.6 & 1.0 \\
\hline Share of FDI & 0.3 & 0.4 & 0.8 & 0.5 & 0.5 & 0.0 & 0.0 & 1.0 & 1.0 \\
\hline $\mathrm{Age}^{3}$ & 34.4 & 27.6 & 1.2 & 19.5 & 17.0 & 1.0 & 0.0 & 74.0 & 72.0 \\
\hline embodied & $\begin{array}{l}\text { Embod- } \\
\text { ied }^{10}\end{array}$ & $\mathrm{No}^{11}$ & & (I) & (II) & (I) & (II) & (I) & (II) \\
\hline Employment & 547.5 & 377.6 & 1.4 & $\begin{array}{l}650.5 \\
1435 .\end{array}$ & 382.0 & 1.1 & 42.0 & 3391.5 & 2852.9 \\
\hline Total sales & 870.6 & 491.0 & 1.8 & 1 & 945.0 & 31.9 & 2.4 & 6958.0 & 6772.2 \\
\hline $\begin{array}{l}\text { Domestic } \\
\text { sales }\end{array}$ & 754.0 & 442.4 & 1.7 & $\begin{array}{r}1085 . \\
6\end{array}$ & 881.2 & 31.9 & 0.0 & 4359.9 & 6334.5 \\
\hline Export share & 0.1 & 0.1 & 1.0 & 0.1 & 0.2 & 0.0 & 0.0 & 0.5 & 1.0 \\
\hline Share of FDI & 0.2 & 0.4 & 0.5 & 0.4 & 0.5 & 0.0 & 0.0 & 1.0 & 1.0 \\
\hline Age & 35.2 & 29.8 & 1.2 & 19.4 & 18.3 & 1.0 & 0.0 & 74.0 & 72.0 \\
\hline disembodied & $\begin{array}{r}\text { Disem- } \\
\text { bodied }^{12}\end{array}$ & $\mathrm{No}^{13}$ & & (I) & (II) & (I) & (II) & (I) & (II) \\
\hline Employment & 471.2 & 398.9 & 1.2 & $\begin{array}{l}543.0 \\
1242 .\end{array}$ & 442.0 & 2.2 & 1.1 & 3391.5 & 2852.9 \\
\hline $\begin{array}{c}\text { Total sales } \\
\text { Domestic }\end{array}$ & 724.6 & 509.3 & 1.4 & 7 & 1034.2 & 2.4 & 7.7 & 6958.0 & 6772.2 \\
\hline sales & 628.3 & 464.5 & 1.4 & 964.4 & 970.0 & 2.4 & 0.0 & 4359.9 & 6334.5 \\
\hline Export share & 0.1 & 0.1 & 1.0 & 0.1 & 0.2 & 0.0 & 0.0 & 0.6 & 1.0 \\
\hline Share of FDI & 0.3 & 0.4 & 0.8 & 0.5 & 0.5 & 0.0 & 0.0 & 1.0 & 1.0 \\
\hline Age & 33.2 & 30.0 & 1.1 & 19.0 & 18.6 & 1.0 & 0.0 & 70.0 & 74.0 \\
\hline extrel_rd & $\begin{array}{r}\text { External } \\
R \& D^{6}\end{array}$ & $\mathrm{No}^{7}$ & & (I) & (II) & (I) & (II) & (I) & (II) \\
\hline Employment & 528.6 & 406.7 & 1.3 & 644.9 & 436.8 & 42.0 & 1.1 & 3391.5 & 2852.9 \\
\hline Total sales & 788.3 & 570.0 & 1.4 & 1465.8 & 1025.5 & 2.4 & 7.7 & 6958.0 & 6772.2 \\
\hline $\begin{array}{l}\text { Domestic } \\
\text { sales }\end{array}$ & 646.63 & 521.2 & 1.2 & 994.2 & 9601.0 & 2.4 & 0.0 & 4359.9 & 6334.5 \\
\hline Export share & 0.1 & 0.1 & 1.0 & 0.1 & 0.2 & 0.0 & 0.0 & 0.5 & 1.0 \\
\hline Share of FDI & 0.1 & 0.4 & 0.3 & 0.4 & 0.5 & 0.0 & 0.0 & 1.0 & 1.0 \\
\hline Age & 34.9 & 30.6 & 1.1 & 20.4 & 18.2 & 1.0 & 0.0 & 67.0 & 74.0 \\
\hline licensing & $\begin{array}{l}\text { Licens- } \\
\text { ing }^{8}\end{array}$ & $\mathrm{No}^{9}$ & & (I) & (II) & (I) & (II) & (I) & (II) \\
\hline Employment & 690.0 & 380.2 & 1.8 & 745.2 & 406.4 & 217.3 & 1.1 & 3391.5 & 2852.9 \\
\hline $\begin{array}{c}\text { Total sales } \\
\text { Domestic }\end{array}$ & 1350.7 & 459.5 & 2.9 & 1764.7 & 891.9 & 126.1 & 2.4 & 6958.0 & 6772.2 \\
\hline sales & 1133.9 & 419.8 & 2.7 & 1278.0 & 831.6 & 125.9 & 0.0 & 4359.9 & 6334.5 \\
\hline Export share & 0.1 & 0.1 & 1.0 & 0.1 & 0.2 & 0.0 & 0.0 & 0.5 & 1.0 \\
\hline Share of FDI & 0.5 & 0.3 & 1.7 & 0.5 & 0.4 & 0.0 & 0.0 & 1.0 & 1.0 \\
\hline Age & 36.8 & 30.5 & 1.2 & 19.9 & 18.5 & 1.0 & 0.0 & 70.0 & 74.0 \\
\hline
\end{tabular}

Notes: Number of firms in sample: $112 ; 1$. standard deviation; 2. Million Mexican pesos; 3. difference between the year in which a firm started operations in current business and the year when the survey was collected, $2004 ; 4.68$ firms; 5. 44 firms; 6.29 firms; 7.83 firms; 8. 21 firms; 9.91 firms.

Source: Author with information from ENESTYC 2005, INEGI 


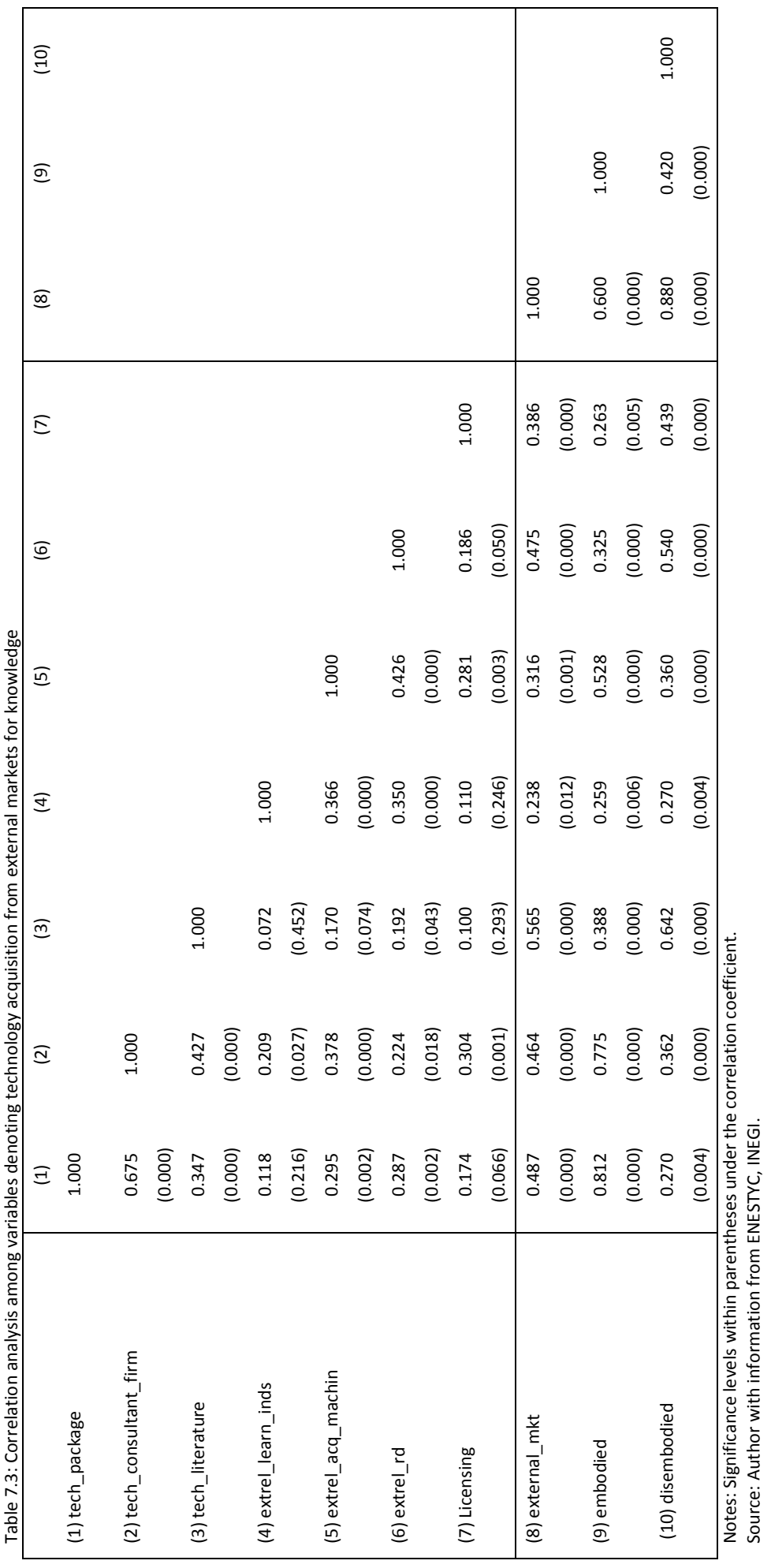


Table 7.4: Mexico: Human resource management practices and control variables included in the analysis by type of external market for technology

\begin{tabular}{|c|c|c|c|c|c|c|c|c|c|c|}
\hline \multirow[b]{2}{*}{ train 04} & \multicolumn{2}{|c|}{ external_mkt } & \multicolumn{2}{|c|}{ embodied } & \multicolumn{2}{|c|}{ disembodied } & \multicolumn{2}{|c|}{ extrel_rd } & \multicolumn{2}{|c|}{ licensing } \\
\hline & no & Yes & no & yes & no & yes & no & yes & no & Yes \\
\hline No & 8 & 4 & 10 & 2 & 10 & 2 & 12 & 0 & 11 & 1 \\
\hline Yes & 36 & 64 & 62 & 38 & 41 & 59 & 71 & 29 & 80 & 20 \\
\hline \multicolumn{11}{|l|}{ internal_external_tr } \\
\hline No & 8 & 4 & 10 & 2 & 10 & 2 & 12 & 0 & 11 & 1 \\
\hline Internal & 8 & 8 & 14 & 2 & 8 & 8 & 13 & 3 & 15 & 1 \\
\hline External & 4 & 8 & 8 & 4 & 4 & 8 & 7 & 5 & 9 & 3 \\
\hline Both & 24 & 48 & 40 & 32 & 29 & 43 & 51 & 21 & 56 & 16 \\
\hline \multicolumn{11}{|l|}{ imp_empowerment } \\
\hline Not implemented & 35 & 35 & 46 & 24 & 40 & 30 & 53 & 17 & 60 & 10 \\
\hline Not important & 5 & 24 & 18 & 11 & 7 & 22 & 21 & 8 & 24 & 5 \\
\hline Very important & 4 & 9 & 8 & 5 & 4 & 9 & 9 & 4 & 7 & 6 \\
\hline \multicolumn{11}{|l|}{ rule_hiring } \\
\hline No & 29 & 30 & 41 & 18 & 35 & 24 & 49 & 10 & 53 & 6 \\
\hline Yes & 15 & 38 & 31 & 22 & 16 & 37 & 34 & 19 & 38 & 15 \\
\hline rem_size* & 7.1 & 6.4 & 7.4 & 6.6 & 7.0 & 6.7 & 7.2 & 6.7 & 8.6 & 6.4 \\
\hline \multicolumn{11}{|l|}{ modern_practice } \\
\hline No & 23 & 14 & 24 & 13 & 27 & 10 & 29 & 8 & 34 & 3 \\
\hline Yes & 21 & 54 & 48 & 27 & 24 & 51 & 54 & 21 & 57 & 18 \\
\hline \multicolumn{11}{|l|}{ export_dummy } \\
\hline No & 23 & 29 & 33 & 19 & 28 & 24 & 39 & 13 & 50 & 2 \\
\hline Yes & 21 & 39 & 39 & 21 & 23 & 37 & 44 & 16 & 41 & 19 \\
\hline \multicolumn{11}{|l|}{ fdi } \\
\hline No & 28 & 49 & 45 & 32 & 33 & 44 & 52 & 25 & 66 & 11 \\
\hline Yes & 16 & 19 & 27 & 8 & 18 & 17 & 31 & 4 & 25 & 10 \\
\hline Total & 44 & 68 & 72 & 40 & 51 & 61 & 83 & 26 & 91 & 21 \\
\hline
\end{tabular}

Notes: ${ }^{*}$ In logarithms, MX\$/person/month.

Source: Author with information from ENESTYC, 2005; INEGI 


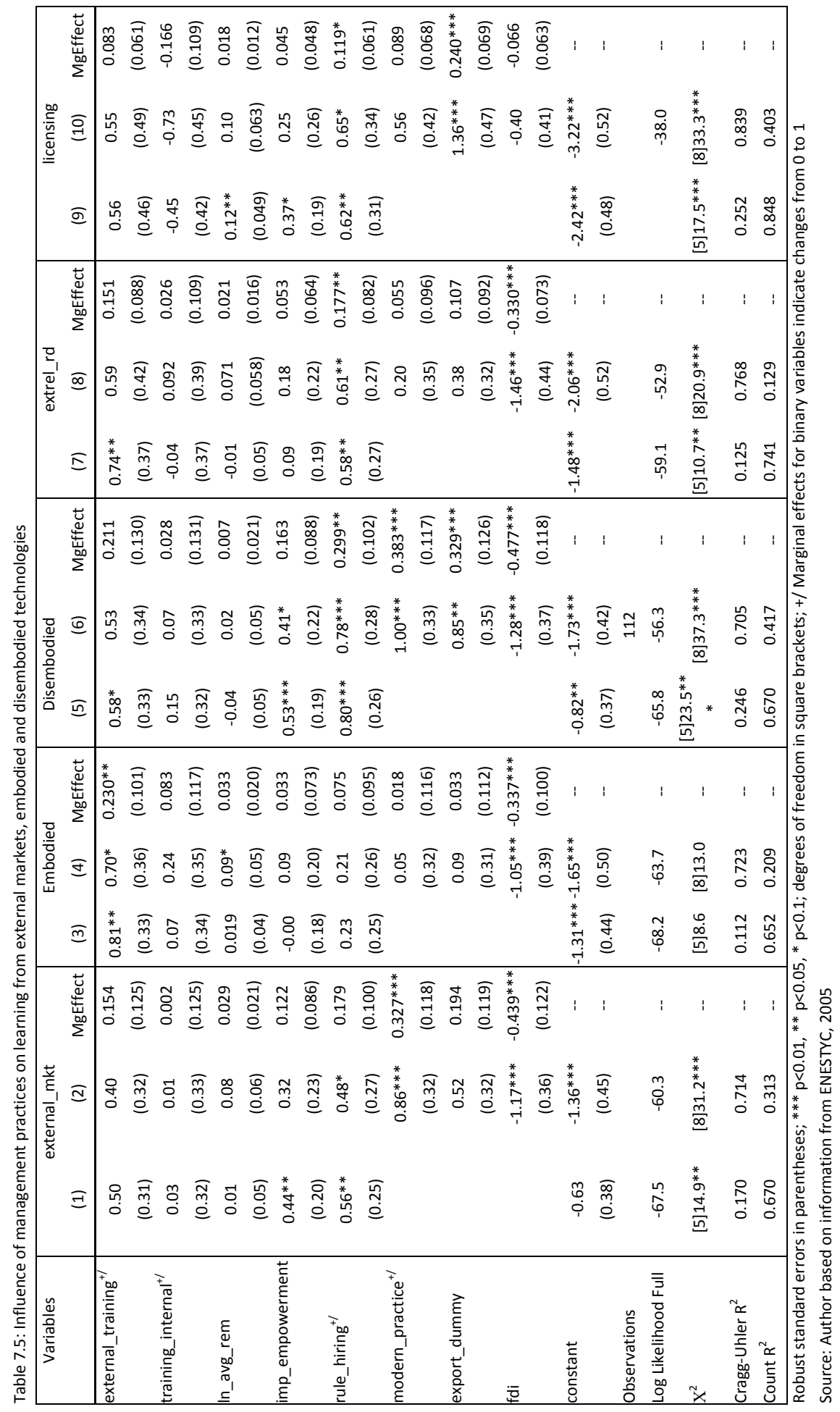




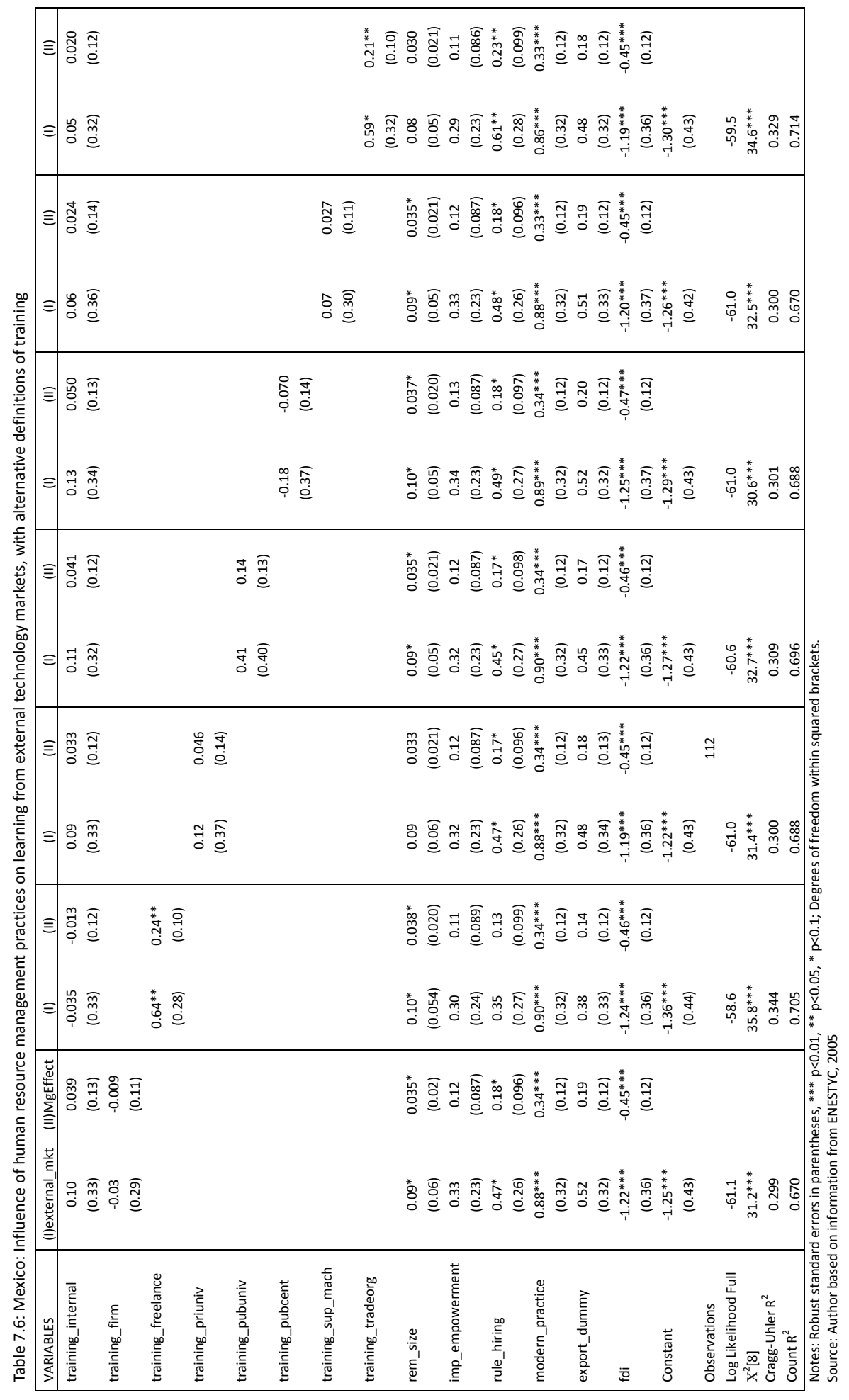




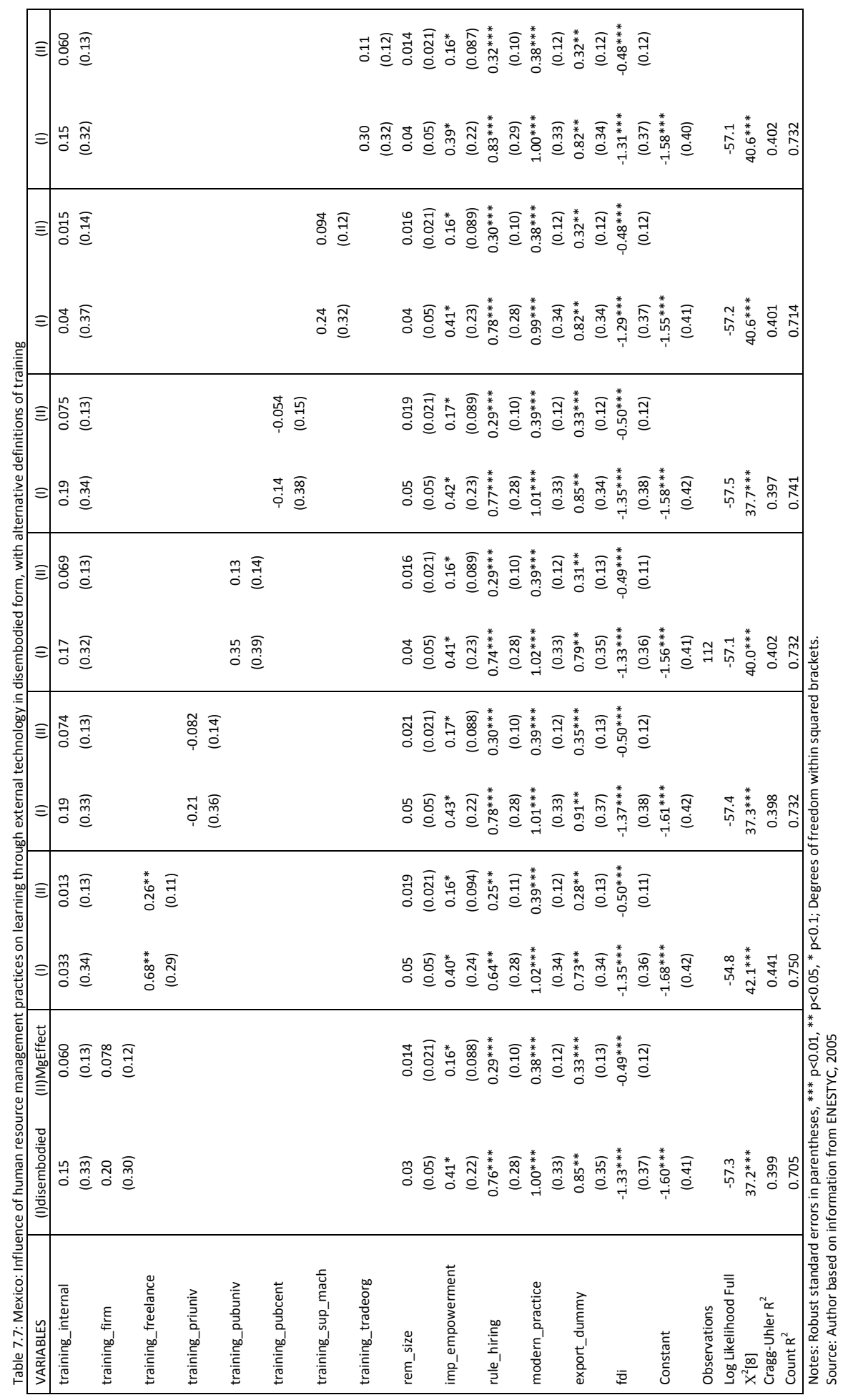




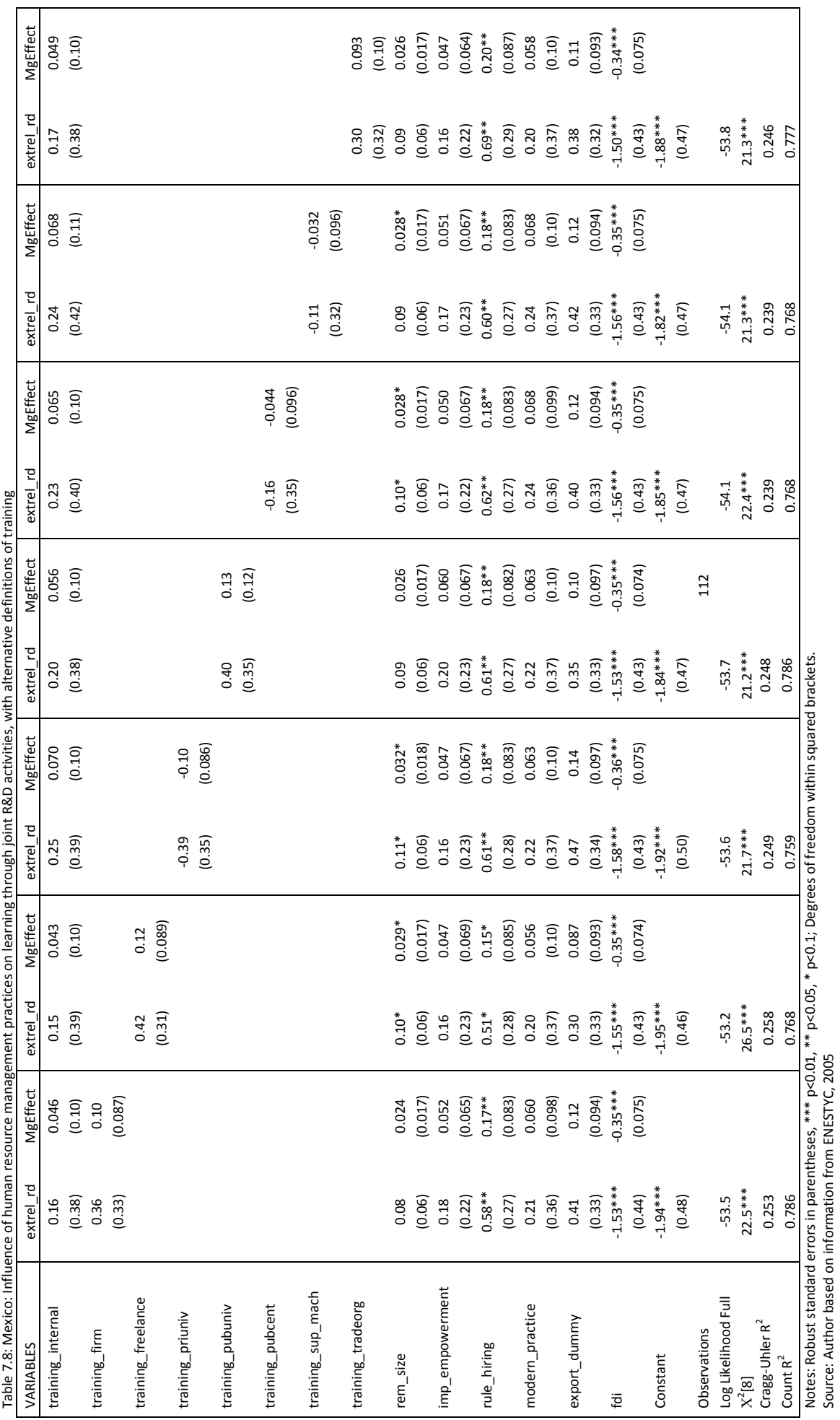




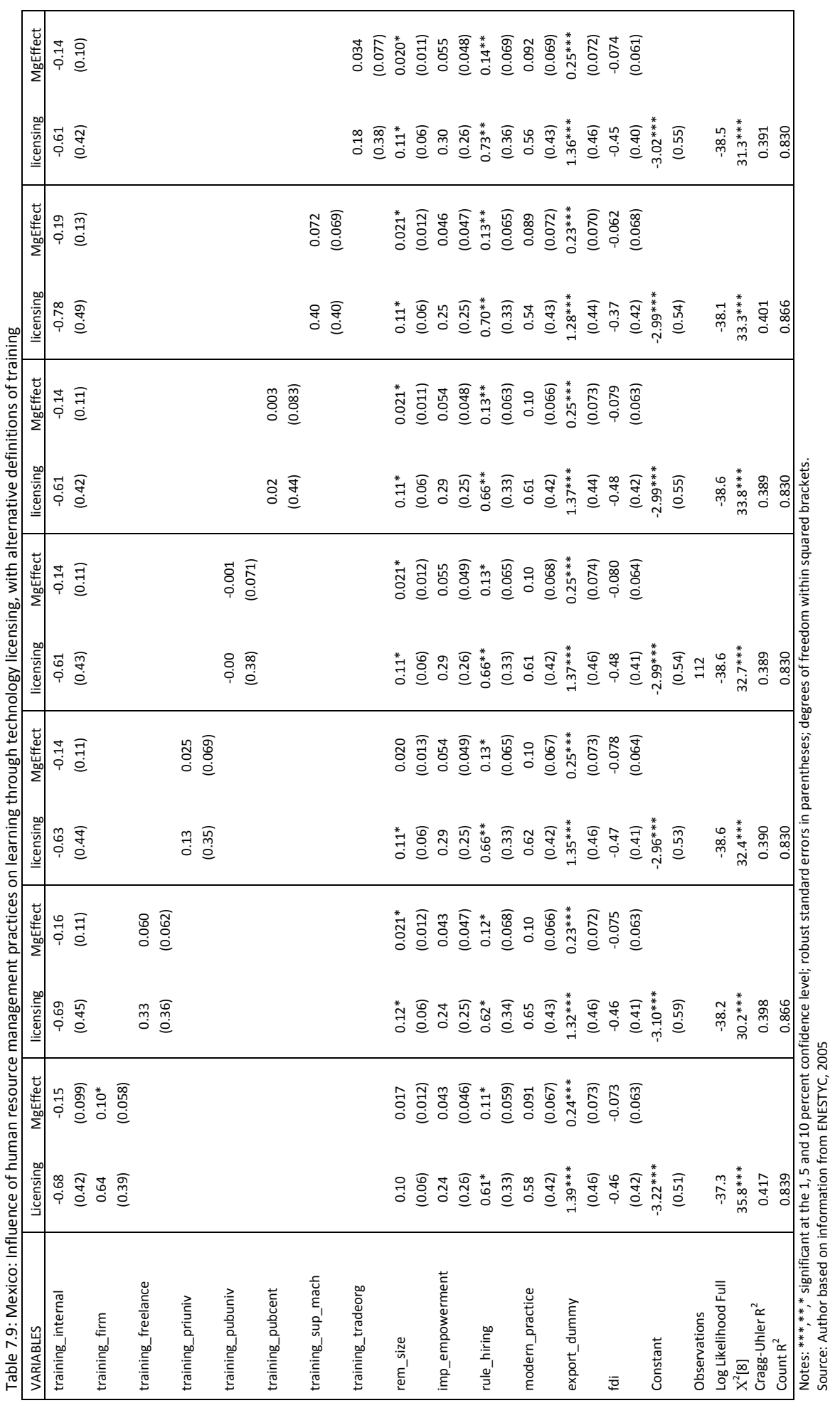





\section{Chapter 8}

\section{Do human resource management practices contribute to combined learning strategies in developing countries?}

\section{Introduction}

This thesis investigates how human resource management practices influence learning for innovation by pharmaceutical firms in Mexico. Chapters 6 and 7 analyzed the extreme cases where firms choose between two mutually exclusive learning strategies: a firm learns by means of internal R\&D efforts only (chapter 6). Alternatively, firms rely, exclusively, on external markets for technology (chapter 7). Chapters 6 and 7 thus documented that the contribution of human resource management practices is somewhat limited as compared to that of variables on firm's characteristics. However limited, such findings suggested that the contribution of management practices is contingent on the choice of either of the two learning strategies. Divergences resulted from the specific outcome pursued by the firm and consequently, from the nature of the knowledge requirements. Based on the discussion in chapter 1 , learning is associated with either knowledge exploitation or exploration. This chapter takes a step forward to document the influence of human resource management practices when internal and external learning strategies are deployed together. The chapter thus follows a wellestablished literature on technology acquisition at firm level (section 2.3, chapter 2).

\subsection{Dual learning strategies in the pharmaceutical industry}

At a global scale the pharmaceutical industry stands out for its technological dynamism and intensive use of internal and external knowledge sources by firms. Inhouse R\&D is key element of success particularly at times of increased competition from generic manufacturers, and a relatively low pace in new drug innovation. Internal technological efforts are insufficient to respond, in a timely manner, to current market conditions. Mergers and acquisitions, outsourcing and off-shoring of $R \& D$ and other innovation-related activities increasingly guide business strategies of global pharmaceutical firms.

The literature equally documents that latecomer pharmaceutical firms can tap into both internal and external sources of knowledge; successful catching up involves strategic combinations of these two approaches. Kim (1997) identified three main channels for firms in developing countries to develop new products: (1) 
by developing new raw materials in-house, hence they can substitute parts of the manufacturing process of patented drugs; (2) by relying on multinationals as source of technology through licensing or technical assistance; and (3) by purchasing active ingredients and excipients in open markets. In any of these three cases, some systematic domestic R\&D efforts are needed to build up the capacities required to manufacture the final drug.

As firms gain in technological complexity and innovation capacity, internal learning activities play increasingly relevant roles moderating the process of learning from external markets (Cattozzella and Vivarelli 2007; Escribano et.al, 2009). In the study about the differences in technological strategies and corresponding innovation behaviours of 37 pharmaceutical firms in Korea, Kim et.al, (1989) categorized firms according to scale of operations and technological capabilities. Large firms with significant technological capabilities used external knowledge to complement domestic technological efforts. They exhibited the highest degree of innovativeness. By contrast, large firms with relatively lower capabilities relied on external knowledge to improve short-term profitability. Finally, smaller firms showed a dual behaviour: On the one hand, firms that had developed some fair technological capabilities relied, almost exclusively, on domestic research efforts; they enjoyed the highest rates of growth. On the other hand, small firms with low capabilities tended to imitate products with relatively limited technological complexity. Mobility of personnel constituted their preferred channel to capture external knowledge.

Recently Singh (2007) documented the progression in the innovative capacity of Indian drug manufacturers. Starting as bulk generic suppliers, Indian firms increasingly contribute to drug discovery and clinical research. Notable in this process has been formation of alliances with large US and European pharmaceuticals, efforts to capture and benefit from knowledge and experience of highly qualified Indian expatriates and significant export orientation (Meyers 2006; Reddy 1997). In addition to some firm and context specific factors, Kim et.al, (1989), Reddy (1997) and Meyers (2006) stressed the contribution that human resources have had for successful catching up of pharmaceutical firms in South Korea and India, respectively. Such contribution was linked to the availability of resources, corporate goals and notably, managerial preferences. Good engineering and research skills, the entrepreneurial orientation of management, dynamic organisational practices and engineering leadership, among other factors, contribute to successful catching up by latecomer firms.

In a study about Mexico, Zúñiga et.al, (2007) looked at in-house R\&D and technology transfer over the period 1994 and 2000. They built on data from the national manufacturing census, which is similar to the dataset used in this thesis. ${ }^{1}$ Furthermore, the analytical framework of Zúñiga and colleagues was analogous to the one used here: they adopted a catching up perspective. The authors concluded

\footnotetext{
${ }^{1}$ The first waves of the ENESTYC were embedded within the manufacturing census. Notwithstanding some differences in the kind of information captured by each of the surveys, their methodological underpinnings are directly comparable.
} 
that internal and external learning strategies are exogenous in the Mexican pharmaceutical industry. In-house R\&D has little bearing on external acquisition of technology; at the same time, technology purchases only marginally affect corporate decisions to invest in R\&D. The authors indicated that the observed low probability of complementarities could be explained by two divergent technological objectives of firms. Market exposure, through exports for example, drives R\&D. By contrast, external procurement of technology responds to searches for increased productivity, capital intensity and company size. This notwithstanding international diversification, through exports, could lead to complementary learning strategies.

This chapter re-examines some of the conclusions by Zúñiga et.al, (2007). In order to do so the analysis incorporates additional information so as to better explain the learning processes occurring inside the firm. Major differences with Zúñiga et.al,'s (2007) study include our finer definitions of the dependent variables: they looked only at whether firms performed R\&D or not, or the participation of pharmaceutical firms in technology licensing. By contrast, this chapter combines some of the finer definitions of internal and external learning indicators (chapters 6 and 7). In addition, the inclusion of the human resource management variables sheds light on how pharmaceutical firms mobilise the human resources involved in distinct combinations of learning activities. Since dissimilar combinations of strategies require distinct forms of organizing personnel, relevant management practices should differ as well. The chapter proceeds as follows: Section 2 presents the variable definitions, the data and the subsequent research strategy. Section 3 examines the extent to which pharmaceutical firms in Mexico combine internal and external learning strategies. Section 4 presents the econometric analysis. The discussion is guided by the research hypotheses in chapter 3 . Finally, section 5 provides some discussion and conclusions of results.

\section{Data and research strategy}

Data used in this paper come from the ENESTYC dataset described in chapter 3 . The variables on internal and external learning were presented in chapters 6 and 7, respectively. Based on those chapters, seven indicators on internal learning strategies are used here (tables 6.1). The external strategy, in turn, is captured by five distinct indicators (tables 7.1).

Human resource management variables: Based on the discussion in chapters 2 and 3, this chapter incorporates the following human resource management interventions: the provision of training, remunerations, worker's empowerment and rules governing staff hiring. In addition, a pertinent distinction was made between internal and external provision of training. ${ }^{2}$ Alternative variables serving to identify the actual external training provider were also considered in the analysis. Remunerations were normalized by taking into account the firm's size; this reduced

\footnotetext{
${ }^{2}$ The results from models with the provision of training, train04, were no significantly different compared to those presented here. However, in some cases the distinction between types of training helped to avoid some specification troubles preventing the models to converge.
} 
potential collinearity problems and captured scale effects.

Control variables: This chapter controls for a firm's characteristics including: adoption of modern management practices; capital ownership and participation in export markets. Tables 6.2 and 7.2 provided correlation analyses for the explanatory and control variables used in this chapter.

\subsection{Research strategy}

The dependent variables in this chapter are binary; they reflect alternative choices of learning strategies made by the firm. The analysis assumes that learning strategies can be deployed together. Such interrelation suggests the presence of some unobservable characteristics of the firm that influence the selection of learning strategies. If modelled inadequately, for example through independent univariate equations, the results can render inconsistent (biased) estimates of the influence of management practices on the choice of learning strategies. A suitable econometric approach to deal with these issues is bivariate probit analysis. ${ }^{3}$ As an extension of probit regression, bivariate analysis allows the running of two simultaneous equations with expected correlation in their disturbance terms (Greene 2003). The resulting system of equations looks as follows:

$\mathrm{y}_{1 \mathrm{i}}{ }^{*}$ and $\mathrm{y}_{2 \mathrm{j}}{ }^{*}$ are latent variables, such that:

$\mathrm{y}_{1 \mathrm{i}}{ }^{*}=$ Different types of in-house R\&D

$\mathrm{Y}_{2 \mathrm{j}}{ }^{*}=$ Diverse indicators on external markets for technology

$\mathrm{M}=$ Vector of management variables that influence the probability of choosing among learning strategies internal and external

$X=$ Vector of firm characteristics (control variables) that influence the probability of choosing among learning strategies

$\varepsilon i, v i=$ Vectors of disturbances

$y_{1 i} *=\beta^{\prime} M+u_{1} X+\varepsilon i, \mathrm{~F}_{\text {internali }}=1$, if $y_{1}^{*}>0,0$ otherwise

$y_{2 j} j^{*}=\delta^{\prime} M+u_{2} X+v i, \mathrm{~F}_{\text {externalj }}=1$, if $y_{2}^{*}>0,0$ otherwise

With $i=1, \ldots, 9$ and $j=1, . ., 5$

Where the sub-indexes $i$ and $j$ in internal ${ }_{i}$ and external ${ }_{j}$ change according to the distinct definitions of the internal and external learning strategies. In other words, internal ${ }_{i}$ captures inhouse_rd, rd_explore, and so on; similarly, external ${ }_{j}$ refer to extrel_mkt; extrel_rd and so on.

\footnotetext{
${ }^{3}$ Multinomial logit regression is an alternative methodology (Greene 2003). However, it was unsuitable considering the limited size of our working sample. More importantly, the perceived interrelation between internal and external learning strategies could lead to violation of the critical assumption of independence of irrelevant alternatives (IIA) (Long and Freese 2006; McFadden 2000). In simple terms, all else being equal, the availability of internal learning strategies influences the adoption of external learning strategies.
} 
The approach assumes:

$$
\begin{aligned}
& E(\varepsilon / m, x)=E(v / m, x)=0, \\
& \operatorname{Var}(\varepsilon / m, x)=\operatorname{Var}(v / m, x)=1, \\
& \operatorname{Cov}(\varepsilon, v / m, x)=\rho
\end{aligned}
$$

In order to test for the adequacy of the bivariate specification, estimates were contrasted with those from equivalent univariate probit equations. In particular, we examined the value and statistical significance of the errors correlation term, $\rho$, for the bivariate models. A positive and significant test indicates that the learning strategies are interrelated; univariate models will capture only partial information and render biased results (Greene 2003).

Modelling proceeded as follows: First, the chapter identified a basic model specification for the pair of dependent variables on in-house R\&D, rd_inhouse, and external knowledge acquisition, extrel_mkt, respectively. Second, the definition of the dependent variables was changed iteratively while keeping the structure on the right hand side of the equation. In such a way the distinct indicators on in-house R\&D paired with distinct specifications of external markets. The exercise documented the different influence of the explanatory variables on the distinct goals and means to acquire technology. Several checks were performed on the robustness of results. First, based on Cassiman and Veugelers (2006), each pair of internal and external learning strategies was regressed on the control variables only. Second, we ran full specification models and compared results. As we comment later, this procedure is an indirect way to test for complementary relationships between learning strategies. Once the basic structure of the models was identified, we ran an additional bivariate specification, this time including only those explanatory variables that showed statistical significance, at the five percent level or lower, in the basic model. For reasons of space and feasibility of the analysis, results from all those equations are omitted from presentation; nevertheless, they are available from the author upon request.

As a complementary way to look at results from probit regression, chapters 6 and 7 reported the computation of marginal effects for the models included in the corresponding analyses. Considering the scope of this chapter, here we report the conditional probability that a firm performs an external learning strategy provided that it is already conducting some kind of learning efforts in-house (Long and Freese 2006). Hence, the analysis identifies how external knowledge sources supplement internal learning activities.

\section{Empirical results}

The discussion of the main results from the empirical analysis splits into two sections: First, we describe the propensity of pharmaceutical firms in Mexico to adopt dual learning strategies. Then we present results from our econometric analysis. 


\subsection{Learning and technology acquisition}

Table 8.1 summarizes the learning behaviour of pharmaceutical firms in Mexico. It shows that internal and external learning strategies are positively and significantly, albeit weakly, correlated: 0.48 . The strongest correlation between external_mkt and the detailed R\&D variables corresponds to improvement of drug manufacturing processes, 0.53 . By contrast, the weakest correlation is found with learning from external sources supporting new process innovations, 0.17 . It is evident that acquisition of disembodied technologies complements efforts to improve drug manufacturing processes.

Table 8.1: Mexico: Correlation analysis for the choice of joint learning strategy by pharmaceutical firms

\begin{tabular}{|lccccccc|}
\hline & $\begin{array}{c}\text { rd_inho } \\
\text { use }\end{array}$ & $\begin{array}{c}\text { rd_design } \\
\text { _meq }\end{array}$ & $\begin{array}{c}\text { rd_improve } \\
\text { process }\end{array}$ & $\begin{array}{c}\text { rd_drug } \\
\text { _design }\end{array}$ & $\begin{array}{c}\text { rd_drug } \\
\text { improvement }\end{array}$ & $\begin{array}{c}\text { rd_exploi } \\
\text { t }\end{array}$ & $\begin{array}{c}\text { rd_explor } \\
\text { e }\end{array}$ \\
\hline external_mkt & $\mathbf{0 . 4 8 4}$ & $\mathbf{0 . 3 4 0}$ & $\mathbf{0 . 5 2 7}$ & $\mathbf{0 . 4 5 5}$ & $\mathbf{0 . 4 2 7}$ & $\mathbf{0 . 4 6 2}$ & $\mathbf{0 . 4 7 2}$ \\
tech_package & $\mathbf{0 . 3 1 2}$ & $\mathbf{0 . 3 2 9}$ & $\mathbf{0 . 3 3 4}$ & $\mathbf{0 . 3 1 2}$ & $\mathbf{0 . 3 9 1}$ & $\mathbf{0 . 3 3 8}$ & $\mathbf{0 . 3 4 4}$ \\
tech_consultant_firm & $\mathbf{0 . 2 9 4}$ & $\mathbf{0 . 4 0 9}$ & $\mathbf{0 . 3 1 0}$ & 0.201 & $\mathbf{0 . 3 7 0}$ & $\mathbf{0 . 3 2 0}$ & 0.234 \\
tech_literature & $\mathbf{0 . 4 1 5}$ & $\mathbf{0 . 3 9 2}$ & $\mathbf{0 . 3 7 6}$ & $\mathbf{0 . 3 9 8}$ & $\mathbf{0 . 3 0 3}$ & $\mathbf{0 . 3 6 0}$ & $\mathbf{0 . 4 2 6}$ \\
extrel_learn_inds & 0.100 & 0.026 & 0.156 & 0.098 & 0.142 & 0.114 & 0.093 \\
extrel_acq_machin & 0.173 & $\mathbf{0 . 2 8 1}$ & 0.190 & 0.149 & 0.226 & 0.191 & 0.196 \\
extrel_rd & $\mathbf{0 . 3 4 9}$ & 0.186 & $\mathbf{0 . 4 4 9}$ & $\mathbf{0 . 3 4 1}$ & $\mathbf{0 . 3 8 1}$ & $\mathbf{0 . 3 7 4}$ & $\mathbf{0 . 3 7 4}$ \\
licensing & $\mathbf{0 . 0 7 5}$ & 0.179 & 0.128 & 0.144 & 0.103 & 0.051 & 0.136 \\
embodied & $\mathbf{0 . 3 5 6}$ & $\mathbf{0 . 3 5 8}$ & $\mathbf{0 . 3 7 3}$ & $\mathbf{0 . 2 8 2}$ & $\mathbf{0 . 4 5 5}$ & $\mathbf{0 . 3 8 9}$ & $\mathbf{0 . 3 0 8}$ \\
disembodied & $\mathbf{0 . 4 4 2}$ & $\mathbf{0 . 3 0 1}$ & $\mathbf{0 . 4 9 6}$ & $\mathbf{0 . 4 2 1}$ & $\mathbf{0 . 3 6 7}$ & $\mathbf{0 . 4 1 4}$ & $\mathbf{0 . 4 4 0}$ \\
\hline
\end{tabular}

Notes: For presentation purposes, the correlations table was truncated in those sections that had been presented already in chapters 6 and 7 . Figures in bolder fonts denote correlations different from zero at $1 \%$ level of significance Source: Author based on data from ENESTYC, 2005, INEGI

Table 8.2 reveals that a significant number of pharmaceutical firms in our sample pursued joint learning strategies, 55.4 percent. More specifically, 53.6 percent of firms adopted dual strategies to exploit existing knowledge. As for the behaviour of each pair of detailed definitions of both in-house R\&D and external technology acquisition, 50 percent or more of the pharmaceutical firms implement dual learning strategies. The exception is rd_design_meq with merely 17.9 percent of firms interacting with other agents during design or improvement of machinery and equipment. This latter finding reflects the separation between drug manufacturers and firms producing capital goods for such industry. The values of the Pearson $X^{2}$ tests failed to accept the null hypothesis of independence between each pair of learning strategies. This clustering suggests some complementarity among learning strategies in the sense that doing more of one increases the expected return on the other (Arora et.al, 2001). Nevertheless such complementarity is week.

A look at indicators on employment, domestic sales and exports and so on, revealed that firms that involve in joint learning efforts tend to outperform those reporting no learning activities at all. For instance, the first group of firms reported average employment, total sales and sales per employee that are about 1.5, 3.0 and 2.4 times larger than those of firms in the second group. By contrast, the average shares of both FDI and exports were lower for firms implementing joint learning strategies ( 25 percent and 6.0 percent, respectively), than those for firms reporting 
no learning activities ( 30.0 percent and 8.0 percent, respectively). In both these cases the bulk of sales target the local market.

Table 8.2: Frequency of learning strategies of pharmaceutical firms in Mexico

\begin{tabular}{|c|c|c|c|c|}
\hline \multirow{2}{*}{$\begin{array}{c}\text { Internal } \\
\text { rd_inhouse }\end{array}$} & \multicolumn{4}{|c|}{ External (Extrel_mkt) } \\
\hline & No & Yes & Total & Pearson $X^{2}(1)$ \\
\hline No & $23(20.5)$ & $6(5.4)$ & $29(25.9)$ & $26.2825 * * *$ \\
\hline Yes & $21(18.7)$ & $62(55.4)$ & $83(74.1)$ & \\
\hline Total* & $44(39.3)$ & $68(60.7)$ & $112(100.0)$ & \\
\hline \multicolumn{5}{|c|}{ rd_improve_process } \\
\hline No & $30(26.8)$ & $11(9.8)$ & $41(36.6)$ & $31.1339 * * *$ \\
\hline Yes & $14(12.5)$ & $57(50.9)$ & $71(63.4)$ & \\
\hline \multicolumn{5}{|l|}{ rd_design_meq } \\
\hline No & $43(38.4)$ & $48(42.9)$ & $91(81.2)$ & $12.9154 * * *$ \\
\hline Yes & $1(0.90)$ & $20(17.9)$ & $21(18.8)$ & \\
\hline \multicolumn{5}{|c|}{ rd_impr_drugs } \\
\hline No & $26(23.2)$ & $12(10.7)$ & $38(33.9)$ & $20.4684 * * *$ \\
\hline Yes & $18(16.1)$ & $56(50.0)$ & $74(66.1)$ & \\
\hline \multicolumn{5}{|l|}{ rd_design } \\
\hline No & $29(25.9)$ & $14(12.5)$ & $43(38.4)$ & $23.1984^{* * *}$ \\
\hline Yes & $15(13.4)$ & $54(48.2)$ & $69(61.6)$ & \\
\hline \multicolumn{5}{|l|}{ rd_exploit } \\
\hline No & $24(21.4)$ & $8(7.1)$ & $32(28.5)$ & $23.9572 * * *$ \\
\hline Yes & $20(17.9)$ & $60(53.6)$ & $80(71.4)$ & \\
\hline \multicolumn{5}{|l|}{ rd_explore } \\
\hline No & $29(25.9)$ & $13(11.6)$ & $42(37.5)$ & $24.9554 * * *$ \\
\hline Yes & $15(13.4)$ & $55(49.1)$ & $70(62.5)$ & \\
\hline
\end{tabular}

Notes: Categories are exclusive; sample includes only firms without missing values, $\mathrm{n}=112 ; * * *$ significant at $1 \%$ level of confidence; percentage share of each cell relative to total firms in sample within parentheses Source: Author with information from ENESTYC, 2005

Table 8.3: Characterisation of human resource management variables included in the analysis, by type of learning strategy

\begin{tabular}{|lcc|c|c|}
\hline \multicolumn{1}{|c}{ Variable } & \multicolumn{2}{c|}{ Learning strategy } \\
\hline & Internal & External & \multicolumn{2}{c|}{ Internal \& external } \\
\hline & & & Yes & No \\
\hline training_internal & 70 & 56 & 53 & 9 \\
external_training & 68 & 56 & 53 & 5.7 \\
rem_size* & 7.0 & 7.1 & 6.9 & \\
imp_empower & & & & 34 \\
Not implemented & 50 & 35 & & 6 \\
Very important & 8 & 9 & & 22 \\
Not important & 25 & 24 & 34 & 28 \\
rule_hiring & 42 & 38 & & \\
\hline
\end{tabular}

* Refers to the minimum and maximum average remuneration in $M X \$ 1000$.

Sample without missing values $=112$

Source: Author with information from ENESTYC, 2005

Table 8.3 presents the human resource management variables included in the analysis according to the choice of joint learning strategies. One observes that a large share of firms adopting dual approaches to learning provided training to employees during 2004; training was both internal and external. In line with the findings in previous chapters, firms performing joint learning strategies report compensation levels above those of firms with more passive stances towards learning. By contrast, worker's participation in decision-making about the workplace 
is either not adopted or not important. Finally about a third of firms implementing joint learning approaches reported that they regulate staffing practices through either collective contract, internal regulations of both. The figures are relatively lower than those of firms that adopt single learning strategies.

\subsection{Econometric results}

\subsubsection{Basic model: Joint internal and external learning strategies}

Table 8.4 presents estimates for bivariate probit models corresponding to the combination of rd_inhouse and external_mkt. The table reveals that the models are statistically significant at the one percent level of confidence; the variables included in the analysis adequately explain learning strategies of pharmaceutical firms in Mexico. The Wald tests on the value of the errors correlation term, $\rho$, are positive and statistically significant at the one percent confidence level. This supports the superiority of bivariate over binary probit specifications.

Table 8.4: Bivariate probit models for joint adoption of internal and external learning strategies

\begin{tabular}{|c|c|c|c|c|c|}
\hline VARIABLES & rd_inhouse & external_mkt & rd_inhouse & external_mkt & cond_prob \\
\hline \multirow[t]{2}{*}{ training_internal } & & & $0.60 *$ & 0.02 & -0.10 \\
\hline & & & $(0.33)$ & $(0.33)$ & (0.09) \\
\hline \multirow[t]{2}{*}{ external_training } & & & $0.65 * *$ & 0.38 & 0.04 \\
\hline & & & $(0.31)$ & $(0.31)$ & (0.11) \\
\hline \multirow[t]{2}{*}{ rem_size } & & & 0.022 & 0.069 & 0.02 \\
\hline & & & $(0.058)$ & $(0.053)$ & $(0.02)$ \\
\hline \multirow[t]{2}{*}{ rule_hiring } & & & 0.091 & $0.44 *$ & $0.15^{*}$ \\
\hline & & & $(0.29)$ & $(0.26)$ & (0.09) \\
\hline \multirow[t]{2}{*}{ imp_empowerment } & & & -0.14 & 0.28 & $0.13^{*}$ \\
\hline & & & $(0.24)$ & $(0.21)$ & $(0.07)$ \\
\hline \multirow[t]{2}{*}{ modern_practice } & 0.34 & $1.02 * * *$ & 0.31 & $0.86 * * *$ & $0.31 * * *$ \\
\hline & $(0.28)$ & $(0.28)$ & $(0.35)$ & $(0.33)$ & $(0.12)$ \\
\hline \multirow[t]{2}{*}{ export_dummy } & $0.70 * *$ & $0.57^{*}$ & $0.70 * *$ & 0.47 & 0.07 \\
\hline & $(0.32)$ & $(0.30)$ & $(0.33)$ & $(0.31)$ & $(0.11)$ \\
\hline \multirow[t]{2}{*}{ Fdi } & $-0.67^{*}$ & $-0.84 * * *$ & $-0.97^{* *}$ & $-1.16 * * *$ & $-0.31 * *$ \\
\hline & $(0.35)$ & $(0.32)$ & (0.39) & $(0.34)$ & $(0.14)$ \\
\hline \multirow[t]{2}{*}{ Constant } & 0.30 & -0.41 & -0.59 & $-1.27^{* * *}$ & \\
\hline & $(0.25)$ & $(0.25)$ & $(0.40)$ & $(0.44)$ & \\
\hline Observations & & & 112 & & \\
\hline Log Likelihood Full & & -115 & & -105 & \\
\hline$x^{2}$ & & {$[6] 23.9 * * *$} & & {$[16] 64.4^{* * *}$} & \\
\hline$\rho$ & & 0.71 & & 0.78 & \\
\hline Wald test, $\rho=0$ & & [1]17.79*** & & [1]19.80*** & \\
\hline
\end{tabular}

Notes: $* * * * * *$ significant at the 1,5 and 10 percent confidence level; robust standard errors in parentheses; Degrees of freedom within squared brackets; marginal effects correspond to changes in conditional probabilities that a firm adopts an external learning strategy provided that it already carries out internal learning efforts. In other words, these are probabilities for combinations of (external=1| internal=1), see STATA manual for further reference; variable definitions in Chapter 3.

Source: Author based on information from ENESTYC, 2005.

Individual estimates reveal that participation in export markets has positive and statistically significant effects on the likelihood that a firm carries out in-house R\&D. By contrast, learning from external markets is positively determined by adoption of modern organisational practices. Foreign ownership produced negative effects on 
the two learning strategies. As for management variables, the only perceptible, positive effect derives from the provision of external training linked to internal learning. The rest of variables rendered little information on their impact on the adoption of joint learning strategies. Overall, the preliminary conclusion is that human resource management plays a limited role as a factor underpinning learning activities of pharmaceutical firms in Mexico.

\subsubsection{Changing definitions of internal and external learning strategies}

As a subsequent step in the analysis alternative models were run in which rd_inhouse and external_mkt were replaced, one at a time, by each of the finer definitions for R\&D and external markets, respectively. Thus the analysis captured the association of human resource management practices with different combinations of learning strategies; distinct innovation outcomes and diverse types of knowledge pursued by the firm. This is as follows:

In-house R\&D for improved/new process/product: Table 8.5 contains results for models that identify in-house R\&D according to the outcome pursued by the firm. The table reveals that human resource management variables have no perceptible contribution on learning underpinning improvements in either existing drugs or drug manufacturing processes. Such contribution is more and more noticeable as knowledge searches increase in their exploratory scope. The provision of training, particularly from external sources, underpins new drug designs and development of new drug manufacturing processes.

Estimates for the control variables equally showed a rather mixed behaviour. Whereas adoption of modern organisational practices is positively and significantly associated with external learning, exports positively induce new drug designs. Finally foreign ownership remains a negative determinant of technological learning.

The computation of conditional probabilities that a firm uses external knowledge, when it already performs in-house $R \& D$, hints at the poor connection between internal and external learning strategies. In such contexts, the role of human resource management practices is also rather limited. The use of worker's empowerment contributes positively to joint learning strategies connected with improvements in drug manufacturing processes. Introducing regulations to guide staffing practices is also positive and significant in the case of learning for new drug design. As for the control variables, the conditional probabilities for modern_practice were positive and significant when associated with product and process improvements. Similar conclusions can be obtained in the case of new drug designs. Finally, whereas fdi conditions negatively learning activities, exports did not show perceptible effects.

Knowledge exploitation and exploration: Table 8.6 depicts the results for two new sets of models: in-house R\&D for knowledge exploitation and exploration, respectively. In both these cases the variable external_mkt remained unchanged. Indicators on the goodness of fit revealed that the models are statistically significant at customary confidence levels. The Wald tests on the value of the errors correlation term, $\rho$, equally support the adequacy of the bivariate specification. 
In the case of learning for knowledge exploitation, individual estimates show that modern_practice and fdi influence learning from external sources; however the effects run in different directions. By contrast those same variables reported no perceptible effects on in-house R\&D. Inclusion of management variables revealed that internal training influences knowledge exploitation via in-house R\&D. In levels the remaining variables on human resource management provided no meaningful information. However, computation of conditional probabilities show that worker's empowerment influences positively and significantly the use of external knowledge as supplement of in-house R\&D. Similar effect results from modern_practice. Finally, fdi leads to negative learning behaviours.

Turning to the models on knowledge exploration, results corroborated that exports and foreign ownership have opposed effects on learning. Whereas the former is positive, the latter is negative. The variable modern_practice remains relevant for external learning. As for the human resource management practices, again, the results render very limited information. However, one can perceive that the provision of external training increases the likelihood that firms perform inhouse R\&D. Regulations governing staff hiring have positive and statistically significant influences on the conditional probability of using external knowledge when an internal learning strategy is already in place.

Knowledge exploitation and exploration with embodied and disembodied technologies: Table 8.7 presents estimates for models where the variable on external knowledge was also modified. The variable is replaced by those on technology acquisition in either embodied or disembodied form. Consequently, the table shows models that distinguish how pharmaceutical firms in Mexico tap into embodied or disembodied technologies to supplement knowledge exploitation and knowledge exploration, respectively. Results in table 8.7 show that the models are statistically significant at customary confidence levels. The values of the errors correlation term, $\rho$, indicate that the bivariate specification adequately explains the adoption of dual learning strategies by pharmaceutical firms.

Individual estimates show that the provision of internal training supports knowledge exploitation combined with the acquisition of embodied technologies. This positive influence is offset by the impact of foreign ownership. The remaining variables on human resource management practices and firm characteristics reported no perceptible effects on learning.

Table 8.7 equally shows that knowledge exploitation and acquisition of disembodied technologies are better explained by firm characteristics. Exports and adoption of modern organisational practices have positive effects, but fdi remains negative. As for the human resource management variables, the presence of rules on staff hiring supports the incorporation of disembodied technologies.

Chapter 7 documented that pharmaceutical firms in Mexico acquire more frequently disembodied technologies than embodied alternatives. This finding is reflected in the models investigating how embodied and disembodied technologies associate with knowledge exploration. Estimates show that firm characteristics are those that better explain adoption of joint learning strategies. In fact the more notorious effects correspond to combinations including rd_explore and 
disembodied knowledge. Although the human resource management variables provide limited information on the adoption of dual learning strategies, it is evident that the provision of external training contributes to R\&D for knowledge exploration. Similarly, rules_hiring underpins adoption of disembodied technology.

Finally, the computation of conditional probabilities revealed a very limited interaction between internal and external learning. In particular changes in the presence of management practices explain very little of the shifts in the probability that firms combine knowledge exploitation or exploration with the acquisition of either embodied or disembodied technologies. An interesting exception was the combination of rd_explore and disembodied knowledge. In that case rules_hiring and imp_empowerment were positive and statistically significant. A similar conclusion applies for modern_practice. By contrast, the conditional probability associated with foreign ownership remained negative and statistically significant.

Knowledge exploitation and/or exploration; contracted R\&D and technology licensing: The literature grants considerable attention to understanding how firms tap into contracted or external R\&D and technology licensing to complement internal learning efforts (Leone and Reichstein 2009; Nakamura and Odagiri 2005). In view of the importance that both these activities have for the pharmaceutical industry, this chapter explored these issues in the context of Mexico. In practice, the variables on rd_external and licensing where coupled with searches supporting either knowledge exploitation or knowledge exploration. Results are presented in table 8.8. According to the Wald tests on the errors correlation term, $\rho$, the bivariate specification was inadequate to analyse the combination of external R\&D and licensing with R\&D for knowledge exploitation. These activities are independent from each other; the equations can be run separately. The analysis will take us back to the analyses in chapters 6 and 7. A similar finding occurred in the case of joint learning strategies involving rd_explore and licensing. In light of these results, the discussion here focuses on models where external $R \& D$ was combined with $R \& D$ for knowledge exploration.

Estimates revealed that participation in export markets induces positive incentives for knowledge exploration through R\&D. The opposite effect is derived from foreign capital ownership on both internal and external learning efforts. Inclusion of human resource management indicators confirmed some previous findings in the case of knowledge exploration. The provision of external training generates positive and significant effects on in-house R\&D. Rule_hiring, in turn, increases the likelihood that a firm contracts R\&D.

Computation of conditional probabilities indicates that the only meaningful changes are associated with the variables rules_hiring and fdi. As has been the case so far, foreign ownership is a negative determinant of learning in the pharmaceutical industry in Mexico.

Changing definitions of external training providers: Firms can interact with several agents in the external environment. Given the scope of this thesis, the focus has been on organisations taking part in the provision of external training. This section reports the results for models that identify each of those specific partners. The analysis distinguished R\&D for either knowledge exploitation or exploration in 
combination with external_mkt. Results are presented in tables 8.9 and 8.10 .

Models in tables 8.9 and 8.10 are statistically significant at customary confidence levels. In addition, the values of the errors correlation term, $\rho$, indicate that the bivariate specifications adequately explain adoption of dual learning strategies by pharmaceutical firms. Individual estimates tell us that the presence of modern organisational practices and foreign ownership consistently influence learning, particularly from external sources. As has been the case so far, the effects from each variable run in diverging directions. By contrast, exports report a more mixed behaviour for either knowledge exploitation or knowledge exploration. On the one hand, the variable renders no significant information as determinant of combinations of rd_exploit and external_mkt. On the other hand, exposure to competition in external markets drives positively exploratory R\&D.

Turning now to the variables on human resource management practices, the results in tables 8.9 through 8.10 corroborate the limited contributions that practices such as remunerations and worker's empowerment have on learning by pharmaceutical firms in Mexico. On the contrary, the provision of training, and to a lesser extent the regulation of staffing practices, reported some meaningful information. In the case of models with R\&D for knowledge exploitation and external_mkt, the findings indicate that firms rely on their own staff to provide R\&Drelevant training; firms tap existing knowledge for that purpose. Nevertheless, internal training lacks relevance as factor sustaining R\&D for knowledge exploration.

Perhaps more interesting is confirmation of the finding -see Chapter 7- that none of the traditional knowledge producers, universities and public research centres, provides meaningful information about their contribution to R\&D-relevant training. Pharmaceutical firms in Mexico tend to lean on independent consultants and/or training centres attached to the industry. Arguably, the contribution of those two agents increases as knowledge searches take a more exploratory nature. It is in the context of training through specialised centres attached to the pharmaceutical industry that rule_hiring gains relevance as a means to learn from external knowledge sources. Interviews with pharmaceutical firms in Mexico hint at some reasons for this; this is part of the discussion in section 4 below.

The conditional probabilities that a firm uses combined learning strategies were computed for the models with a specification for each external training partner; these are shown in table 8.11. The marginal probabilities corroborated that a firm's characteristics are the main determinants of learning activities in the pharmaceutical industry in Mexico. More specifically, the more relevant variables are the adoption of modern organisational practices and foreign ownership. As for export_dummy, the variable rendered no statistically significant information.

The analysis of conditional probabilities for the variables on human resource management practices revealed that changes in worker's empowerment is positive and statistically significant for learning strategies underpinning knowledge exploitation. In other words as opportunities to participate in decision-making rise, so does the likelihood that firms implement joint learning strategies. The provision of training in partnership with external consultants is relevant for joint strategies supporting knowledge exploitation. As for exploration-related activities, rule_hiring 
remains the most significant human resource management practice. Finally, none of the remaining management practices provided consistent information about their influence on the adoption of joint learning strategies.

\section{Discussion and concluding remarks}

This chapter set out to investigate the influence of human resource management practices on the joint implementation of internal and external learning strategies by pharmaceutical firms in Mexico. Firms can develop technology by performing some domestic efforts, notably R\&D. At the same time, firms can tap into knowledge already available in technology markets; hence they gain complementary assets, additional knowledge inputs to underpin innovative efforts. This perspective was inspired by recent literature on complementarity between learning strategies; more specifically it built on studies on absorptive capacity building by pharmaceutical firms in catching up contexts. Those studies show that in general, combined approaches should produce larger returns as compared to individual strategies.

As a learning activity, in-house R\&D was distinguished by specific innovation outcomes--whether for product or process--, and the corresponding learning processes undertaken by the firm--weather for knowledge exploitation or knowledge exploration. A further distinction was made by specific external market from which a firm can acquire technology. The emphasis was put on technology acquisition in either embodied or disembodied form. Hence, this chapter investigated how learning processes differ depending on the goals and activities pursued during the innovation processes. In this regard, among the several factors that influence organisational learning, we focused on the management of human resources. The empirical evidence referred to pharmaceutical firms in Mexico.

The analysis revealed that, in general, pharmaceutical firms in Mexico pursue combined learning strategies. In principle, this is positive as it indicates that internal knowledge generation in the industry accompanies active absorption of external knowledge. Arguably, knowledge exchanges between pharmaceutical firms and external agents should contribute to advance the technological complexity of the local industry and eventually, the overall economic environment. Identification of some explanatory variables whose effects are specific for a particular learning strategy coincides with some previous innovation studies on complementarity -see chapter 2. In the presence of learning strategies $A$ and $B$, some variables will influence strategy $A$ provided that strategy $B$ is already in place, and vice versa.

However, the perceived complementarity between learning strategies in the pharmaceutical industry in Mexico is rather week. This is evident by looking at the creation of capacity to generate future knowledge flows via exploration activities. Arguably, in-house R\&D and technology licensing are independent from each other, notably for activities that emphasize knowledge exploration. Our results are therefore in line with those in Zúñiga et.al, (2007). Pharmaceutical firms in Mexico make limited use of licensing as a means to leap their technological capabilities. Licensing merely provides manufacturing rights, but seldom the consent to enhance the technology incorporated in the product. As for domestic firms, these prefer to 
wait for patent expiration so that they can proceed with the development and manufacturing of a generic drug.

A note of caution is pertinent here. In order to draw stronger conclusions about the nature of complementarity between learning strategies more direct tests are needed, together with finer gradations of both the dependent and explanatory variables. In the literature at least two approaches are available to test for complementarity. According to Athey and Stern (1998), the most "direct" way is to use a productivity function where an indicator of innovation performance is regressed on a defined set of explanatory variables. In general, such approaches have been developed for models where dependent variables are continuous. Alternative models for categorical variables -see Miravete and Pernias (2006) and Cattozzella and Vivarelli (2007)-, impose strong data and computing requirements that face considerable limitations for relatively small datasets. Our dataset faces strong limitations in both these fronts. ENESTYC lacks information about customary indicators of R\&D output, i.e. patent counts, product launches, share of sales of innovative products and so on. The relatively small size of the pharmaceutical industry in Mexico limits the possibility to carry out the necessary tests.

An alternative approach to research is to perform "indirect", albeit weaker tests for complementarity based on the notion of clustering (Athey 1998). This eliminates the need for proper performance indicators such as those required in more direct tests (Cattozzella, 2007). This type of indirect approach is the one used in this study and by Zúñiga et. al, (2007). The limitations of the approach are not of particular concern for this study as our interest was in understanding innovation more as a process than as concrete outcomes. The goal was to shed light on how human resource management practices influence adoption of distinct combinations of learning strategies. Our results are consistent with these objectives.

From the above, some of the best results from our models corresponded to those combining in-house $R \& D$ for knowledge exploration with acquisition of disembodied knowledge. This is consistent with some findings in chapter 7; pharmaceutical firms in Mexico actively consult specialised literature as a means to learn from external sources. Reading of specialised biotechnology journals was quoted as customary by companies at some advanced stages of technological capabilities; meaning those conducting some formal in-house R\&D (Interviews with firms 03,05 and 10). Certainly the emphasis is in development more than on research. In addition to specialised literature, the variable disembodied includes items such as R\&D and licensing. These two, in themselves, are mechanisms of great relevance to acquire technology in the industry.

This study was able to identify some management practices that support adoption of joint learning strategies by pharmaceutical firms in Mexico. The provision of training and to a lesser extent, regulations on staff hiring are relevant for learning. Under very specific conditions, i.e. knowledge exploration, worker's participation in decision-making rendered some positive results as well. By contrast, the effects of the variable on remunerations were not statistically significant. Overall the contribution of human resource management is contingent on the goals pursued and corresponding knowledge requirements of the firm. 
Estimates associated with the adoption of dual strategies involving knowledge exploitation revealed that only the provision of internal training influenced in-house R\&D. The conclusion held almost irrespectively of the specific definitions of external markets for technology. If firms limit learning activities to those underpinning efficiency and/or productivity gains, they only need to search within their cumulated knowledge bases. A firm self-fulfils its knowledge requirements profiting from staff experience and expertise.

Worker's empowerment was relevant only when the analysis distinguished among external training providers. In fact, the effect was perceptible only via the computation of the conditional probability that a firm uses external knowledge when an internal learning strategy is already in place. This result is appealing as it pertains to a variable that was measured in terms of its perceived importance for the firm -see chapter 3 . As workers gain in decision-making capacity, more evident contributions to learning can also be obtained; the practice facilitates absorption and assimilation of new knowledge. Dutrénit (2006) for example documented that learning activities can be enhanced if workers are given the opportunity to manipulate and 'play around' with the newly acquired knowledge. Learning is potentiated if staff are allowed to try-out new machinery, experiment with novel excipients and so on. Interviews at a Mexican manufacturer revealed that from the perspective of a development analyst, great learning opportunities were associated with the capacity to call excipients' suppliers, to interact with them and to get acquainted with whatever new products or ingredients were available in the market (Interviews with firm 06).

As for strategies involving knowledge exploration in the pharmaceutical industry in Mexico, these characterise by an increased importance of practices such as the provision of external training, and rules to guide new staff hiring. The relevance of external training hints at the fact that as innovation gains in complexity, firms need to access alternative knowledge sources searching for inputs otherwise unavailable in-house. Interactions with specialised agents assist efforts to enrich knowledge available in-house, particularly for the performance of unfamiliar activities (Okada and Kawara 2004). Interactions do not arise from scratch, they take time, require commitment and sustained efforts; interactions are constantly evaluated. Relevant partners can change over time according to the knowledge requirements and technological attainment of a firm. Firms 11 and 14 provide good examples. As they gained in technological capabilities the firms started to interact more actively with local research organisations, including specialised institutes affiliated to the UNAM in Mexico. Today both these firms have well established relationships with the Center for Disease Control (CDC) in the US, and universities and research organisations abroad.

Intriguingly our analysis in this chapter corroborated the findings in chapters 6 and 7, namely that universities and other traditional knowledge producers are of little relevance for the learning of pharmaceutical firms in Mexico. Learning through linkages with third parties within the industry, including consultants and research centres were more relevant. ENESTYC lacks detailed information on the exact nature of the knowledge flows exchanged between pharmaceutical firms and their partner 
organisations; hence, explaining this finding is problematic. Nevertheless, our interviews indicated that training by consultants and training centres attached to the industry is preferred because these agents are better acquainted with the structure, technological attainment and operation of the industry (Interviews with Trade2). By contrast, researchers at universities tend to be rather abstract, generalist and with serious difficulties to translate research findings into practical solutions (Interviews with firms 03, 06 and 13).

The limited reliance on universities as a source of training reflects some deficiencies faced by those organisations to meet the industry's requirements. Both Mexican and multinational firms expressed dissatisfaction about the lack of adequate infrastructure at the universities (Interviews with firms 03, 06 and 13); hence "it is hard to replicate and learn about the most modern synthesis and analytical techniques, manufacturing and laboratory practices used by the industry" (Interview at firm 03). This is compounded by the "absence of faculty with sufficient experience and understanding of the industry" (Interview at firm 03), or the difficulties to observe all the confidentiality requirements of the firm (Interview at firms 03 and 06). In other occasions, traditional disconnections between basic research carried out at universities and the actual needs of the industry were also stated. Firms and knowledge producers in Mexico seem to evolve at different pace and diverging directions.

In the literature remunerations and reward for performance are usually part of comprehensive management and learning systems. Consequently our inability to obtain meaningful information about the impact of remunerations on learning strategies is intriguing. Exploring this issue further is difficult given the limited information available in our dataset. Nevertheless some hypotheses stemming from our literature review and interviews can be considered. In principle, management studies argue that raising remuneration levels is not all what it takes to promote enhanced performance of Mexican workers (Tello and Greene 1996). Motivation, commitment and drive towards improved performance require the creation of work environments where incentives to learning are accompanied by the means, resources and opportunities for continuous professional development. This is consistent with literature suggesting that in science-based industries, R\&D staff prefer, as remuneration mechanism, opportunities to further develop intellectual capital over performance-linked rewards. Arguably, in environments where opportunities to conduct R\&D as a professional activity are scarce, people interested in such a career can work for companies that allow them to do even if salaries are not really attractive. This hypothesis takes us back to the discussion in chapter 1 about the incentives provided by labour markets for the development of R\&D.

As discussed in chapter 7 an alternative explanation for the lack of statistical significance of the variable on remunerations results from the frequent mark-up on pecuniary remunerations observed in Mexico. Remunerations function as mechanisms to retain personnel but seldom as means to motivate learning of new abilities and skills. No surprisingly our interviewees frequently decried that the pharmaceutical industry records high staff turn-over and strong competition for human resources, particularly at managerial and technical positions (Interviews with 
firms $02,03,10$ and 13). People move to places where compensation is closer to what they perceive is fair for their knowledge. The interviewees stressed that offering financial support to participate in external training helps to overcome some limitations to increase wages. In general, training will be undertaken at private universities and will not necessarily lead to obtaining a new degree.

A brief note on estimates for the control variables is obliged, as firm's characteristics seem to account for most of the explanatory power of the models in this and previous chapters. Indeed, such variables have a more notorious explanatory power than that of human resource management practices. To begin with, the descriptive analysis in this chapter signalled relatively low or negligible differences in learning behaviours associated with indicators such as foreign capital ownership or exports. This is why we find subsequent estimates rather interesting. Foreign ownership systematically impacted negatively on learning. Elsewhere in this thesis we have proposed that this reflects the position that Mexico occupies in the business strategies of global pharmaceutical firms. Local performance of systematic R\&D efforts falls short from the objectives of multinational affiliates, except for outsourcing of clinical trials to local research organisations. Basically multinationals 'exploit' local research capacities and country specific conditions offered by Mexico. As clinical trials are normally undertaken through contracts with public hospitals or individual medical doctors; no managerial responsibility other than adequate compensation link firms to those agents.

This chapter corroborated that participation in export markets induces knowledge exploration. Competition in external markets for goods, in this case pharmaceutical products, compels firms to search for knowledge outside familiar knowledge bases (Arora et.al, 2001). This finding recalls the very much debated and often controversial implementation of liberalisation programmes in Mexico and other Latin American countries. In principle one would agree that increased competition promotes incentives for enhanced technological profiles among pharmaceutical firms. However, competition does not limit to the domestic market. Parallel implementation of more decisive policies to promote exports by local firms can encourage domestic firms to implement more decisive efforts to innovate. The literature shows that successful catching up in South East Asia involved countries where domestic economic activities leaned strongly towards export markets.

Last but not least, adoption of modern organisational practices was positive and statistically significant particularly for external learning strategies. In our view this reflects the reputation that Mexico has gained as a modern drug manufacturing centre. As discussed in chapter 5, multinational firms operating in the domestic market are already incorporating some of the most novel manufacturing techniques such as Process Automated Technologies (PATs), which require investment in machinery and enhanced organisational techniques. Nevertheless, their impact on technological efforts involving in-house R\&D remains negligible. Opportunities to tap into some of the country's capacities, in drug manufacturing, generic drug development and in the use of biotechnology to build stronger R\&D bases, remain largely unexplored and unexploited. 


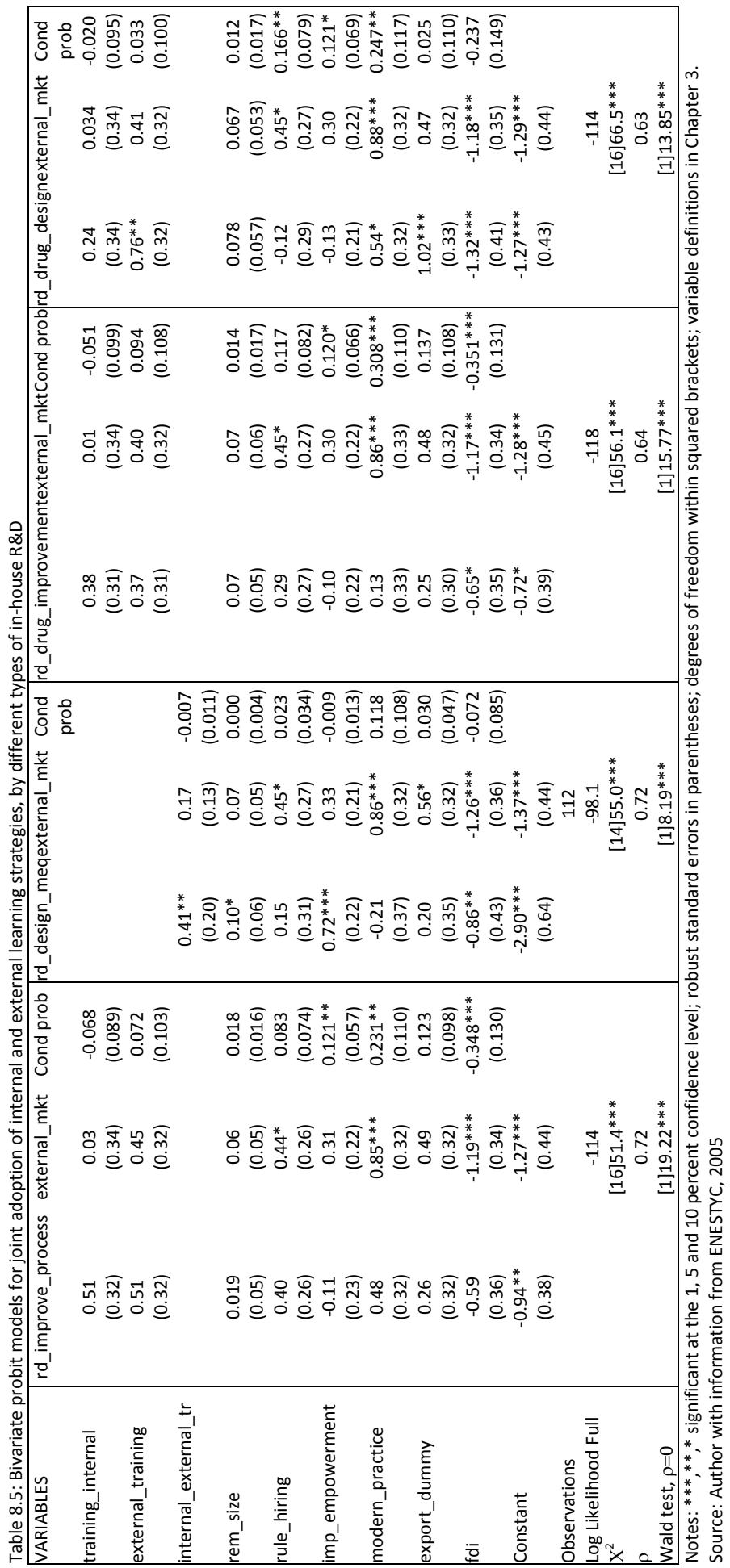


Table 8.6: Bivariate probit models for internal and external learning strategies underpinning knowledge exploitation and exploration activities

\begin{tabular}{|c|c|c|c|c|c|c|}
\hline Variables & rd_exploit & external_mkt & Cond Prob & rd_explore & external_mkt & Cond Prob \\
\hline \multirow[t]{2}{*}{ training_internal } & $0.67 * *$ & -0.004 & -0.108 & 0.31 & 0.03 & -0.034 \\
\hline & $(0.31)$ & $(0.33)$ & $(0.093)$ & $(0.34)$ & $(0.34)$ & $(0.091)$ \\
\hline \multirow[t]{2}{*}{ external_training } & 0.47 & 0.41 & 0.079 & $0.80 * *$ & 0.41 & 0.022 \\
\hline & $(0.30)$ & $(0.32)$ & $(0.107)$ & $(0.32)$ & $(0.32)$ & $(0.097)$ \\
\hline \multirow[t]{2}{*}{ rem_size } & 0.046 & 0.07 & 0.018 & 0.065 & 0.067 & 0.014 \\
\hline & $(0.06)$ & $(0.05)$ & $(0.017)$ & $(0.057)$ & $(0.054)$ & $(0.017)$ \\
\hline \multirow[t]{2}{*}{ rule_hiring } & 0.30 & $0.44^{*}$ & $0.132 * *$ & -0.15 & $0.44^{*}$ & 0.099 \\
\hline & $(0.28)$ & $(0.26)$ & $(0.066)$ & $(0.29)$ & $(0.27)$ & $(0.064)$ \\
\hline \multirow[t]{2}{*}{ imp_empowerment } & -0.15 & 0.29 & 0.116 & 0.014 & 0.29 & $0.170 * *$ \\
\hline & $(0.23)$ & $(0.22)$ & $(0.084)$ & $(0.22)$ & $(0.22)$ & $(0.079)$ \\
\hline \multirow[t]{2}{*}{ modern_practice } & 0.15 & $0.87^{* * *}$ & $0.322^{* * *}$ & 0.35 & $0.88 * * *$ & $0.278 * *$ \\
\hline & $(0.35)$ & $(0.33)$ & $(0.115)$ & $(0.33)$ & $(0.33)$ & $(0.112)$ \\
\hline \multirow[t]{2}{*}{ export_dummy } & 0.36 & 0.48 & 0.125 & $1.00 * * *$ & 0.47 & 0.022 \\
\hline & $(0.34)$ & $(0.32)$ & $(0.111)$ & $(0.33)$ & $(0.32)$ & $(0.110)$ \\
\hline \multirow[t]{2}{*}{ fdi } & $-0.84^{* *}$ & $-1.16 * * *$ & $-0.326^{* *}$ & $-1.35^{* * *}$ & $-1.18^{* * *}$ & -0.222 \\
\hline & $(0.38)$ & $(0.33)$ & $(0.138)$ & $(0.40)$ & $(0.35)$ & $(0.149)$ \\
\hline \multirow[t]{2}{*}{ constant } & $-0.64 *$ & $-1.27^{* * *}$ & & $-1.16^{* * *}$ & $-1.29 * * *$ & \\
\hline & $(0.39)$ & $(0.44)$ & & $(0.42)$ & $(0.44)$ & \\
\hline Observations & & & & & 112 & \\
\hline Log Likelihood Full & & -109 & & & -113 & \\
\hline$X^{[1]}$ & & {$[16] 57.8 * * *$} & & & {$[16] 68.5^{* * *}$} & \\
\hline$\rho$ & & 0.73 & & & 0.65 & \\
\hline Wald test, $\rho=0$ & & {$[1] 17.84^{* * *}$} & & & {$[1] 15.12^{* * *}$} & \\
\hline
\end{tabular}

Notes: $* * * * *, *$ significant at the 1,5 and 10 percent confidence level; degrees of freedom in parentheses; degrees of freedom within squared brackets. For variable definitions see Chapter 4.

Source: Author with information from ENESTYC, 2005 


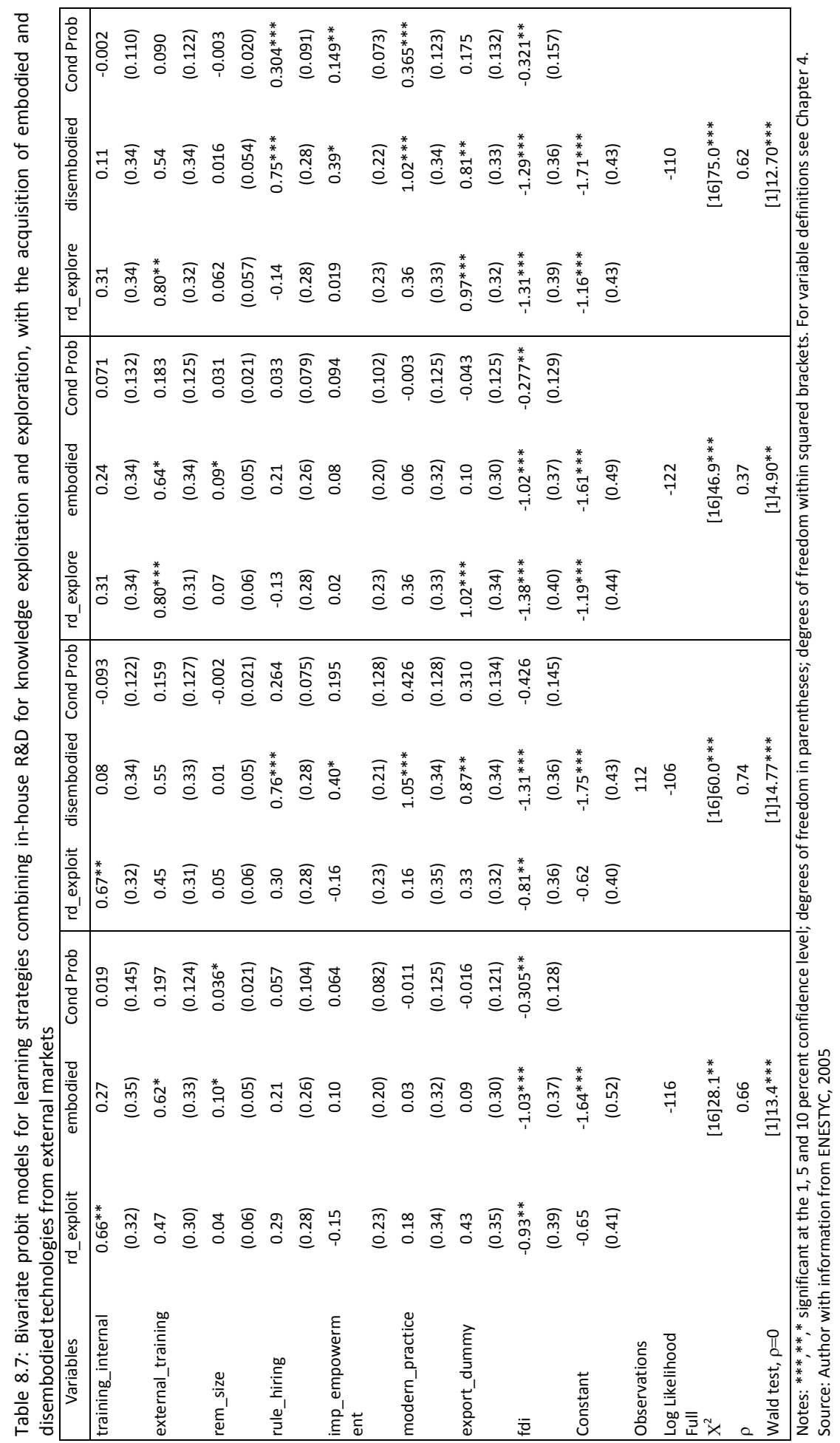


Table 8.8: Bivariate probit models for learning strategies including knowledge exploration and external R\&D

\begin{tabular}{|c|c|c|c|}
\hline VARIABLES & rd_explore & extrel_rd & Conditional Probability \\
\hline \multirow[t]{2}{*}{ training_internal } & 0.29 & 0.11 & 0.007 \\
\hline & $(0.34)$ & $(0.40)$ & $(0.142)$ \\
\hline \multirow[t]{2}{*}{ external_training } & $0.81 * *$ & 0.55 & 0.099 \\
\hline & $(0.32)$ & $(0.41)$ & $(0.132)$ \\
\hline \multirow[t]{2}{*}{ rem_size } & 0.07 & $0.10^{*}$ & 0.031 \\
\hline & $(0.06)$ & $(0.06)$ & $(0.020)$ \\
\hline \multirow[t]{2}{*}{ rule_hiring } & -0.17 & $0.61 * *$ & $0.261 * * *$ \\
\hline & $(0.28)$ & $(0.27)$ & $(0.101)$ \\
\hline \multirow[t]{2}{*}{ imp_empowerment } & -0.01 & 0.17 & 0.069 \\
\hline & $(0.23)$ & $(0.23)$ & $(0.081)$ \\
\hline \multirow[t]{2}{*}{ modern_practice } & 0.38 & 0.22 & 0.035 \\
\hline & $(0.34)$ & $(0.37)$ & $(0.130)$ \\
\hline \multirow[t]{2}{*}{ export_dummy } & $1.04 * * *$ & 0.37 & 0.011 \\
\hline & $(0.33)$ & $(0.31)$ & $(0.123)$ \\
\hline \multirow[t]{2}{*}{ fdi } & $-1.39 * * *$ & $-1.46^{* * *}$ & $-0.334 * * *$ \\
\hline & $(0.40)$ & $(0.40)$ & $(0.102)$ \\
\hline \multirow[t]{2}{*}{ constant } & $-1.18^{* * *}$ & $-2.26 * * *$ & \\
\hline & $(0.45)$ & $(0.53)$ & \\
\hline Observations & & 112 & \\
\hline Log Likelihood Full & & -108 & \\
\hline $\mathrm{X}^{\varpi}$ & & {$[16] 46.5^{* * *}$} & \\
\hline$\rho$ & & 0.66 & \\
\hline Wald test, $\rho=0$ & & [1]11.12*** & \\
\hline
\end{tabular}

Notes: $* * *, * * *$ significant at the 1,5 and 10 percent confidence level;

degrees of freedom within squared brackets. For variable definitions, see Chapter 4 .

Source: Author with information from ENESTYC, 2005 


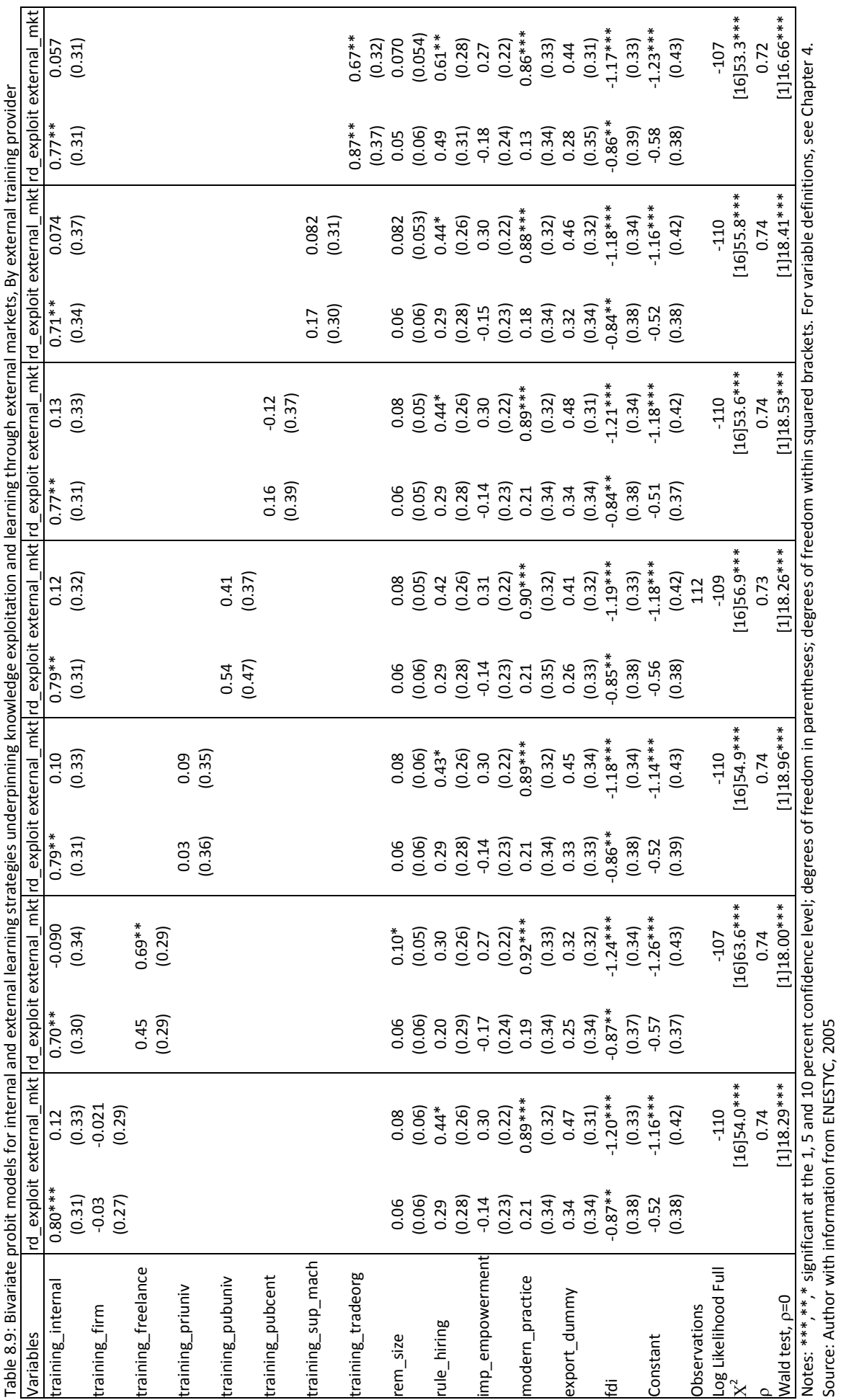




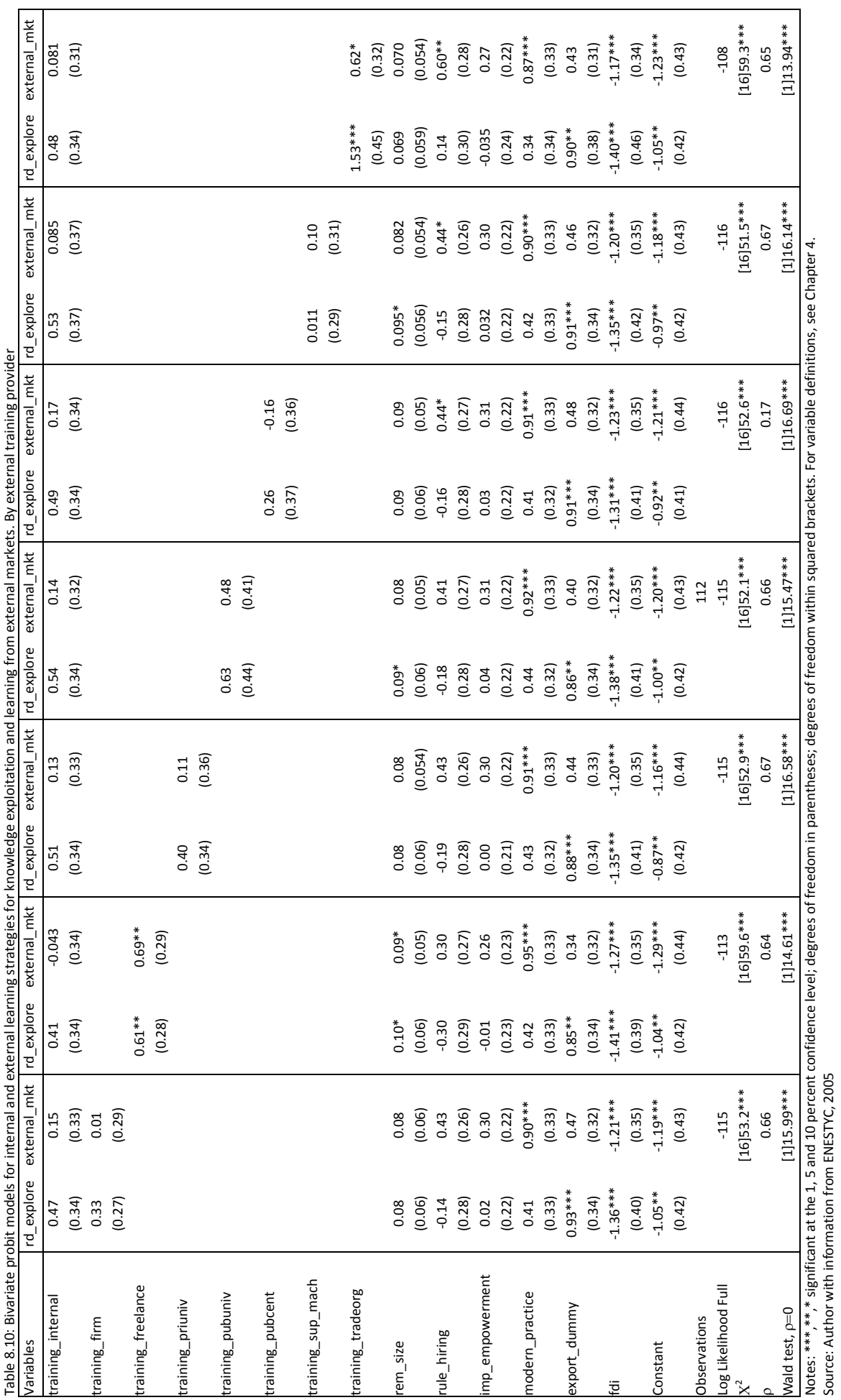




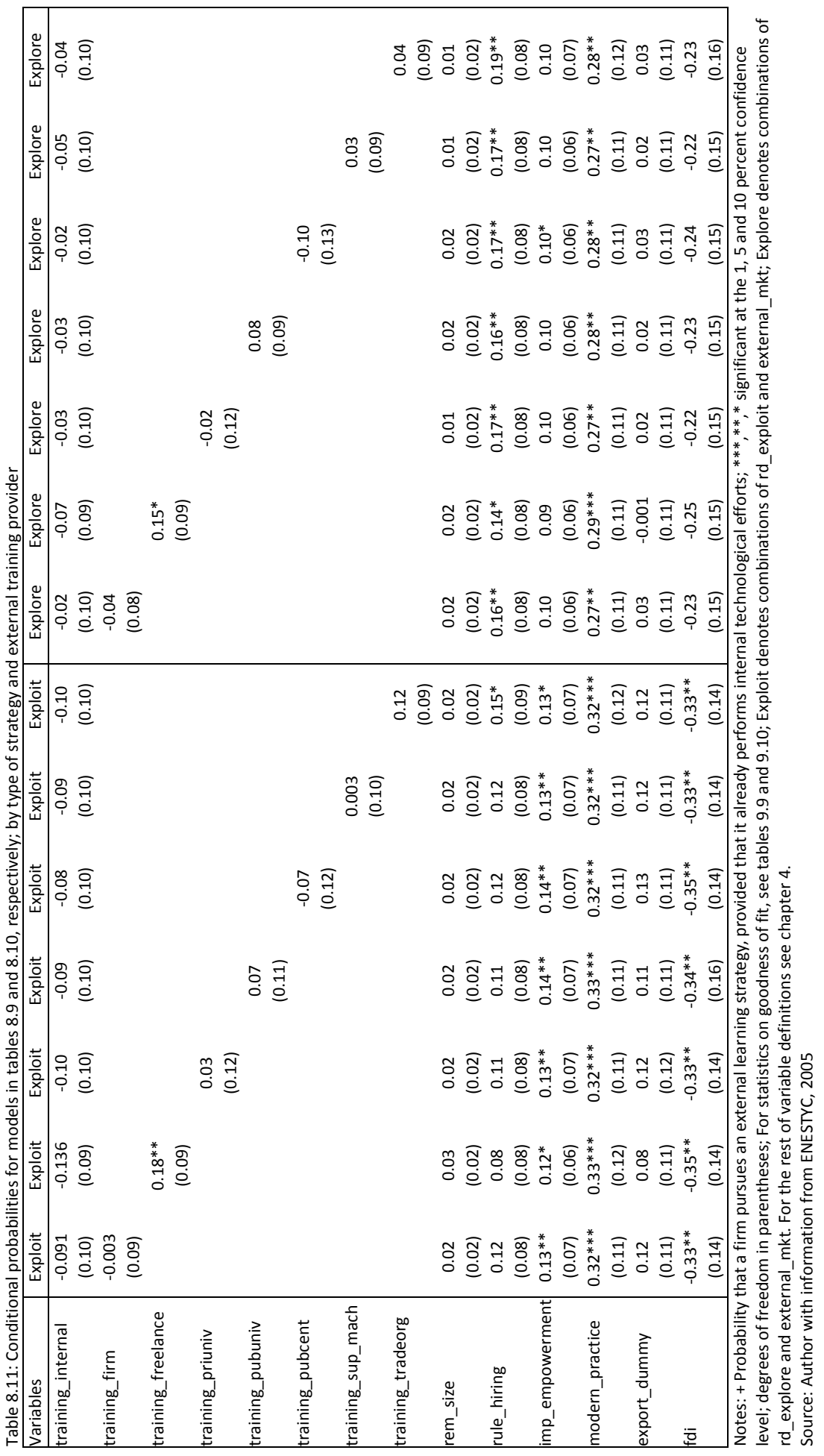




\section{Chapter 9}

\section{Integrated view: human resource management practices and learning for innovation}

During the process of writing this thesis, in April 2009, a major and unprecedented sanitary emergency erupted in Mexico. What was the cause? Outbreak of an as yet unknown strain of a swine flu virus, $A(H 1 N 1)$. For a few weeks, and with the aim of mitigating against widespread contagion among the Mexican population and beyond its borders, local health authorities applied strict preventive measures, such as shutting down schools, bringing to a halt all non-critical economic and related activities in most affected areas, notably Mexico City; and a total suspension of all activities that might lead to large gatherings of people. However difficult to determine, the economic costs of the emergency were estimated at 0.3 percent of Mexico's GDP; in some provinces the expected cost was even higher. To some extent the scenarios helping to assess the cost built on the similar threat of the Severe Acute Respiratory Syndrome (SARS) in Asia.

To a certain extent the reaction of the Mexican authorities revealed an inability to distinguish between people suffering from the new $\mathrm{A}(\mathrm{H} 1 \mathrm{~N} 1)$ virus, and from those affected by some other kind of respiratory-related disease. The new virus exposed some deficiencies in local health systems. More importantly, the outbreak highlighted great voids in terms of STI activities in the country. Mexico relied on laboratories and scientists from Canada and the US to identify cases of people affected by the virus. It took a few weeks before the country could import, install and operate facilities and diagnostics to support the identification of positive cases of $A(H 1 N 1)$. The situation was compounded by the already low investment in R\&D, particularly within the health sector -see chapter 5 . Slow response by Mexican health authorities equally underscored the limited S\&T capacity of local early warning systems in the event of a disaster or potential epidemic.

As international health authorities, more specifically the World Health Organisation (WHO), communicated the possibility of a worldwide pandemic, the international community was prompted to cooperate in controlling the spread of the virus. Efforts included the proliferation of sanitary regulations, messaging that urged people to restrict human contact, and sanctions on imports and travel to Mexico. Reaction was strong in China, where the footprint of SARS was still fresh. Authorities in countries such as Brazil, Cuba, Colombia and Argentina justified suspension of travel from and to Mexico on the grounds that they were not prepared to deal with a threat on this scale. Argentina, in particular, was already 
fighting a Malaria epidemic. In addition to weaknesses in local healthcare systems, the fear expressed by the countries cited above, as well as other developing countries, reflected their own lack of scientific, technical and financial resources to respond to an emergency of this magnitude. After all, only "the strength of a country's health system will make the biggest difference in sickness and survival during an influenza pandemic (...) countries, especially in the developing world, where populations are most vulnerable, should prepare to see more than [a] small number of severe cases" (Chan 2009).

In August 2010 the World Health Organisation declared the end of the pandemic (WHO 2010). Daily routines are officially restored to normal, although risks of contagion had already diminished considerably earlier in 2010 following the successful development of a vaccine against the $A(H 1 N 1)$ virus. Important challenges remained however as mass producing, delivery and distribution of new vaccines took time and required significant resource mobilization. One should not forget that the mutability and recombinant capacity of viruses keeps international health authorities in the look out for new events.

From the start, the new strain of the swine flue virus pushed science, on a global scale, to search within and outside current knowledge bases for a solution to the problem. As noted by WHO authorities during the early days of the contagion, "Scientists, clinicians, and epidemiologists are capturing abundant signals. But we do not have the scientific knowledge to interpret these signals with certainty. We have clues, many clues, but very few firm conclusions" (Chan 2009). The outbreak of the influenza pandemic reminded us that the best way to respond to this and any other future threat is for countries to build their capacities in several areas, from health systems, to research and other more economic-related activities. As discussed in chapter 4 , there are strong linkages between detection and prevention of health needs, operation of healthcare systems, public policy and notably, pharmaceutical innovation-figure 4.2.

The outbreak of the $A(H 1 N 1)$ virus incited debate concerning the costs of a global pandemic and, more specifically, on how to share the burden among the international community (Chan 2009). ${ }^{1}$ The pandemic reminded us that although pharmaceutical innovation is a rather cumbersome, time-consuming, resourcedraining process, it remains an attractive business. Take as an example firms such as Roche and GSK, the multinationals that manufacture the main antiviral used against swine flu: Aseltamivir (Tamiflu ${ }^{\mathrm{TM}}$ ), and Zanamivir (Relenza ${ }^{\mathrm{TM}}$ ). Rising sales of both of those products boosted the valuation of these companies in world stock markets; considerable profits poured in for these companies during 2009. Likewise, Sanofi Pasteur, one of the largest vaccine developers in the world, benefited from important grants from the US government for production of a bulk $A(H 1 N 1)$ vaccine valued at US\$190 million (Sanofi-Pasteur 2009). The benefits for other firms were significant as well, as the US government was ready to invest US\$1 billion in clinical

\footnotetext{
${ }^{1}$ Mexican Health authorities proposed the creation of a global contingency fund, supported by the World Bank and the International Monetary Fund, to compensate those countries that notify promptly about the outbreak of a pandemic, or other major health risk with potential international diffusion (Secretaría de Salud 2009)
} 
research and development of a new vaccine against the $A(H 1 N 1)$ virus (HHS 2009).

To what extent developing countries, and particularly domestic firms, can benefit from a sanitary emergency like the one just described above? It was clear, right from the outset, the limited capacity of countries such as Mexico to participate more actively in the development of the new vaccine against the $A(H 1 N 1)$. Unfortunately such limitations only added to the restrictions already faced by Mexico and other developing countries to respond to other more common diseases affecting local populations. So-called neglected tropical diseases impose equally or even stronger, more sustained threats than the $\mathrm{A}(\mathrm{H} 1 \mathrm{~N} 1)$ for local healthcare and research systems. The emergency motivated significant cooperation and exchanges between Mexican scientists and their peers throughout the world; Mexican researchers participated in efforts to characterize the molecular and genomic structure of the virus using modern biotechnology tools (UNAM April 30 2009). Nevertheless the dearth of adequate scientific and related infrastructures, not to mention mediocre funding capacity, hindered possibilities to participate in subsequent actions against the swine virus.

The vulnerability of developing countries in the face of global and domestic disasters aggravates by the lack of a sufficient human resources base, including both the knowledge and experience needed to perform more systematic R\&D efforts; in this case to support the development of novel pharmaceutical products. At a more general level, the swine flu case dramatically illustrated some of the serious challenges developing countries face to generate the scientific and technological knowledge needed to meet the myriad of socioeconomic challenges they face.

Turning back to the discussion in the introductory chapter of this thesis, there is room to do research on the contribution of education systems to the building of sound human resource bases for STI. Education, particularly at postgraduate level, provides individuals with capacities, tools and ways to systematically understand and address pressing problems faced by society. Distinct strands of literature, notably including that on the national systems of innovation, document several challenges and opportunities to strengthen the contribution of education organisations to social and economic progress. Noteworthy is the construction and improvement of the supply of highly qualified human resources.

Equally important it is to consider the role of factors that, from the perspective of demand, determine the development of human resources for STI. In particular, firms contribute to the development of such human resource bases via the organisation and management of the people involved in innovation-related activities, notably R\&D. Based on the empirical evidence used in this thesis, I will now discuss some of the conclusions drawn from this study. The conclusions follow a progressive disaggregation, from the macro view of factors influencing learning and innovation in a country such as Mexico, down to the more intermediate facets related to the local pharmaceutical industry. Finally, I analyse a number of more micro aspects associated with the characteristics of human resource management interventions inside the firm. The discussion amalgamates three kinds of findings, namely: those that lend support to existing literature on human resource management practices, learning and innovation performance at firm level; those 
that contrast the conclusions from previous studies; and more importantly, the conclusions that add to the debate in the field.

\section{Lessons from a study on human resource management practices and learning for innovation in a developing country context}

This thesis built on the notion that the organisation and management of personnel inside a firm can positively influence innovation performance at firm level. Two major gaps were identified in the existing literature: first, traditional approaches to research fail to sufficiently explain the nature of the relationships linking human resource management practices to innovation performance. In other words, why and how human resource management practices influence innovation? Second, so far we know very little about how human resource management practices hold sway of innovation performance by firms in developing countries? This thesis advanced the discussion around these two questions. In relation to the first question, the thesis analysed the role of learning as intermediary factor linking human resource management practices to innovation performance at the firm level. It looked at firms within the more ample environment around them. Hence we found a number of factors that shape the relationships between human resource management practices and learning for innovation. Such factors relate to the overall macro environment around STI activities, the characteristics of innovation processes in the (local) industry, and notably, the decisions about learning strategies adopted by firms. As for the second question, evidence about the pharmaceutical industry in Mexico substantiates our main findings.

A third relevant set of findings relate to both the identification of the human resource management practices likely to influence learning for innovation. We also explained how and why such practices do so in the context of a developing country such as Mexico. As we comment latter, the provision of training showed the more consistent and positive effects on distinct kinds of learning and learning strategies. The effects associated with the remaining practices included in the analysis tended to be weaker, somehow subordinated to firm characteristics such as export behaviour and origin of capital ownership. We confirmed however, the more notorious effects of human resource management practices as firms tend to launch more ambitious learning outside their customary knowledge bases.

Socioeconomic contexts matter for learning and innovation: The discussion about the $\mathrm{A}(\mathrm{H} 1 \mathrm{~N} 1)$ virus demonstrated that health-related problems arising in one part of the world have the potential to threaten global stability. Those problems call for stronger coordination between systems designed to alert on emerging global disasters, the structure and operation of public healthcare organisations and R\&D systems. The latter system is a core element of strategies to improve the operation of the former two instances. Countries such as Mexico accuse strong disconnection among healthcare, R\&D, and productive systems; they show greater vulnerability to global contingencies, not to mention the capacity to fight endemic diseases. Reliance on knowledge generated in more developed countries implies risks of being always late to respond, or fail to sufficiently take into account local conditions and 
resources. Opportunities to develop and 'use' a dynamic local STI workforce are equally low.

From the above, this thesis documented that in Mexico the environment around STI activities in general, and the operation of the pharmaceutical industry in particular, is poorly conducive to more intense learning and innovation activities, particularly by domestic firms. Mexico endures a number of challenges in policymaking and policy implementation, namely, poor incentives to R\&D as the basis for successful business strategies, little interaction between relevant components of the national and sectoral systems of innovation, and scarcity in human resources and research infrastructure. In such an environment, the chances for the local pharmaceutical industry to gain relevance in global pharmaceutical innovation are rather bleak; the potential for human resources to contribute to a firm's innovative performance in the industry is rather low.

Firms at a micro level and, by extension, countries at a more macro level contribute to and benefit differently from learning and innovation in distinct sectors/industries. Both micro- and macroeconomic factors combine to induce performance among firms and countries alike. Dynamics of consumption, R\&D and regulations around science and technology-related activities will continue to influence future developments of the global pharmaceutical industry. Emerging economies are called to play an increasingly important role; hence the importance of learning about the successful stories of emerging economies such as India or China. However, one must question the extent to which such cases can inform strategies intended to further advance the base of human resources for innovation in other developing countries.

Understanding the nature of the $R \& D$ process, innovation more broadly defined, in specific industries paves the way to better appreciate the influence of human resource management practices on innovation performance at firm level: Chapter 1 documented that available studies on innovation performance and human resource management practices have explored the relationships between those variables at a single point in time. Such studies look for industry and market differences leading to greater heterogeneity in innovation outcomes. By contrast, research has overlooked ways in which firms and countries contribute to innovation in specific industries, and how such specialisation feeds back to the characteristics of human resource management practices adopted by firms.

This thesis showed that the strategic position of an industry, as driver of broader economic performance, determines both the incentives to do, and the scope of R\&D and innovation. This observation calls for more careful appreciation of the nature of innovation processes, the environmental conditions around such processes, and how those factors ultimately relate to the influence of human resource management practices on firm's performance. In countries such as Mexico, improved innovation performance begins by enhancing incentives and conditions for firms to carry out R\&D as a basis for more formal and systematic innovation efforts.

From the above, chapter 4 documented the several instances shaping pharmaceutical innovation, from public interest and national wellbeing, to pure 
business opportunities. All those dimensions involve distinct agents and institutional frameworks to govern both individual activities and interactions within the industry. Perhaps more than in other industries, the innovation cycle in the pharmaceutical industry is long and complex, it actively involves scientific research and technological developments, as well as ethical considerations concerning research involving humans. Some such dimensions are frequently overlooked in the literature. As a research intensive activity, pharmaceutical innovation systematically involves and can significantly affect human beings. Continuous promotion of learning and creativity are crucial for success in pharmaceutical innovation. Innovation in the industry requires commitment, sustained efforts to keep up with new knowledge about the world and how to use it for specific purposes. Strong regulation of the industry shapes, often limits the scope of and potential for innovation by firms.

In a country such as Mexico pharmaceutical innovation is closely related with drug manufacturing activities, particularly of generic drugs; it is mostly incremental in nature and somehow constrained by a series of factors associated with the local culture and overall socioeconomic conditions of the country. Firms need to enhance capacities to innovate even within the narrow boundaries allowed by both local regulation and the inherent nature of development and manufacturing of generic drugs. These observations take us back to the discussion about how narrowly or how broadly systems of innovation should be defined in the context of developing countries -chapter 1 . Here we argued that the two approaches are complementary; in effect mutually reinforcing. R\&D systems are strongly linked to productive activities and need to be responsive to societal needs; in other words, R\&D and socio-economic problems are dimensions with strong feedback loops. Figure 4.2 illustrated the case of pharmaceutical R\&D.

Human resource management practices as starting point for the construction of systems of innovation. This thesis endorsed Lorenz and Wilkinson (2003) and Lundvall and Valeyre (2007) who have stressed the need for more systematic and comparative studies on how dynamic work environments are built and how they impact performance in terms of innovation, learning and, in general, technical change. The literature draws attention to developments at the firm level; nevertheless, this is only to identify factors likely to influence the construction and dynamics of systems of innovation over time. In other words, the firm remains the focal point from which cumulative learning and innovation unfold. Interest in better understanding the dynamic processes inside the firm motivates enquiries about the linkages between research on human resource management practices and innovation. Success however remains contingent on improved understandings of the conditions, organisational and development requirements, and the capacities and aspirations of people involved in activities such as R\&D.

Chapter 2 presented some alternative approaches to research on human resource management practices and innovation; arguably each of those analytical frameworks can be used to study the case of developing countries. Extending the scope of the analysis implies understanding that, in general, environmental conditions around innovation in developing countries can be less dynamic, more 
cumbersome than in developed countries. Moreover, it can be more difficult to define innovation according to commonly accepted indicators centred on patent or paper counts and other customary outcomes. The look at alternative views of innovation set the stage for some of the main contributions of this thesis to the literature.

Learning as intermediary process between human resource management and innovation performance: This thesis focused on learning as intermediary process between management practices and firm performance. ${ }^{2}$ Learning was broadly interpreted as a mechanism promoting absorptive capacity and supporting technology capability-building. We thus explored how human resource management practices influence learning for pharmaceutical innovation. In order to do so we discarded some underlying assumption of studies about developed countries. Firms' performance was not captured in terms of innovation outcomes but in terms of the learning dynamics, and technological accumulation through R\&D.

Firms learn by implementing different strategies: Analysis in this thesis centred attention on learning activities supporting technological and innovative capability building. Firms fulfil innovation-relevant knowledge requirements by relying on either internal or external technology sources or both. To the best of our knowledge, this is the first time such a distinction among learning strategies is made in the context of studies on human resource management and innovation. The split of the analysis in three interrelated chapters helped to study the effects of management practices on learning for innovation from different perspectives, but always along comparable theoretical backgrounds. In such a way we got closer to the firm's actual decisions underpinning technological learning and innovation. This thesis showed that although firms in the Mexican pharmaceutical industry tend to pursue in-house R\&D, such activities are still very much isolated from those of other knowledge producers in the Mexican system of innovation. Internal knowledge sources prevail as the main sources for pharmaceutical R\&D in Mexico. By contrast, the use of external knowledge sources was disconnected from in-house technological efforts.

Based on the empirical literature on capability building, carefully combined approaches to learning were expected to provide superior results than individual learning strategies. Although the analysis in chapter 8 granted some support to this observation, data limitations make it difficult to conclude with more certainty on the complementarity of internal and external strategies for pharmaceutical firms in Mexico. The notion of complementarity is an area that attracts great attention in current innovation literature, particularly in developing countries where scarce resources need to be maximized. In Mexico, interactivity is constrained at three levels, along a continuum. At a macro level the structure and functioning of national systems of innovation is poorly conducive to such dynamic interactions; the systems characterise by low investment in $R \& D$, inadequate or limited research infrastructure and human resources. At a more disaggregated level, the structure and operation of firms and public research organisations respond to different,

\footnotetext{
${ }^{2}$ Creativity is an alternative dimension.
} 
somewhat difficult to reconcile incentives and aspirations. Last but not least scientific communities face limited, even contradictory incentives to interact with private firms. In some cases researchers need to overcome strong peer criticism as to the extent a balance is maintained between research goals in terms of commercial purposes and that of contributing to the overall pull of scientific knowledge.

Learning involves different knowledge flows depending on the goals pursued by the firm: An additional contribution of this thesis stems from the study of the knowledge flows involved during the innovation process, whether for exploitation or exploration -an alternative view to the classical dichotomy between incremental and radical innovations. This is together with the relative specialisation of a firm in conducting searches for particular pieces of knowledge. In such a way, the traditional distinction between process and product innovations became only an additional, albeit important, category for the analysis. Perceiving innovation merely in terms of outcomes masks the more intricate learning processes taking place inside the firm. Our research strategy was in line with Delery (1998) who advised the use of multiple performance indicators in investigations about human resource management practices. In this case we introduced distinct definitions of the R\&D variable, each of which denoted different uses of knowledge during the R\&D process.

Human resource management practices play different roles as determinants of learning for innovation: Different learning strategies on the one hand, and the search for distinct pieces of knowledge on the other, require mobilization of different kinds of resources. Such resources contribute differently to distinct learning strategies. As part of internal learning efforts, management practices support absorptive capacity building; and human beings are building blocks upon which such building processes unfold (Simon 1991). In addition, human resource management practices condition the nature of interactions between firms and other agents in the environment. Those practices assist in channelling, absorbing and, eventually, transferring knowledge from and to the external environment. If consideration falls onto knowledge flows, human resource management practices intervene in two main areas: First, they guide the mobilization and exploitation of knowledge already residing in the firm. Second, they steer the search and exploration for knowledge previously unavailable within the firm; they effectively contribute to enriching the knowledge base of a firm.

The need to address more explicitly the dynamics of knowledge accumulation and how this is accompanied by the organisation of human resources: Identification of the alternative ways in which human resource management practices can influence learning performance supports Lorenz and Wilkinson's criticism against previous studies in the field (Lorenz and Wilkinson 2003). The authors contend that human resource management practices conform to some innovative definitions or systems of practices. This is what they interpret as the one-dimensional ranking of firms from traditional to dynamic working environments; the more innovative such management practices are, the better the expected performance of a firm (Ichniowski et.al, 1997). Our study showed that distinct innovation outcomes 
associate with different human resource management practices across firms. This reflects the different knowledge inputs required to achieve the desired goals. In other words, the role of management practices depends on the scale of a firm's technological capabilities, as measured by the type of learning processes and associated innovation outcomes being generated there. Open for debate is the extent to which advancement in technological capabilities is tied to changes in organisational practices and worker characteristics.

Relevant relationship between human resource management practices and learning for new product innovation: The dynamism and technological complexity of drug innovation in Mexico is considerably more limited than that of more developed countries. Specialisation in generic drugs means the country's capacity to enhance the technological frontier in the industry is quite limited. Limitations are more evident if one considers that our reference for defining novelty of innovation was the firm. Nonetheless, to some extent our findings support recent research suggesting that human resource management practices significantly impact R\&D for new product innovation (Christensen and Lundvall 2004; Greve 2007); in this particular case the design of drugs that are new to the firm. Chapter 6 demonstrated that the more novel the drug, the greater the evidence of the influence of human resource management interventions. Knowledge exploration demands more systematic learning efforts; mobilization of human resources becomes more formal and systematic.

How firms, industries and countries contribute to global innovation processes condition the impact of management practices on learning for innovation. Multinational affiliates in Mexico report very dynamic management systems, clearly defined procedures to govern industrial relations, intensive provision of training and so on. Interviews with pharmaceutical affiliates corroborated this; management systems were much more dynamic and advanced as compared to those implemented by local firms. Human resource management practices within multinationals usually follow models developed in parent companies but with careful adaptation to the Mexican context. This does not necessarily mean that affiliates are more innovative than some more modest local firms; at least not in terms of in-house R\&D performance. Domestic and multinational firms differ both in the likelihood of conducting R\&D, and more importantly, in the nature and expected outcomes from such activities. Affiliates of pharmaceutical firms carry out R\&D in Mexico, but with a limited technological content and novelty, as compared to the activities those same firms conduct at parent locations and, only exceptionally, in developing countries, notably India and China. Even in the case of clinical research, the most relevant decisions in terms of design and planning of research protocols, take place at the parent companies. This distinction is key between this and previous studies.

Human resource management practices influence interactions between a firm and external knowledge providers: Placed at the centre of the system of innovation, firms' bounded knowledge bases lead them to search for new ideas, new knowledge residing outside their cognitive, even physical boundaries. Firms incorporate whatever knowledge they find strategically, according to defined business strategies, 
specific projects and so on. Pharmaceutical firms in Mexico tend to link to research and academic organisations mostly as means to complement whatever learning activity they carry out in-house. Interactions go from pure consulting activities to joint project development; these consider the distinct degrees of technological complexity existing not only between firms and research centres, but across firms. Our findings suggest that the provision of training by external agents and the adoption of rules to govern strategic hiring assist firms to achieve the objectives of learning from external knowledge sources. These two practices capture the state of development and consequently, the type of agents a firm interacts with.

We documented the privileged position of agents directly related with the industry, for instance private consultants and training centres linked to the trade organisations of the pharmaceutical industry in Mexico. Even as technological efforts gained in complexity, training from traditional knowledge producers failed to show statistical significance. The discussion in chapters 7 and 8 highlighted some serious restrictions remaining in some basic areas shaping interactions between pharmaceutical firms and other agents in the Mexican system of innovation. More decisive public policy intervention is needed to tackle some of these issues-see below.

Which human resource management practices matter for learning and innovation in pharmaceuticals in Mexico? Although difficult to identify with certainty -see discussion in next section; this thesis incorporated a number of human resource management practices expected to influence learning and thereby innovation at the firm level. By far, the provision of training was the practice with the more notorious and positive effects on different learning strategies. This particular finding indicates the need for continuous learning inside firms, as ingredient for successful learning strategies at the firm level. Additional practices such as worker's remuneration, staff hiring practices and worker's empowerment showed distinct degrees of relevance depending precisely on the type of learning activities and learning strategies endorsed by pharmaceutical firms in Mexico.

As can be expected, this study has several limitations:

Identification of relevant human resource management variables is subject to debate: A fundamental question inspired by the discussion in chapters 1 and 3 refers to the human resource management practices that matter the most for learning and innovation. The subsequent discussion of the literature illustrated some of the complexities faced in defining such human resource management practices. Those interventions are heterogeneous, a number of technological, market related, institutional, even idiosyncratic factors condition approaches to the organisation of personnel. Even more problematic is to find out exactly how human resources management practices enhance tacit and other kinds of knowledge underpinning a firm's improved performance over time. Finding adequate indicators to capture cognitive and other latent processes inside the firm is problematic. The number of practices suitable for the analysis is rather large; interesting constructs and associated interactions can be left aside. Innovation studies have thus joined management scholars in the broad and complex debate about factors linking management practices to firms' performance (Boseli et.al, 2005; Combs et.al, 2006). 
This study offers some further insights to continue the debate.

Limitations in the scope and structure of available data sources: Research about science, technology and innovation in developing countries is usually confronted with the lack of data, or the limited quality and reliability of relevant available indicators. Chapter 3 in this thesis highlighted additional shortcomings related to data on human resource management practices implemented by firms in developing countries. Both the literature and the instruments supporting data collection show conceptual biases towards management practices in manufacturing. By contrast, scant attention is given to human resource management practices shaping work environments around R\&D and related activities. Systematic research in this area is therefore problematic. Whereas case studies are insightful, advancement of theory calls for additional efforts to improve quantitative data, notably through survey instruments.

The structure of ENESTYC illustrates the aforementioned gap. This kind of survey collects data about general management practices but fails to capture other indicators such as teamwork, communication, delegation of decision-making capacity, let alone finer indicators on performance evaluation (publications, patent counts, product developments, and so on), and compensation for performance, use of distinct career ladders, and so on. These and related practices are prominent in the literature about R\&D and innovation management-see approaches type 2 and 3 in Chapter 2. Information about interactions of R\&D staff with external partners during the performance of R\&D is also missing. This is a major limitation of our dataset.

Insufficient exploration of complementarities between process and product innovation in the pharmaceutical industry: The literature often portrays product and process innovations as closely related, yet driven by different factors (Rouvinen 2002). Although difficult to test given the structure of our data, such interrelation is evident in pharmaceuticals. Close regulation and supervision applicable to the industry implies that drug manufacturing, irrespective of the degree of novelty of the product, has to comply with strict specifications about the productive process. Changes in the characteristics of a product are constrained by eventual needs to modify the manufacturing process; hence the risk that the manufacturing process will require recertification and the need to obtain new marketing authorization. This reduced freedom can ultimately explain the limited influence of some human resource management practices on learning for pharmaceutical R\&D in Mexico.

Some policy implications also emerged from the analysis:

The need to improve the overall conditions around learning and innovation: The macroeconomic environment in Mexico is not conducive to more active learning and innovation activities. The structure of incentives provided via public procurement, funding of public research organisations, and the generation of demand for new technologies with strong local content remains a major limitation. Promotion of enhanced interactivity in the system requires more decisive interventions, particularly from organisations responsible for the implementation of science and technology policy, to bring together distinct agents in the system. Empirical and theoretical literature suggests that progress in this area requires 
policy interventions to align with the actions, interests and contributions of the rest of agents in the system. Policy interventions need to promote co-evolution in the system (Kuruvilla et.al, 2002; Lijima and Tachiki 1994; Metcalfe 1994 and 1997).

This thesis identified some specific barriers to academy-industry interaction for pharmaceutical R\&D in Mexico. Such barriers relate to the type and complexity of the knowledge flows required, the activities performed by firms during the distinct stages of the R\&D process. Factors such as adequacy and availability of research infrastructure, presence and characteristics of human resources, as well as incentives and perceptions of agents in the system come distinctly into play as factors supporting/hindering interactivity in systems of innovation. The thesis suggests that promoting increased interactivity requires enhanced understanding of the specific knowledge requirements that firms seek to fulfil and how they do so via interaction with agents such as universities and public research centres. The discussion in this thesis should also inform about the organisation of the human factors intervening in R\&D and other connected processes; hence it is possible to redefine or formulate programs targeting the development of human resources beyond education systems.

The importance of enhancing the export orientation of domestic pharmaceutical firms: Chapters 6-8 stated that participation in export markets has positive effects on learning for innovation in the pharmaceutical industry. The effect was especially perceptible in the case of R\&D for new drug designs. This conclusion is consistent with previous studies suggesting that successful advancement of latecomer pharmaceutical firms has included, as a strategic element, an aggressive export orientation of those firms (Chaturvedi et.al, 2007; Kale and Little 2007; Kim et.al, 1989; Singh 2007). Unfortunately, our evidence suggests that pharmaceutical firms in Mexico participate relatively little in export markets; the share of exports to total sales rounds up at ten percent or lower. This finding calls for more specific and targeted policy interventions via the promotion of and support to exports by local pharmaceutical firms. Progress in the area remains constrained however by the current ideological stance of the Mexican government. Debate exists about the success or failure of the liberalisation strategy in the country. Over the last 20 years or so, Mexican governments have believed that inducing stronger competition via liberalization of local markets should drive enhanced incentives for productivity, efficiency and ultimately, innovation. Tapping external demand to induce incentives to innovate remains insufficiently exploited.

It is important to re-think the impulse to innovation stemming from the public market: Sales of Mexican pharmaceutical firms remain tied to the public sector. In this regard, significant opportunities to induce innovation could result from a reevaluation of factors such as quality, technological content and domestic origin during public procurement. As discussed in chapter 6, for several reasons the mechanisms currently in place privilege low prices over quality of products. The fundamentalist logic of cutting public healthcare expenditures without efforts to promote the development of innovation capacities among local pharmaceutical firms threatens sustainability of the local industry in the long-run.

Reshape the role of multinational affiliates as sources of technology and 
innovation capacity: It is important here to restate one of the conclusions in chapter 9. Mexico needs to carefully reconsider its stance towards the use of foreign investment as a source of external technology. Global pharmaceutical firms have clearly defined roles for host countries within their innovation and commercial strategies. The experiences of countries such as South Korea, China and India show that complementary actions are needed. Countries need to improve the overall business environment, to strengthen the use of science, technology and innovation as core elements of development strategies. Otherwise, the possibilities for catchup by leaping FDI look rather poor.

More money helps but would not solve all problems: Insufficient funding to science and technology is characteristic of developing countries. Increasing financial investment to science and technology is not the single most imperative factor. Great challenges relate to promoting enhanced interactivity within the system of innovation. Promoting the co-evolution of research agendas by pharmaceutical firms and public research systems, particularly in the area of health, is needed. So far, the agents find themselves running at very different speeds and in different directions. Whereas firms privilege development, universities and other similar organisations favour research.

Understanding organisational environments around $R \& D$ : Programs in support of $R \& D$ in private firms need to better understand the organisational environments in which public resources will, eventually, be used. Since human beings are at the heart of innovative organisations, the dynamics of working environments, as created via human resource management interventions, can lead to the potential success or failure of public funding to R\&D. It is our conviction that this thesis shed light on how, why and which human resource management practices support learning for innovation in developing countries such as Mexico. 



\section{Bibliography}

ABPI, 2006. Manufacturing pharmaceuticals. Association British Pharmaceutical Industry.

Abramo, Luis, 1997. Políticas de capacitación y gestión de la mano de obra en un contexto de modernización productiva, in Competitividad, redes productivas y competencias laborales. Marta Novick and María Gallart. CINTERFOR, pp. 79-116.

Achemamerica, 2005. La veta de plata en el mercado farmacéutico de México. 2a Exposición Internacional sobre Tecnologías de Procesos. Vol. 5. ACHEMAMERICA, Mexico City.

Albano, Mark, 2008. Understanding the pharmaceutical manufacturing process: Tools and techniques to integrate PAT into your process. In Pharmaceutical processing: New technology for the pharmaceutical industry. Honeywell.

Alcorta, Ludovico and Wilson Peres, 1998. Innovation systems and technological specialisation in Latin America and the Caribbean. In Research Policy, 26:7-8, pp. 857-81.

Alic, John A, 1995. Organizational Competence: Know-How and Skills in Economic Development. In Technology in Society, 17:4, pp. 429-36.

Allen, Thomas, 1988. Distinguishing Engineers from Scientists, in Managing Professionals in Innovative Organizations: a Collection of Readings. Ralph Katz ed. Cambridge, Massachusetts: Harper Management, pp. Chapter 13-18.

Allende, Francisco, 2000. Balance del proceso de adaptación legislativa al ADPIC en América Latina. Federación Latinoamericana de la Industria Farmacéutica.

Amabile, Teresa, 1996. Managing for Creativity. Harvard Business School Publishing: Re-print 9-396-271, pp. 1-13.

Amabile, Teresa, 1997. Motivating creativity in organizations: on doing what you love and loving what you do. In California Management Review, 40:1, pp. 39-58.

Amabile, Teresa, Constance Hadley, and Steven Kramer, 2002. Creativity under the gun. In Harvard Business Review, 80:8, pp. 52-61.

Amboina, Véronique and Cliff Bowman, 2001. Tacit knowledge: some suggestions for operationalization. In Journal of Management Studies, 38:6, pp. 811-29.

AMC-FCCT, 2005. Una reflexión sobre el Sistema Nacional de Investigadores a 20 años de su creación. 146. Academia Mexicana de Ciencias and Foro Consultivo Científico y Tecnológico, Mexico

AMIIF. Folleto Corporativo. 28. Asociación Mexicana de Industrias de Investigación Farmacéutica A C.

Andre, Nicolas, 2005a. Improvements in regulation trigger hikes in R\&D Expenditures. In Pharmaceutical Executive, 25:SS10.

Andre, Nicolas, 2005b. Keeping an eye out for partners. In Pharmaceutical Executive, 25:SS17.

Andre, Nicolas, 2005c. Mexico: The ninth largest pharmaceutical market in the World. In Pharmaceutical Executive, 25:2. 
Andre, Nicolas, 2005d. No Pain no Gain. In Pharmaceutical Executive, 25:SS15.

Angell, Marcia, 2004. The Truth About the Drug Companies: How they deceive us and what to do about it. New York: Random House.

Anonymous, 2009. Incumplen 51. La Jornada, Mexico.

Archibugi, Daniel and Carlo Pietrobelli, 2003. The globalization of technology and its implications for developing countries: Windows of opportunity or further burden? In Technological Forecasting and Social Change, 70:9, pp. 861-83.

Argote, Linda, Bill McEvily, and Ray Reagans, 2003. Introduction to the Special Issue on Managing Knowledge in Organizations: Creating, Retaining, and Transferring Knowledge. In Management Science, 49:4, pp. v-viii.

Arora, Ashish, Andrea Fosfuri, and Alfonso Gambardella, 2001. Markets for technology: Why do we see them, why don't see more of them, and why we should care, in Markets for technology-The economics of innovation and corporate strategy: MIT Press, pp. 1-14.

Arora, Ashish and Alfonso Gambardella, 1990. Complementarity and external linkages: the strategies of the large firms in biotechnology. In The Journal of Industrial Economics, XXXVIII:4, pp. 361-79.

Arrow, Kenneth, 1962. Economic welfare and the allocation of resources for invention, in The Rate and Direction of Inventive Activity. R. Nelson ed. Princeton: Princeton University Press, pp. 609-25.

Arundel, Anthony and Isabelle Kabla, 1998. What percentage of innovations are patented? Empirical estimates for European firms. In Research Policy, 27, pp. 12741.

Arundel, Anthony, Edward Lorenz, Bengt-Ake Lundvall, and Antoine Valeyre, 2007. How Europe's economies learn: a comparison of work organization and innovation mode for the EU-15. In Industrial and Corporate Change, 16:6, pp. 1175-210.

Badawy, Michael, 1988. What We've Learned: Managing Human Resources. In Research Technology Management, 31:5, pp. 139-45.

Bae, Johnseogk and Cris Rowley, 2004. Macro and micro approaches in human resource development: context and content in South Korea. In Journal of World Business, 39:4, pp. 349-61.

Ball, Derrick, 1998. The needs of R\&D professionals in their first and second managerial appointments: are they being met? In R\&D Management, 28:3, pp. 13945.

Banker, Rajiv, Joy Field, Roger Schroeder, and Kingshuk Sinha, 1996. Impact of Work Teams on Manufacturing Performance: A Longitudinal Field Study. In Academy of Management Journal, 39:4, pp. 867-90.

Barney, Jay, 1991. Firm resources and sustained competitive advantage. In Journal of Management, 17:1, pp. 99-120.

Bartlett, Kenneth, John Lawler, Johngseok Bae, Shyh-jer Chen, and David Wan, 2002. Differences in international human resource development among indigenous firms and multinational affiliates in East and Southeast Asia. In Human Resource Development Quarterly, 13:4, pp. 383-405.

Barton, Harry and Rick Delbridge, 2001. Development in the learning factory: training human capital. In Journal of European Industrial Training, 25:9, pp. 465-72. 
Becerril, Mari Carmen, 2006. Farmacovigilancia, in La Industria Farmacéutica Mexicana: Orígenes, desarrollo y perspectivas. Asociación Nacional de Fabricantes de Medicamentos. México: Porrúa Hnos, pp. 87-97.

Bell, Martin, 1984. Learning and the Accumulation of Industrial Technological Capacity in Developing Countries, in Technological Capability in the Third World. Martin Fransman and Kenneth King eds. Hong Kong: The Macmillan Press Ltd, pp. 187-209.

Beneito, Pilar, 2002. Choosing among alternative technological strategies: an empirical analysis of formal sources of innovation. Research Policy, 32:4, pp. 693713.

Benner, Mary and Michael Tushman, 2002. Process management and technological innovation: A longitudinal study of the Photography and Paint industries. In Administrative Science Quarterly, 47:4, pp. 676-706.

Beret, Pierre, Ariel Mendez, Claude Paraponaris, and Nadine Richez-Battesti, 2003. R\&D personnel and human resource management in multinational companies: between homogenization and differentiation. In International Journal of $\mathrm{Hu}$ man Resource Management, 14:3, pp. 449-68.

BHSP, 2006. Developing a National Registry of Pharmacologic and Biologic Clinical Trials Workshop Report. 126. Board on Health Science Policy: Washington.

Bierly, Paul and Alok Chakrabarti, 1996. Generic knowledge strategies in the US pharmaceutical industry. In Strategic Management Journal, 17, pp. 123-35.

BLS-USLD, 2007. Career Guide to Industries, 2008-09 Edition, Pharmaceutical and Medicine Manufacturing. Bureau of Labor Statistics, US Department of Labor.

BMI, 2006. Mexico pharmaceuticals and healthcare report Q4 2006. 78. Business Monitor International: London.

Boggs, Raymond, Linda Bayuk, and David McCamey, 1999. Speeding developing cycles. In Research Technology Management, 42:5, pp. 33-38.

Bolívar, Francisco, 1997. Biotechnology in Mexico: Planning for the future. $\mathrm{Na}-$ ture Biotechnology, 15: August, pp. 742-43.

Boseli, Paul, Graham Dietz, and Corien Boon, 2005. Commonalities and contradictions in HRM and performance research. In Human Resource Management Journal, 15:3, pp. 67-94.

Brodovsky, Joan, 1997. La industria farmacéutica y farmoquímica Mexicana en los años 90, in Apertura Económica y Desregulación en el Mercado de Medicamentos. Jorge Katz, Gustavo Burachik, Joan Brodovsky and Sergio Queiroz eds. Buenos Aires: CEPAL/IDRC-Alianza Editorial, pp. 167-99.

Brusoni, Stefano, 2002. Innovation in the knowledge economy: a summary of research issues. SPRU Report 2A-D2A project IST-1990-220782: Science and Technology Research Unit, University of Sussex.

Bush, K, 2004. Antibacterial drug discovery in the 21st century. In Clinical Microbiology and Infectious, 10, 10-17.

Butcher, Eugene, Ellen Berg, and Eric Kunkel, 2004. Systems biology in drug discovery. In Nature Biotechnology, 22:10, pp. 1253-59.

Cantwell, John and Elena Kosmopolou, 2001. Determinants of internationalization of corporate technology. DRUID Working Paper 01-08: 36: Aalborg. 
Cardinal, Laura, 2001. Technological innovation in the Pharmaceutical Industry: The use of Organizational control in Managing Research and Development. In Organization Science, 12:1, pp. 19-36.

Cardinal, Laura and Donald Hatfield, 2000. Internal knowledge generation: the research laboratory and innovative productivity in the pharmaceutical industry. In Journal of Engineering and Technology Management, 17:3-4, pp. 247-71.

Cardon, Melissa and Christopher Stevens, 2004. Managing human resources in small organizations: What do we know? Human Resource Management Review: 14, pp. 295-323.

Carrillo, Jorge and Miguel Ramírez, 1997. Reestructuración, eslabonamientos productivos y competencias laborales en México, in Competitividad, redes productivas y competencias laborales. M Novick and M A Gallart (Eds.) CINTERFOR, pp. 35192.

Casas, Rosalba (Ed.), 2001. La formación de redes de conocimiento: Una perspectiva regional desde México. Barcelona and México: Rubí Anthropos IIS-UNAM.

Casas, Rosalba, 2005. Exchange and knowledge flows between large firms and research institutions. Innovation: Management, Policy and Practice, 7:2-3, pp. 18899.

Cassiman, Bruno and Reinhilde Veugelers, 2000. External technology sources: Embodied or disembodied technology acquisition. Working Papers Department of Economics and Business, Universitat Pompeu Fabra, Economics.

Cassiman, Bruno and Reinhilde Veugelers, 2006. In Search of Complementarity in the Innovation Strategy: Internal R\&D and External Knowledge Acquisition. Management Science, 52:1, pp. 68-82.

Cassiolato, Jose, Helena Lastres, and María Maciel (Eds.), 2003. Systems of Innovation and Development: Evidence from Brazil. UK and USA: Edward Elgar Publishing.

Casson, Mark, 1990. Entrepreneurship. International Library of Critical Writings in Economics, 13.

Castaños-Lomnitz, Heriberta, 2004. La migración de talentos en México. Mexico: UNAM-IIEc.

Cattozzella, Alessandra and Marco Vivarelli, 2007. The catalizing role of in-house $R \& D$ in fostering the complementarity of innovative inputs. Discussion Paper Series, IZA DP. IZA.

Caves, Richard, Mark Hurwitz, and Michael Whinston, 1991. Patent Expiration, Entry and Competition in the US Pharmaceutical Industry. In Brookings Papers in Economic Activity, pp. 1-48.

Chan, Margaret, 2009. Power of public health lies in strong health systems. Geneva, Zwitzerland.

Chang, Pao-Long and Hsin-Yu Shih, 2004. The innovation systems of Taiwan and China: a comparative analysis. In Technovation: 24, pp. 529-39.

Chaturvedi, Kalpana, Joanna Chataway, and David Wield, 2007. Policy, markets and knowledge: Strategic synergies in Indian pharmaceutical firms. In Technology Analysis \& Strategic Management 19:5, pp. 565-88. 
Chiesa, Vittorio, 1996. Separating Research from Development: Evidence from the Pharmaceutical Industry. In European Management Journal, 14:6, pp. 638-47.

Christensen, Jasper and Bengt-Ake Lundvall, 2004. Product innovation, interactive learning and economic performance. Amsterdam.

Christofides, Louis, J Hardin, and Thanasis Stengos, 2000. Corrigendum to on the calculation of marginal effects in the bivariate probit model. In Economics Letters, 68:3, pp. 339.

Christofides, Louis, Thanasis Stengos, and Roberto Swidinsky, 1997. On the calculation of marginal effects in the bivariate probit model. In Economics Letters, 54:3, pp. 203-08.

Chung-Jen, C. and Jing-Wen, H. 2009. Strategic human resource practices and innovation performance - the mediating role of knowledge management capacity. Journal of Business Research, 62, 104-114.

Cimoli, Mario (Ed.), 2000. Developing Innovation Systems: Mexico in a global context. London and New York: Thomson Learning.

Cimoli, Mario and Roberto Constantino, 2000. Systems of innovation, knowledge and networks: Latin America and its capability to capture benefits, in Knowledge Flows in National Systems of Innovation: a comparative analysis of sociotechnical constituencies in Europe and Latina America. Roberto López-Martínez and Andrea Piccaluga eds. UK and US: Edward Elgar Publisher, pp. 56-82.

Cockburn, lain, 2004. The changing structure of the pharmaceutical industry. Health Affairs, 23:1, pp. 10-22.

Cockburn, lain and Rebecca Henderson, 2001. Scale and Scope in Drug Development: Unpacking the Advantages of Size in Pharmaceutical Research. In Journal of Health Research, 20:6, pp. 1033-57.

Cockburn, lain, Rebecca Henderson, and Scott Stern, 1999a. Balancing incentives: The tension between basic and applied research. NBER Working Papers: 47, Cambridge, Ma.

Cockburn, lain, Rebecca Henderson, and Scott Stern, 1999b. The Diffusion of Science Driven Drug Discovery: Organizational Change in Pharmaceutical Research. NBER Working Papers: 55; Cambridge, Ma.

Cohen, Wesley and Daniel Levinthal, 1989. Innovation and learning: The two faces of R\&D. In The Economic Journal, 99:397, pp. 569-96.

Cohen, Wesley and Daniel Levinthal, 1990. Absorptive capacity: A new perspective on learning and innovation. In Administrative Science Quarterly, 35:1, pp. 12852.

Collinson, Simon, 2001. Knowledge management capabilities in R\&D: a UK-Japan company comparison. In R\&D Management, 31:3, pp. 335-47.

Colmenares, Octavio, 1992. Administration Strategic: Cases de Empresas Mexicanas. Mexico City: EDAMEX SA de CV.

Combs, James, Yongmei Liu, Angela Hall, and David Ketchen, 2006. How much do high-performance work practices matter? A meta-analysis of their effects on organizational performance. In Personnel Psychology, 59:3, pp. 501-28.

CONACYT, 2007. Informe general del estado de la ciencia y tecnología en México. 380. Consejo Nacional de Ciencia y Tecnología: México. 
Cordero, Rene, Georgancye Farris, and N DiTomaso, 1998. Technical Professionals in Cross-functional Teams: Their Quality of Work Life. In Journal of Product Innovation Management, 15:6, pp. 550-63.

Coriat, Benjamin and Olivier Weinstein, 2002. Organizations, firms and institutions in the generation of innovation. In Research Policy, 31:2, pp. 273-90.

Corona, Leonel (Ed.), 1997. Cien Empresas Innovadoras en Mexico. Mexico: UNAM-M.A.Porrúa.

Creswell, John, 2003. Research Design: Qualitative, Quantitative, and Mixed Methods Approaches. $2^{\text {nd }}$ Edition. United States, Sage Publications, Inc. pp. 246.

Crossley, Roger, 2004. The quiet revolution: outsourcing in pharma. Drug Discovery Today, 9:16, pp. 694.

Daar, Abdallah and Peter Singer, 2005. Pharmacogenetics and geographical ancestry: implications for drug development and global health. In Nature Reviews, 6: 241-46.

Datta, Deepak, James Guthrie, and Patrick Wright, 2003. HRM and Firm Productivity: Does Industry Matter? Paper presented to the National Academy of Management Meetings: 36: Seattle, WA.

Dávila, Anabel and Marta Elvira, 2007. Psychological contracts and performance management in Mexico. In International Journal of Man Power, 28:5, pp. 384-402.

de la Fuente, Juan Ramón, Jaime Martuscelli, and Donato Alarcón-Segovia, 2004. El futuro de la investigación médica en México. In Gaceta Médica de México, 140:5, pp. 519-24.

Debackere, Koen, Dirk Buyens, and Tine Vandenbossche, 1997. Strategic career development for R\&D professionals: lessons from field research. In Technovation, 17:2, pp. 53-62.

Delery, John, 1998. Issues of Fit in Strategic Human Resource Management Implications for Research. In Human Resource Management Review, 8:3, pp. 289-309.

DHHS, FDA, and CDER, 1998. The CDER Handbook. US Department of Human Health Services; US Food and Drug Administration; US Center for Drug Evaluation and Research.

Dijkema, G, P Ferrao, P Herder, and Manuel Heitor, 2006. Trends and opportunities framing innovation for sustainability in the learning society. In Technological Forecasting and Social Change, 73:3, pp. 215-27.

DiMasi, Joseph, 2000. New Drug Innovation and Pharmaceutical Industry Structure: Trends in the Output of Pharmaceutical Firms. In Drug Information Journal, 34:44, pp. 1169-94.

DiMasi, Joseph, 2001a. New drug development in the United States from 1963 to 1999. In Clinical Pharmacology \& Therapeutics, 69:5, pp. 286-96.

DiMasi, Joseph, 2001b. Risks in new drug development: Approval success rates for investigational drugs. In Clinical Pharmacology \& Therapeutics, 69:5, pp. 297307.

DiMasi, Joseph, Ronald Hansen, and Henry Grabowski, 2003. The price of innovation: new estimates of drug development costs. Journal of Health Economics: 22, pp. 151-85. 
Doeringer, Peter, Edward Lorenz, and David Terkla, 2003. The adoption and diffusion of high-performance management: lessons from Japanese multinational in the West. In Cambridge Journal of Economics, 27:2, pp. 265-86.

DOJ-FTC. 6th April, 1995. Antitrust guidelines for the licensing of intellectual property US Department of Justice and Federal Trade Commission. 31.

Domínguez, Lilia and Flor Brown, 1998. The impact of flexible automation on scale and scope in the Mexican engineering industry, in Flexible Automation in Developing Countries The impact on scale and scope and the implications for location of production. Ludovico Alcorta ed. London and New York: Routledge, pp. 217-57.

Drennan, Kaye, 2001. Editorial: Have the ultimate benefits of clinical trials been maligned beyond repair? In Drug Discovery Today, 6:12, pp. 597-99.

Drews, Jurgen, 2000. Drug Discovery: A Historical Perspective. In Science, 287, pp. 1960-64.

Du, Rong and Shizhong Ai, 2008. Cross-organizational knowledge acquisition through flexible hiring and joint R\&D: Insights from a survey in China. In Expert Systems with Applications, 35:1-2, pp. 434-41.

Dussel, Enrique, 1999. Las Industrias Farmacéutica y Farmoquímica en México y el Distrito Federal. CEPAL: Mexico.

Dussel, Enrique, 2003. Características de las actividades generadoras de empleo en la economía mexicana (1988-2000) In Investigación Económica, LXIII:243, pp. 123-54.

Dussel, Enrique, 2004. Conditions and Evolution of Employment and Wages in Mexico. TLWNSI Issue Brief, Sustainable Development: 1-8.

Dutrénit, Gabriela, 2000. Learning and Knowledge Management in the Firm: From Knowledge Accumulation to Strategic Capabilities: Edward Elgar.

Dutrénit, Gabriela, 2006. Instability of the technology strategy and building of the first strategic capabilities in a large Mexican firm. In International Journal of Technology Management 3:1/2/3, pp. 43-61.

Dutrénit, Gabriela, 2007. The transition from building-up innovative technological capabilities to leadership by latecomer firms. Asian Journal of Technology Innovation, 15:2, pp. 125-49.

Dutrénit, Gabriela, Arturo Torres, Juan Corona, Claudia De Fuentes, Jose Sampedro, Noe Becerra and Marcela Amaro, 2010. Interactions between universities and firms: searching for paths to support the changing role of universities in the South. Technical Report of Mexico. International Development Research Centre.

Dutrénit, Gabriela and Valeria Arza 2010, Channels and benefits of interactions between public research organisations and industry in Latin America: comparisons, Science and Public Policy, 37(7).

Edquist, Charles, 1997. Systems of Innovation Approaches -Their Emergence and Characteristics, in systems of innovation: technologies, institutions and organizations. Charles Edquist ed. London and Washington: Pinter, pp. 1-35.

Edquist, Charles and Björn Johnson, 1997. Institutions and organizations in systems of innovation, in Systems of innovation: technologies, institutions and organizations. Charles Edquist ed. London and Washington: Pinter, pp. 41-64. 
Edquist, Charles and Maureen McKelvey (Eds.), 2000. Systems of Innovation: Growth, Competitiveness and Employment. London and New York: Edward Elgar Ltd.

Escribano, Álvaro, Andrea Fosfuri, and Josep Tribó, 2009. Managing external knowledge flows: the moderating role of absorptive capacity. In Research Policy 38:1, pp. 96-105.

Faulkner, Wendy, Judith Senker, and Léa Velho, 1995. Knowledge Frontiers: Public Sector Research and Industrial innovation in Biotechnology, Engineering Ceramics, and Parallel Computing. Oxford: Clarendon Press.

FCCT, 2006. Bases para una Política de Estado en Ciencia y Tecnología e Innovación en México. Mexico: Foro Consultivo Científico y Tecnológico.

FDA, 2001. Guidance for Industry: Acceptance of Foreign Clinical Studies. 4.

FDA, 2003. Guidance for Industry: Bioavailability and Bioequivalence Studies for Orally Administered Drug Products -General Considerations. Revision 1: United States.

FDA, 2004a. Guidance for industry PAT-A framework for innovative pharmaceutical development, manufacturing, and quality assurance. Pharmaceutical CGMPs. Food and Drug Administration.

FDA, 2004b. Innovation and continuous improvement in pharmaceutical manufacturing: Pharmaceutical CGMPs for the 21st Century. Food and Drug Administration.

FDA/ORA. Compliance Program Guidance for Industry: Good Laboratory Practices. Food and Drug Administration.

Figueiredo, Paulo, 2003. Learning, capability accumulation and firms differences: evidence from latecomer steel. In Industrial and Corporate Change, 12:3, pp. 60743.

Fiol, C Marlene, 1994. Consensus, diversity and learning in organizations. Organization Science, 5:3, pp. 403-20.

Fiol, C Marlene and M. A. Lyles, 1985. Organizational learning. In Academy of Management Review, 10:4, pp. 803-13.

Florida, Richard and Jim Goodnight, 2005. Managing for Creativity. In Harvard Business Review: Reprint R0507L, pp. 8.

Flynn, G, 1994. HR in Mexico: What You Should Know. In Personnel Journal, 73:8, pp. 34-44.

Forbes, Naushad and David Wield, 2000. Managing R\&D in technology-followers. In Research Policy, 29:9, pp. 1095-109.

Forest, Mariah, 1994. Thinking of a Plant in Mexico? In Academy of Management Executives, 8:1, pp. 3-40.

Freeman, Chris, 1987. Technology Policy an Economic Performance: Lessons from Japan. London: Pinter.

Freeman, Chris, 1995. The National System of Innovation in Historical Perspective. Cambridge Journal of Economics, 19:1, pp. 5-24.

Freeman, Chris, 2002. Continental, National, Sub-National Innovation Systems Complementarity and Economic Growth. Research Policy, 31:2, pp. 191-212. 
Gallart, María, 2001. La Articulación entre el Sector Público y la Empresa Privada en la Formación Profesional de América Latina, in Formación para el trabajo: ¿pública o privada? Guillermo (coord.) Labarca, CINTERFOR/OIT/CEPAL/GTZ, pp. 23-60.

García, Alejandro, 2002. Del paradigma fordista-taylorista al toyotista en la industria automotríz terminal: los casos de General Motors Distrito Federal y Silao, Guanajuato, in Innovación, Universidad e Industria en el Desarrollo Regional. Leonel Corona and Ricardo Hernandez eds. Mexico: Plaza y Valdéz, S A de C V, pp. 323-43.

García, Rosanna and Roger Calantone, 2002. A critical look at technological innovation typology and innovativeness terminology: a literature review. In The Journal of Product Innovation Management, 19, pp. 110-32.

Gaudillière, Jean-Paul, 2004. Hormones, Régimes d'innovation et Stratégies d'entreprise: Les Exemples de Schering et Bayer. Entreprises et Histoire:36, pp. 84102.

Gibbons, Michael and Ron Johnston, 1974. The roles of science in technological innovation. In Research Policy, 3:3, pp. 117-38.

Gibbons, Michael, Camile Limoges, Helga Nowotny, Simon Schwartzman, Peter Scott, and Martin Trow, 1994. Evolution of Knowledge Production In The New Production of Knowledge: the Dynamics of Science and Research in contemporary societies. London: SAGE Publications.

Gilsing, Victor, 2006. Exploration and exploitation in innovation systems: The case of pharmaceutical biotechnology. In Research Policy, 35:1, pp. 1-23.

Ginsburg, Geoffrey and Jeanette McCarthy, 2001. Personalized medicine: revolutionizing drug discovery and patient care. In Trends in Biotechnology, 19:12, pp. 491-96.

Govinda, Rao, 1998. Accommodating Public Expenditure Policies: the Case of Fast Growing Asian Economies. In World Development, 26:4, pp. 673-94.

GPWI. Las mejores empresas para trabajar en México.

Grace, Cheri, 2004. The Effect of Changing Intellectual Property on Pharmaceutical Industry Prospects in India and China: Considerations for Access to Medicines. 68. Department of International Development/Health Systems Resource Centre.

Grant, Robert, 1996a. Prospering in dynamically-competitive environments: Organizational capability as knowledge integration. In Organization Science, 7:4, pp. 375-87.

Grant, Robert, 1996b. Toward a Knowledge-Based Theory of the Firm Strategic Management Journal, 17:Special Issue: Knowledge and the Firm, pp. 109-22.

Gray, David, Sue Cundell, David Hay, and Jean O'Neill, 2004. Learning through the workplace: a guide to work-based learning. Spain: Nelson Thrones, Ltd.

Greenan, Natalie, 2003. Organisational change, technology, employment and skills: an empirical study of French manufacturing. In Cambridge Journal of Economics:27, pp. 287-316.

Greene, William, 2003. Econometric Analysis: Pearson Education.

Greve, Henrich, 2007. Exploration and exploitation in product innovation. In Industrial and Corporate Change, 16:5, pp. 945-75.

Gupta, Ashok and Arvind Singhal, 1993. Managing human resources for innovation and creativity. In Research Technology Management, 36:3, pp. 41-48. 
Guzmán, Alenka, 2005. Naturaleza de la lyD y las Patentes de la Industria Farmacéutica en México, in Industria Farmacéutica y Propiedad Intelectual: Los países en desarrollo. Alenka Guzmán and Gustavo Viniegra eds. Mexico: H Cámara de Diputados LIX Legislatura, UAM-Iztapalapa, M. A. Porrúa pp. 267-322.

Guzmán, Alenka and Gustavo Viniegra (Eds.), 2005. Industria Farmacéutica y Propiedad Intelectual: Los países en desarrollo. México: H Cámara de Diputados LIX Legislatura, UAM-Iztapalapa, M A Porrúa

Hara, Takuji, 2003. Innovation in the Pharmaceutical Industry: The Process of Drug Discovery and Development. UK and US: Edward Elgar.

Hayden, Cori, 2005. Mexico's Generics Revolution. CLAS: University of Berkeley.

Hemmert, Martin, 1998. Reorganization of R\&D in Japanese Manufacturing Firms: Preserving competitiveness for the twenty-first century, in Technology and Innovation in Japan: Policy and Management for the twenty-first century. M Hemmert and C Oberländer eds. London and New York: Routldge, pp. 129-50.

Hemmert, Martin and Christian Oberländer (Eds.), 1998. Technology and Innovation in Japan: Policy and Management for the twenty-first century. London and New York: Routledge.

Henderson, Rebecca and lain Cockburn, 1994. Measuring competence? Exploring Firm Effects on Pharmaceutical Research. In Strategic Management Journal, 15:Special Issue Competitive Organizational Behaviour, pp. 63-84.

Hernández, Ricardo, Cecilia López, and Mauricio Jasso, 2002. Estrategias de Innovación y modernización tecnológica en la industria siderúrgica: casos de las empresas Hylsamex y Ahmsa, in Innovación, Universidad e Industria en el Desarrollo Regional. Leonel Corona and Ricardo Hernandez eds. Mexico: Plaza y Valdéz, S A de C V, pp. 299-321.

HHS, 2009. HHS takes additional steps toward development of vaccine for the novel influenza A(H1N1) News release: 1. US Department of Health \& Human Services.

Hikino, Takashi and Alice Amsdem, 1994. Staying behind, stumbling back, sneaking up, soaring ahead: Late industrialisation in historical perspective, in Convergence of Productivity: Cross-National studies and historical evidence. W J Baumol, R Nelson and E N Wolff (Eds.): Oxford University Press, pp. 285-315.

Hise, Richard, Roberto Solano-Mendez, and Larry Gresham, 2003. Doing business in Mexico. Thunderbird International Business Review, 45:2, pp. 211-24.

Hobday, Michael, 1995. Innovation in East Asia: The Challenge to Japan: Edward Elgar, Publishing.

Hobday, Michael, Howard Rush, and John Bessant, 2004. Approaching the innovation frontier in Korea: the transition phase to leadership. In Research Policy, 33:10, pp. 1433-57.

Hofstede, Geert, 1980. Culture's Consequences: International Differences in Work-related Values. London: Sage Publications.

Hollis, Aidan, 2002. The importance of being first: evidence from Canadian generic pharmaceuticals. In Health Economics, 11, pp. 723-34. 
Hope Pelled, Lisa and Katherine Xin, 1997. Work values and their human resource management implications: A theoretical comparison of China, Mexico, and the United States. In Journal of Applied Management Studies, 6:2, pp. 185-98.

Hullman, Angela, 2000. Generation, transfer and exploitation of new knowledge, in Changing Innovation in the Pharmaceutical Industry: Globalization and New Ways of Drug Development. Andre Jungmittag, Guido Reger and Thomas Reiss eds. Berlin: Springer, pp. 71-96.

Ichniowski, Casey, Thomas Kochan, David Levine, Craig Olson, and George Strauss, 1996. What works at work: Overview and assessment. In Industrial Relations, 35:3, pp. 299-333.

Ichniowski, Casey, Kathryn Shaw, and Giovanna Prennushi, 1997. The effects of Human Resource Management Practices on Productivity: A Study of Steel Finishing Lines. In The American Economic Review, 87:3, pp. 291-313.

IDRC, 2007. National Innovation Systems in Brazil, Russia, India, China and South Africa (BRICS). Project 104227.

IMS-Health, 2006. Retail drug monitor: Tracking 13 key global pharma markets. 5.

IMS-Health, 2009a. IMS health forecasts 4.5 -5.5 percent growth for global Pharmaceutical market in 2009, exceeding \$820 Billion.

IMS-Health, 2009b. Retail drug monitor. 1. IMS-Health.

INEGI. Encuesta Industrial Anual. Instituto Nacional de Estadística, Geografía e Informática: México.

Islas, Laura, 2003. Management en Iberoamérica: Influencia de la Cultura Laboral Mexicana en la Gestión de los Recursos Humanos. 1-30. Fundación Getulio Vargas.

James, William, 2002. Best HR practices for today's innovation management. In Research Technology Management, 45:1, pp. 57-60.

Johnson, B and Bengt-Ake Lundvall, 2003. Promoting innovations systems as a response to the globalizing learning economy, in Systems of Innovation and Development: Evidence from Brazil. J; $\mathrm{H}$ Lastres and M Maciel Cassiolato ed. UK and US: Edward Elgar Publishing, pp. 141-84.

Johnson, Joanne, John Baldwin, and Brent Diverty, 1996. The implications of Innovation for Human Resources Strategy. Futures, 28:2, pp. 103-19.

Jones, Oswald, 1996. Strategic HRM: The implications for pharmaceutical R\&D. In Technovation, 16:1, pp. 21-32.

Joonmo, Cho, 2004. Human resource management, corporate governance structure and corporate performance in Korea: a comparative analysis of Japan, US and Korea. Japan and the World Economy.

Joshi, Hemant, 2003. Analysis of the Indian Pharmaceutical Industry with Emphasis on Opportunities in 2005. Pharmaceutical Technology: January, pp. 74-94.

Jungmittag, Andre, Guido Reger, and Thomas Reiss (Eds.), 2000a. Changing Innovation in the Pharmaceutical Industry: Globalization and New Ways of Drug Development. Berlin: Springer.

Jungmittag, Andre, Guido Reger, and Thomas Reiss, 2000b. Introduction, in Changing Innovation in the Pharmaceutical Industry: Globalization and New Ways of 
Drug Development. Andre Jungmittag, Guido Reger and Thomas Reiss eds. Berlin: Springer, pp. 1-6.

Kaitin, Kenneth and Elaine Healy, 2000. The New Drug Approvals of 1996, 1997, and 1998: Drug Development Trends in the User Fee Era. In Drug Information Journal, 34, pp. 1-14.

Kale, Dinar and Steve Little, 2007. From imitation to innovation: The evolution of R\&D capabilities and learning processes in the Indian pharmaceutical industry. In Technology Analysis \& Strategic Management, 19:5, pp. 589-609.

Kaplinsky, Raphael, 1995. Technique and System: The Spread of Japanese Management Techniques to Developing Countries. In World Development, 23:1, pp. 5771.

Katz, Jorge, Gustavo Burachik, Joan Brodovsky, and Sergio Queiroz, 1997. Apertura Económica y Desregulación en el Mercado de Medicamentos. Buenos Aires: CEPAL/IDRC-Alianza Editorial.

Katz, Ralph (Ed.), 1988. Managing professionals in innovative organizations: a collection of readings. Cambridge, Massachusetts: Harper Management.

Kay, Neil, 2000. Pattern in coorporate evolution: Oxford University Press.

Kessler, Eric, Paul Bierly, and Shanti Gopalakrishnan, 2000. Internal vs. External Learning in New Product Development: Effects on Speed, Cost and Competitive Advantage. R\&D Management, 30:3, pp. 213-23.

Kettler, Hannah and Rajiv Modi, 2001. Building local research and development capacity for the prevention and cure of neglected diseases: the case of India. Bulletin of the World Health Organization, 79:8, pp. 742-47.

Kidder, Tracy, 1982. The soul of a new machine. New York: Avon.

Kim, Lin Su, 1998. Crisis construction and organizational learning: capability building in catching-up at Hyunday Motor. In Organization Science, 9:4, pp. 506-21.

Kim, Lin Su, 1997. Imitation to Innovation: The dynamics of Korea's Technological Learning. Boston: Harvard University Press.

Kim, Youngbae and Jongseok Cha, 2000. Career Orientations of R\&D professionals in Korea. In R\&D Management, 30:2, pp. 121-37.

Kim, Youngbae, Lin Su Kim, and Jinjoo Lee, 1989. Innovation strategy of local pharmaceutical firms in Korea: A multivariate analysis. In Technology Analysis and Strategic Management, 1:1, pp. 29-44.

KPMG, 2004. The Pharmaceutical Industry in Mexico. 53. KPMG: Mexico.

Kuemmerle, Walter, 1999. Foreign direct investment in industrial research in the pharmaceutical and electronics industries-results from a survey of multinational firms. Research Policy, 28:2-3, pp. 179-93.

Kuhlman, J, 1997. Drug research: from the idea to the product. In International Journal of Clinical Pharmacology and Therapeutics, 35:12, pp. 541-52.

Kuruvilla, Sarosh, Christopher Erickson, and Alvin Hwang, 2002. An Assessment of the Singapore Skills Development System: Does it constitute a viable model for other developing countries? In World Development, 30:8, pp. 1461-76.

Labarca, Guillermo, 1999a. Formación para el Trabajo: Observaciones en América Latina y El Caríbe; Chapter 1, in Formación y empresa. Guillermo Labarca (Ed.): CINTERFOR/OIT/CEPAL/GTZ, pp. 19-58. 
Labarca, Guillermo, 1999b. Formación y empresa: CINTERFOR/OIT/CEPAL/GTZ.

Lace era, Nicola, lain Cockburn, and Rebecca Henderson, 2004. Do Firms Change Capabilities by Hiring New People? A Study of the Adoption of Science-Based Drug Discovery. MIT Working Papers: 28.

Lane, Christen and Jocelyn Prober, 2007. The external sourcing of technological knowledge by US pharmaceutical companies: Strategic goals and interorganizational relationships. Industry and Innovation, 14:1, pp. 5-25.

Lane, Peter and Michael Libation, 1998. Relative absorptive capacity and interorganizational learning. In Strategic Management Journal, 19:5, pp. 461-77.

Laursen, Keld, 2002. The importance of sectoral differences in the application of complementary HRM practices for innovation performance, International Journal of the Economics of Business, Vol. 9(1), pp. 139-156.

Laursen, Keld and Nicolai Foss, 2003. New human resource management practices, complementarities and the impact on innovation performance. Cambridge Journal of Economics:27, pp. 243-63.

Laursen, Keld and Volker Mahnke, 2001. Knowledge Strategies, Firm Types, and Complementarity in Human-Resource Practices. In Journal of Management and Governance, 5:1, pp. 1-27.

Laursen, Keld and Amon Salter, 2004. Searching high and low: what types of firms use universities as a source of innovation? In Research Policy, 8:33, pp. 120115.

Lazear, Edward and Paul Oyer, 2004. Internal and external labor markets: a personnel economics approach. In Labour Economics 11:5, pp. 527-54.

Le Bas, Christian and Christophe Sierra, 2002. Location versus home country advantages in R\&D activities: some further results on multinationals' locational strategies. In Research Policy, 31:4, pp. 589-609.

Legewie, Jochen, Daniel Dirks, Martin Hemmert, Hendrik Meyer-Ohle, and Franz Waldenberger, 2000. The Japanese employment system in transition. In International Business Review, 9:5, pp. 525-53.

Lenartowicz, Tomas, James Johnson, and Caroline White, 2003. The neglect of intracountry cultural variation in international management research. In Journal of business research, 56:12, pp. 999-1008.

Leonard-Barton, Dorothy, 1992. Core capabilities and core rigidities: a paradox in managing new product development. In Strategic Management Journal, 13:S1, pp. 111-25.

Leone, Maria and Toke Reichstein, 2009. Does licensing foster rapid invention? DRUID-DIME Academy Winter 2009 PhD Conference on Economics and Management of Innovation, Technology and Organizational Change: Aalborg.

Levinthal, Daniel and James March, 1993. The myopia of learning. In Strategic Management Journal, 14: Special Issue: Organizations, Decision Making and Strategy pp. 95-112.

Li, Ying, Wim Vanhaverbeke, and Wilfred Schoemakers, 2008. Exploration and exploitation in innovation: reframing the interpretation. Creativity and innovation management, 17:2, pp. 107-26. 
Liao, Tim Futing, 1994. Interpreting Probability Models: logit, probit and other generalized linear models. New York SAGE Publications.

Lichtenberg, Frank, 1994. Have International Levels of Educational Attainment Narrowed, in Convergence of Productivity: Cross-National studies and historical evidence. W J Baumol, R Nelson and E N Wolff (Eds.): Oxford University Press, pp. 225-42.

Lijima, K and D Tachiki, 1994. Developing Human Resources for Sustainable Economic Growth: Public Policy Lessons from Japan, the Asian NIEs, and DPEs. 53. Sakura Institute of Research: Centre for Pacific Business Studies: Tokio, Japan.

Livesay, Howard, David Lux, and Marilyn Brown, 1996. Human factors and the innovation process. In Technovation, 16:4, pp. 173-86.

Liyanage, Shantha, Paul Greenfield, and Robert Don, 1999. Towards a fourth generation R\&D management model-research networks in knowledge management. In International Journal of Technology Management, 18:3/4, pp. 372-94.

Loasby, Brain, 2002. The evolution of knowledge: beyond the biological model. In Research Policy, 31, pp. 1227-39.

Long, Scott and Jeremy Freese, 2006. Regression Models for Categorical Dependent Variables using STATA: STATA Press.

López, Eduardo, 2006. Evolución de la industria farmacéutica en México, in $L a$ industria farmacéutica mexicana. Mexico: ANAFAM-Porrúa, pp. 21-28.

Lorca, Antonio and Luis Schmidt, 1994. From minimum to maximum. Managing Intellectual Property, pp. 28-30.

Lorenz, Edward and Antoine Valeyre, 2004. Organisational Change in Europe: National Models or the Diffusion of a New One Best Way? DRUID Working Papers: 25.

Lorenz, Edward and Antoine Valeyre, 2005. Organizational innovation, human resource management and labour market structure: A comparison of the EU-15. In Journal of Industrial Relations, 47:4, pp. 424-42.

Lorenz, Edward and Frank Wilkinson, 2003. Forum: Organisational change, human resource management and innovative performance: comparative perspectives. In Cambridge Journal of Economics, 27:2, pp. 239-41.

Lovett, Steve, Tom Coyle, and Russel Adams, 2004. Job satisfaction and technology in Mexico. In Journal of World Business, 39:3, pp. 217-32.

Luhnow, David, 2005. Potent Prescription: In Mexico, Maker of Generics Adds Spice to Drug Business; Using Clinics and Pinups, Mr. Gonzalez Boosts Sales; Now, a Run for President; One 'Chica' Kiss Per Question. Wall Street Journal: A1: New York.

Lundvall, Bengt-Ake, 1988. Innovation as an interactive process: From userproducer interaction to the National System of innovation, in Technical Change and Economic Theory. Giovanni Dosi, C Freeman, R Nelson, G Silverberg and L Soete eds. London: Pinter, pp. Chapter 17: 349-69.

Lundvall, Bengt-Ake, 1992. National Systems of Innovation: Towards a Theory of innovation and Interactive Learning. London: Pinter.

Lundvall, Bengt-Ake and Bjorn Johnson, 1994. The learning economy. In Journal of Industrial Studies, 1:2. 
Lundvall, Bengt-Ake, Bjorn Johnson, Esven Andersen, and Ben Dalum, 2002. National Systems of Production, Innovation and Competence Building. In Research Policy, 31:2, pp. 213-31.

Lundvall, Bengt-Ake and Antoine Valeyre, 2007. How Europe's economies learn: A comparison of work organization and innovation mode for the EU-15. In Industrial and Corporate Change, 16:6, pp. 1175-210.

Luthans, Fred, Paul Marsnik, and Kyle Luthans, 1997. A Contingency Matrix Approach to IHRM. Human Resource Management, 36:2, pp. 183-99.

Macher, Jeffrey and Jackson Nicherson, 2006. Pharmaceutical manufacturing research project: Final benchmarking report. 462. Georgetown University Washington University in St Louis.

Maiti, Rituparna and M Raghavendra, 2007. Clinical Trials in India. Pharmacological Research, 56:1, pp. 1-10.

Malerba, Franco, 2002. Sectoral systems of innovation and production. In Research Policy, 31(2):247-264

Malerba, Franco and Luigi Orsenigo, 2002. Innovation and Market Structure in the Dynamics of the Pharmaceutical Industry and Biotechnology: Towards a HistoryFriendly Model. In Industrial and Corporate Change, 11:4, pp. 667-703.

Mani, Sunil, 2002. Government, Innovation and Technology Policy: An alternative Comparative Analysis: Edward Elgar.

March, James, 1991. Exploration and exploitation in organizational learning. In Organization Science, 2:1, pp. 71-87.

Martínez, Sandra and Peter Dorfman, 1998. The Mexican Entrepreneur: An Ethnographic Study of the Mexican Empresario. International Studies of Management and Organizations, 28, pp. 97-123.

McFadden, Daniel, 2000. Economic choices. Nobel prize lecture.

McKelvey, Maureen, Luigi Orsenigo, and Fabio Pammolli, 2004. Pharmaceuticals analyzed through the lens of a sectoral Innovation system, in Sectoral systems of innovation: Concepts, issues and analyses of six major sectors in Europe. Franco Malerba (Ed.): Cambridge University Press, pp. 73-120.

Mertens, Leonardo, 2005. La Transferibilidad de las Nuevas Competencias en Empresas Innovadoras y de Alto Desempeño: un Acercamiento a la Empleabilidad. Estudios de caso de la Industria Mexicana. Analysis: 29.

Metcalfe, J Stan, 1997. Technology systems and technology policy in an evolutionary framework, in Technology, Globalisation and Economic Performance. Daniel Archibugi and Jonathan Michie eds. Cambridge: Cambridge University, pp. 268-96.

Metcalfe, Stan, 1994. Evolutionary economics and public policy. In Economic Journal, 104:425, pp. 931-44.

Meyers, Eric, 2006. Globalization of Drug Development: India. Cambridge Healthtech Associates.

Michie, Jonathan and Maura Sheehan, 1999. HRM Practices, R\&D Expenditure and Innovation investment: Evidence from the UK's 1990 Workplace Industrial Relations Survey (WIRS) In Industrial and Corporate Change, 8:2, pp. 211-34.

Michie, Jonathan and Maura Sheehan, 2003. Labour market deregulation, 'flexibility' and innovation. In Cambridge Journal of Economics: 27, pp. 123-43. 
Milgrom, Paul and Jon Roberts, 1990. The Economics of Modern Manufacturing Technology, Strategy and Organization. In American Economic Review, 80:3, pp. 511-28.

Miravete, Eugenio and Jose Pernias, 2006. Innovation Complimentarity and Scale Production. In The Journal of Industrial Economics, LIV:1, pp. 1-29.

Mohnen, Pierre and Lars-Hendrik Roller, 2005. Complementarities in innovation policy. In European Economic Review:49, pp. 1431-50.

Molina, Raul and Jose Rivas, 1998. Sobreprecio y acceso a los medicamentos: el caso de los medicamentos esenciales en México. Cad. Saúde Pública, Rio de Janeiro, 14:3, pp. 501-06.

Morgan, David and Rachid Zeffane, 2003. Employee involvement, organizational change and trust in management. In International Journal of Human Resource Management, 14:1, pp. 55-75.

Muchi, Mamo, Peter Gammeltoft, and Bengt-Ake Lundvall (Eds.), 2003. Putting Africa First: The Making of African Innovation Systems. Aalborg: Aalborg University Press.

Muller, Hellen and Monica Rowell, 1997. Mexican Women Managers: an Emerging Profile. In Human Resource Management, 36:4, pp. 423-35.

Mumford, Michael, 2000. Managing Creative People: Strategies and Tactics for Innovation. In Human Resource Management Review, 10:3, pp. 313-51.

Murphy, David, 2006. Global leadership potential in Mexican firms. Management Research News, 29:3, pp. 80-91.

Myers, Scott and Ann Baker, 2001. Drug discovery-an operating model for a new era. In Nature Biotechnology, 19, pp. 727-30.

Mytelka, Lynn and Fulvia Farinelli, 2003. From Local Clusters to Innovation Systems, in Systems of Innovation and Development: Evidence from Brazil. Jose Cassiolato, H Lastres and M Maciel eds. UK and US: Edward Elgar, pp. 273-90.

Nakamura, Kenta and Hiroyuki Odagiri, 2005. R\&D boundaries of the firm: An estimation of the double-hurdle model on commissioned R\&D, joint R\&D, and licensing in Japan. In Economics of Innovation and New Technology 14:7, pp. 583-615.

Nelson, Richard, 1959. The Basic Economics of Scientific Research. In The Journal of Political Economy, 67:3, pp. 297-306.

Nelson, Richard, 1991. Why do firms differ, and how does it matter? In Strategic Management Journal, 12:Special Issue: Fundamental Research Issues in Strategy and Economics, pp. 61-74.

Nelson, Richard, 1993. National Innovation Systems: A Comparative Analysis. New York: Oxford University Press.

Nelson, Richard and Sidney Winter. 1982. An evolutionary Theory of Technical Change. Cambridge, Ma: Beknap Harvard.

Nonaka, Ikujiro, 1994. A dynamic theory of organizational knowledge creation. Organizational Science, 5:1.

Nonaka, Ikujiro and Hirotaka Takeuchi, 1995. The knowledge-creating company. New York and Oxford: Oxford University Press.

NSF, 2004. Science and Engineering Indicators 2004. National Science Foundation: Arlington, VA. 
NSF, 2008. Science and Engineering Indicators 2008. 2009. National Science Foundation: Arlington, VA.

O'Boyle, Michael, 2002. Cheap drugs. Business Mexico, 12: 44.

Odagiri, Hiroyuki, 1998. The Japanese business system for creation and diffusion of technological knowledge: time for a change? In Technology and Innovation in Japan: Policy and Management for the twenty-first century. M Hemmert and C Oberländer eds. London and New York: Routldge, pp. 115-28.

OECD, 1995. The Measurement of Scientific and Technological Activities. Manual on the Measurement of Human Resources Devoted to S\&T Canberra Manual. Paris: OECD.

OECD, 1998. The OECD Jobs Strategy. Technology, Productivity and Job Creation: Best Policy Practices. Paris: OECD.

OECD, 1999. Managing National Innovation Systems. Paris: OECD.

OECD, 2005. Guidelines for the collecting and interpreting technological innovation data: Oslo Manual: OECD-Eurostat.

Okada, Aya, 2004. Skills Development and Interfirm Learning Linkages under Globalization: Lessons from the Indian Automobile Industry. World Development, 32:7, pp. 1265-88.

Okada, Yosuke and Akihiro Kawara, 2004. Research Productivity in the Japanese Pharmaceutical Industry -Economies of Scale, Economies of Scope and Spillovers-. In OPIR Research Paper Series: 46.

Omta, SWF, LM Bouter, and JML van Engelen, 1997. Management control of biomedical research and pharmaceutical innovation. In Technovation, 17:4, pp. 16779.

Ortega, Silvia, Elsa Blum, Giovana Valenti, Marco Ramirez, and Gloria del CastiIlo, 2002. Investing in Knowledge-CONACYT's Scholarship Program. Mexico: SEPCONACYT, AMC/CCC, Plaza y Valdéz,.

Oyelaran-Oyeyinka, Banji and Lou Ann Barclay, 2004. Human Capital and Systems of Innovation in African Development. In African Development Review/African Development Bank, 16:1.

Patel, Pari and Keith Pavitt, 1994. National Innovation Systems: Why they are important, and How they Might be Measured and Compared. Economics of Innovation and New Technology:3, pp. 77-95.

Patel, Pari and Modesto Vega, 1999. Patterns of internationalization of corporate technology: location vs. home country advantages. Research Policy, 28:2-3, pp. 145-55.

Pavitt, Keith, 1984. Sectoral patterns of technical change: Towards a taxonomy and a theory. Research Policy, 13, pp. 343-73.

Pavitt, Keith, 1998. The social shaping of the national science base. Research Policy, 27:8, pp. 793-805.

Peck, Carl, 1997. Drug Development: Improving the Process. Food and drug law journal, 52, pp. 163-67.

Penrose, Edith, 1959. The theory of the growth of the firm: Oxford; Basil Blackwell. 
Penrose, Edith, 1997. The theory of the growth of the firm: Oxford; Basil Blackwell.

Piachaud, B.S, 2002. Outsourcing in the pharmaceutical manufacturing process: an examination of the CRO experience. Technovation, 22:2, pp. 81-90.

Piga, Claudio and Marco Vivarelli, 2004. Internal and external R\&D: A sample selection approach. Oxford Bulletin of Economics and Statistics, 66:4, pp. 457-82.

Polanyi, Michel. 1966. The tacit dimension. New York: Double Day.

Quinn, Michael A and Stephen Rubb, 2006. Mexico's labor market: The importance of education-occupation matching on wages and productivity in developing countries. In Economics of Education, 25, pp. 147-56.

Randle, Keith, 1996. The whitecoated worker in the high performance company. In Management Research News, 19:4/5, pp. 25-27.

Rao, Pramila and Hildy Teegen, 2001. Human Resource Issues: US-Mexico Joint Ventures. Paper presented to the Iberoamerican Academy of Management: 34: Mexico, City.

Reddy, Prasada, 1997. New trends in globalization of corporate R\&D and implications for innovation capability in host countries: a survey from India. In World Development, 25:1, pp. 1821-37.

Reichert, Janice, 2003. Trends in Development and Approval Times for New Therapeutics in the United States. In Nature Reviews, 2, pp. 695-702.

Reiss, Thomas and Sybille Hinze, 2000. Innovation Process and Techno-scientific Dynamics, in Changing Innovation in the Pharmaceutical Industry: Globalization and New Ways of Drug Development. Andre Jungmittag, Guido Reger and Thomas Reiss eds. Berlin: Springer, pp. 53-69.

Reza, Mohammed, Graciela Gonzalez, and Lawrie Reavill, 1998. An Empirical Investigation of the Relationship between Quality Improvement Techniques and Performance-A Mexican Case. In Journal of Quality Management, 3:2, pp. 265-92.

Rothaermel, Frank and David Deeds, 2004. Exploration and exploitation alliances in biotechnology: A system of new product development. In Strategic Management Journal, 25:3, pp. 201-22.

Rouvinen, Petri, 2002. Characteristics of product and process innovators: some evidence from the Finnish innovation survey. In Applied Economic Letters, 9:9, pp. 575-80.

Ruíz, Estela, 2004. Ingenieros en la industria manufacturera: formación, profesión y actividad laboral. Mexico: CESU-UNAM, Plaza y Valdez.

Salud, Secretaría de, 2009. La epidemia de influenza A(H1N1) en México. Comunicado de Prensa Núm 151.

Samstad, James and Seth Pipkin, 2005. Bringing the Firm Back In: Local Decision Making and Human Capital Development in Mexico's Maquiladora Sector. World Development, 33:5, pp. 805-22.

Sanofi-Pasteur, 2009. Sanofi-Pasteur receives order from U.S. government to produce new influenza $A(H 1 N 1)$ vaccine. Philadellphia, Lyon.

Santamaría, Luis, María Jesús Nieto, and Andrés Barge-Gil, 2009. Beyond formal R\&D: Taking advantage of other sources of innovation in low- and mediumtechnology industries. In Research Policy, 38:3, pp. 507-17. 
Santiago, Fernando, 2009. Facing the trial of internationalizing clinical research to developing countries: evidence from Mexico, in Multinationals and emerging economies: The quest for innovation and sustainability. Wilfred Dolfsma, Geert Duysters and Ionara Costa (Eds). Edward Elgar, pp. 58-74.

Santiago, Fernando 2010. Governing ethical clinical research in developing countries: Exploring the case of Mexico. In Science and Public Policy, 37(8) pp. 583-596.

Sanz-Menéndez, Luis and Laura Cruz-Castro, 2005. science and technology human resources back in: the Spanish Ramón y Cajal programme. Science and Public Policy, 32:1, pp. 39-53.

Sargent, John and Linda Matthews, 1997. Skill Development and Integrated Manufacturing in Mexico. World Development, 25:10, pp. 1669-81.

Schuler, Randall, Susan Jackson, Edward Jackofsky, and John Slocum, 1996. Managing Human Resources in Mexico: A Cultural Understanding. Business Horizons, 39:3, pp. 55-61.

Scolnick, Edward, 2000. Leading R\&D in the pharmaceutical industry. Research Technology Management, 43:3, pp. 35-38.

SECOFI, 1984. Decreto para el Fomento y la Regulacion de la Industria Farmaceutica. ISSSTE Jure: Mexico.

Secretaría de Salud, 1984. Ley General de Salud. 151. Diario Oficial de la Federación: Mexico.

Secretaría de Salud, 1998a. NORMA Oficial Mexicana NOM-164-SSA1-1998, Buenas prácticas de fabricación para fármacos. Mexico.

Secretaría de Salud, 1998b. NORMA Oficial Mexicana NOM-176-SSA1-1998, Requisitos sanitarios que deben cumplir los fabricantes, distribuidores y proveedores de fármacos utilizados en la elaboración de medicamentos de uso humano. México.

Secretaría de Salud, 1999. Norma Oficial Mexicana NOM-177-SSA1-1998 que establece las pruebas y procedimientos para demostrar que un medicamento es intercambiable. Requisitos a que deben sujetarse los terceros autorizados que realicen las pruebas. 24. Diario Oficial de la Federación, 7 mayo: México.

Secretaría de Salud, 2005a. Hacia una Política Farmacéutica Integral para México. 162: Mexico.

Secretaría de Salud, 2005b. Norma Oficial Mexicana NOM-220-SSA1-2002 Instalación y Operación de la Farmacovigilancia. México.

Seiter, Andreas, 2005. Pharmaceuticals: Local Manufacturing. Health Nutrition and Population,: 5. the World Bank,.

Senge, Peter, 1990. The Fifth Discipline: The art and practice of the Learning Organization. New York: A Currency Book.

Sharma, D, 2004. Feature: India pressed to relax rules on clinical trials. Drug companies claim changes are essential, but critics fear Indian patients will become guinea pigs. The Lancet, 363:9420, pp. 1528-29.

Sheiner, Lewis, 1997. Learning versus confirming in clinical drug development. In Clinical Pharmacology \& Therapeutics, 61:3, pp. 275-91.

Shiu-Wang, Hung and Tang Ruei-Hung, 2008. Factors affecting the choice of technology acquisition mode: An empirical analysis of the electronic firms of Japan, Korea and Taiwan. Technovation, 28, pp. 551-63. 
Simon, Herbert, 1991. Bounded rationality and organizational learning. In Organization Science, 2:1, pp. 125-34.

Singh, Seema, 2007. Indian pharma enters the Global Arena. Cell, 128:5, pp. 81114.

Smith, Keith, 2000. Innovation as a Systemic Phenomenon: Rethinking the Role of Policy. In Enterprise \& Innovation Management Studies, 1:1, pp. 73-102.

Staropoli, Carin, 1998. Cooperation in R\&D in the Pharmaceutical Industry -The Network as an Organizational Innovation Governing Technological Innovation. In Technovation, 18:1, pp. 13-23.

Stephan, Paula, 1996. The Economics of Science. In Journal of Economic Literature, XXXIV, pp. 1199-235.

Stephan, Paula and David Audrestsch (Eds.), 2000. The Economics of Science and Innovation.

Stephens, Gregory and Charles Greer, 1995. Doing Business in Mexico: Understanding Cultural Differences. Organizational Dynamics, 24:1, pp. 39-55.

Sternberg, Robert, Linda O'Hara, and Todd Lubbart, 1997. Creativity as investment. In California Management Review, 40:1, pp. 8-21.

Styhre, Alexander and Mats Sundgren, 2003. Management is evil: management control, technoscience and saudade in pharmaceutical research. In Leadership \& Organization Development Journal, 24:7/8, pp. 436-46.

Ta-Cheng, Hsiao, 1997. Capability Development and Management of R\&D Professionals in a Developing Country Context, Taiwan. In Technovation, 17:10, pp. 569-81.

Taczir, Ezequiel, 2009. Choosing a career in science and technology. 7th International Conference, Globelics 2009: 36: Dakar, Senegal.

Tapon, Francis and Mona Thong, 1999. Research collaborations by multinational research oriented pharmaceutical firms: 1988-1997. In R\&D Management, 29:9, pp. 219-31.

Tecanhuey, Eva, 2002. Cambio Tecnológico y Desempleo. La industria manufacturera en Mexico, 1989-1991, in Innovación, Universidad e Industria en el Desarrollo Regional. Leonel Corona and Ricardo Hernandez eds. Mexico: Plaza y Valdez, S A de C V, pp. 263-97.

Teece, David, Gary Pisano, and Ami Shuen, 1997. Dynamic capabilities and strategic management. Strategic Management Journal, 18:7, pp. 509-33.

Teichler, U, 1999. Higer Education policy and the world of work: changing conditions and challenges. Higher Education Policy, 12, pp. 285-312.

Tello, Marco and Walter Greene, 1996. US managerial strategies and applications for retaining personnel in Mexico. In International Journal of Man Power, 17:8, pp. 54-94.

Terziovski, Milé and John Morgan, 2006. Management practices and strategies to accelerate the innovation cycle in the biotechnology industry. Technovation, 26:5-6, pp. 1-8.

Teubal, Morris and Dominique Foray, 1996. An Introduction to Technological Infrastructure and Technological Infrastructure Policy. Dordrecht/Boston/London: Kluwer Academic Publishers. 
Texeira, Aurora, 2004. Strategic Complementarities between innovation and human capital: The neglected role of human capital demand. In Revista Brasileira de Inovacao, 3:1, pp. 169-200.

The Lancet, 2007. Editorial: Strengthening clinical research in India. The Lancet, 369:9569, pp. 1233.

Thompson, Óscar and Leopoldo Vega, 2001. Diseños de investigación en las ciencias biomédicas. Revista Mexicana de Pediatria, 68:4, pp. 147-51.

Ulrich, Roger and Stephen Friend, 2002. Toxicogenomics and drug discovery: will new technologies help us produce better drugs? Nature Reviews, 1, pp. 84-88.

UNAM. April 30 2009. Puede la UNAM caracterizar molecular y genéticamente el virus de influenza. Banco de Boletines.

Uríbe, Jaime, 2005. Las reformas de las leyes de patentes en la industria farmacéutica de México, in Industria Farmacéutica y Propiedad Intelectual: Los países en desarrollo. Alenka Guzmán and Gustavo Viniegra eds. Mexico: H Cámara de Diputados LIX Legislatura; UAM-Iztapalapa; Porrúa pp. 323-49.

Valenti, Iovanna, Varela, and Gloria del Castillo, 2000. Human Resources and Competencies, in Developing Innovation Systems: Mexico in a global context. Mario Cimoli ed. London and New York: Thomson Learning, pp. 137-53.

Vargas, Fernando, 2004. 40 preguntas sobre competencia laboral. Montevideo, Uruguay: CINTERFOR/OIT/CEPAL/GTZ.

Velloso, Jacques (Ed.), 2002. A pos-Graduacao no Brasil: Formacao e trabalho de Mestres e Doutores no pais: CAPES-UNESCO.

Veugelers, Reinhilde, 1999. Make and Buy in innovation strategies: evidence from Belgian manufacturing firms. In Research Policy, 28, pp. 63-80.

Villaseñor, Carlos, 2006. El abasto al sector salud como motor de desarrollo industrial y columna vertebral de la seguridad social, in La industria farmacéutica mexicana. Mexico: ANAFAM-Porrúa, pp. 145-61.

Vinding, Anker, 2004. Human Resources; Absorptive Capacity and Innovative Performance, in Research on Technological Innovation, Management and Policy. Jesper Christensen and B-A Lundvall eds. Amsterdam: Elsevier, pp. 155-78.

Vinding, Anker, 2006. Absorptive capacity and innovative performance: a human capital approach. In Economics of Innovation and New Technology, 14:4/5, pp. 50717.

Viotti, Eduardo, 2002. National Learning Systems: A new approach on technological change in late industrializing economies and evidences from the cases of Brazil and South Korea. In Research Policy, 69:7, pp. 653-80.

von Zedtwitz, Max and Ove Gassmann, 2002. Market versus Technology Drive in R\&D Internationalization: Four different patterns of managing research and development. In Research Policy, 31:4, pp. 569-88.

Wagner, Cynthia, 1998. Biotechnology in Mexico: placing science in the business of services. In Technology in Society, 20:1, pp. 61-73.

Walker, D K, 2004. The use of pharmacokinetic and pharmacodynamic data in the assessment of drug safety in early drug development. In British Journal of Clinical Pharmacology, 58:6, pp. 601-08. 
Wei, James, 2005. Engineering for a post-industrial world. In Technology in Society, 27, pp. 123-32.

Weller, Jurgen, 2000. Reformas Económicas, Crecimiento y Empleo: Los Mercados de Trabajo en América Latina y El Caríbe. Santiago, Chile: CEPAL/Fondo de Cultura Económica.

White, Franklin, 2002. Capacity-building for health research in developing countries: a manager's approach. Revista Panamericana de Salud Pública/Pan Am Journal of Public Health, 12:3, pp. 165-72.

Wilkens, Uta and Peter Pawlowsky, 1997. Human resource management or machines that change the world in the automotive industry? In Management International Review, 37 Special Issue:1, pp. 105-26.

Williamson, Oliver, 1975. Markets and Hierarchies. New York: Free Press.

Williamson, Oliver, 1985. The Economic Institutions of Capitalism. Firms, Markets, Relational Contracting. New York: Free Press.

WHO 2010. H1N1 in post-pandemic period. Director-General's opening statement at virtual press conference. 10 August 2010 World Health Organization. http://www.who.int/mediacentre/news/statements/2010/h1n1_vpc_20100810/en /index.html Last access 12th September, 2010.

Wright, Patrick, Benjamin Dunford, and Snell Scott, 2001. Human resources and the resource based view of the firm. In Journal of Management, 27:6, pp. 701-21.

Wright, Patrick, Timothy Gardner, and Lisa Moynihan, 2003. The impact of HR practices on the performance of business units. In Human Resource Management Journal, 13:3, pp. 21-36.

Yalcinkaya, Goksel, Roger Calantone, and David Griffith, 2006. An Examination of Exploration and Exploitation Capabilities: Implications for Product Innovation and Market Performance. In Journal of International Marketing, 15:4, pp. 63-93.

Zack, Michael, 1999. Developing a knowledge strategy. In California Management Review, 41:3, pp. 125-45.

Zanko, Michael, Paul Couchman, Richard Badham, Maren Schubert, and Zuhraiti Zainuddin, 1998. The role of human resource management in concurrent approaches to product innovation: Australian and Indonesian experiences. Human Factors and Ergonomics in Manufacturing, 8:2, pp. 125-39.

Zivin, Justin, 2000. Understanding clinical trials. In Scientific American:April, pp. 69-75.

Zucker, Lynne and Michael Darby, 1997. Present at the Biotechnological Revolution: Transformation of Technological Identity for a Large Incumbent Pharmaceutical Firm. In Research Policy, 26:4-5, pp. 429-46.

Zúñiga, Maria and Emmanuel Combe, 2002. Introducing patent protection in the pharmaceutical sector: a first evaluation of the Mexican case. In Revue Région et Devéloppement, 16, pp. 191-221.

Zúñiga, María, Alenka Guzmán, and Flor Brown, 2007. Technology acquisition strategies in the pharmaceutical industry in Mexico. In Comparative Technology Transfer and Society, 5:3. 
Websites

AMIIF. Asociación Mexicana de Industrias de Investigación Farmacéutica A C, http://www.amiif.org.mx. [April 6, 2010].

ANAFAM. Asociación Nacional de Fabricantes de Medicamentos. Mexico. http://www.anafam.org.mx/ [April 7, 2010].

Banxico. Banco de México. Mexico. http://www.banxico.org.mx; [ May 16, 2010.

CANIFARMA. Cámara Nacional de la Industria Farmacéutica. http://www.canifarma.org.mx. [April 6, 2010].

CCINSHAE. Comisión Coordinadora de Institutos Nacionales de Salud y Hospitales de Alta Especialidad, http://www.salud.gob.mx/unidades/cgins/acerca.html. [April 6, 2010].

COFEPRIS. Comisión Federal para la Protección contra Riesgos Sanitarios. http://www.cofepris.gob.mx/. [April 7, 2010].

CONACYT . Consejo Nacional de Ciencia y Tecnología: México.

FDA. Definitions. http://www.fda.gov/cder/about/smallbiz/definitions.htm. [June 20, 2009].

IFAI. Instituto Federal de Acceso a la Información Pública. http://www.ifai.org.mx/. [April 5, 2010.

IMS-Health. http://www.imshealth.com/portal/site/imshealth [June 1st 2010

IMSS. Instituto Mexicano del Seguro Social, http://www.imss.gob.mx/imss. [April $5,2010]$.

INEGI. Instituto Nacional de Estadística, Geografía e Informática. Mexico. http://www.inegi.org.mx/inegi/default.aspx [June 1st 2010].

ISSSTE. Instituto de Seguridad y Servicios Sociales para los Trabajadores del Estado. Mexico. http://www.issste.gob.mx/ [June 1st 2010].

STPS. Secretaría del Trabajo y Previsión Social. Mexico. http://www.stps.gob.mx/ [June 1st 2010]. 

Estimado informante, el objetivo central de esta investigación es conocer la contribución de las prácticas de gestión de recursos humanos a las actividades de innovación en la industria farmacéutica en México. Toda la información será utilizada únicamente para fines estrictamente académicos y tratada con absoluta confidencialidad y reserva.

El cuestionario incluye preguntas relativas a actividades de innovación en dos áreas concretas: (i) la manufactura de productos farmacéuticos; y, (ii) investigación y/o desarrollo tecnológico. El énfasis es en la estrategia que caracteriza la gestión de los recursos humanos involucrados en actividades de innovación en su empresa durante los últimos cinco años.

Actividades innovativas denotan todas aquellas acciones necesarias para el desarrollo de productos/procesos nuevos o mejorados, se puede incluir: investigación y desarrollo de nuevos productos/procesos; diseño e ingeniería; adquisición de tecnologías incorporadas a capital (maquinaria y equipo) y no incorporadas a capital (patentes, licencias, know-how, marcas, servicios computacionales o científico-técnicos relacionados con la implementación de innovaciones); modernización organizacional (orientadas a reducir tiempos de producción, modificaciones en el diseño de líneas de producción, justo a tiempo, círculos de calidad, calidad total, etc.); comercialización (actividades relacionadas con el lanzamiento de productos nuevos o mejorados, incluyendo investigación de mercado, gastos en publicidad, medios de entrega, etc.); capacitación se refiere al entrenamiento de mano de obra relacionada con las actividades de innovación de la empresa.

Investigación y desarrollo (I\&D): Se refiere al trabajo creativo y sistemático que incrementa el conocimiento, así como el uso del conocimiento para obtener nuevas aplicaciones o mejorar las ya existentes, incluyendo la construcción, diseño y pruebas de prototipos.

Dudas o preguntas acerca de cómo responder a este cuestionario, por favor comuníquese con Fernando Santiago, a los teléfonos: 53198590 y/o 044 55-2515 9566. Correo Electrónico: rodríguez@merit.unu.edu

¡Muchas gracias por su participación!

\title{
Nombre, departamento, cargo y firma de la persona que responde al cuestionario
}

\author{
Teléfono (incluye LADA) y correo electrónico
}

¿Le interesa obtener información sobre los resultados finales de este estudio? Sí ; No Número de Control (uso exclusivo del grupo de investigación)

Facultad de Contaduria, Administracion e Informatica, UNAM
Universidad Autonoma

MetropolitanaXochimilco
Universiteit Maastricht 
I. DATOS GENERALES

\begin{tabular}{|c|c|c|c|c|}
\hline \multicolumn{5}{|c|}{ 1. Nombre o Razón Social de la empresa: } \\
\hline \multirow{2}{*}{\multicolumn{3}{|c|}{$\begin{array}{l}\text { 3. Indique el(los) producto(s) principal(es) de la empresa según su contribución a ventas } \\
\text { totales en } 2006 \text { : } \\
\text { Total }\end{array}$}} & $\begin{array}{l}\text { Número } \\
\text { productos }\end{array}$ & $\begin{array}{c}\% \\
\text { ventas }\end{array}$ \\
\hline & & & --------- & $100 \%$ \\
\hline \multicolumn{5}{|c|}{01 Principios activos farmacéuticos } \\
\hline \multicolumn{5}{|c|}{02 Productos farmacéuticos } \\
\hline \multicolumn{5}{|c|}{ (a) De patente/éticos } \\
\hline \multicolumn{5}{|c|}{ (b) Innovadores cuya patente ha vencido } \\
\hline \multicolumn{5}{|c|}{ (c) Genéricos intercambiables (GI) } \\
\hline \multicolumn{5}{|l|}{ (d) Similares } \\
\hline \multicolumn{5}{|c|}{03 Productos de consumo (OTC) } \\
\hline \multicolumn{5}{|c|}{04 Productos auxiliares para la salud (equipos médicos, prótesis, agentes de diagnóstico, etc.) } \\
\hline \multicolumn{5}{|c|}{05 Productos químicos y reactivos farmacéuticos } \\
\hline \multicolumn{5}{|l|}{06 Biofármacos } \\
\hline \multicolumn{5}{|c|}{07 Otros ingresos (como \% de ventas totales): } \\
\hline \multicolumn{5}{|c|}{\begin{tabular}{l|l} 
(a) Producción por con- & $\begin{array}{l}\text { (b) Licenciamiento te } \\
\text { nología/patentes }\end{array}$ \\
trato
\end{tabular}} \\
\hline \multicolumn{5}{|c|}{ 4. Mercado principal según distribución de sus ventas } \\
\hline 01 Sector Gobierno & 02 Sector Privado & $\%$ & 03 Exportaci & $\%$ \\
\hline
\end{tabular}

5. Origen del capital de la empresa

\begin{tabular}{ll|ll}
$\square \quad 01$ Nacional___ $\quad \%$ & $\square \quad 02$ Extranjero___ \% & $\square \quad 03$ Mixto (Indique \% nacional)
\end{tabular}

6. Ordene en una escala de 1-3 todos los procesos de manufactura presentes en sus plantas en México (donde 1=más importante, 3=menos importante)
01 Biológicos
02 Farmacéuticos
03 Químicos

7. ¿Cuenta con certificación para manufacturar y exportar medicamentos por parte de agencias extranjeras?

$\square \quad 01 \mathrm{Si}$ (especifique):

(a) FDA (EUA); (b) EMEA (Europa); (c) Otro (¿cuáles?)

$\square \quad 02$ Ninguna

8. Indique en número de personas, el empleo total y su distribución por área/departamento al 31 de diciembre de 2006:

\begin{tabular}{l|l|l|l|l} 
Producción___ & Investigación y/o desarrollo___ & Departamento Médico__ & Ventas___ Total___
\end{tabular}

9. Indique el número de personas en su empresa que cuentan actualmente con los niveles de escolaridad siguientes:

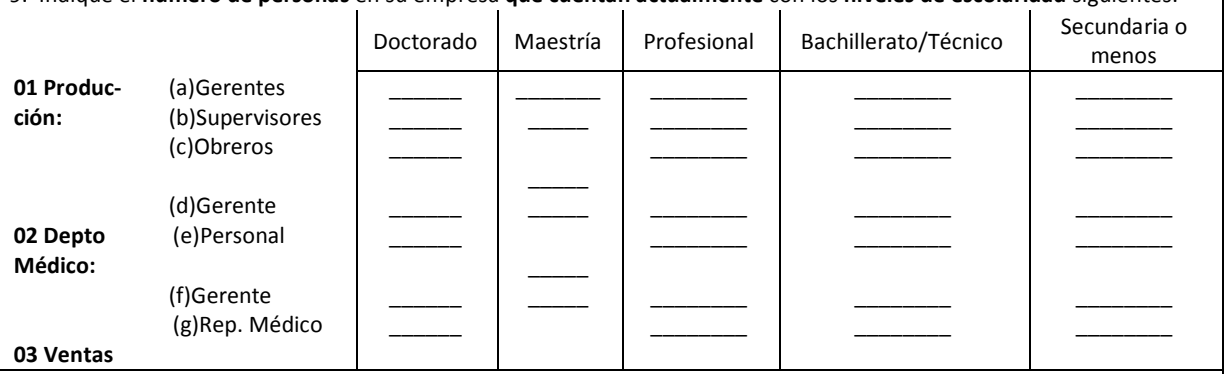

10. Volumen promedio mensual de producción en 2006 (Millones de Unidades)

(a) Principios Activos Farmacéuticos

11. Indique el valor total (miles de pesos) en $2006 \mathrm{de}$

01 Producción:

(b) Formulaciones Farmacéuticas

02 Activos fijos:

03 Inversión Bruta Fija:

12. En los últimos tres años el comportamiento de sus ventas ha sido:

\begin{tabular}{l|lll|lll}
02 & 02 & Permanecido sin cam- & 03 & Descenso \\
01 Crecimiento continuo & bio & & & tinuo_
\end{tabular}




\section{Cuadro 1}

(Por favor lea este cuadro como auxiliar para responder a las preguntas 13-16)

Un producto o servicio nuevo puede ser nuevo para su empresa o para el mercado y cuyas características tecnológicas o de uso difieren significativamente de todos los productos que su empresa produce actualmente.

Una mejora significativa de producto o servicio se refiere a un producto previamente existente cuyo desempeño fue sustancialmente aumentado. Un producto complejo que consiste de varios componentes o subsistemas integrados puede ser perfeccionado por cambios parciales en alguno de sus componentes o subsistemas. Los cambios que son básicamente estéticos o de estilo, no deben ser considerados.

Un nuevo proceso de producción es un proceso recientemente incorporado a su empresa o al sector. Involucran la introducción de nuevos métodos, procedimientos, sistemas, maquinaria y equipo que difieren sustancialmente de los utilizados por su empresa.

Una mejora significativa a los procesos de producción involucra cambios tecnológicos importantes y parciales en procesos ya usados. Cambios pequeños y/o de rutina no deben ser considerados.

Una innovación organizacional denota cambios significativos en la estructura organizacional, introducción de técnicas avanzadas de gestión o instrumentación de estrategias de negocio nuevas o sustancialmente modificadas. En principio una innovación organizacional cuenta como tal sólo si ello se traduce en cambios cuantificables en la productividad o las ventas de la compañía.

13. Innovaciones de producto: Señale número de productos tecnológicamente nuevos o mejorados introducidos en 2004-2006

Descripción por tipo de producto

01 Producto nuevo para su empresa, pero existente en mercado

02 Producto nuevo para el mercado nacional

03 Producto nuevo para el mercado internacional

14. Señale participación porcentual de ventas de productos nuevos o significativamente mejorados introducidos en 2004-2006 en sus ventas totales de 2006 (Si respondió "ninguno" a todos los conceptos de la pregunta 13, pase a pregunta 15)

Descripción por tipo de producto

01 Ventas nacionales de nuevos productos

02 Ventas nacionales de productos mejorados

03 Exportaciones de nuevos productos

04 Exportaciones de productos mejorados

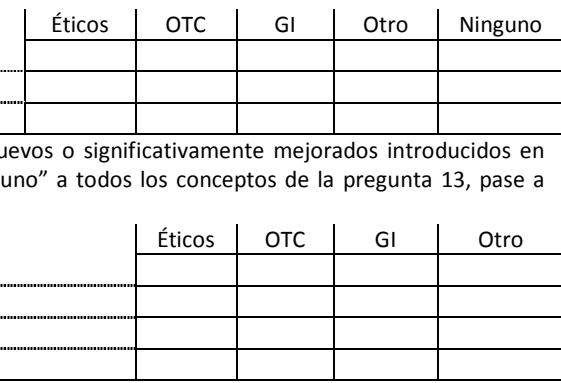

15. Innovaciones de proceso: Señale el número de procesos tecnológicamente nuevos o mejorados introducidos en 2004-2006, y el impacto que tuvieron sobre las operaciones de su empresa

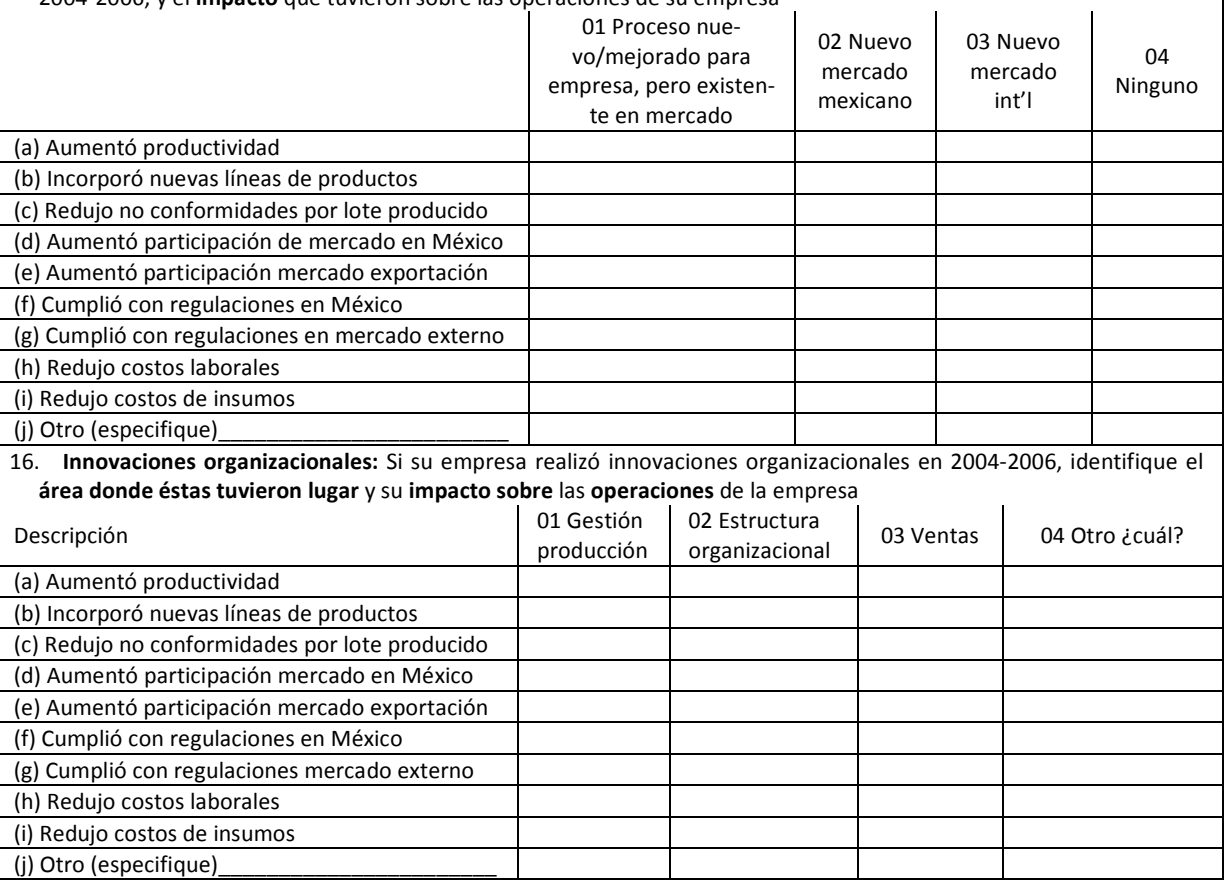




\begin{tabular}{|c|c|c|}
\hline \multicolumn{3}{|c|}{$\begin{array}{l}\text { Indique la importancia de los siguientes programas para el personal en el área de manufactura: (Donde: } 1=\text { no aplica; } \\
2=\sin \text { importancia; } 3=\text { poco importante; } 4=\text { =importante; } 5=\text { =muy importante) }\end{array}$} \\
\hline (a) Plan carrera: & (b) Plan sucesión: & (c) Plan retención y desarrollo talentos \\
\hline \multicolumn{3}{|c|}{ III.1 Trabajo en equipo en el área de manufactura } \\
\hline \multirow{2}{*}{\multicolumn{3}{|c|}{$\begin{array}{l}\text { 17. Indique la afirmación que mejor describe el trabajo en equipo para la innovación en manufactura (donde } \\
\text { 1=organización se asemeja principalmente a la afirmación del lado izquierdo de la numeración, } 5=\text { la organización se } \\
\text { asemeja principalmente a la afirmación del lado derecho de la numeración) } \\
01 \text { El trabajo en equipo: }\end{array}$}} \\
\hline & & \\
\hline Se promueve formal y activamente & (1) (2) (3) (4) (5) & $\begin{array}{l}\text { Surge de manera informal y es- } \\
\text { pontánea entre el personal }\end{array}$ \\
\hline \multicolumn{3}{|c|}{02 La conformación de los equipos de trabajo incluye: } \\
\hline Sólo personal del área de manufactura & (1) (2) (3) (4) (5) & $\begin{array}{l}\text { Personal de diversas áreas en } \\
\text { empresa }\end{array}$ \\
\hline \multicolumn{3}{|l|}{03 Los equipos interactúan: } \\
\hline $\begin{array}{l}04 \text { En su composición, los equipos de traba } \\
\text { Estables }\end{array}$ & 04 En su composición, los equipos de trabajo son: & Cambian constantemente \\
\hline \multicolumn{3}{|c|}{05 La retroalimentación para los empleados en relación con su trabajo en el equipo es: } \\
\hline Frecuente y abierta & (1) (2) (3) (4) (5) & Esporádica e individualizada \\
\hline \multicolumn{3}{|c|}{$06 \mathrm{El}$ trabajo en equipo contribuye a difundir/compartir conocimientos } \\
\hline Siempre & $(1)(2)(3)(4)(5)$ & Esporádicamente \\
\hline \multicolumn{3}{|c|}{07 Los equipos de trabajo intervienen en la toma decisiones sobre diversos aspectos del trabajo } \\
\hline Siempre & (1) (2) (3) (4) (5) & Esporádicamente \\
\hline \multicolumn{3}{|c|}{$08 \mathrm{El}$ trabajo en equipo es clave para establecer objetivos de trabajo } \\
\hline Siempre & (1) (2) (3) (4) (5) & Esporádicamente \\
\hline \multicolumn{3}{|c|}{09 El trabajo en equipo es clave para evaluar el cumplimiento de objetivos de trabajo } \\
\hline Siempre & $(1)(2)(3)(4)(5)$ & Esporádicamente \\
\hline 10 Los equipos de trabajo intervienen en & a de soluciones a & emas \\
\hline Siempre & (1) (2) (3) (4) (5) & Esporádicamente \\
\hline 11 El trabajo en equipo es clave para la me & ntinua de procesos & \\
\hline Siempre & (1) (2) (3) (4) (5) & Esporádicamente \\
\hline III.2 Comunicación interna en el área de $\mathrm{m}$ & tura & \\
\hline $\begin{array}{l}\text { 18. Indique afirmación que mejor descr } \\
\text { manufactura (donde } 1=\text { organización se a } \\
5=\text { organización se asemeja principalmen }\end{array}$ & $\begin{array}{l}\text { trategia de comunica } \\
\text { a principalmente a la a } \\
\text { afirmación del lado de }\end{array}$ & $\begin{array}{l}\text { ón para sus actividades de innovación en } \\
\text { mación del lado izquierdo de la numeración, } \\
\text { ho de la numeración) }\end{array}$ \\
\hline 01 En general la comunicación es: & & \\
\hline $\begin{array}{l}\text { Vertical, de arriba hacia abajo según la } \\
\text { jerarquía }\end{array}$ & (1) (2) (3) (4) (5) & Horizontal, independiente de jerarquía \\
\hline 02 En cuanto a su frecuencia, número de $\mathrm{p}$ & antes y duración, las $r$ & niones de trabajo son: \\
\hline Bien delimitadas & (1) (2) (3) (4) (5) & Totalmente libres \\
\hline 03 La información requerida para manten & cluir los proyectos de & ovación funcionando es: \\
\hline $\begin{array}{l}\text { Exclusiva del líder de proyecto/jefe de } \\
\text { área }\end{array}$ & $(1)(2)(3)(4)(5)$ & Abierta para todo el personal involucrado \\
\hline 04 La retroalimentación para los emplead & elación con su trabajo & \\
\hline Frecuente y abierta & (1) (2) (3) (4) (5) & Esporádica e individualizada \\
\hline ategia de comunicación busca & creación y difusión & ocimiento en la empresa \\
\hline Siempre & (1) (2) (3) (4) (5) & Esporádicamente \\
\hline $\begin{array}{l}06 \text { La comunicación buscar mantener } \\
\text { profesionales en la empresa }\end{array}$ & o del personal & ctura con otras áreas $y$ \\
\hline Siempre & (1) (2) (3) (4) (5) & Esporádicamente \\
\hline 07 La estrategia de comunicación se ence & difundir objetivos de & cio entre el personal \\
\hline Siempre & (1) (2) (3) (4) (5) & Esporádicamente \\
\hline de comunicación busca & el trabajo en equipo & \\
\hline Siempre & (1) (2) (3) (4) (5) & Esporádicamente \\
\hline La co & a encontrar solu & blemas \\
\hline Siempre & (1) (2) (3) (4) (5) & Esporádicamente \\
\hline
\end{tabular}


III.3 Capacitación y/o Entrenamiento al personal de manufactura

19. ¿Cuál fue su presupuesto anual para capacitación y/o entrenamiento del personal de manufactura en 2006? Miles de pesos Como \% de ventas

20. Indique el número promedio de cursos de capacitación y/o entrenamiento recibidos por el personal de manufactura en2006 \begin{tabular}{|lll} 
(a) Gerentes & (b) Supervisores & (c) Obreros \\
\hline Evalúe el tipo de habilidades y/o conocimientos que mejor caracterizan la capacitación y/o entrenamiento recibi- \\
dos por el personal de manufactura involucrado en actividades de innovación durante 2006 (Donde: 1=no aplica;
\end{tabular} 2=sin importancia; 3=poco importante; 4 =importante; 5=muy importante)

01 Habilidades básicas (leer, escribir, etc.)

02 Conocimientos técnicos especializados que no conducen a obtención de grado académico

03 Conocimientos técnicos especializados que conducen a obtención de grado académico

04 Metodologías para el diseño y/o conducción de experimentos

05 Operación/mantenimiento de maquinaria y equipo

06 Habilidades gerenciales (negociación, comunicación, trabajo en equipo, presentación en público)

07 Procedimientos de seguridad

08 Buenas prácticas de manufactura

09 Operación de cuartos limpios

10 Idiomas

11 Otro ¿Cuál?

\begin{tabular}{|l|l|l|}
\hline Gerente & Supervisor & Obrero \\
\hline & & \\
\hline & & \\
\hline & & \\
\hline & & \\
\hline & & \\
\hline & & \\
\hline & & \\
\hline & & \\
\hline & & \\
\hline & & \\
\hline
\end{tabular}

21. Evalúe la relevancia del entrenamiento/capacitación recibido según agente proveedor de la capacitación en 2006 (donde 1=no aplica; 2=sin importancia; 3=poco importante; 4=importante; 5=muy importante)

01 Personal de la propia empresa (salón)

02 Personal de propia empresa (en sitio de traba-

jo)

03 Empresas de consultoría

( )

( )

( )

04 Cámaras empresariales

05 Universidades en México

( )

06 Universidades en el extranjero

( )

07 Proveedores

08 Otros (especifique)

( )

III.4 Evaluación y Retribución por desempeño al personal de manufactura

2. La evaluación formal del desempeño tiene lugar

veces al año

3. Por favor indique en una escala de 1-5 la afirmación que mejor describe la evaluación y retribución por desempeño del personal en la manufactura (donde 1=su organización se asemeja principalmente a la afirmación del lado izquierdo de la numeración, 5=su organización se asemeja principalmente a la afirmación del lado derecho de la numeración)

01 De acuerdo con la evaluación por desempeño:

Los objetivos deben cumplirse (1) (2) (3) (4) (5)

Existe absoluta flexibilidad en el cumplimiento de los totalmente objetivos

$02 \mathrm{El}$ personal participa en la definición de sus propios objetivos laborales:

Ocasionalmente $\quad$ (1) (2) (3) (4) (5) Siempre

03 La evaluación del desempeño incluye retroalimentación y guía para el trabajador:

Ocasionalmente $\quad$ (1) (2) (3) (4) (5) Siempre

04 La evaluación de desempeño involucra:

Únicamente al jefe y al empleado evaluado $\quad$ (1) (2) (3) (4) (5)

05 La evaluación informa planes de capacitación y/o entrenamiento:

Ocasionalmente

(1) (2) (3) (4) (5)

Al jefe, pares y subordinados del personal evaluado 
24. Indique todos los factores relevantes para informar la retribución por desempeño del personal involucrado en actividades de innovación en manufactura (donde 1=no aplica; 2=sin importancia; 3=poco importante; 4=importante; 5=muy importante)

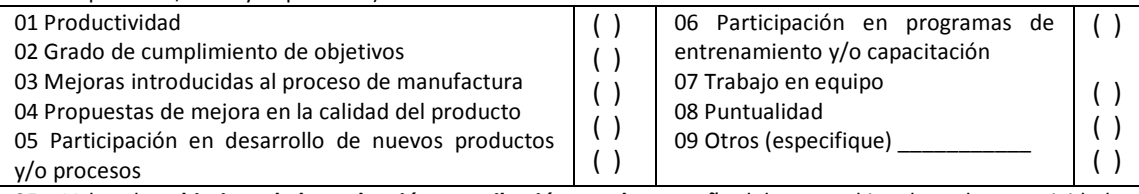

25. Valore los objetivos de la evaluación y retribución por desempeño del personal involucrado en actividades de innovación en el área de manufactura (donde: 1=no aplica; 2=sin importancia; 3=poco importante; 4=importante; 5=muy importante)

01 Facilitar cooperación y difusión del conocimiento

(1) (2) (3) (4) (5)

02 Elevar la satisfacción por el trabajo

(1) (2) (3) (4) (5)

03 Promover la iniciativa individual

(1) (2) (3) (4) (5)

04 Fomentar trabajo en equipo

(1) (2) (3) (4) (5)

05 Promover desarrollo continuo del personal

(1) (2) (3) (4) (5)

06 Retener y desarrollar talentos

(1) (2) (3) (4) (5)

07 Otro (especifique)

(1) (2) (3) (4) (5)

26. Remuneración promedio mensual (en pesos) pagada a su personal en el área de manufactura durante 2006 (incluya sueldos, salarios, bonos y otras prestaciones)

Gerente__ Supervisor_obrero_____ Administrativo______ Ventas

27. Por favor, evalúe todos los factores considerados para contratar nuevo personal en el área de manufactura (donde 1=no aplica; $2=$ sin importancia; 3=poco importante; 4=importante; 5=muy importante)

01 Antecedentes académicos

02 Desarrollo profesional previo

(1) (2) (3) (4) (5)

03 Experiencia previa en la industria farmacéutica

(1) (2) (3) (4) (5)

04 Recomendaciones personales

(1) (2) (3) (4) (5)

05 Vínculos familiares

(1) (2) (3) (4) (5)

06 Existencia de personal en la empresa con potencial para ser promovido

(1) (2) (3) (4) (5)

07 Aspiraciones económicas del candidato

(1) (2) (3) (4) (5)

08 Edad del candidato

(1) (2) (3) (4) (5)

09 Otro ¿cuál?

(1) (2) (3) (4) (5)

(1) (2) (3) (4) (5)

\section{INVESTIGACIÓN Y/O DESARROLLO TECNOLÓGICO}

\section{8. ¿Su empresa realiza actividades de investigación y/o desarrollo tecnológico? (excluye investigación clínica)}

$\square \quad 01 \mathrm{Si}$ (especifique en dónde)

(a) En México (continúe a pregunta 31); (b) Sólo en el extranjero (continúe a Sección V)

29. ¿Cuál fue su inversión en investigación y/o desarrollo tecnológico en 2006?

01 En miles de pesos

02 Como \% de sus ventas en México

30. Indique el lugar donde se realizan sus actividades de investigación y/o desarrollo tecnológico

$\square \quad 01$ Unidad/departamento especializado perteneciente a la empresa

$\square \quad 02$ Centro de investigación y/o desarrollo asociado a la empresa (Especifique)

$\square \quad 03$ Instalaciones de terceros (donde: 1=no aplica; 2=sin importancia; 3=poco importante; 4=importante; 5=muy importante):

(a) Universidades

(b) Centro Público de Investigación

(d) Otras empresas

(c) Otras empresas del grupo

(e) Otros (¿dónde?)

31. Indique los principales resultados de las actividades de investigación y/o desarrollo tecnológico en 2004-2006

01 Descubrimiento de nuevas moléculas

02 Nuevas combinaciones de moléculas existentes

03 Desarrollo de nueva/mejorada forma de dosificación

04 Nuevas aplicaciones de terapias existentes

05 Desarrollo de nuevos productos genéricos

06 Desarrollo nuevos productos de consumo (OTC)

07 Desarrollo de nuevas formas de presentación, medios de suministro,

empaques

08 Otro (especifique)

\begin{tabular}{l|l|} 
número & \% de ventas en 2006 \\
\hline & \\
\hline & \\
\hline & \\
\hline & \\
\hline & \\
\hline & \\
\hline
\end{tabular}




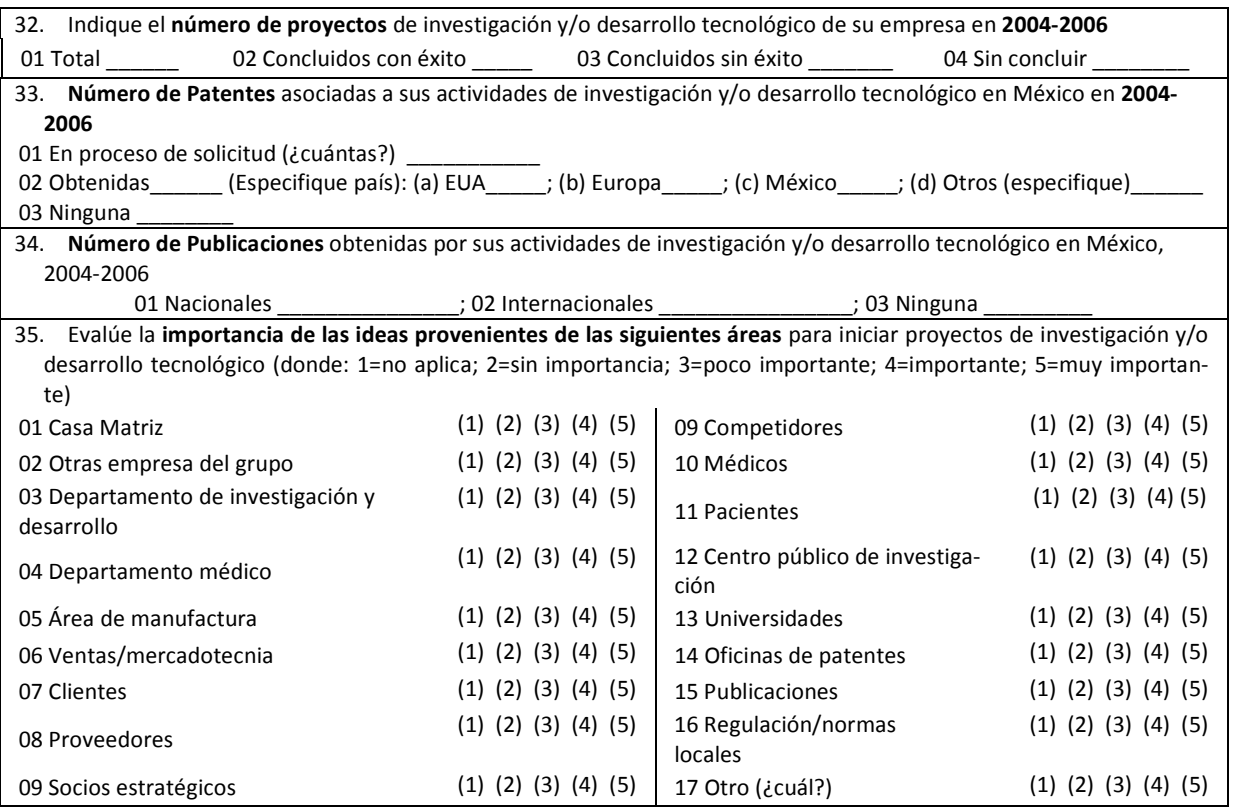

\section{INVESTIGACIÓN CLÍNICA}

\section{6. ¿Realiza investigación clínica?}

$\square \quad 01 \mathrm{Si}$ (especifique en dónde)

(a) En México (continúe a pregunta 39); (b) Sólo en el extranjero (pase a

$\square \quad 02$ No (pase a Sección VI) Sección VI)

37. Indique el número de protocolos de investigación clínica patrocinados en 2006

38. ¿Cuál fue su inversión en investigación clínica en México en 2006?

01 Miles de pesos

02 Como \% de sus ventas en México

39. Indique quién se encarga de redactar los protocolos de investigación clínica de manera rutinaria:

01 Si su empresa es transnacional La casa matriz

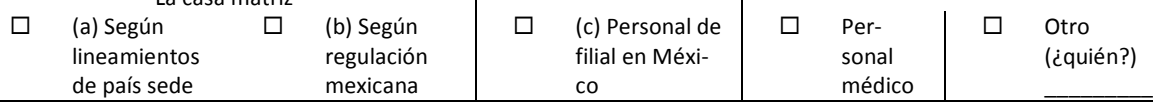

40. Evalúe por su importancia, la institución a la que recurre para llevar a cabo las actividades de investigación clínica (donde: 1=no aplica; 2=sin importancia; 3=poco importante; 4=importante; 5=muy importante)

01 Universidad_ 02 Inst. Público Salud $\quad 03$ Org. de investigación por contrato___ 04 Hospital Privado

41. Evalúe el tipo de proyectos de investigación clínica patrocinados por la empresa durante 2005-2006, (donde: 1=no aplica; 2=sin importancia; 3=poco importante; 4=importante; 5=muy importante)

$\square \quad 01$ Estudios Fase I (Primera evaluación de un nuevo fármaco en humanos; identificación de dosis seguras para realizar estudios posteriores)

$\square \quad 02$ Estudios Fase II (Estudios cuyo objetivo es estimar la actividad clínica y toxicidad de una nueva droga; ensayos clínicas no controlados)

$\square \quad 03$ Estudios Fase III (Prueba de eficacia y seguridad de un nuevo fármaco en ensayos clínicos controlados, utilizados como herramienta de medición comparativa)

$\square \quad 04$ Estudios Fase IV (Estudios posteriores a la aprobación de una droga para una determinada indicación o padecimiento. Se evalúan nuevas indicaciones y/o aplicaciones, además de evaluar usos terapéuticos que no habían analizado previamente)

$\square \quad 05$ Biodisponibilidad y Bioequivalencia

$\square \quad 06$ Otro(s) (especifique) 
VI. GESTIÓN Y DESARROLLO DE RECURSOS HUMANOS EN INVESTIGACIÓN Y/O DESARROLLO

(Si no realiza actividades de investigación y/o desarrollo tecnológico en México concluya el cuestionario)

(Considere la estrategia de gestión característica de su empresa durante los últimos cinco años)

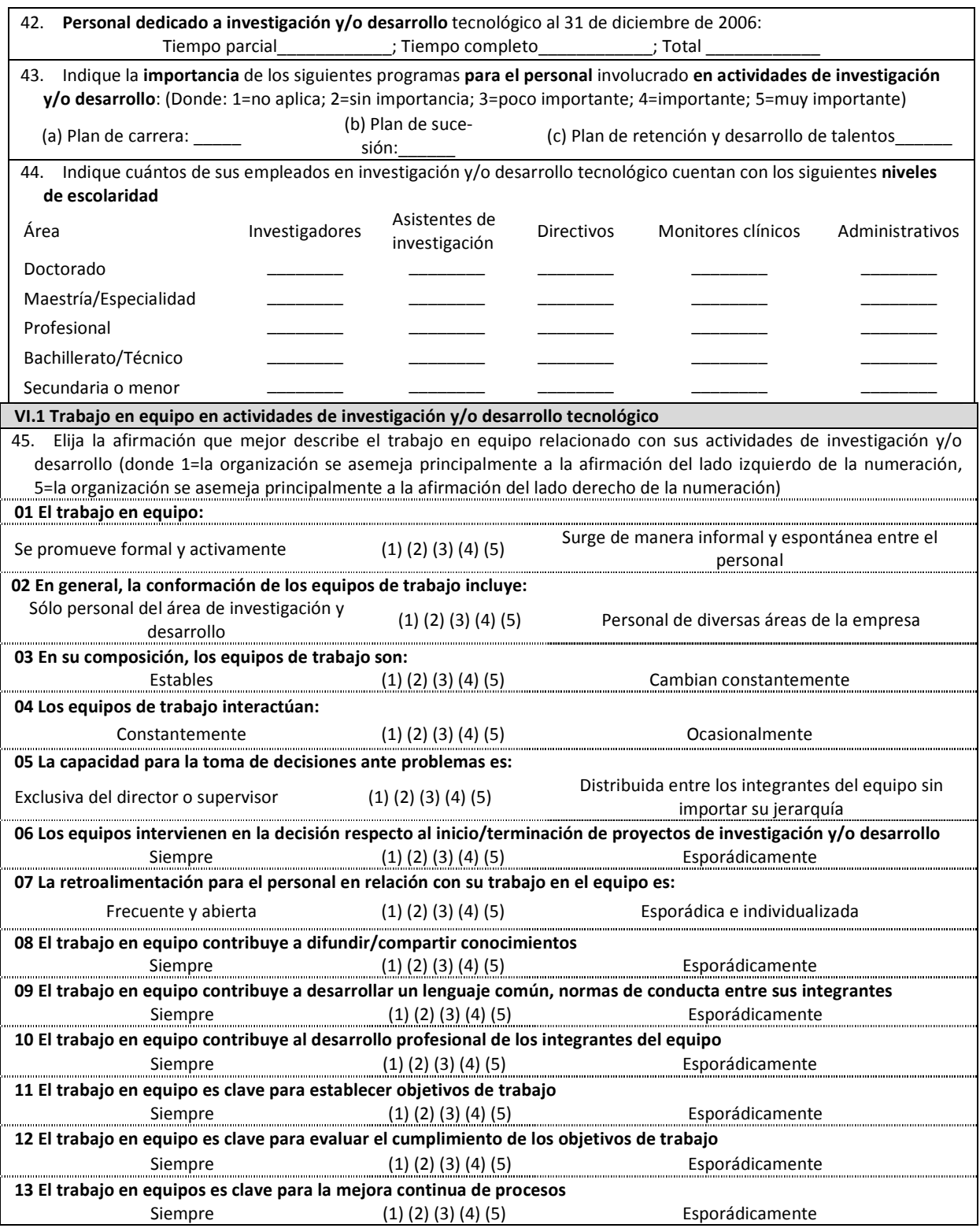




\section{VI.2 Comunicación interna y externa en actividades de investigación y/o desarrollo tecnológico}

46. Por favor indique la afirmación que mejor describe la comunicación interna entre su personal en actividades de investigación y/o desarrollo (donde $1=s u$ organización se asemeja principalmente a la afirmación del lado izquierdo de la numeración, 5=su organización se asemeja principalmente a la afirmación del lado derecho de la numeración)

01 En general la comunicación es:

Vertical, de arriba hacia abajo según la jerar- $\quad$ (1) (2) (3) (4) (5) Horizontal, independientemente de la jerarquía quía

(1) (2) (3) (4) (5)

02 En cuanto a su frecuencia, número de participantes y duración, las reuniones de trabajo son: Bien delimitadas Totalmente libres

03 La información requerida para mantener los proyectos de investigación y/o desarrollo funcionando es:

Exclusiva del líder de proyecto o jefe del área $\quad$ (1) (2) (3) (4) (5) Abierta para todo el personal involucrado

04 La información requerida para concluir los proyectos de investigación y/o desarrollo funcionando es:
Exclusiva del líder de proyecto o jefe del área
(1) (2) (3) (4) (5)
Abierta para todo el personal involucrado

05 La retroalimentación para los empleados en relación con su trabajo de investigación y/o desarrollo es: Frecuente y abierta

(1) (2) (3) (4) (5) Esporádica e individualizada

06 La estrategia de comunicación busca facilitar creación y difusión del conocimiento a lo largo de la empresa
Siempre
(1) (2) (3) (4) (5)
Esporádicamente

07 La comunicación permite al personal científico/técnico conocer necesidades de otras áreas de la empresa

$$
\text { Siempre } \quad(1)(2)(3)(4)(5) \quad \text { Esporádicamente }
$$

$08 \mathrm{El}$ personal requiere conocer el desarrollo del mercado, la técnica/ciencia internacional y traducirlos en respuestas a necesidades corporativas Siempre

(1) (2) (3) (4) (5) Esporádicamente

09 En su trabajo, el personal necesita integrar demandas de investigación, desarrollo, producción y mercadotecnia Siempre (1) (2) (3) (4) (5) Esporádicamente

47. Indique la importancia de las siguientes afirmaciones respecto a la comunicación externa por parte de su personal en investigación y/o desarrollo (Donde: 1=no aplica; 2=sin importancia; 3= poco importante; 4=importante; 5=muy importante)

01 El personal publica su trabajo en:

$02 \mathrm{El}$ personal presenta su trabajo en seminarios y congresos en:

03 La empresa promueve co-autorías entre su personal con investigadores en:

48. Durante sus actividades de investigación y/o desarrollo el personal científico/técnico interactúa activamente con sus pares en

\section{Otras empresas en:}

02 Instituciones de investigación en:

03 Instituciones de educación superior en: (a) México

(b) El extranjero

(1) (2) (3) (4) (5)

(1) (2) (3) (4) (5)

(1) (2) (3) (4) (5)
(1) (2) (3) (4) (5)

(1) (2) (3) (4) (5)

(1) (2) (3) (4) (5) (a) México

(b) El extranjero
(1) (2) (3) (4) (5)
(1) (2) (3) (4) (5)
(1) (2) (3) (4) (5)
(1) (2) (3) (4) (5)
(1) (2) (3) (4) (5)
(1) (2) (3) (4) (5)

49. Evalúe los objetivos de la comunicación interna y externa por parte de su personal en investigación y/o desarrollo tecnológico (Donde: 1=no aplica; 2=sin importancia; 3=poco importante; 4=importante; 5=muy importante)

01 Facilitar creación y difusión del conocimiento

(1) (2) (3) (4) (5)

02 Encontrar solución a problemas

(1) (2) (3) (4) (5)

03 Difundir objetivos de negocio entre el personal

(1) (2) (3) (4) (5)

04 Integrar al personal de diferentes áreas y especialidades

(1) (2) (3) (4) (5)

05 Mantener contacto del personal técnico/científico con el resto de la empresa

(1) (2) (3) (4) (5)

06 Aumentar la reputación y reconocimiento interno de los investigadores

(1) (2) (3) (4) (5)

07 Aumentar la reputación y reconocimiento externo de los investigadores

(1) (2) (3) (4) (5)

08 Otro (especifique)

(1) (2) (3) (4) (5) 
50. Presupuesto anual para capacitación y/o entrenamiento del personal de investigación y/o desarrollo tecnológico en 2006?

Miles de pesos Como \% de ventas

51. ¿Durante 2006 recibió capacitación el personal de investigación y/o desarrollo tecnológico?

52. Indique el número promedio de cursos de capacitación y/o entrenamiento recibidos por el personal de investigación y/o desarrollo tecnológico durante 2006

(a) Directivos

(b) Investigadores

(c) Asistentes de investigación

(d) Administrativos

(e) Monitores clínicos

53. Evalúe la relevancia del entrenamiento/capacitación recibido por el personal de investigación y/o desarrollo, según agente capacitador en 2006 (Donde: 1=no aplica; 2=sin importancia; 3=poco importante; 4=importante; 5=muy importante)

01 Personal de la propia empresa (salón) 02 Personal de la propia empresa (en el sitio de trabajo)

03 Empresas de consultoría

04 Cámaras empresariales

\begin{tabular}{l|l} 
( ) & 05 Universidades en México \\
( ) & 06 Universidades en el extranjero \\
( ) & 07 Socios de investigación \\
( ) & 08 Otros (especifique)
\end{tabular}

54. Evalúe las habilidades y/o conocimientos que mejor describen la capacitación y/o entrenamiento recibidos por el personal de investigación y/o desarrollo en 2006 (Donde: 1=no aplica; 2=sin importancia; 3=poco importante; 4=importante; 5=muy importante)

01 Habilidades básicas (leer, escribir, etc.) 02 Conocimientos técnicos especializados que no conducen a obtención de grado académico 03 Conocimientos técnicos especializados que conducen a obtención de grado académico 04 Habilidades gerenciales (negociación, comunicación, trabajo en equipo)

05 Buenas prácticas de manufactura

06 Principios de buenas prácticas de laboratorio 07 Principios de buenas prácticas clínicas 08 Metodología para el diseño y/o conducción de experimentos

09 Operación/mantenimiento de maquinaria y equipo

10 Procedimientos de seguridad

11 Idiomas

12 Otros (especifique)

\begin{tabular}{|c|c|c|c|c|}
\hline Directivo & Investigador & $\begin{array}{l}\text { Asistente de } \\
\text { investigación }\end{array}$ & $\begin{array}{l}\text { Monitor } \\
\text { clínico }\end{array}$ & Administrativo \\
\hline & & & & \\
\hline & & & & \\
\hline & & & & \\
\hline & & & & \\
\hline & & & & \\
\hline & & & & \\
\hline & & & & \\
\hline & & & & \\
\hline & & & & \\
\hline & & & & \\
\hline & & & & \\
\hline & & & & \\
\hline
\end{tabular}

VI.4 Evaluación y Retribución por desempeño del personal de investigación y/o desarrollo tecnológico

55. Evaluación formal del desempeño del personal de investigación y/o desarrollo tecnológico tiene lugar __veces al año

56. Indique en una escala de 1-5 la afirmación que mejor describelas características de la evaluación por desempeño de su personal de investigación y/o desarrollo tecnológico (donde con respecto a la numeración, 1=organización se asemeja principalmente a la afirmación del lado izquierdo, 5= organización se asemeja principalmente a la afirmación del lado derecho)

01 De acuerdo con la evaluación por desempeño:

Los objetivos deben cumplirse totalmente

(1) (2) (3) (4) (5)

Existe absoluta flexibilidad en cumplimiento de objetivos

02 El personal participa en la definición de sus propios objetivos laborales:

Ocasionalmente $\quad(1)(2)(3)(4)(5)$

Siempre

03 La evaluación del desempeño incluye retroalimentación y guía para el trabajador
Ocasionalmente
(1) (2) (3) (4) (5)
Siempre

04 La evaluación de desempeño involucra:

Únicamente al jefe y al empleado evaluado

(1) (2) (3) (4) (5)

Al jefe, pares y subordinados del personal evaluado

05 La evaluación informa planes de capacitación y/o entrenamiento:: 


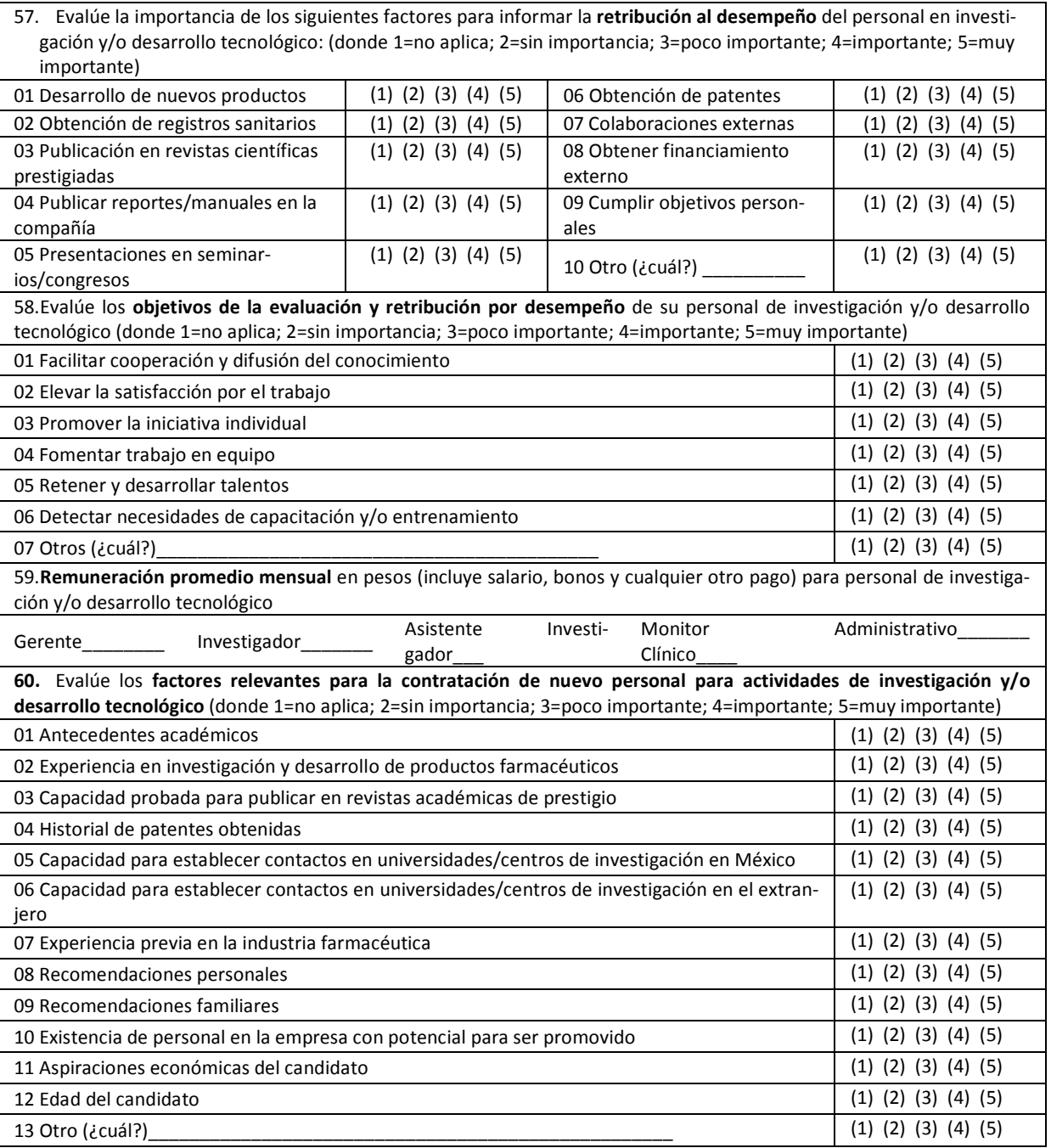


Annex 2: Pharmaceutical firms operating in Mexico, 2007

\begin{tabular}{|c|c|c|c|}
\hline & CANIFARMA & AMIIF & ANAFAM \\
\hline Abbott Laboratories de México, S.A. de C.V. & $\mathrm{x}$ & $\mathrm{x}$ & \\
\hline Alcon Laboratorios, S.A. de C.V. & $\mathrm{x}$ & & \\
\hline \multicolumn{4}{|l|}{ Allen Laboratorios S.A. de C.V. } \\
\hline Allergan, S.A. de C.V. & $\mathrm{X}$ & & \\
\hline Almirall, S.A. de C.V. & $\mathrm{X}$ & & \\
\hline Alpharma & & & $\mathrm{X}$ \\
\hline Altana Pharma, S.A. de C.V./byk gulden & $\mathrm{X}$ & $\mathrm{x}$ & \\
\hline \multicolumn{4}{|l|}{ Alvartis Pharma, S.A. de C.V. } \\
\hline Antibióticos de México, S.A. DE C.V. & $\mathrm{X}$ & & \\
\hline APITEX & & & $\mathrm{X}$ \\
\hline Aplicaciones Farmacéuticas, S.A. de C.V. & $\mathrm{X}$ & & \\
\hline Armstrong Laboratorios de México, S.A. de C.V. & $\mathrm{X}$ & $\mathrm{X}$ & \\
\hline Asofarma de México, S.A. de C.V. & $\mathrm{X}$ & & \\
\hline Aspid, S.A. de C.V. & $\mathrm{X}$ & & \\
\hline Astrazeneca, S.A. de C.V. & $\mathrm{X}$ & $\mathrm{X}$ & \\
\hline Atlantis & & & $\mathrm{X}$ \\
\hline Baxter, S.A. de C.V. & $\mathrm{X}$ & & \\
\hline Bayer de México, S.A. de C.V. & $\mathrm{X}$ & $\mathrm{X}$ & \\
\hline Beckman Laboratories México, S.A. de C.V. & $\mathrm{X}$ & & \\
\hline \multicolumn{4}{|l|}{ Biofarma Natural CMD } \\
\hline \multicolumn{4}{|l|}{ Bioresearch de México, S.A. de C.V. } \\
\hline Boehringer Ingelheim Promeco, S.A. de C.V. & $x$ & $\mathrm{X}$ & \\
\hline Bristol Myers Squibb de México, S de RL de CV & $\mathrm{X}$ & $\mathrm{X}$ & \\
\hline \multicolumn{4}{|l|}{ BRULUAGSA S.A. de C.V. } \\
\hline Chinoin & & $\mathrm{X}$ & \\
\hline Compañía Internacional de Comercio, S.A. de C.V. & $\mathrm{X}$ & & \\
\hline \multicolumn{4}{|l|}{ Codifarma } \\
\hline \multicolumn{4}{|l|}{ Degort's Chemical S.A. de C.V } \\
\hline \multicolumn{4}{|l|}{ Diba S.A. } \\
\hline \multicolumn{4}{|c|}{ Distribuidora de Alimentos Naturales y Nutricionales S.A. de C.V. } \\
\hline Eli Lilly y Compañía de México, S.A. de C.V. & $\mathrm{X}$ & $\mathrm{X}$ & \\
\hline Específicos Stendhal, S.A. DE C.V. & $\mathrm{X}$ & & \\
\hline \multicolumn{4}{|l|}{ Farmacéutica Wandel, S.A. de C.V. } \\
\hline \multicolumn{4}{|l|}{ Farmacéuticos Ederka, S.A. de C.V. } \\
\hline Farmacéuticos Rayere, AS & $\mathrm{X}$ & & \\
\hline Fármacos Continentales, S.A. de C.V. & $\mathrm{X}$ & & \\
\hline Ferring, S.A. DE C.V. & $\mathrm{X}$ & $x$ & \\
\hline \multicolumn{4}{|l|}{ Fersinsa/GIST Brocades, S.A. de C.V. } \\
\hline Fresenius Kabi México, S.A. de C.V. & $\mathrm{X}$ & & \\
\hline Galderma México, S.A. de C.V. & $\mathrm{X}$ & & \\
\hline \multicolumn{4}{|l|}{ Genética Laboratorios, S.A. de C.V. } \\
\hline Genzyme México, S de RL de CV & $\mathrm{X}$ & & \\
\hline GlaxoSmithKline México, S.A. de C.V. & $\mathrm{X}$ & $\mathrm{X}$ & \\
\hline \multicolumn{4}{|l|}{ Goñi's S.R.L. de C.V. } \\
\hline \multicolumn{4}{|l|}{ Grimann S.A. de C.V. } \\
\hline Grisi Hermanos, SA & $\mathrm{X}$ & & \\
\hline Grünenthal de México S.A. de C.V. & & $\mathrm{X}$ & \\
\hline Grupo Carbel, S.A. de C.V. & $\mathrm{X}$ & & $\mathrm{X}$ \\
\hline Grupo Roche Syntex de México, S.A. de C.V. & $\mathrm{X}$ & & \\
\hline Hospira, S DE RLL DE CV & $x$ & & \\
\hline ICN Farmacéutica, S.A. de C.V. & $x$ & & \\
\hline
\end{tabular}




\begin{tabular}{|c|c|c|c|}
\hline & CANIFARMA & AMIIF & ANAFAM \\
\hline Importadora y Manufacturera Bruluart, SA & $\mathrm{x}$ & & $\mathrm{x}$ \\
\hline Industria Farmacéutica Andromaco, S.A. de C.V. & $\mathrm{x}$ & & \\
\hline \multicolumn{4}{|l|}{ Industrias Suanca, S.A. de C.V. } \\
\hline Instituto Bioclón, S.A. de C.V. & $\mathrm{x}$ & & \\
\hline Investigación Farmacéutica, S.A. de C.V. & $\mathrm{x}$ & & \\
\hline Italmex, SA & $\mathrm{x}$ & & \\
\hline Ivax Pharmaceuticals México, S.A. de C.V. & $\mathrm{x}$ & & $\bar{x}$ \\
\hline Janssen-Cilag, S.A. de C.V. & $\mathrm{x}$ & $\mathrm{x}$ & \\
\hline \multicolumn{4}{|l|}{ Keton de México S.A. de C.V. } \\
\hline Laboratorio Bioquímico & & & $\mathrm{x}$ \\
\hline \multicolumn{4}{|l|}{ Laboratorio Bioquímico Mexicano, S.A. De C.V } \\
\hline Laboratorio de Especialidades Homeopáticas Millenium, S.A. de C.V. & $\bar{x}$ & & \\
\hline Laboratorio Farmacológico Nutrimedi S.A. de C.V. & $\mathrm{X}$ & & \\
\hline \multicolumn{4}{|l|}{ Laboratorio Médico Químico Biológico, S.A. de C.V. } \\
\hline Laboratorios Cryopharma, S.A. de C.V. & $\mathrm{x}$ & & \\
\hline Laboratorios Grossman, SA & $\mathrm{x}$ & & \\
\hline Laboratorios Hexal, S.A. de C.V. & $\mathrm{x}$ & & \\
\hline Laboratorios Hormona, S.A. de C.V. & $\mathrm{x}$ & & $\mathrm{x}$ \\
\hline Laboratorios Kendrick, SA & $\mathrm{x}$ & & $x$ \\
\hline Laboratorios Kener, S.A. de C.V. & $\mathrm{x}$ & & $\mathrm{x}$ \\
\hline Laboratorios Liomont, S.A. de C.V. & $\mathrm{x}$ & & $\mathrm{x}$ \\
\hline Laboratorios Manuell SA & & & $\mathrm{x}$ \\
\hline Laboratorios Pisa, S.A. de C.V. & $\mathrm{x}$ & & $x$ \\
\hline Laboratorios Pizzard, S.A. de C.V. & $\mathrm{x}$ & & \\
\hline Laboratorios Quimpharma, S.A. de C.V. & $\mathrm{X}$ & & \\
\hline \multicolumn{4}{|l|}{ Laboratorios Raam de Sahuayo, S. A. de C. V } \\
\hline Laboratorios Salus, S.A. de C.V. & $\mathrm{x}$ & & \\
\hline Laboratorios Sanfer, S.A. de C.V. & $\mathrm{x}$ & $\mathrm{x}$ & \\
\hline \multicolumn{4}{|l|}{ Laboratorios Sardel de Xalapa, S.A. de C.V. } \\
\hline \multicolumn{4}{|l|}{ Laboratorios Serral S.A } \\
\hline Laboratorios Senosiain, S.A. de C.V. & $x$ & & $\mathrm{x}$ \\
\hline Laboratorios Servier, S.A. de C.V. & $\mathrm{x}$ & & \\
\hline Laboratorios Silanes, S.A. de C.V. & $x$ & & $x$ \\
\hline Laboratorios Solfran, S.A. DE C.V. & $\mathrm{x}$ & & \\
\hline Laboratorios Sophia, S.A. de C.V. & $\mathrm{x}$ & & \\
\hline Laboratorios Valdecasas, SA & $\mathrm{x}$ & & $\mathrm{x}$ \\
\hline \multicolumn{4}{|l|}{ Laboratorios Zafiro, S.A. de C.V. } \\
\hline Laboratorios Zerboni, SA & $\mathrm{x}$ & & $\mathrm{x}$ \\
\hline Landsteiner Scientific S.A. de C.V. & & & $\mathrm{x}$ \\
\hline Lemery, S.A. de C.V. & $\mathrm{x}$ & & $\mathrm{x}$ \\
\hline Lundbeck México, S.A. de C.V. & $\mathrm{x}$ & & \\
\hline \multicolumn{4}{|l|}{ Marcel S.A. de C.V. } \\
\hline Medix & & & $\mathrm{x}$ \\
\hline Merck Sharp \& Dohme de México, S.A. de C.V. & $\mathrm{x}$ & $\mathrm{x}$ & \\
\hline Merck, S.A. de C.V. & $\mathrm{x}$ & & \\
\hline Merz & & $\mathrm{x}$ & \\
\hline Monticello Drug Company, SA & $\mathrm{x}$ & & \\
\hline \multicolumn{4}{|l|}{ Novag Infancia, S.A. de C.V } \\
\hline Novartis Farmacéutica, S.A. de C.V. & $\mathrm{x}$ & $\mathrm{x}$ & \\
\hline Novo Nordisk Mexico, S.A. de C.V. & $x$ & $\mathrm{x}$ & \\
\hline \multicolumn{4}{|l|}{ NUCITEC, S.A. de C.V. } \\
\hline Octapharma, S.A. de C.V. & $x$ & & \\
\hline
\end{tabular}




\begin{tabular}{|c|c|c|c|}
\hline & CANIFARMA & AMIIF & ANAFAM \\
\hline \multicolumn{4}{|l|}{ Offenbach Mexicana, S.A. de C.V. } \\
\hline \multicolumn{4}{|l|}{ Olnatura S.A. de C.V } \\
\hline Organon Mexicana, S.A. de C.V. & $\mathrm{x}$ & $\mathrm{x}$ & \\
\hline Pfizer, S.A. de C.V.-Pharmacia Upjhon & $\mathrm{x}$ & $\mathrm{x}$ & \\
\hline Pharmacos Exakta, S.A. de C.V. & $\mathrm{x}$ & & $\mathrm{x}$ \\
\hline Pharmanova, S.A. de C.V. & $\mathrm{x}$ & & \\
\hline Precimex S.A. de C.V. & & & $\mathrm{X}$ \\
\hline Probiomed, S.A. de C.V. & $\mathrm{x}$ & & \\
\hline Productos Farmacéuticos, S.A. de C.V. & $\mathrm{x}$ & & \\
\hline Productos Mavi, S.A. de C.V. & $\mathrm{X}$ & & \\
\hline \multicolumn{4}{|l|}{ Productos Químicos Naturales, S.A. } \\
\hline Protein, S.A. de C.V. & $\mathrm{x}$ & & \\
\hline Pro-Ventas, S.A. de C.V. & $\mathrm{x}$ & & \\
\hline \multicolumn{4}{|l|}{ Provit S.A. de C.V. } \\
\hline Psicofarma, S.A. de C.V. & $\mathrm{x}$ & & $\mathrm{x}$ \\
\hline Química y Farmacia, S.A. de C.V. & $\mathrm{x}$ & & $\mathrm{x}$ \\
\hline Randall laboratories, S.A. de C.V. & $\mathrm{x}$ & & \\
\hline Representaciones e Investigaciones Médicas, S.A. de C.V. & $\mathrm{x}$ & & $\mathrm{x}$ \\
\hline \multicolumn{4}{|l|}{ Representaciones Mex-América, S.A. de C.V. } \\
\hline Romsa de México, S.A. de C.V. & $\mathrm{x}$ & & \\
\hline Sanofi Synthelabo de México, S.A. de C.V. & $\mathrm{x}$ & & \\
\hline Sanofi-Aventis & & $\mathrm{x}$ & \\
\hline SBL Pharmaceuticals, S de RL de CV & $\mathrm{x}$ & & \\
\hline Schering Mexicana, S.A. de C.V. & $x$ & $\mathrm{x}$ & \\
\hline Schering Plough, S.A. de C.V. & $\mathrm{x}$ & $\mathrm{x}$ & \\
\hline Schwabe México, S.A. de C.V. & $x$ & & \\
\hline Serono de México, S.A. de C.V. & $\mathrm{x}$ & $\mathrm{x}$ & \\
\hline Siegfried Rhein, S.A. de C.V. & $\mathrm{x}$ & & \\
\hline Stiefel Mexicana, S.A. de C.V. & $\mathrm{x}$ & & \\
\hline Streger, SA & $x$ & & \\
\hline Tecnofarma, S.A. de C.V. & $x$ & & $x$ \\
\hline \multicolumn{4}{|l|}{ Terapia Infantil S.A. de C.V. } \\
\hline \multicolumn{4}{|l|}{ Ultra Laboratorios, S.A de C.V } \\
\hline Unipharm de México, S.A. de C.V. & $x$ & & \\
\hline Valeant Farmacéutica, S.A. de C.V. & $\mathrm{x}$ & $\mathrm{x}$ & \\
\hline \multicolumn{4}{|l|}{ Wermar Pharmaceuticals S.A. de C.V. } \\
\hline Wyeth, S.A. de C.V. & $\mathrm{x}$ & $\mathrm{x}$ & \\
\hline
\end{tabular}

Source: Author with information from CANIFARMA, AMIIF, ANAFAM; Pharmacopea de los Estados Unidos Mexicanos; Internet sites of firms and other organizations specialised in the industry. See chapter 4 for a more ample discussion. Source: Author 


\section{Samenvatting}

Dit proefschrift draagt bij aan de literatuur over Human Resource Management (HRM) praktijken, en het leerproces bij innovatie in de context van ontwikkelingslanden. Het brengt bij elkaar literatuur over: (1) innovatie systemen, (2) HRM praktijken en innovatieve prestaties op bedrijfsniveau, en (3) leren door middel van R\&D. Het proefschrift interpreteert R\&D als "leren", een mechanisme ter bevordering van opname capaciteit en ter ondersteuning van de opbouw van technologische capaciteiten.

Empirisch bewijs verwijst naar de farmaceutische industrie in Mexico en bouwt voort op twee soorten gegevens: kwalitatieve en kwantitatieve uit zowel primaire als secundaire bronnen. Primaire gegevens werden verzameld door zowel een enquête uitgevoerd door de Mexicaanse regering als door een reeks diepte-interviews met vertegenwoordigers van de farmaceutische industrie, medisch onderzoek, en regulerende organisaties. Secundaire gegevens kwamen uit uitgebreide zoekopdrachten op archiefmateriaal en andere documentaire bronnen, het bijwonen van gespecialiseerde seminars, presentaties, internet, etc.

De empirische analyse maakt onderscheid tussen leren als strategie, en het leren in termen van kennis inhoud. Met andere woorden, bedrijven onderschrijven verschillende leerstrategieën en vereisen verschillende soorten kennis tijdens het R\&Dproces. Voor wat het voormalige betreft, kunnen bedrijven technologie produceren gebaseerd op interne technologische, - R\&D-inspanningen -, of de externe technologie markten aanboren als een exclusieve bron van kennis. Als alternatief kunnen ondernemingen streven naar complementariteit tussen beide leerstrategieën.

In termen van kennis inhoud, en in overeenstemming met op kennis gebaseerde ondernemingstheorieën, kunnen de farmaceutische bedrijven in Mexico of de kennis die binnen hun gebruikelijke kennisbasis aanwezig is exploiteren, of op zoek gaan naar die delen van de kennis die tot nu toe niet beschikbaar voor hen zijn. Verschillende kennis eisen associëren met distinctieve R\&D-resultaten met verschillende gradaties van noviteit, althans voor de onderneming. Derhalve onderzocht het proefschrift hoe de farmaceutische R\&D die leidt tot de goedkeuring van verbeterde of nieuwe (generieke) medicijnen en/of drugs productieprocessen door HRM praktijken wordt onderbouwt.

Het gebruik van leren als relevante dimensie voor de analyse is een belangrijke bijdrage van dit proefschrift; het bouwt verder op een aantal eerdere studies op dit gebied die rechtstreekse verbindingen tussen HRM praktijken en de innovatieve prestaties op bedrijfsniveau traceren. Hoewel dergelijke studies vaak positieve relaties tussen deze variabelen aantreffen, zijn ze niet in staat om uit te leggen waarom dit zo is. Dit proefschrift werpt licht op hoe en waarom management praktijken, leren voor innovatie, onderbouwen: de verwantschappen zijn afhankelijk van factoren zoals de verwachte uitkomst van R\&D, of de noviteit van de vereiste kennis van de onderneming. De verschillende HRM interventies dragen ieder anders bij aan de 
aanleg van de noodzakelijke opnamecapaciteit en innovatiecapaciteit van farmaceutische bedrijven.

De analyse toonde aan dat de sociaal-economische context van belang is voor leren en innovatie; ze bepaalt hoe landen, sectoren en ondernemingen inbrengen en bijdragen aan de innovatie in specifieke sectoren/bedrijfstakken. Landen zoals Mexico karakteriseren zich door strikte arbeids controles, beperkte R\&D en een specialisatie in incrementele innovaties; de kenmerken van een onderneming derhalve, in het bijzonder de exportpositie en de oorsprong van het kapitaal bezit, verklaren grotendeels het leergedrag van farmaceutische bedrijven in het land.

Niettemin, HRM praktijken grijpen in op twee belangrijke gebieden. Ten eerste begeleiden ze de mobilisatie en de exploitatie van kennis die al in het bedrijf aanwezig is. Ten tweede sturen ze het zoeken naar en verkennen van kennis die eerder niet beschikbaar binnen de onderneming; zij dragen bij aan de verrijking van de kennisbasis van een bedrijf. Verschillende HRM praktijken associëren met verschillende R\&D processen en verwachte resultaten van innovatie; zij beinvloeden ook interacties tussen een bedrijf en externe kennisaanbieders. Het aanreiken van opleidingen en het aannemen van regels om het strategische inhuren te besturen zijn management praktijken die leren door middel van R\&D in de farmaceutische industrie in Mexico bijstaan.

Dit proefschrift stelt voor dat een beter begrip van organisatorische omgevingen rondom R\&D nodig is aangezien de mens aan de basis staat van innovatieve organisaties; de dynamiek van de werkomgeving, zoals geschapen door HRM interventies, kan het leren versterken door middel van R\&D. 


\section{Curriculum vitae}

Fernando Santiago Rodriguez joined UNU-MERIT as a PhD student in September 2003. Since February 2010 he is based in Ottawa, Canada where he works for Canada's International Development Research Centre (IDRC). As part of the program Innovation, Technology and Society, Fernando is responsible for projects in Northern, Eastern and Southern Africa and the Middle East.

Fernando is an economist with extensive experience in economic development, innovation management, pharmaceuticals and energy. He has substantial work experience within the Mexican government, including: the Ministries of Foreign Affairs, and Finance and Public Credit, respectively, and at the Council of Science and Technology (CONACYT).

His achievements include membership in the Mexican expert group responsible for preparing the Background Report to the OECD's Country Review of Mexico's National System of Innovation; membership in an international expert group which conducted a comprehensive evaluation of the Mexican government's STI policy programme over the period 2000-2006; and visiting researcher at the United Nations Industrial Development Organization (UNIDO).

Fernando holds a Bachelors Degree in Economics from the National Autonomous University in Mexico (UNAM for its name in Spanish), and an MSc in Science and Technology Policy from SPRU, University of Sussex, UK.

Fernando's research interests include science, technology and innovation in terms of both policy, and its role in social and economic development. 